EGG-WMO-10244

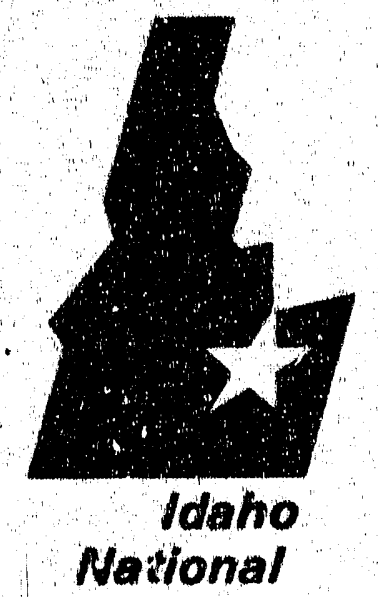

Engineering

Laboratory

Managed

- by the U.S.

Department

of Energy
April 1992

\section{Mixed and Low-Level Waste Treatment Facility Project}

Volume 3

Waste Treatment Technologies

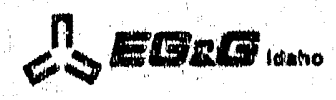

Work porformad under DOE Contract NO. DE-ACD7-761DO1570
}

\title{
(Draft)
}


This document contains new concepts or the author(s) interpretation of new calculations and/or irreasurements; accordinghy, EG\&G Idaho, Inc. is required by the United States Government to include the following disclaimer:

\section{DISCLAIMER}

This report was propured as an account of work sponsorwd by an woncy of the Unitod Statos Government. Neither the Unitod States Govemment nor any agency thenof, nor any of their employes, makes any warranty, express or implied, or as. sumes any loged liability or responsibility for the accuracy, completeness, or usefulness of any information, apparatus, product, or process diaclosed, or represents that its use would not infringe privately owned rights. Reterence herein to any specific commercial product, process, or senvic by trade name, tredemank, manutacturer, or otherwise, does not nocessarily constitute or imply its endorsement, recommendation, or favoring by the United States Govemment or any agency thereof. The views and opinions of authors expressed herein do not necessarity state or reflect those of the Uniled Statms Govemment or any agency thereof. 


\section{Volume 3 \\ Waste Treatment Technologies}

Published April 1992

\section{Idaho National Engineering Laboratory \\ EG\&G Idaho, Inc. \\ Idaho Falls, Idaho 83415}

Prepared for the

U.S. Depariment of Energy

Offlce of Environmental Restoration and Waste Management

Under DOE Idaho Fleld Office

Contract DE-AC07-761D01570 


\section{CONTENTS}

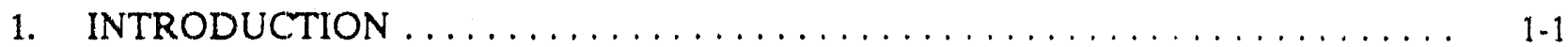

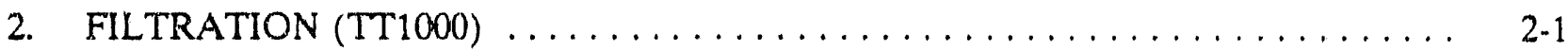

2.1 Disposable Filters $(\mathrm{TT} 1100) \ldots \ldots \ldots \ldots \ldots \ldots \ldots \ldots, 2.1$

2.1.1 Cartridge Filters $(\mathrm{TT} 1200) \ldots \ldots \ldots \ldots \ldots \ldots \ldots \ldots \ldots, 2-2$

2.1.2 Bag-Type Filters (TT1300) $\ldots \ldots \ldots \ldots \ldots \ldots \ldots \ldots \ldots \ldots . \ldots \ldots$

$2.2 \quad$ Reusable Filters $(\mathrm{TT} 1400) \ldots \ldots \ldots \ldots \ldots \ldots \ldots \ldots \ldots \ldots \ldots \ldots \ldots \ldots, 2.4$

2.2.1 Reusable Fillers Without Precoat $($ TT1500) . . . . . . . . . . . 2-4

2.2.2 Reusable Filters With Precoat (TT1600) $\ldots \ldots \ldots \ldots \ldots \ldots \ldots$. 2.6

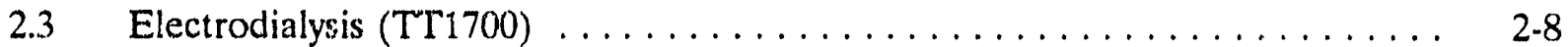

$2.4 \quad$ Ultrafiltration $(\mathrm{TT} 1800) \ldots \ldots \ldots \ldots \ldots \ldots \ldots \ldots \ldots \ldots \ldots, 2-10$

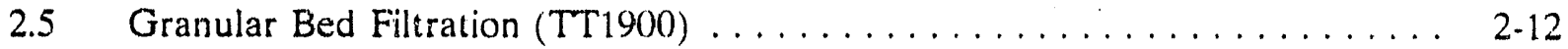

2.6 References $\ldots \ldots \ldots \ldots \ldots \ldots \ldots \ldots \ldots \ldots \ldots \ldots \ldots \ldots \ldots \ldots \ldots \ldots, 2.14$

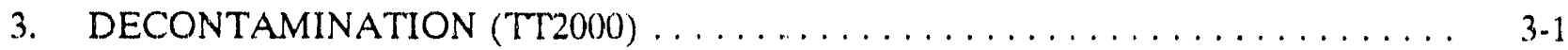

3.1 Mechanical Decontamination $(\mathrm{TT} 2100) \ldots \ldots \ldots \ldots \ldots \ldots \ldots \ldots, 3-1$

3.2 Chemical Decontamination $(\mathrm{TT} 2200) \ldots \ldots \ldots \ldots \ldots \ldots \ldots \ldots, 3-3$

$3.3 \quad$ References $\ldots \ldots \ldots \ldots \ldots \ldots \ldots \ldots \ldots \ldots \ldots \ldots \ldots \ldots \ldots \ldots \ldots, 3.5$

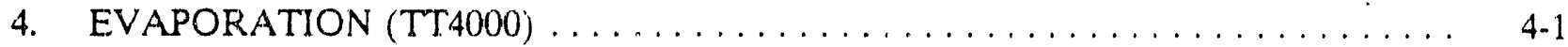

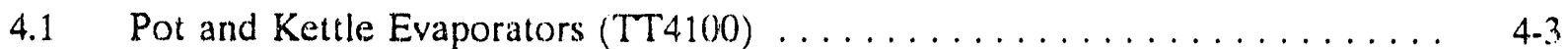

4.2 Natural Circulation Evaporators (TT4200) ................... 4.4

4.3 Forced Circulation Evaporators $($ TT 4.300$) \ldots \ldots \ldots \ldots \ldots \ldots \ldots, 4-6$

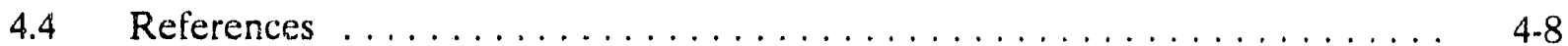

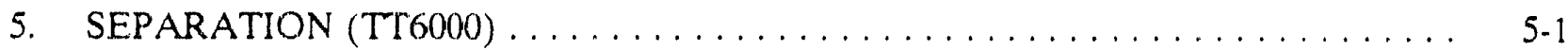

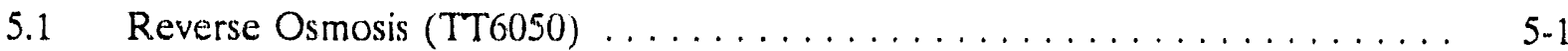

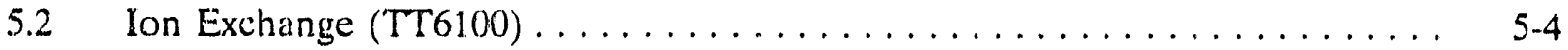




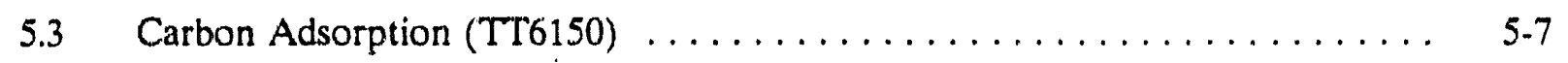

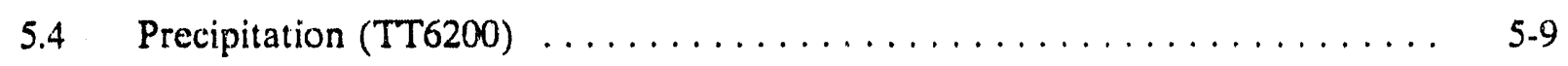

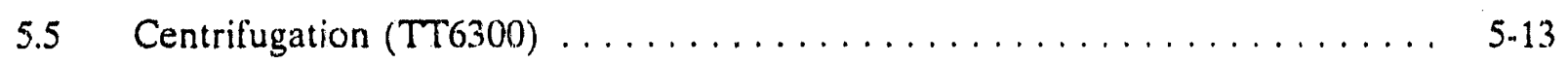

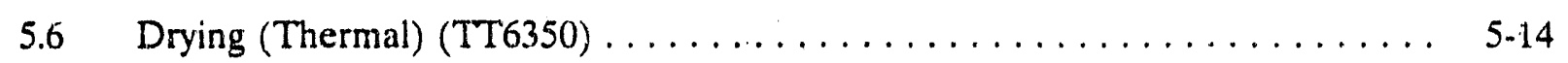

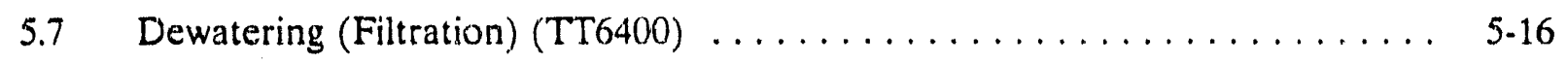

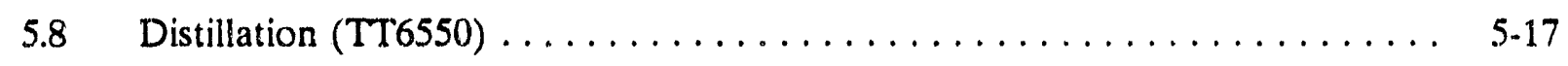

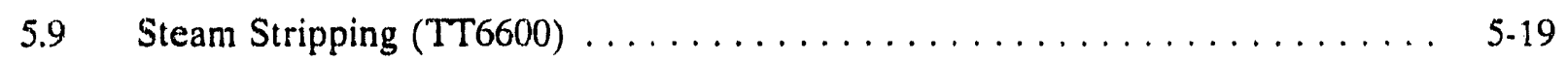

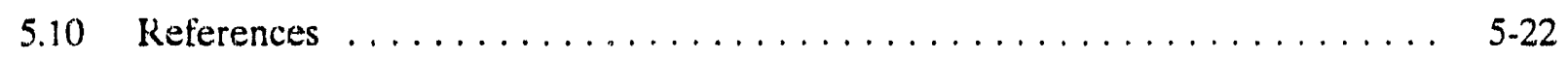

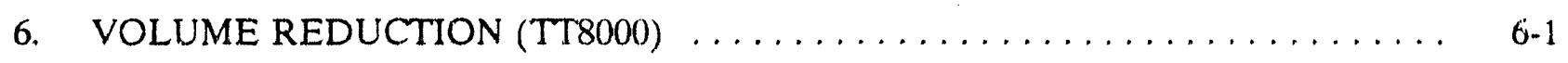

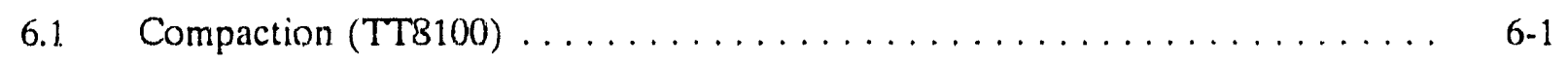

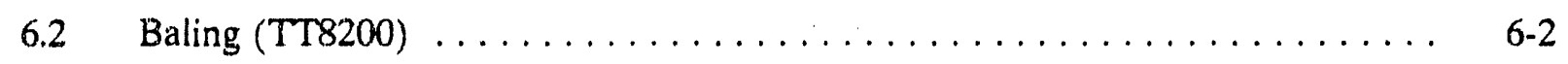

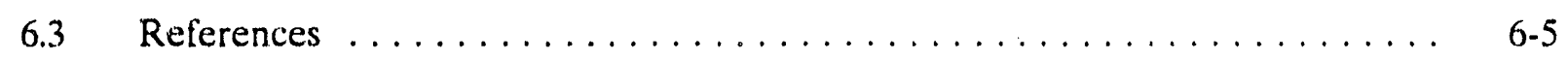

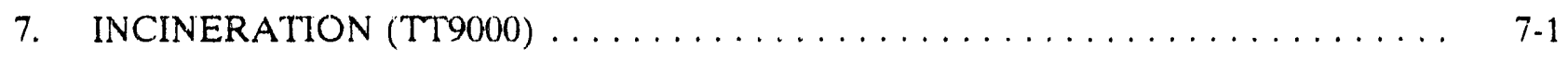

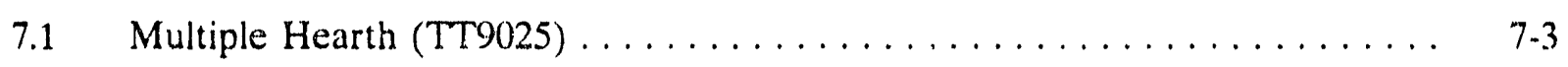

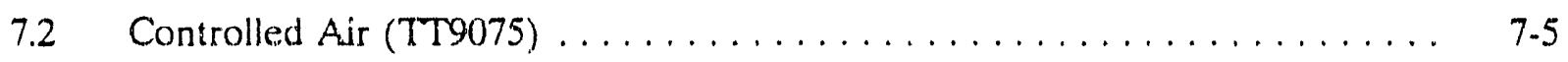

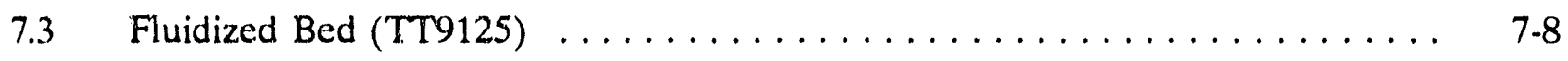

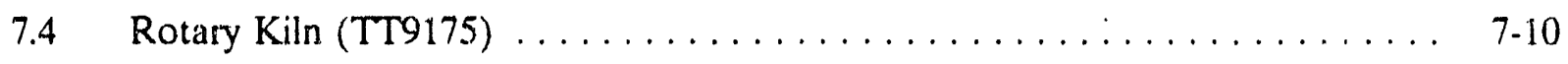

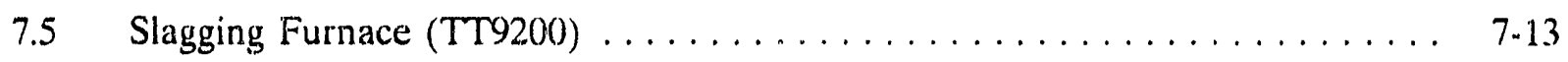

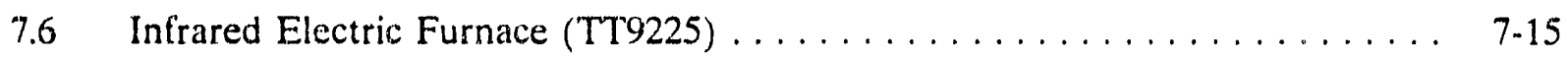

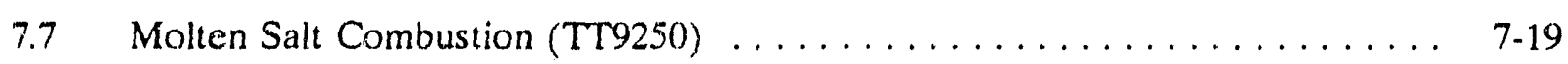

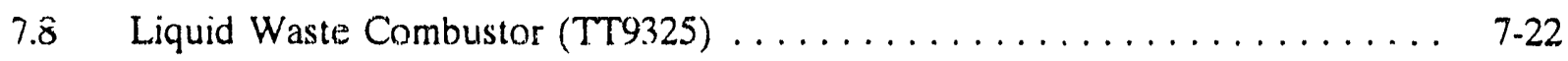

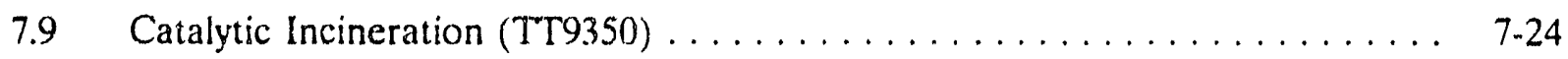

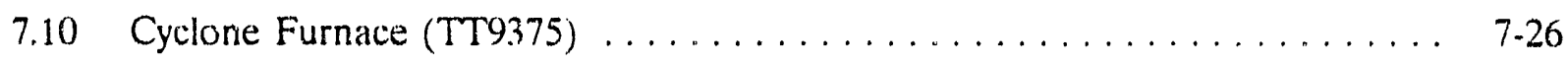

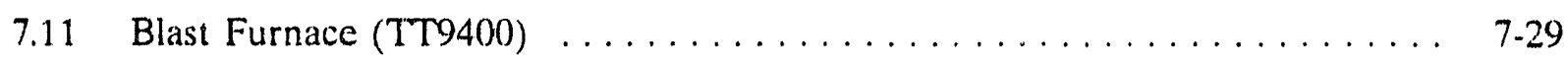




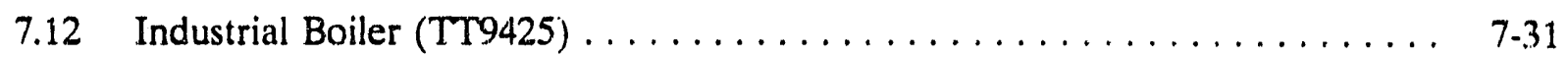

7.13 Industrial Kiln (TT9450) $\ldots \ldots \ldots \ldots \ldots \ldots \ldots \ldots \ldots \ldots \ldots \ldots . .33$

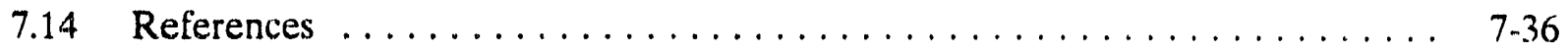

8. THERMAL DEGRADATION/VOLATILIZATION (TT10000) $\ldots \ldots \ldots \ldots \ldots .8-1$

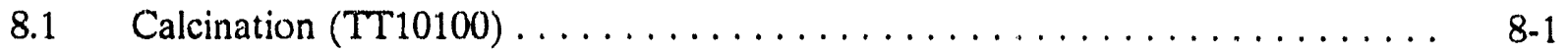

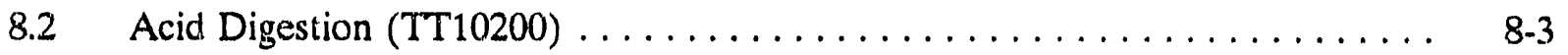

8.3 Chemical Oxidation-Reduction (TT10300) $\ldots \ldots \ldots \ldots \ldots \ldots \ldots \ldots$. 8 .5

8.4 Wet Air Oxidation $(\mathrm{TT} 10500) \ldots \ldots \ldots \ldots \ldots \ldots \ldots \ldots \ldots \ldots$

8.5 Supercritical Fluid Oxidation $($ TT10600) $\ldots \ldots \ldots \ldots \ldots \ldots \ldots, \ldots .8$

$8.6 \quad$ References $\ldots \ldots \ldots \ldots \ldots \ldots \ldots \ldots \ldots \ldots \ldots \ldots \ldots \ldots \ldots, 8,11$

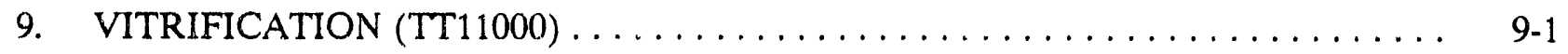

9.1 Glass Furnace (Joule Heated Melter) $($ TT11100) ................ 9-1

9.2 Plasma Arc Heated Melter (Transierred Arc) (TT11200) . . . . . . . . . . . . 9. 9-4

9.3 Plasma Torch Heated Melter (Nontransferred Arc) (TT11300) . . . . . . . 9. 9.7

9.4 Shaft Furnace (Cupola) (TT11400) . . . . . . . . . . . . . . . . . . . . . 9.9

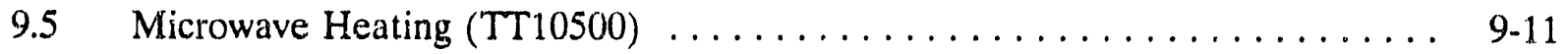

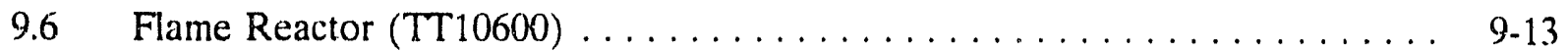

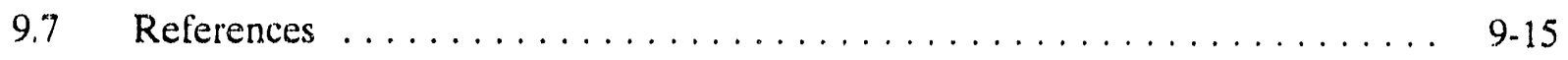

10. IMMOBILIZATION/STABILIZATION $($ TT12000) $\ldots \ldots \ldots \ldots \ldots \ldots \ldots \ldots$ 10-1

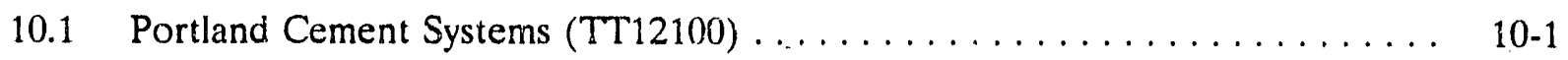

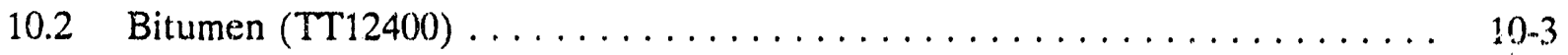

10.3 Vinyl Ester, Organic Polymers $(\mathrm{TT} 12500) \ldots \ldots \ldots \ldots \ldots \ldots \ldots \ldots \ldots \ldots$ 10-4

10.4 Lime Fly Ash Pozzolan Process $(\mathrm{TT} 127()()) \ldots \ldots \ldots \ldots \ldots \ldots \ldots \ldots$. 10.5

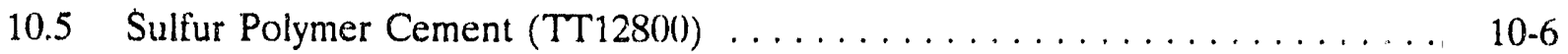




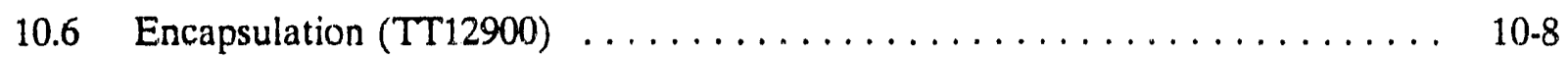

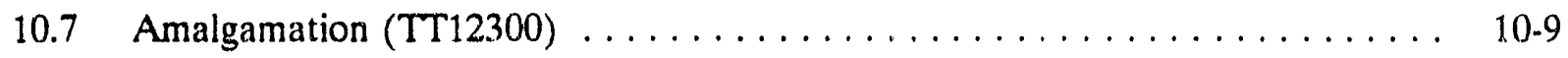

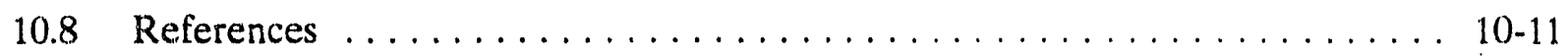

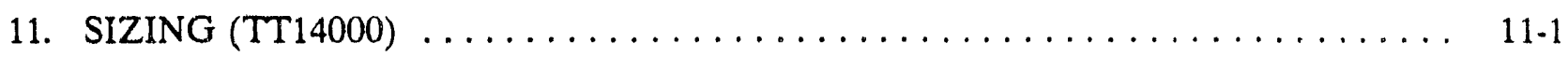

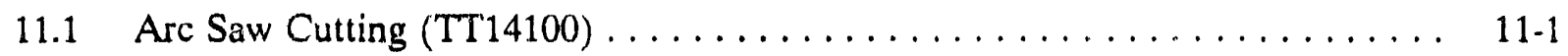

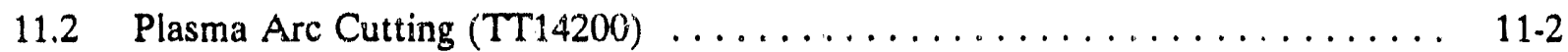

11.3 Oxygen Burning (TT14300) $\ldots \ldots \ldots \ldots \ldots \ldots \ldots \ldots \ldots \ldots \ldots \ldots \ldots \ldots \ldots \ldots \ldots, 11.4$

11.4 Hacksaws and Guillotine Saws $($ TT14400) $\ldots \ldots \ldots \ldots \ldots \ldots \ldots \ldots, 11-5$

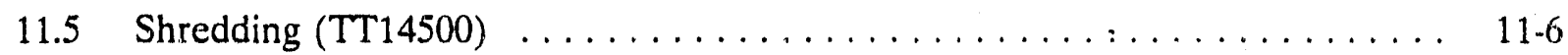

11.6 Cryogenic Fracturing (TT14600) $\ldots \ldots \ldots \ldots \ldots \ldots \ldots \ldots \ldots \ldots \ldots \ldots \ldots \ldots \ldots$

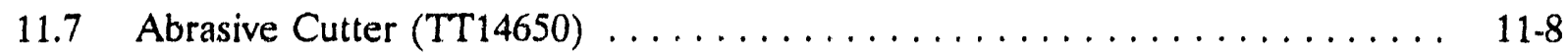

11.8 Thermite Reaction Lance $(\mathrm{TT} 14700) \ldots \ldots \ldots \ldots \ldots \ldots \ldots \ldots \ldots \ldots \ldots \ldots$

11.9 Laser Cutting (TT14800) ......................... 11-10

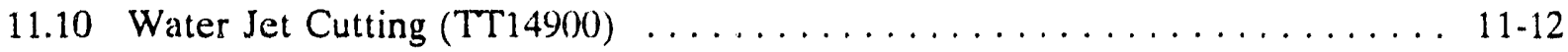

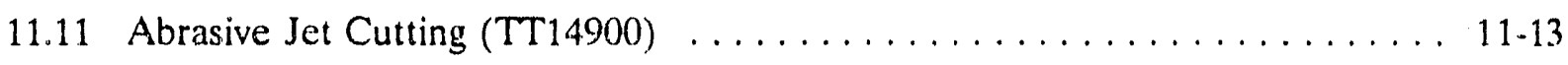

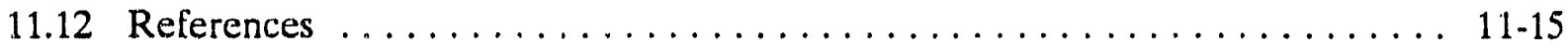

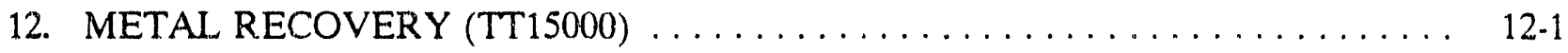

12.1 High Temperature Metals Recovery $(\mathrm{TT} 15100) \ldots \ldots \ldots \ldots \ldots \ldots \ldots . \ldots \ldots$

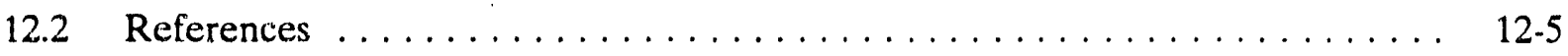

13. PHYSICAL/CHEMICAL TREATMENT $($ TT16000) $\ldots \ldots \ldots \ldots \ldots \ldots \ldots \ldots, 13-1$

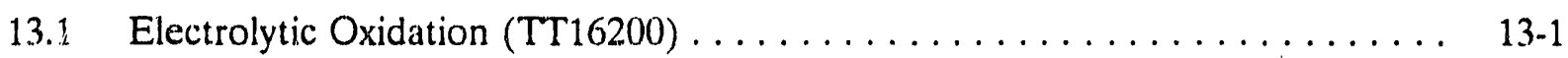

13.2 Alkali Metal Dechlorination $($ TT16300) $\ldots \ldots \ldots \ldots \ldots \ldots \ldots \ldots \ldots$. $13-3$

13.3 Alkali Metal/PEG Dechlorination (TT16400) $\ldots \ldots \ldots \ldots \ldots \ldots \ldots$ 13-4

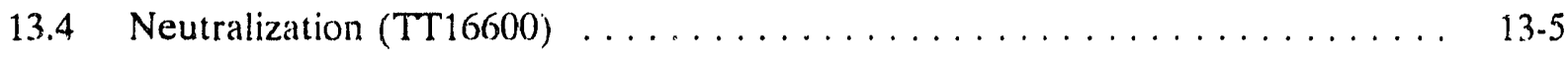


13.5 Oxidation/Reduction (TT16700) $\ldots \ldots \ldots \ldots \ldots \ldots \ldots \ldots \ldots \ldots \ldots \ldots$

13.6 Solvent Extraction $(\mathrm{TT} 16800) \ldots \ldots \ldots \ldots \ldots \ldots \ldots \ldots \ldots \ldots \ldots$

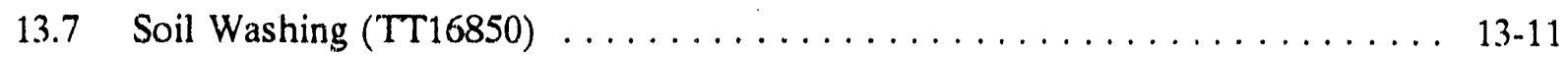

13.8 Controlled Water Reaction $($ TT16900) $\ldots \ldots \ldots \ldots \ldots \ldots \ldots \ldots$ 13-12

13.9 Photochemical Dehalogenation (TT16950) $\ldots \ldots \ldots \ldots \ldots \ldots \ldots \ldots$

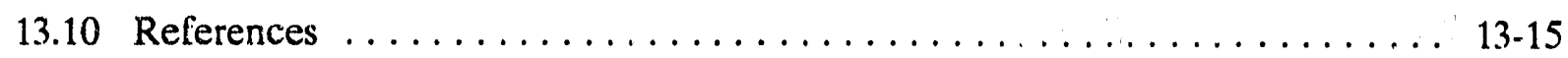

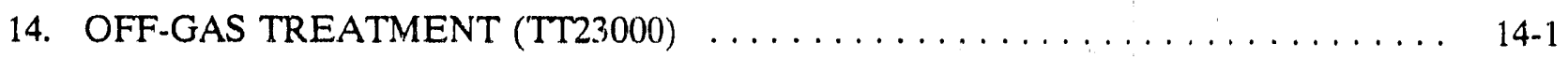

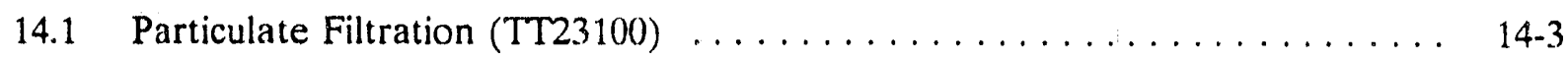

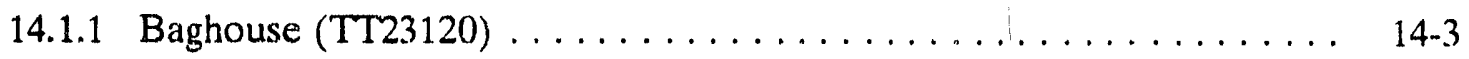

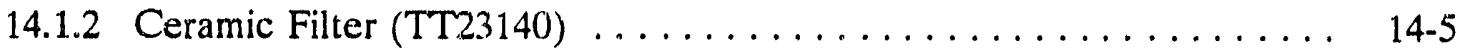

14.1.3 Metal Filter $($ TT23160) $\ldots \ldots \ldots \ldots \ldots \ldots \ldots \ldots \ldots \ldots \ldots$ 14-8

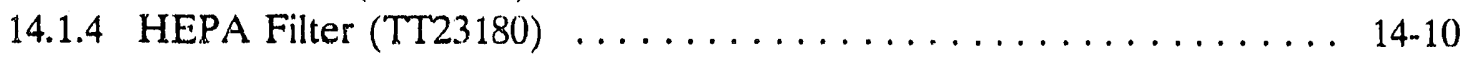

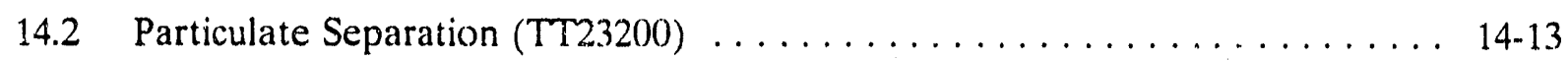

14.2.1 Gravity Separators (TT23220) . . . . . . . . . . . . . . . 14-13

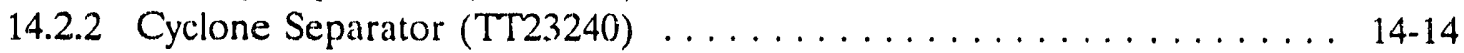

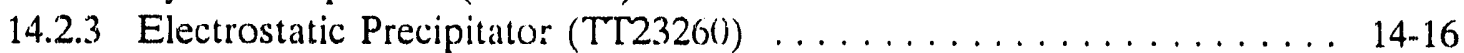

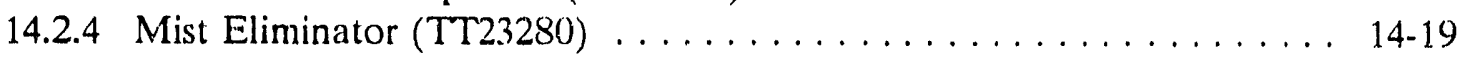

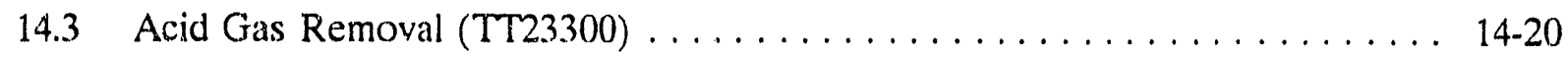

14.3.1 Wet Scrubbing (TT23320) . . . . . . . . . . . . . . . 14-21

14.3.2 Dry Acid Gas Removal (TT23340) . . . . . . . . . . . . . 14-31

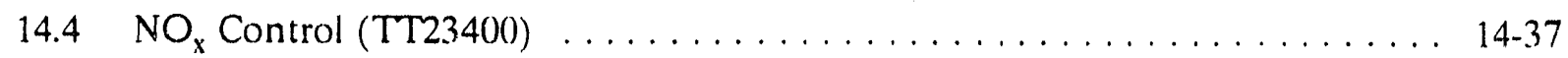

14.4.1 In-furnace $\mathrm{NO}_{\mathrm{x}}$ Controls $(\mathrm{TT2} 3410) \ldots \ldots \ldots \ldots \ldots \ldots$ 14-38

14.4.2 Selective Catalytic Reduction $(\mathrm{TT} 23420) \ldots \ldots \ldots \ldots \ldots \ldots$. . . . . . . . . . . . . . .

14.4.3 Selective Noncatalytic Reduction (TT23430) . . . . . . . . . . . . 14-42

14.4.4 Nonselective Noncatalytic Reduction (TT23440) . . . . . . . . . . . . 14-44

14.4.5 Nonselective Catalytic Reduction (TT23450) . . . . . . . . . . . 14-45

14.4.6 Direct Decomposition (TT23460) . . . . . . . . . . . . . . . 14-46

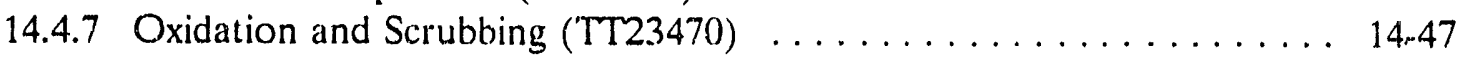

14.4.8 Chelation and Scrubbing $($ TT23480) $\ldots \ldots \ldots \ldots \ldots \ldots \ldots$ 14-48

14.5 Heavy Metals Removal $(\Gamma T 23500) \ldots \ldots \ldots \ldots \ldots \ldots \ldots \ldots$. . . . . . . . . . . . . . . .

14.5.1 Activated Carbon Absorption $($ TT23520) . . . . . . . . . . . 14-51 
14.5.2 Sodium Sulfide Injection $(\mathrm{TT} 23540) \ldots \ldots \ldots \ldots \ldots \ldots \ldots \ldots$ 14-52

14.5.3 Other Mercury Control Processes (TT23560) . . . . . . . . . . 14-53

14.6 Off-gas Cooling/Heating (TT23600) $\ldots \ldots \ldots \ldots \ldots \ldots \ldots \ldots \ldots \ldots \ldots$

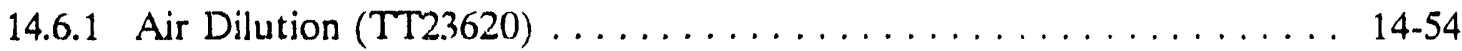

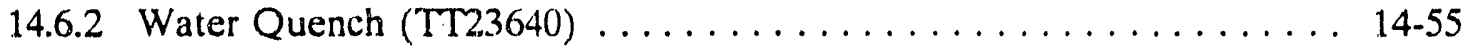

14.6.3 Heat Exchanger (TT23660) . . . . . . . . . . . . . . . . . 14-57

14.6.4 Flue Gas Reheating (TT23680) . . . . . . . . . . . . . . 14-59

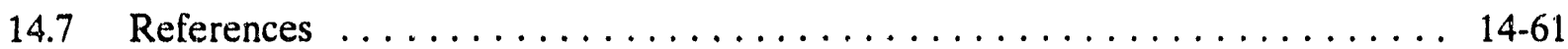

\section{FIGURES}

7-1. Schematic of a multiple hearth furnace $\ldots \ldots \ldots \ldots \ldots \ldots \ldots \ldots \ldots \ldots$

7-2. Schematic of a controlled-air incinerator $\ldots \ldots \ldots \ldots \ldots \ldots \ldots \ldots \ldots$

7-3. Schematic of a fluidized bed furnace $\ldots \ldots \ldots \ldots \ldots \ldots \ldots \ldots$

7-4. Schematic of a rotary kiln incinerator $\ldots \ldots \ldots \ldots \ldots \ldots \ldots \ldots \ldots \ldots \ldots \ldots$

7-5. Schematic of a slagging kiln incinerator $\ldots \ldots \ldots \ldots \ldots \ldots \ldots \ldots \ldots \ldots$

7-6. Schematic of an electric intrared furnace $\ldots \ldots \ldots \ldots \ldots \ldots \ldots \ldots$

7-7. Schematic of a conventional temperature pyrolyzer (batch leed) $\ldots \ldots \ldots \ldots \ldots$ 7-18

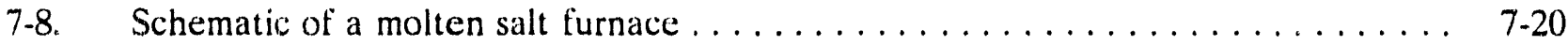

7-9. Schematic of a liquid-injection incinerator and burner $\ldots \ldots \ldots \ldots \ldots \ldots \ldots$

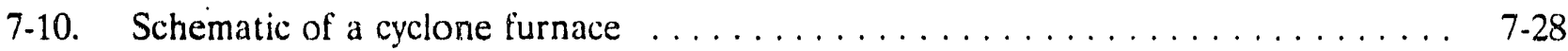

7-11. Schematic of an industrial blast turnace $\ldots \ldots \ldots \ldots \ldots \ldots \ldots \ldots \ldots$

7-12. Schematic of an industrial kiln (typical lor cement, lime, and aggregate kilns) $\ldots \quad$ 7-34

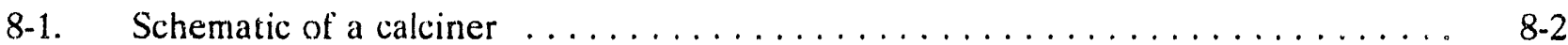

8-2. Schematic of a wet air oxidation process $\ldots \ldots \ldots \ldots \ldots \ldots \ldots \ldots \ldots$

8-3. Schematic of modar oxidation system process thow $\ldots \ldots \ldots \ldots \ldots \ldots \ldots$. . . . .

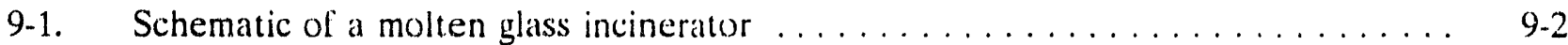

9.2. Schematic of the plasma centrifugal reactor $\ldots \ldots \ldots \ldots \ldots \ldots \ldots \ldots$ 
9-3. Schematic of a plasma torch furnace $\ldots \ldots \ldots \ldots \ldots \ldots \ldots \ldots \ldots \ldots$

9-4. Schematic designs of vertical shaft reictors $\ldots \ldots \ldots \ldots \ldots \ldots \ldots \ldots \ldots \ldots$

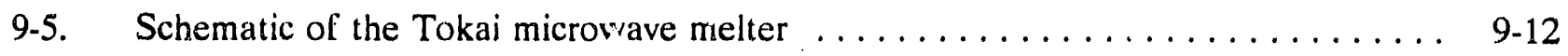

14-1. Typical baghouse schematics, (a) cutaway view (Northern Blower Co.),

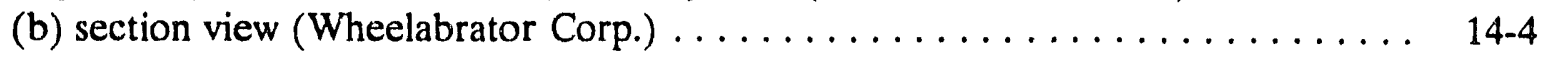

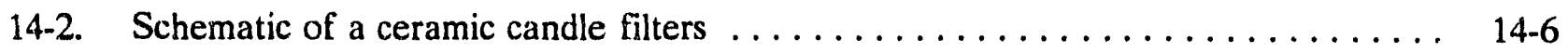

14-3. Schematic of a HEPA filter house nuclear Karlsruhe type $\ldots \ldots \ldots \ldots \ldots \ldots$. . . . 11

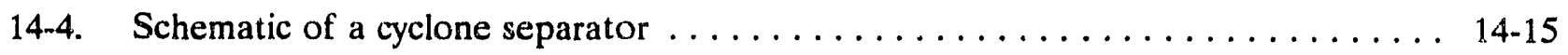

14-5. Schematic of an electrostatic precipitator $\ldots \ldots \ldots \ldots \ldots \ldots \ldots \ldots \ldots \ldots \ldots$

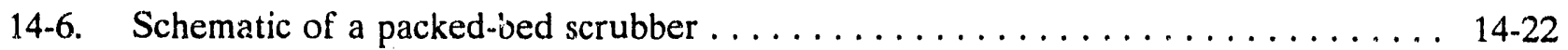

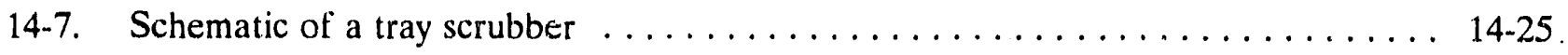

14-8. Schematic of a fluidized-bed scrubber $\ldots \ldots \ldots \ldots \ldots \ldots \ldots \ldots \ldots \ldots \ldots \ldots \ldots$

14-9. Schematic of a venturi-packed bed scrubber system $\ldots \ldots \ldots \ldots \ldots \ldots \ldots \ldots$

14-10. Schematic of dry lime injection/fabric filter scrubbing system $\ldots \ldots \ldots \ldots \ldots$ 14-33

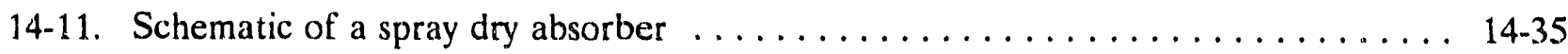

14-12. Schematic of a water injection cooling system $\ldots \ldots \ldots \ldots \ldots \ldots \ldots \ldots \ldots$

14-13. Schematic of a waste heat boiler $\ldots \ldots \ldots \ldots \ldots \ldots \ldots \ldots \ldots \ldots \ldots \ldots \ldots$

TABLES

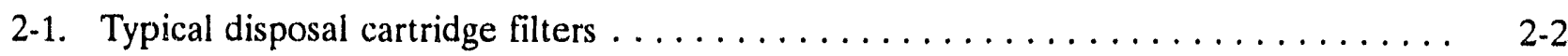

2-2. Typical reusable filters that do not require a precoat $\ldots \ldots \ldots \ldots \ldots \ldots \ldots \ldots$

2-3. Typical reusable filters that require a precoat $\ldots \ldots \ldots \ldots \ldots \ldots \ldots \ldots \ldots \ldots$

2-4. Advantages of ultrafiltration modules $\ldots \ldots \ldots \ldots \ldots \ldots \ldots \ldots \ldots \ldots \ldots \ldots \ldots \ldots$

5-1. Advantages of reverse osmosis modules $\ldots \ldots \ldots \ldots \ldots \ldots \ldots \ldots \ldots \ldots \ldots \ldots$ 


\section{Volume 3 \\ Waste Treatment Technologies}

\section{INTRODUCTION}

One of the major tasks associated with the preengineering studies documented in this report was the identification of potential treatment strategies. Since the treatment strategies for each waste stream are documented in a separate engineering design file (EDF), the proposed technologies are described in this volume, avoiding redundancy in the numerous waste stream files.

The technology information provided in this report is only the first step toward the identification and selection of process systems that may be recommended for a proposed mixed and low-level waste treatment facility. More specific information on each technology will be required to conduct the system and equipment tradeoff studies that will follow these preengineering studies. For example, capacity, maintainability, reliability, cost, applicability to specific waste streams, and technology availability must be further defined. This report does not currently contain all needed information; however, all major technologies considered to be potentially applicable to the treatment of mixed and low-level waste are identified and described herein. Future reports will seek to improve the depth of information on technologies.

The technology information is provided in the following format:

- First, the common name for a treatment technology is given followed by a brief description of the underlying principles of operation, what the system looks like, and how it works.

- Next, input streams are discussed in order to identify the contaminants and waste medias (aqueous wastes, soils, sludges, etc.) that are typically handled by the treatment system.

- Then, a description follows of the output streams, or secondary waste streams that can be expected from the process. For example, this could include gaseous emissions, solidified waste forms, or removal/destruction of hazardous components from a waste stream.

- Advantages are given so the technology can be compared relative to other treatment options.

- Known system limitations are listed as disadvantages.

- Finally, the technology status is given as an assessment of the current level of technology development. 
The technology status is often the deciding factor when recommending a technology for treating a mixed or low-level wasie stream. To facilitate the selection of treatment technologies, each technology was categorized into one of three categories defined below:

- A technology that has been used in nuclear facilities at the scale considered for use at the INEL is proven.

- A technology that has been used in nonnuclear situations at the scale considered for use at the INEL is available.

- A technology that has not yet been operated at the scale required for use at the INEL is emerging.

During the identification of potential treatment strategies, project guidance required the selection of proven or available technologies. Occasionally, stror.gly emerging technologies were recommended in the EDFs, and in some cases, a technology was included in this volume to satisfy a reviewer's request that a technology, though not recommended in the waste stream files, be included for comparison purposes. Since the emphasis is on proven technologies, some emerging technologies may not be included in this volume. As applicable technologies are identified, the listing will be updated.

The technologies presented in this report were placed into one of several general categories, and given reference numbers so they could be easily referenced in the waste stream files. The general categories include filtration, decontamination, evaporation, separation, volume reduction, incineration, thermal degradation, vitrification, stabilization, sizing, metals recovery, physical/chemical, and off-gas treatment. The categories and reference numbers were created so that a treatment system identified in a waste stream EDF could be referenced at the group level [e.ga, stabilization (TT12000)] when no specific technology was warranted for that application, or a more specific reference [i.e., lime fly ásh pozzolan stabilization (TT12700); could be made if necessary.

The technologies discussed in this report were selected from those described in recent technical reports, journal articles, conference proceedings, EPA best developed available technology (BDAT) background documents, and textbooks on the treatment of radioactive and hazardous waste. References to specific sources of information are noted at the beginning of the discussion for each technology. 


\section{FILTRATION $(T T 1000)^{1,2,3}$}

Fiftration is defined as the separation of suspended, undissolved, particulate solids from a fluid mixture by passage of most of the fluid through a permeable medium that retains the solids on or within itself. The mixture to be separated is called the feed, feed slurry, free slurry, influent, or prefilt. The solids to be separated are sometimes termed contaminant, crud, dirt, or suspendew solids. The fluid that passes through the permeable inedium is called the effluent or filtrate. When separated solids accumulate in amounts that visibly :over the medium, they are called the filter cake. In order to obtain fluid flow through the filter medium, a pressure drop must be applied across the medium. The fluid will continue to flow through the tiv er until the flow drops excessively or until the maximum pressure drop $(\Delta P)$ across the medium is reached due to plug ging of the filter medium. Depending upon the filter type, this maximum $\Delta \mathrm{P}$ varies fiom 15 to 100 nsi. Filters selected for radwaste service should be capable of producing an effluent concentration of less than $1 \mathrm{ppm}$ insolubles.

A filter is the assemble ge of equipment that provides (1) housing for the filter medium. (2) room for cake accumulation (if needed). (3) holdup space for the leed and filtrate, (4) drainage channels for the filtrate. (5) mears for the supply and removal or approprate streams, and (6) control devices and instruments.

Specific types of filtration processes and their applicability to particular wasta types are discussed as follows:

Section Technology

$2.1 \quad$ Disposable Filters

2.2 Reusable Filters

$2.3 \quad$ Electrodialysis

$2.4 \quad$ Ultrafiltration

$2.5 \quad$ Granular Bed Filtration

\subsection{Disposable Filters $(\pi 1100)^{1,2}$}

Disposable cartridge filters contain from one to several replaceable elements that are discarded when they become contaminated or loaded to the extent that the differential pressure across the filter reaches a preset value. In the nuclear industry, multiple elements are often mounted in a single removable supporting structure and, to minimize radiation exposure, the entire assembly is discarded at changeout. Disposable elements used in nuclear power plants typically have filter media of woven fabric, wound fiber (string), or pleated paper, supported on a rigid inner core ol perforated stainless steel. For this type of element, the liquid flow is from outside to inside. Also, pleated or matted paper elements are available that are externally supported by a stainless steel basket to accommodate fluid flow from the inside to the outside of the element. In this case, the solids that are removed can be crntained within the supporting basket should the cake be sloughed off due to interruption of flow. 
Two generic types of disprssable filters currently in use at nuclear facilities are cartridge filters and bas type filters. Disposable filters are best suited for the removal of gross contamination from low-pressure, low-temperature.systems. Disposable filters range in filtration capability from $10 \mu \mathrm{m}$ to several hundred microns. Such fine particles often produce an impermeable cake with unusually higl resistance for a small thickness. Therefore, the maximum cake thickness typically is appro "mately $0.318 \mathrm{~cm}(0.125 \mathrm{in}$.) due to the $\Delta \mathrm{P}$ considerations. Consequently, cartridge filtration is used primarily to clarify low.solids containing fluids to an optically clear condition, or to a much lower level of contamination measurable by microscopic or automatic particle-counting techniques, or to a sterile stage by quantitatively removing all bacteria. Disposal filters are limited to fluids containing no more than $0.01 \%$ solids, and where cake handling is unnecessary.

\subsubsection{Cartilidge Filters (TT1200) $)^{1,2}$}

Cartridge filters usually consist of a tiber yarn wound around a perforated-metal core. Depending upon the application, the fibers comnonly used are resin-impregnated wool or cellulose, cotton-viscose, polypropyler $r_{\text {e }}$, nylon, or glass. Cartridge filters are constructed so the entire flow stream is directed through the filter. For high temperature and pressure applications, porous-metal cartridges made of 316 stainless steel, inconel, monel, or nickel are used. The advantages and disadvanıages of typical disposable cartridge filters are listed in Table 2-1 below.

Table 2-1. Typical disposal cartridge filters.

\begin{tabular}{|c|c|c|}
\hline Filter Type & Advantages & Disadvantages \\
\hline Wound Cartridge & $\begin{array}{l}\text { - Compact } \\
\text { - Now solid waste volume } \\
\text { - Crood solids removal }\end{array}$ & $\begin{array}{l}\text { Remote or automatic changeout diffirult because of } \\
\text { nonuniformity and poor arrangement } \\
\text { Changeoul trequemly done on radiation level mather than } \\
\text { pressure drop } \\
\text { Media migration may occur }\end{array}$ \\
\hline Pbeated-paper & $\begin{array}{l}\text { - Lompact } \\
\text { - Now solid waste volume } \\
\text { - Good solids gas or liquid to treat }\end{array}$ & $\begin{array}{l}\text { Remote or automatic changeout difficult because of } \\
\text { nonuniformity and poor arrangement } \\
\text { Changeout frequently done on radiation level rather than } \\
\text { pressure drop } \\
\text { Media migration may occur }\end{array}$ \\
\hline Pleated-nvire Scroen & $\begin{array}{l}\text { - Can operate at elevated temperatures } \\
\text { - Good solids removal } \\
\text { - Little or no media migration }\end{array}$ & $\begin{array}{l}\text { Fair mechanical strength when adequately suppored } \\
\text { Plugging may cause une en thow and non uniform cake } \\
\text { buildup }\end{array}$ \\
\hline
\end{tabular}

\section{Input Streams}

Input streams consist of liquids or gases containing no more than $0.01 \%$ solids. Cartridge filters are not recommended for processing streams that require cake handling.

\section{Output Strearns}

Output strearns consist of a liquid or gas with a particle size of $10 \mu \mathrm{m}$ and smaller particles and the used filters themselves with their filtered particulates. 


\section{Advantages}

Some general advantages of disposable cartridge filters include (1) compact, (2) low solid waste volume, (3) require no backflush gas or liquid, (4) have good solids removal, (5) can operate at elevated temperatures, (6) little or no media migration, and (7) rapid changeout.

\section{Disadvantages}

Some general disadvantages of disposable cartridge filters include (1) a higher operating cost than reusable filters, (2) remote or automatic changeout is difficult, and (3) cannot be used in a high solids environment.

\section{Technology Status}

Proven: Disposable filters are a proven technology that have been used in radioactive waste treatment systems.

\subsubsection{Bag-Type Filters $(T T 1300)^{1,2,3}$}

Bag filters may consist of fiber-mesh bags typically made from nylon, polypropylene, rayon, nomex teflon wool-silk or wool-cotton. Nominal minimum particle size retention is $15 \mu \mathrm{m}$. These filters perform exceptionally well and can be changed out in a few minutes.

\section{Input Streams}

Input streams consist of liquids or gases containing no more than $0.01 \%$ solids. Bag-type filters are not recommended for processing streams that require cake handling.

\section{Output Streams}

Output streams consist of a liquid or gas with a particle size of $15 \mu \mathrm{m}$ and smaller particles, and the used filters themselves with their filtered particulates.

\section{Advantages}

Bag filters have the advantages of (1) rapid changeout (2) broad chemical stability with proper choice of synthetic fibers, (3) especially suitable for straining slurries or dispersions, (4) good roughing filter, and (5) require no backflush gas or liquid.

\section{Disadvantages}

Bag filters have the disadvantages of (1) manual changeout has limited use to treating lowactivity streams at low temperature and pressure, (2) remote or automatic changeout is difficult, and (3) cannot be used in a high solids environment, and (4) a higher operating cost than reusable filters. 


\section{Technology Status}

Proven: Bag filters have been used in radioactive waste treatment systems.

\subsection{Reusable Filters $\left(T^{1} 1400\right)^{1,2}$}

Reusable filters are cleaned by backflushing when they become contaminated or loaded to the extent that the differential pressure across the filter reaches a preset valve. This is accomplished by a reversed-flow blast of gas followed by a liquid rinse through the filter. The filter cake is pushed from the filter as a sludge. After backflushing, the filters are reused. The reusable filters are classified as filters that do not require a precoat and filters that require a precoat. Each type of filter is discussed below.

\subsubsection{Reusable Filters Without Precoat $(T 1500)^{1,2}$}

Several types of backflushable filters do not require precoats. Among these are porous-metallic filters, porous-ceramic filters, and stacked etched-disk filters. A description of the advantages and disadvantages of these filters are discussed in Table 2-2.

\section{Input Streams}

Input streams consist of liquid, sludge, slurry, or gas containing a solids content greater than $0.01 \%$. These filters can be used for processing streams that require cake handling.

\section{Output Streams}

Output streams consist of a liquid or gas with a particle size of $25 \mu \mathrm{m}$ and smaller, separated particulates along with the gases and liquids used for backflushing.

\section{Advantages}

Reusable filters that do not require a precoat have the advantages of (1) lower solid waste generation than reusable filters that require a precoat, (2) lower operating cost than disposable filters, and (3) can handle a fluids containing a higher solids content than the disposable filters.

\section{Disadvantages}

Reusable filters that do not require a precoat have the disadvantages of (1) does not remove particles below $5 \mu \mathrm{m}$ as well as reusable filters that use precoat materials, (2) limited ability to remove oils, and (3) filter life is limited.

\section{Technology Status}

Proven: Reusable filters have been used in radioactive waste treatment systems. 
Table 2-2. Typical reusable filters that do not require a precoat.

\begin{tabular}{|c|c|c|c|c|}
\hline Filter Type & Cleaning Method & Removal Efficiency & Advantages & Disadvantages \\
\hline $\begin{array}{l}\text { Porous-metallic } \\
\text { Fitters: Consists of } \\
\text { woven wire or } \\
\text { sintered metal }\end{array}$ & $\begin{array}{l}\text { Backflushed with } \\
\text { cleaning agents }\end{array}$ & $\begin{array}{l}\text { Best suited for } \\
\text { filtration of large } \\
\text { size particles. Can } \\
\text { be used to remove } \\
\text { particles in the } 5 \text { to } \\
10 \mu m \text { range }\end{array}$ & $\begin{array}{l}\text { - Fair mechanical strength } \\
\text { May be used at } \\
\text { temperature up to } \\
1000^{\circ} \mathrm{F}\end{array}$ & $\begin{array}{l}\text { Backflushing of fine } \\
\text { particles can be } \\
\text { difficult } \\
\text { Eventual permanent } \\
\text { plugging may force } \\
\text { replacement } \\
\text { Filter life unknown or } \\
\text { limited } \\
\text { Harsh cleaning agents } \\
\text { can cause corrosion. }\end{array}$ \\
\hline $\begin{array}{l}\text { Porous-ceramic } \\
\text { Filter: }\end{array}$ & $\begin{array}{l}\text { Backflushed with } \\
\text { cleaning agents }\end{array}$ & $\begin{array}{l}\text { Will remove } 98 \% \text { of } \\
\text { particles }>25 \mu \mathrm{m} \text { or } \\
95 \% \text { of particles } \\
>7 \mu \mathrm{m}\end{array}$ & $\begin{array}{l}\text { - Fair mechanical strength } \\
\text { Resistant to attack by } \\
\text { cleaning solutions } \\
\text { May be used at } \\
\text { temperatures in the } \\
\text { range of } 1000 \text { to } 2000^{\circ} \mathrm{F}\end{array}$ & $\begin{array}{l}\text { Eventual permanent } \\
\text { plugging may force } \\
\text { replacement } \\
\text { Filter life unknown or } \\
\text { limited }\end{array}$ \\
\hline $\begin{array}{l}\text { Stacked Etched-dist } \\
\text { Fiter: Vertically } \\
\text { mounted, closed } \\
\text { pressure vessel } \\
\text { containing iilter } \\
\text { elements comprosed } \\
\text { of stacks of } \\
\text { chemically-etched, } \\
\text { mechanically- } \\
\text { compressed, stainless } \\
\text { steel disks }\end{array}$ & $\begin{array}{l}\text { Backflushed (when } \\
\Delta \mathrm{P} \text { reaches } 75 \mathrm{psi} \\
\text { or high turbidity } \\
\text { observed) by a } \\
\text { burst of air ( } 350 \\
\text { psi) followed by } \\
\text { water }\end{array}$ & $\begin{array}{l}\text { Will remove } 100 \% \\
\text { of } 5 \mu \mathrm{m} \text { particles }\end{array}$ & $\begin{array}{l}\text { - Short backflush time with } \\
\text { thorough cleaning (about } \\
3 \text { to } 8 \% \text { of the time } \\
\text { required for a pressure } \\
\text { tube filter) } \\
\text { - Expected to last for plant } \\
\text { life } \\
\text { - Amenable to automatic } \\
\text { and/or remote operation } \\
\text { - Low solid waste volume } \\
\text { - Compact } \\
\text { High mechanical strength } \\
\text { Precoating can be used } \\
\text { for specific jobs such as } \\
\text { oil or color removal }\end{array}$ & $\begin{array}{l}\text { Low crud-holding } \\
\text { capability } \\
\text { Corrosion } \\
\text { characteristics } \\
\text { unknown } \\
\text { Backwash waste to } \\
\text { treat } \\
\text { Low oil-holding } \\
\text { capacity } \\
\text { Backflushing required } \\
\text { more frequently than } \\
\text { for other types of } \\
\text { precoated filters } \\
\text { because of lower } \\
\text { solids-holding capacity }\end{array}$ \\
\hline
\end{tabular}




\subsubsection{Reusable Filters With Precoat $(\mathrm{TT} 1600)^{1,2}$}

During normal operation, precoat filters will remove particles down to $1 \mu \mathrm{m}$ in diameter. The two basic types of reusable filters with precoat, based on the discharge from the filter are (1) the widely used tubular-support, pressure-precoat filter which discharges slurries, and (2) the flat-bed, clamshell, and centrifugal-discharge filters that produce cake products. The advantages and disadvantages of typical reusable filters that require a precoat are discussed in Table 2-3.

Reusable filters are precoated by first circulating a 5 to $10 \%$ dilute slurry of precoat material through the support mesh or septum. The precoat material particles bridge the small dimensions of the mesh openings and build a coating on the support element. The precoat is held in place by the water pressure. When the recirculating fluid appears clear, the precoat material has been coated on the filter element and the filter is ready for service. About $0.5 \mathrm{~kg} / \mathrm{m}^{3}$ of precoat is applied to the filter surface. The filter is kept in service until the pressure drop indicates the filter medium is becoming plugged. When this occurs, the buildup material is removed, and the filter is precoated again.

Precoat materials used in waste treatment are (1) diatomaceous earth (light friable, natural siliceous material composed of diatom skeletons), (2) Solka Floc (cellulosic fiber), (3) perlite (volcanic glass with a concentric shelly structure), (4) asbestos (fibrous mineral that is chemically resistant), and (5) powdered resins (fine powdered resin made by crushing anionic, cationic, or mixed ion exchange resin). Precoat filters that use powdered resin have both filtration and ion-exchange capabilities. Powdered resin requires a fine mesh as a substrate. When the filter element mesh is unsuitable for powdered resin, a coating of diatomaceous earth or Solka Floc is applied first, and a coat of powdered resin is placed over this substance. Powdered resin can be readily processed when backwashed from the filter.

\section{Input Stream}

Input streams consist of liquid, sludge, slurry, or gas containing a solids content greater than $0.01 \%$. These filters can be used for processing streams that require cake handling.

\section{Output Streams}

Output streams consist of a liquid or gas with $1 \mu \mathrm{m}$ and smaller particles, and separated particulates along with the gases and liquids used for backflushing.

\section{Advantages}

The advantages of reusable precoat filters include (1) the filtration can be automatic or remote operation, (2) precoat filters can handle a solution with a higher solids loading than disposables, (3) powdered resin can be used as a precoat medium to give both filter and ion exchange capabilities, and (4) precoat filters can remove particles down to $1 \mu \mathrm{m}$. 
Table 2-3. Typical reusable filters that require a precoat.

\begin{tabular}{|c|c|c|c|c|}
\hline Filter Type & Precoat & Removal Efficiency & Advantages & Disadvantages \\
\hline $\begin{array}{l}\text { Pressure-tube Filter: } \\
\text { consists of a bundle } \\
\text { of as many as several } \\
\text { hundred perforated } \\
\text { or porous vertical } \\
\text { tubes. }\end{array}$ & $\begin{array}{l}\text { Diatomaceous earth or } \\
\text { cellulose and powdered } \\
\text { resin }\end{array}$ & & $\begin{array}{l}\text { Arnenable to automatic } \\
\text { and/or remote operation } \\
\text { Powdered resin and/or } \\
\text { diatomaceous earth } \\
\text { precoat can be used } \\
\text { Relatively compact }\end{array}$ & $\begin{array}{l}\text { Precoat loss upon loss of } \\
\text { flow or fluctuation in } \\
\text { pressure } \\
\text { Excess or uneven cake } \\
\text { can cause strain and } \\
\text { possible collapse of } \\
\text { supporting screen } \\
\text { Incomplete backflushing } \\
\text { causes uneven precoat }\end{array}$ \\
\hline $\begin{array}{l}\text { Centrifugal- discharge } \\
\text { Futter: consists of } \\
\text { wire-mesh screens } \\
\text { mounted on } \\
\text { horizontal leaves } \\
\text { attached to an axially } \\
\text { mounted hollow } \\
\text { vertical shaft }\end{array}$ & $\begin{array}{l}\text { Precoated using the } \\
\text { standard method }\end{array}$ & $\begin{array}{l}\text { Will remove } 98 \text { to } \\
99 \% \text { of all particles in } \\
\text { the } 1 \text { to } 5 \mu \mathrm{m} \text { range }\end{array}$ & \begin{tabular}{|l} 
High solids-holding \\
capacity \\
Can handle automatically \\
and remotely all plant \\
wastes with same filter \\
Low maintenance \\
requirements \\
No precoat loss caused by \\
loss of flow, pressure, or \\
power
\end{tabular} & 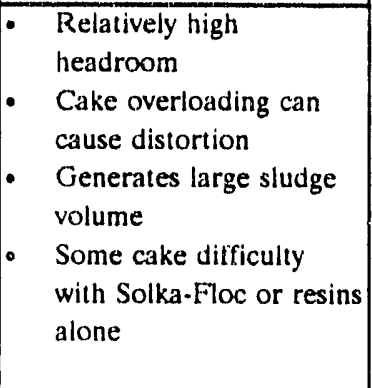 \\
\hline $\begin{array}{l}\text { Flatbed: consists of } \\
\text { horizontal traveling } \\
\text { permanent-screen } \\
\text { (belt) }\end{array}$ & Diatomaceous earth & $\begin{array}{l}\text { Will remove over } 95 \% \\
\text { of particles greater } \\
\text { than } 1 \mu \mathrm{m}\end{array}$ & $\begin{array}{l}\text { High crud-holding capacity } \\
\text { Can handfe automatically } \\
\text { and remotely all planı } \\
\text { was!es with same liiter } \\
\text { No precoal loss caused by } \\
\text { loss of flow, pressure, or } \\
\text { power }\end{array}$ & $\begin{array}{l}\text { Relatively large tloor } \\
\text { space and high } \\
\text { headroom } \\
\text { Cake overloading can } \\
\text { cause belt wear } \\
\text { Generates large sludge } \\
\text { volume } \\
\text { Some cake difficulty } \\
\text { with resin alone } \\
\text { May require tairly high } \\
\text { belt maintenance }\end{array}$ \\
\hline Clamshell: & Diatomaceous earth & $\begin{array}{l}\text { Will remove over } 95 \% \\
\text { of particles greater } \\
\text { than } 1 \mu \mathrm{m}\end{array}$ & $\begin{array}{l}\text { High crud-holding capacity } \\
\text { Can handle automatically } \\
\text { and remotely all types of } \\
\text { plant waste } \\
\text { Can be fully automated } \\
\text { based on precoat time, } \\
\text { maximurn } \Delta \mathrm{P} \text {, or cake } \\
\text { depth } \\
\text { No precoat loss caused by } \\
\text { loss of tlow, pressure, or } \\
\text { power } \\
\text { Relatively small floor } \\
\text { space }\end{array}$ & $\begin{array}{l}\text { Relatively high } \\
\text { headroom, generates } \\
\text { large sludge volume } \\
\text { Maintenance } \\
\text { requirements unknown } \\
\text { No nuclear oper'tion } \\
\text { data to date } \\
\text { Will remove limited } \\
\text { amounts of oil trom } \\
\text { liquid waste }\end{array}$ \\
\hline
\end{tabular}




\section{Disadvantages}

The disadvantages of reusable precoat filters include (1) precoat filters produce the largest volumes of sludge, (2) precoat filters have higher operating costs than reusable filters that do not require precoating, and (3) precoat filters require a longer downtime in order to backwash, and recoat the filter media.

\section{Technology Status}

Proven: Reusable precoat filters have been used in radioactive waste treatment systems.

\subsection{Electrodialysis $(T 1700)^{1,2,4,5,6}$}

Electrodialysis concentrates, separates, or removes ionic species contained in a water solution. A simplified electrodialysis cell consists of an anode and a cathode separated by an anion permeable membrane adjacent to the anode, and a cation permeable membrane adjacent to the cathode. Channels are available for water flow on either side of each membrane. The water to be treated flows through the channel between the two membranes, and electrode rinse water flows in the channels containing the electrodes. A direct current electrical charge is applied across the electrodes. The positively charged ions are drawn through the cation permeable membrane to the cathode. The negatively charged ions are drawn through the anode permeable membrane to the anode. As a result, both positive and negative ion concentrations are significantly reduced in the intermediate channel containing the treated effluent.

Electrodialysis systems are generally stacks of many compartments between two electrodes, separated by alternating cation and anion permeable membranes. The process water flows through all compartmonts. The electric field is induced through all compartments in the stack by the two electrodes. In the electric field, ions will migrate to the appropriate electrode until they are halted by a membrane that is permeable only to the opposite charge. This way, every other flow channel becomes ion-depleted, and the adjacent channels become ion-enriched. Both positive and negative ions are concentrated in the ion-enriched compartments.

Each pass through a cell results in 30 to $60 \%$ deionization of the input ion concentration in one portion of the input stream, and equivalent increases in the other portion. The ion-depleted stream can be up to $90 \%$ of the input stream. Passing the wastewater through several stacks in series reduces the ion concentration in the depleted stream to about $10 \%$ of the input level. The ionenriched stream may contain ions in concentration levels of up to $20 \%$ or more. This stream may be recoverable, recyclable, or may require further treatment prior to disposal because of concentrated amounts of the target contaminants.

The most critical components in electrodialysis are the ion-selective membranes. These are thin sheets of ion exchange resin reinforced by a synthetic fiber backing. The membranes are kept apart by plastic mesh or other types of screens to maintain compartment thicknesses to about $1 \mathrm{~mm}$. This reduces ohmic loss.

In order to reduce membrane fouling, most new electrodialysis systems use reversible electrodialysis. By reversing the polarity in the cells, ionic flow in the concentrating and depleting 
cells is reversed. Fouling, precipitates, and surface films tend to either redissolve or are physically dislodged. Reversible electrodialysis is possible using membranes that can operate in either anion or cation selective modes and using platinum-coated titanium electrodes.

Electrodialysis is most suitable for acidic streams containing a single principal metal ion, but can also be used for treating some streams with $\mathrm{pH}$ of up to 14. Elevated temperatures can reduce power consumption. The process can remove heavy metals or some organics from groundwater.

Pretreatment of the wastewater is often necessary to prevent fouling of the membranes. Pretreatment may include removing suspended solids, oxidizing materials, and ferrous or manganous ions. Because the separations are imperfect and the pretreatment is complex, complications may arise. The pH may need to be adjusted to acidify the catholyte stream.

\section{Input Streams}

The input stream consists of a water stream containing undesirable inorganic or organic ions, such as heavy metal salts.

\section{Output Streams}

The output streams include (1) an ion-depleted and ion-enriched water streams, (2) an iondepleted stream that is often much larger than the ion-enriched stream, (3) gaseous hydrogen and oxygen that may evolve from the electrodes, and (4) discarded membranes from periodic replacement to maintain process efficiency.

\section{Advantages}

The advantages of electrodialysis included (1) electrodialysis cells can operate at nominal pressures and temperatures, (2) the ion-enriched stream can be concentrated to salt levels of $20 \%$ or more, which is higher than available from other processes such as reverse osmosis, (3) when the wastewater is sufficiently pretreated and the membranes are cleaned regularly, they can operate for five years.

\section{Disadvantages}

The disadvantages of electrodialysis include (1) suspended solids or high organic levels can clog or foul the membranes, (2) oxidizing materials and ferrous or manganous ions of concentrations greater than $0.3 \mathrm{mg} / \mathrm{L}$ can damage the membrane, (3) at alkaline $\mathrm{pH}$ readings, membrane life may diminish, (4) calcium concentrations above $400 \mathrm{mg} / \mathrm{L}$ can cause precipitation of calcium sulfate scale, (5) during operation, off-gases including highly reactive hydrogen and oxygen streams must be monitored and handled safely, (6) the membrane performance must be closely monitored due to a decrease in efficiency and (7) the capital equipment required to remove $250 \mathrm{mg} / \mathrm{L}$ salt from a $500 \mathrm{mg} / \mathrm{L}$ stream is comparable to removing $2500 \mathrm{mg} / \mathrm{L}$ from a $5000 \mathrm{mg} / \mathrm{L}$ stream due to a decrease in efficiency resulting from a lower electrolyte conductivity in the purified water stream. 


\section{Technology Status}

Available: Electrodialysis is used in several industries, including salt removal from brine and demineralization of brackish waters. Newer applications are or have been developed for electrodialysis in the food and pharmaceutical industry because this relatively gentle separation does not damage or thermally decompose the products. Dilute radioactive wastewater has been treated using granular ion-exchange resins that are continuously regenerated by the electric current. New developments in membrane technology are increasing the utility of electrodialysis, but the treatment of mixed wastes still requires further development.

\subsection{Uitrafiltration (TT1800) $)^{1,2,4,5,7}$}

The process of ultrafiltration is related to reverse osmosis in that contaminated water is forced through a membrane under pressure. However, the ultrafiltration membrane is considerably more porous than the reverse osmosis membrane. As a result, most soluble species, including inorganic salts, pass through the membrane with the water. Colloids, suspended solids, and high-molecularweight organic molecules do not pass through the membrane with the water. The porous nature of the ultrafiltration membrane allows the process to be operated with high lluxes at relatively low pressures (25 to $200 \mathrm{psig}$ ). This is possible because the osmotic pressure of colloids and highmolecular-weight organics are extremely low. The degree and quantity of the separation are a result of (1) the pore size of the membrane, and (2) the molecular structure, size, shape, and tlexibility of the colloids and organic molecules. Pore sizes range from 0.001 to $0.01 \mu \mathrm{m}$ that allow separation from solution of molecules with a molecular weight between 500 and 300,000 .

Ultrafiltration can be used to selectively remove dissolved metal ions from dilute aqueous solutions. A high molecular weight chelating agent is added to the incoming waste solution to form macromolecular complexes. The solution is then processed through an ultrafiltration membrane system that collects the macromolecular complexes (retentate) on the membrane but allows uncomplexed ions such as sodium, potassium, calcium, chloride, sulfate, and nitrate to pass through as filtered water (permeate).

The basic components of a ultrafiltration unit are membrane elements, a membrane support structure, a containing vessel, feed and collection tanks, a pump, and instrumentation. A system to periodically clean the membranes will also be required and consists of a cleaning solution tank, pump, and receiving tank for the cleaning waste stream.

Membranes are assembled into modules for use in a treatment system. The modules come in several forms: (1) tubular, with inner diameters greater than $10 \mathrm{~mm}$, (2) hollow fiber, with inner diameters less than $1.3 \mathrm{~mm}$, (3) spiral wound, and (4) plate and frame. Each type has advantages and disadvantages in processing efficiency, equipment size, operating temperatures, chemical resistance, and water pretreatment requirements.

Some advantages and disadvantages of the different treatment systems types are listed in Table $2-4$ below.

The most commonly used membrane materials are cellulose acetate, aromatic polyamides, and thin film composites. The process limitations of each material are listed below. 
Table 2-4. Advantages of ultrafiltration modules.

\begin{tabular}{|c|c|c|}
\hline Module Type & Advantages & Disadvantages \\
\hline Tubular & $\begin{array}{l}\text { - Easiest type to clean chemically or mechanically if } \\
\text { membranes become fouled } \\
\text { - Can process high-suspended-solids feed with } \\
\text { minimal pretreatment } \\
\text { - Good hydrodynamic control } \\
\text { - Individual tubes can be replaced } \\
\text { - High Pressure ( } 1500 \text { psig) equipment available }\end{array}$ & $\begin{array}{l}\text { Relative high volume required per unit membrane } \\
\text { area } \\
\text { - Relatively expensive }\end{array}$ \\
\hline Spiral wound & $\begin{array}{l}\text { - Excellent membrane surface/volume ratio } \\
\text { - Less expensive than tubular and hollow fiber } \\
\text { modules }\end{array}$ & $\begin{array}{l}\text { - Susceptible to plugging by particulates } \\
\text { - Badly fouled memoranes are difficult to clean- } \\
\text { basically limited to chemical cleaning }\end{array}$ \\
\hline Hollow fiber & $\begin{array}{l}\text { - Compact } \\
\text { - Good membrane surface/volume ratio } \\
\text { - Economical }\end{array}$ & $\begin{array}{l}\text { - Susceptible to plugging by particulates } \\
\text { - Badly fouled membrane modules are hard to } \\
\text { clean-limited to chemical and mechanical methods }\end{array}$ \\
\hline Plate and frame & $\begin{array}{l}\text { - Good membrane surface/volume ratio } \\
\text { - Well-developed equipment }\end{array}$ & $\begin{array}{l}\text { - Susceptible to plugging at flow-stagnation points } \\
\text { - Potentially difficult to clean } \\
\text { - Expensive }\end{array}$ \\
\hline
\end{tabular}

$\begin{array}{llll}\text { Membrane Material } & \text { pH Limits } & \begin{array}{l}\text { Temperature } \\ \text { Limits }{ }^{\circ} \mathrm{C}\left({ }^{\circ} \mathrm{F}\right)\end{array} \\ \text { Cellulose acetate } & 2.5-7 & 0-50(32-122) \\ \text { Aromatic polyamides } & 4-11 & 0-46(32-115) \\ \text { Thin-film coinipusites } & <1-13 & 0-79(32-175)\end{array}$

Other Limitations

Biologically degradable Cannot tolerate chlorine Can tolerate moderate chlorine levels $(100 \mathrm{ppm})$

The process produces a concentrated waste stream (comprising less than 5\% of the influent volume) that requires treatment or disposal. A cleaning cycle must be included and the membrane should never be allowed to dry out when in contact with the feed material. After the run cycle, the entire ultrafiltration plant must be rinsed with water including the tanks, pipelines, pumps, etc., until the exit water appears clean (for the hollow fiber unit, backflushing with water or permeate should also be done).

\section{Input Stream}

Input streams consist of aqueous solutions containing suspended solids, high-molecular-weight organic molecules (between 500 and 300,000 molecular weight), colloids, and chelated metal macromolecular complexes.

\section{Output Stream}

The output steams from the process include (1) a permeate (usually water) stream containing dissolved salts and low-molecular-weight organic molecules, (2) a concentrated waste stream that approximates $5 \%$ of the influent stream volume (may be as high as $70 \%$ solids), (3) solutions from cleaning the membranes, and (4) discarded membranes from periodic replacement to maintain process efficiency. 


\section{Advantages}

The advantages of ultrafiltration include (1) ultrafiltration can selectively remove dissolved metal ions from dilute aqueous solutions, (2) ultrafiltration can be easily integrated with other processes,

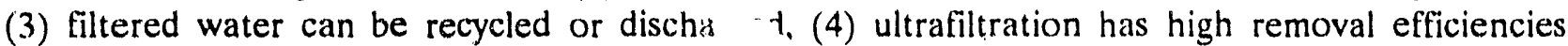
(approaching 100\%), (5) separation process dc ust require an energy-intensive phase change such as is required for distillation or evaporation, (6) capital costs are relatively low, (7) equipment does not require a large amount of space, and (8) membranes can be selected for separation of different molecular sizes.

\section{Disadvantages}

The disadvantages of ultrafiltration include (1) the membrane systems require a liquid that has a low level of particulate contamination, (2) many membranes are susceptible to chemical attack by materials dissolved in the water being treated. (3) the retel.cate must be treated further and (4) little or no removal occurs of dissolved ionized solids and dissolved ionized gases.

\section{Technology Status}

Proven: Ultrafiltration has been used in radioactive waste treatment systems at the Crystal River Nuclear Plant (Florida Power Corporation).

\subsection{Granular Bed Filtration (TT1900) $)^{1,2,5,7}$}

For relatively large volume tlows, granulated media such as sand, garnet, or anthracite coal are used singly or in combination to trap suspended solids within the pore spaces of the media. The granular bed particles are contained within a basin and supported by an underdrain system that allows the filtered liquid to be drawn off while still retaining the filter media. The wastewater is either gravity-fed or pumped through the granular bed media and filtered until either the flow drops excessively or the pumping pressure becomes too high because of plugging of the granular filter media. Granular media filters are usually cleaned by backwashing with previously filtered water in an upflow manner to expand the bed, loosen the media granules, and resuspend the entrapped filte:ed solids. The backwash water, which is 1 to $5 \%$ of the filtered wastewater volume (may be as much as $10 \%$ of the filtered wastewater volume), is then returned to the head of the wastewater treatment system so the filtered solids in the backwash water can be settled out of solution and the water refiltered prior to discharge.

To achieve continuous operation with granular bed filters operated in a batch mode as described above, two filters must be installed in parallel, so that one can be backwashed while the other is operating. Dual and multimedia filter arrangements allow high flow rates and efficiencies.

\section{Input Stream}

Input is a high volume of liquid waste containing suspended solids. 


\section{Output Stream}

liquid.

Output is filtered liquid waste and a slurry of the filtered particles suspended in the backwash

\section{Advantages}

The advantages of granular bed iltration include (1) economical in treating wastes containing less than 100 to $200 \mathrm{mg} / \mathrm{L}$ suspended : olids, (2) reliable and effective for removing low levels of solids from wastes, (3) simple, readily available equipment, (4) easy to operate and control, (5) easily integrated with other processes, (6) small space requirements, (7) available in mobile or onsite systems, and (8) well developed, widely $\ldots$ ed process.

\section{Disadvantages}

The disadvantages of granular bed filtration include (1) the bed must be backflushed to prevent plugging, (2) the backwash requires further treatment, (3) effluent quality is sensitive to large tlow variations, (4) it is marginally effective in treating colloidal-size particles, and (5) pilot plant studies should be conducted to determine optimum size, bed depth, flow velocity, and combination of filter material.

\section{Technology Status}

Proven: Granular bed filtration has been used in radioactive waste treatment systems. The operation of a sand filter in one nuclear plant was deemed unsatisfactory because the continuous addition of polyelectrolyte to the feed stream was required for efficient performance. 


\subsection{References}

1. R. L. Jolley, et al., Low-Level Radioactive Waste From Commercial Nuclear Reactors, Volume 2. Treatment, Storage, Disposal, and Transportation Techmologies and Constraints, ORNL/TM-9864.Vol.2, May 1986.

2. A. A. Moghissi, H. W. Godbee, S. A. Hobart, Radioactive Waste Technology, New York: The American Society of Mechanical Engineers, 1986.

3. P. A. Schweitzer, Ed., Handbook of Separation Techniques for Chemical Engineers, New York, McGraw-Hill Book Company, 1979.

4. Remedial Technology Information System (RTIS) Database, EG\&G Idaho, Inc., Idaho Falls, Idaho, 1991.

5. H. M. Freeman, Editor, Standard Handbook of Hazardous Waste Treatment and Disposal, New York: McGraw-Hill Book Company, 1989.

6. R. H. Perry and C. H. Chilton, Chemical Engineers' Handbook, 5th Edition, New York: McGraw Hill, 1973.

7. S. D. Clinton, Low-Level Radioactive Waste Treatment Technology, DOE/LLW-13Tc, July 1984. 


\section{DECONTAMINATION (TT2000) ${ }^{1}$}

Decontamination is the removal of radioactive contamination deposited at or near the surface of equipment, supplies, tools, hardware, or other solids. The process will normally not completely remove all contamination. However, it can reduce the radiological hazards and result in reclassification of the waste to a lower level. On the other hand, the process creates a secondary waste stream containing the removed contaminants.

Decontamination techniques can be broadly classitied as either mechanical or chemical techniques. In practice, the two types of processes are usually either combined or performed sequentially so that the categorical separation is somewhat arbitrary. The two categories of decontamination processes and their applicability to particular waste types are discussed as follows:

Section Technology

$3.1 \quad$ Mechanical Decontamination

3.2 Chemical Decontamination

\subsection{Mechanical Decontamination $(\pi 2100)^{2,3,4,5,6,7}$}

Mechanical decontamination methods are based on physically dislodging the surface contamination. A variety of methods are available including wiping/scrubbing, grinding/machining, media blasting, high pressure water or steam jets, vacuum cleaning, ultrasonic cleaning, and vibratory finishing. Wiping and scrubbing are labor intensive, involving manual cleaning with cloths or pads. Abrasive media can be used with the wipes, the abrasiveness varied depending on the type of surface and deposit involved. Mechanical decontamination can be combined with chemical decontamination when various chemical agents are added to react with and loosen the deposits and/or improve the ability of the wipes to retain the loosened material. Grinding and machining are essentially mechanically assisted variations of the manual wiping/scrubbing process.

Cleaning with water can be accomplished by simply flushing a surface if the deposits are easily dislodged. If more aggressive deposit removal is required, jets of high pressure water or steam can be empl jed, as well as detergents or cleansers. Equipment requirements for high pressure applications include a supply of water of stearn, a pump, hose and nozzle for delivery, and handling tools, as appropriate, for positioning the nozzle.

Media blasting is based on the use of solid particles suspended in a tluid that is sprayed at high pressure to abrasively dislodge the contamination from the surface. Various media can be used depending on the abrasiveness required. These media include minerals such as sand or garnet, solid carbon dioxide, glass beards, plastic beads, ground nut shells, and wheat starch. Equipment requirements for media blasting are similar to those for water jets.

The vacuum cleaning process is suitable for removing loose or easily removed particulate contamination by drawing the particulate into a vacuum system. Equipment requirements include a source of vacuum. hoses, nozzles, brushes, and a filtration system to collect the removed particulate. 
The basis of ultrasonic cleaning is the immersion of the items to be decontaminated into a liquid bath that is ultrasonically excited. The excitation causes the liquid to cavitate at the interface with the solid surface. Water is usually used in the ultrasonic bath, and chemicals can be added to assist in softening or solubilizing the contamination. The equipment required is an immersion tank and the associated system necessary to induce the desired level of ultrasonic excitation.

\section{Input Streams}

Input streams for mechanical decontamination consist of surface contaminated solid materials.

\section{Output Streams}

Output streams vary based on the decontamination method used. A list of typical mechanical decontamination processes with their associated output streams are listed below.

\section{Process Output Streams}

Water cleaning

Media blasting

Vacuum cleaning

Ultrasonic cleaning

Vibratory finishing
- Solids with redured surface contamination

- Contaminated water

- Solids with reduced surface contamination

- Contaminated abrasive sludge or slurry

- Solids with reduced surface contamination

- Contaminated particulates

- Solids witts reduced surface contamination

- Contaminated liquids used in the ultrasonic cleaning bath

- Solids with reduced surface contamination

- Contaminated abrasive media

\section{Adtrantages}

The advantages of mechanical decontamination include, (1) mechanical decontamination is well developed, (2) it can result in reclassification of large waste items, making them much easier and cheaper to dispose, (3) many processes create either a relatively small waste streams, or a waste streams that can be further processed such that the overall result is a smaller waste stream. (4) with some methods the waste wash can be regenerated and reused, and (5) the various blasting techniques are well suited for use on large, complex surfaces. 


\section{Disadvantages}

The disadvantages of mechanical decontamination include (1) limited to surface and near-surface deposits, (2) surface contamination on internal surfaces is usually more difficult to remove than external surface contamination, (3) the secondary waste streams must be treated, (4) water flushing, steam cleaning, and media blasting can generate large volumes of waste, and can also cause significant splashing and spread of contamination if not controlled carefully, (5) ultrasonic and vibratory cleaning create lower volumes of waste that must be treated, (6) the scrubbing and wiping techniques are labor intensive and are less applicable to large workpieces, and (7) vacuuming is effective for only loose contamination.

\section{Technology Status}

Proven: All techniques are well developed and have been used with radioactive wastes.

\subsection{Chemical Decontamination (TT2200) $)^{2,3,4,5,6,7}$}

Chemical decontamination includes methods that use chemical agents to loosen or solubilize the surface contamination. Contact may be achieved either by immersion of the workpiece in a chemical bath or by surface application of the agent as a liquid, foam, gel, or paste. Chemical agents that are most commonly used include aqueous solutions of mineral or organic acids, chelating agents, or detergents used separately or in various combinations. Chemical decontamination is often done in conjunction with some form of mechanical process such as wiping/scrubbing, grinding, or ultrasonic cleaning. In particular, flushing the surface with water after chemical application is a chemical process enhanced by the effect of a llowing liquid.

For chemical decontamination by immersion, the requipment required incudes a tank, pump, and agitator. The system can be modified to include the appropriate electrochemical equipment to assist the process by enhancing appropriate oxidation/reduction reactions. For surface application, the equipment includes a reservoir for the chemical agent, a pump, hose and nozzles. Since the surfaceapplied chemicals are usually removed by flushing with water, additional equipment includes a source of water and water delivery system.

\section{Input Streams}

Input streams for chemical decontamination consist of the surface contaminated solid matcrials.

\section{Output Streams}

Output streams include the treated solids with reduced surface contamination and contaminated chemical cleaning and rinse solutions.

\section{Advantages}

The advantages of chemical decontamination include (1) it can result in reclassification of large waste items, making them much easier and cheaper to dispose, (2) the waste wash can be regenerated and reused, and (3) immersion in chemical baths generates low volumes of waste. 


\section{Disadvantages}

The disadvantages of chemical decontamination include (1) limited to surface and near-surface deposits, (2) surface contamination on internal surfaces is usually more difficult to remove than external surface contamination. (3) the secondary waste streams must be treated, and (4) water flushing can generate large volumes of waste, and can also cause significant splashing and spread of contamination if not controlled carefully.

\section{Technology Status}

Proven: All techniques are well developed and have been used with radioactive wastes. 


\subsection{References}

1. W. S. Roesener, Unit Systems for the Treatment of TRU Contaminated Waste, WM-PD-92-002, EG\& G Idaho, Inc., February 1992, p. 17-21.

2. Treatment of Alpha Bearing Wastes, Technical Reports Series No. 287, Vienna: International Atomic Energy Agency, 1988.

3. DOE National Low-Level Radioactive Waste Management Program Handbook Series, LowLevel Radioactive Waste Treatment Technology, DOE/LLW-13c, July 1984.

4. A. A. Moghissi, H. W. Godbee, and S. A. Hobart, Radioactive Waste Technology, New York: American Society of Mechanical Engineers, 1986.

5. Management of Abnormal Radioactive Wastes at Nuclear Power Plunts, Technical Reports Series No. 307, Vienna: International Atomic Energy Agency, 1989.

6. United States Environmental Protection Agency, Hazardous Waste Engineering Research Laboratory, Guide for Decontaminating Buildings, Structures, and Equipment at Superfund Sites, EPA/600/2-85/028, March 1985.

7. Treatment of Low- and Intermediate-Level Solid Radioactive Wastes, Technical Reports Series No. 223, Vienna: International Atomic Energy Agency, 1983. 


\section{EVAPORATION (TT4000) $)^{1,2,3,4,5,6,7}$}

Evaporation is the physical conversion of a material from a liquid to a gaseous state. Evaporation is commonly used in industrial operations and hazardous waste treatment. Usually evaporation is used to remove some or most of a solvent from a mixture of dissolved solutes and suspended solids. The solution to be treated may be either a liquid or a slurry mixture and may contain low to high levels of dissolved materials and suspended solids. During the evaporation process, the concentration of some solutes may exceed their solubility. Crystallization of these solutes will occur in the saturated mixture, resulting in increased suspended solids. Drying is the complete removal of the solvent to form a solid material from the liquid stream.

Output streams from evaporation are a relatively pure solvent stream and a more concentrated mixture of dissolved materials in a smaller volume of solvent. The volume of the concentrated output stream is smaller than the input stream. The solvent must be much more volatile than the solutes, or else the vaporized stream of solvent will also contain significant levels of solutes. If the solutes are not significantly less volatile than the solvent, then distillation is required to achieve high purity separation.

Evaporation is most commonly used to vaporize water from aqueous solutions or slurries. This process is widely used in the nuclear industry to reduce the volume of liquid radioactive waste and achieve good decontamination of the evaporated water stream. Most hazardous and radioactive contamination resides in the concentrated stream. The concentrated output stream is easier to dispose of than the untreated waste stream, because it is lower in volume. Volume reduction factors for the concentrated output stream typically range from 100 to 500. Decontamination factors of the vapor stream range from $10^{4}$ to $10^{6}$, depending on the waste stream composition, evaporator design, and operation. Some radionuclides with higher volatilities, which are more difficult to separate from the evaporated water stream, include iodine, boron, and tritium. These more volatile radionuclides may have decontamination factors of 100 .

In order to improve disentrainment of liquid and improve decontamination factors, many evaporators are equipped with vapor-liquid separation devices at the vapor outlet. These devices can include disengagement chambers, columns, beds of packing material, cyclones, baftles, and demisters.

Several limitations exist for evaporation processes, especially in the nuclear industry. These limitations include relatively high operating costs due to (1) energy intensive operation and (2) operational and maintenance problems. Although evaporation is a simple process, common problems can include corrosion, salting, scaling, fouling, entrainment, and foaming. Since most liquid feedstreams contain constituents that will cause at least one of these problems, pretreatment is often required before evaporation. These problems can also be mitigated by proper evaporator design, operation, and construction materials.

Corrosion in evaporation processes can be much more severe than in many other processes. Corrosion can occur due to high temperatures, high velocities (which cause erosion corrosion), vaporliquid concentration gradients, suspended solids (erosion corrosion), feedstream chemical composition, and $\mathrm{pH}$. Measures used to minimize corrosion include filtration and addition of chemical inhibitors and $\mathrm{pH}$ buffers. Construction materials compatible with some corrosive streams include stainless 
steels, titanium, and heat treated, finished or cladded metals. Operational remedies to limit corrosion can include lower fluid velocities and operation under a vacuum to reduce evaporation temperatures.

Scaling occurs when suspended solids or precipitates deposit on evaporator and piping internal surfaces. Scale deposits reduce heat transfer and can increase corrosion. Hard scale compounds include sulfates and silicates of calcium and magnesium. Carbonates and hydroxides of calcium and magnesium form soft scale. Measures to limit scale formation include addition crystal seeds as nuclei for precipitation to occur. Forced circulation and additives also reduce scale formation. Scale removal can be expensive and labor intensive, and the maintenance requires facility outages. Scale may be removed by mechanical or chemical means.

Most radioactive liquid wastes tend to foam. Foaming is caused by the presence of detergents, high $\mathrm{pH}$ levels, suspended matter, salt levels, or other conditions such as temperature gradients that cause viscosity and surface tension variations. The agitation and boiling common in evaporation units increases foaming, which can result in carryover of radioactive elements and other contaminants. Methods used to minimize foaming include hydrodynamic methods, coils, liquid level control, jets, antifoaming agents, and baffles.

Many different evaporators have been designed for different feedstreams and evaporator functions to obtain the desired evaporation and minimize problems inherent to evaporation processes. Solar evaporation is the simplest of all evaporation systems and can be effective and inexpensive. Water is evaporated from sludges and other mixtures in surface ponds without artificial heat input. The ponds are usually lined to limit leaching of contaminants into the underlying soil or groundwater. Capital investment and operating expenses are low. Nonhomogeneous or other difficult to treat streams may be processed using solar evaporation. Several disadvantages include dependence on climatic conditions, large land requirements, attractiveness to waterfowl, and dependence on the integrity of the liner.

Many variations of mechanical evaporator designs are available. The most common designs used for radioactive liquid wastes include:

- Pot, kettle, or pan evaporators

- Natural circulation systems

- Forced circulation systems

Pot, kettle, or pan evaporators are simple single vessel systems used for batch operation. Heat transfer and evaporation occur in the same vessel. Natural circulation systems are those where the fluid circulates by natural convection and turbulence, without added pumping of the fluid through the evaporator to improve heat transfer. Heat transfer and evaporation may occur in separate steps. Forced circulation designs rely on pumps to circulate the fluid from a reservoir through a heat transfer section. In forced circulation, heat transfer and evaporation are separate steps. Flash evaporation occurs when the heated fluid returns to the reservoir, which is at a lower pressure.

Depending mewhat on the design, radioactive liquid waste evaporators may be operated as batch, semibatch, or continuous processes. In semibatch operation, liquid waste is continuously feed 
into the process to maintain a constant level, until the desired concentration factor and density is achieved. Modified semibatch processing is also done, where the feed is stopped after the charge has reached one-half of the desired concentration. This reduces the time span for the final concentration step, reducing tendencies for fouling, corrosion, or scaling.

Other designs that have also been used less frequently for radioactive liquid waste treatment include vapor compression evaporators, wiped-film evaporators, evaporators/crystallizers, nonboiling, evaporators, and submerged combustion evaporators. Submerged combustion evaporators make use of combustion gases bubbling through the liquid as a means of heat transfer, rather than using heat transfer surfaces.

Since these three evaporator designs are most commonly used for treating radioactive wastes, they are discussed in more detail in the following sections.

Section Technology

4.1 Pot and Kettle Evaporators

$4.2 \quad$ Natural Circulation Evaporators

4.3 Forced Circulation Evaporators

\subsection{Pot and Kettle Evaporators (TT4100) ${ }^{6}$}

Pot and kettle type evaporators are the simplest of the many types of mechanical evaporators. Heat transfer and evaporation occur inside a single vessel that is externally heated by a heating jacket, or internally heated by a heating coil. Steam heating tubes are typically $U$ or $V$ shaped and are mounted on a removable plate in the vessel wall for easy removal for cleaning. Operation is usually a batch or semibatch process. Heating may be done using steam or electrical resistance heating.

\section{Input Streams}

Input streams are liquid wastes with dissolved contaminant concentrations that range from less than $1 \%$ to saturated levels, as high as the contaminant solubilities will allow.

\section{Output Streams}

Output streams include vaporized or recondensed water, and a concentrated, reduced volume liquid that contains the majority of the radioactive and hazardous contaminants. The liquid product can be saturated, or a portion of the solutes may be precipitated or crystallized out of solution. Periodically, waste products may occur from maintenance, particularly scale, fouling, or other deposits removed from the vessel or the heating elements.

\section{Advantages}

The advantages of pot and kettle evaporators include (1) simple design, (2) comparatively inexpensive, (3) limited space requirements in a facility, and (4) the variation that uses removable steam heated coils is easy to clean by cold shocking or by removing the coils making the design especially useful for evaporating scale-forming liquids. 


\section{Disadvantages}

The disadvantages of pot and kettle evaporators include (1) pot or kettle evaporators are not suitable for high throughput processes, (2) designs are usually batch or semibaich operations that can incur frequent cycling, and (3) the units have a high holdup and residence time.

\section{Technology Status}

Proven: Pot or kettle evaporators have been used frequently at small facilities that have small liquid waste streams that require treatment.

\subsection{Natural Circulation Evaporators $(T 4200)^{6,8}$}

Natural circulation evaporators include a number of different designs including rising film and falling film long tube vertical (LTV) heaters, recirculating LTV evaporators, short tube evaporators, propeller calandria, and horizontal tube evaporators. In rising film evaporators, feed enters at the bottom of a vertically oriented heat transfer tube bundle. The tubes are externally steam heated and can be 6 to $11 \mathrm{~m}$ ( 20 to $35 \mathrm{ft}$ ) long. Heating and boiling of the feed begins in the tubes. As the boiling in the tubes progresses, the velocities increase. At the tube outlets, the high velocity vapor and liquid impinges on deflector plates above the tube sheet in a separation chamber or vapor body. Vapor exits the top of the vapor body, and the concentrated liquid product drains from the bottom of the vapor body. In recirculating LTV evaporators, this concentrated product is partially recycled to obtain higher concentration factors. The heated tube bundle is separate from the vapor body in recirculating evaporators for easier access during cleaning and maintenance. If the feedstream is shut off and the entire product is recycled, the recirculating evaporator can become a batch process.

Falling film LTV evaporators have a vertically oriented tube bundle for heat transfer and a vapor body at the bottom rather than the top of the tube bundle. Liquid feepd enters the tubes at the top and falls downward in the tubes as a film. Heat transfer and evaporation occur within the tubes. After exiting the bottom of the tube bundle, the vapor and concentrated liquid are separated in the vapor body. Vapor exits the vapor body and concentrated liquid exits from a reservoir at the bottom of the vapor body. The concentrated product can be partially recycled for improved concentration factors. Variations in falling film evaporator designs include using bundles of heat transfer plates rather than tube bundles.

Short tube evaporators are an earlier design type and have limited current use. Short [1.2 to $1.8 \mathrm{~m} \mathrm{(4} \mathrm{to} 6 \mathrm{ft}$ ) long], vertical heat transfer tube bundles are located within a vertical body. The tubes are partially or completely submerged in the feed liquid. Turbulence of boiling and density gradients of the evaporating liquid in the tubes causes natural circulation of liquid through the tubes. Vapor exits the top of the body and product is drained from the bottom. The propeller calandria is a variation of short tube evaporators. A propeller in the fluid downtake provides some forced circulation to the heating elements. This variation can increase short tube evaporator capacities by a factor of two.

Horizontal tube evaporators are less common in radioactive waste treatment processes. These are similar to kettle evaporators, but incorporate natural circulation and design features such as liquid sprays. 


\section{Input Streams}

Input streams can include liquid wastes with dissolved contaminant concentrations ranging from less than $1 \%$ to saturated levels, as high as the contaminant solubilities will allow.

\section{Output Streams}

Output streams include vaporized or recondensed water, and a concentrated, reduced volume liquid that contains the majority of the radioactive and hazardous contaminants. The liquid product can be saturated, or a portion of the solutes may be precipitated or crystallized out of solution. Periodically, waste products may occur from maintenance, particularly scale, fouling, or other deposits removed from the vessel or the heating elements.

\section{Advantages}

Many variations of this general type of evaporator are available. Some advantages of the various types include:

Long tube evaporators - (1) Low cost, (2) large heating surface, (3) low holdup, (4) small tloor space, (5) good heat transfer at reasonable temperature differences (rising film), (6) good heat transfer at all temperature differences (falling film), (7) most applicable for clear, foaming, or corrosive liquids, low temperatures (falling film), and (8) most applicable for large evaporation loads

Short tube evaporators - (1) High heat transfer at high temperature differences, (2) low headroom, (3) easy mechanical descaling, (4) relatively inexpensive, and (5) most applicable for clear, scaling liquids with crystalline product (propeller circulated).

Horizontal tube evaporators - (1) Low headroom, (2) large vapor-liquid disengagement area, (3) low cost (for straight-tube), (4) good heat transfer, (5) easy descaling (bent-tube), and (6) vacuum operation available.

\section{Disadvantages}

Disadvantages of the various types of natural circulation evaporators include:

Long tube evaporators - (1) High headroom, (2) unsuitable for salting or scaling liquids, (3) poor heat transfer for rising film designs at low temperature differences, (4) recirculation usually required for falling film version, (5) rising film units are sensitive to operating conditions, and (6) poor feed distribution in falling film units.

Short tube evaporators - (1) Poor heat transfer at low temperatures, low temperature differences or viscous liquids, (2) high floor space and weight, and (3) high holdup.

Horizontal tube evaporators - (1) Unsuitable for salting or scaling liquids (straight-tube), and (2) high cost (bent-tube). 


\section{Technology Status}

Proven: Natural circulation evaporators are well developed and in use in many industries including food processing, water desalinization, and hazardous, mixed, and radioactive waste liquid treatment. Many natural circulation evaporators are in use at nuclear research installations and power plants.

\subsection{Forced Circulation Evaporators $(\pi 4300)^{2,6,8}$}

Forced circulation evaporators use additional mechanical energy to improve the heat transfer and agitate the liquid, and remove or prevent scaling, fouling or other deposits. This added energy may be from pumps for liquid recirculation or scrapers or wipers for deposit removal. Liquid velocities are typically higher to improve heat transier and limit scale deposition on heat transfer surfaces. Tube velocities range from 1.5 to $3 \mathrm{~m} / \mathrm{s}(5$ to $10 \mathrm{ft} / \mathrm{s})$. Higher tube velocities are possible if erosion corrosion is not prevalent. The heat transfer unit is typically separate from the evaporation and separation chamber. Typically, fluid is pumped through the heat exchanger and then discharged to the evaporation chamber where vapor flashes under lower pressure. Some types are designed for boiling in the heat transfer tubes, but these types are not suited for salting or scaling tluids. Vapor is vented from the evaporation and separation chamber. Concentrated product from the bottom of the chamber is partially recycled.

A variation of the forced circulation evaporator is the multistage evaporator, such as the Bohler type evaporator. Two stages are linked using a direct contact condenser so that the heat of condensation of the vapor from the first stage serves to heat and evaporate the fluid in the second stage.

\section{Input Stream}

Input streams can include liquid wastes with dissolved contaminant concentrations ranging from less than $1 \%$ to saturated levels, as high as the contaminant solubilities will a!low. The input streams can contain salting or scaling solutes or suspended solids, or be relatively viscous.

\section{Output Streams}

Output streams include vaporized or recondensed water, and a concentrated, reduced volume liquid that contains the majority of the radioactive and hazardous contaminants. The liquid product can be saturated, or a portion of the solutes may be precipitated or crystallized out of solution. Periodically, waste products may occur from maintenance, particularly scale, fouling, or other deposits removed from the vessel or the heating elements. In some cases significant amounts of precipitated or crystallized solids may be included with the concentrated product.

\section{Advantages}

Advantages of forced circulation evaporators are (1) high heat transfer, (2) positive circulation, (3) relative freedom from salting, scaling, or deposition, (4) corrosive or viscous solutions can be readily treated, and (5) the product can include crystalline material. 


\section{Disadvantages}

Disadvantages of forced circulation evaporation can include high cost, higher power requirements, higher holdup or residence time, plugging of tube inlets, poor circulation from higher than expected head losses, erosion, corrosion, and salting in tubes where boiling occurs.

\section{Technology Status}

Proven: Forced circulation evaporators are commonly used in many industries including nuclear research and power generation. Many forced circulation evaporators are in use at nuclear installations worldwide. In recent years, a particular forced circulation design has gained favor in the nuclear power industry. This design features a large flash chamber with a conical bottom, a vertical external reboiler, and mechanical disentrainment followed by a distillation tower. Undissolved solids are controlled and removed by the forced circulation and the conical bottom. Another recent design, the evaporator/crystallizer, is designed to concentrate about $50 \mathrm{wt} \%$ solids in the concentrated liquid. 


\subsection{References}

1. DOE National Low-Level Radioactive Waste Management Program Handbook Series, LowLevel Radioactive Waste Treatment Technology, DOE/LLW-13c, July 1984.

2. A. A. Moghissi, H. W. Godbee, and S. A. Hobart, Radioactive Waste Technology, New York: American Society of Mechanical Engineers, 1986.

3. H. M. Freeman, Editor, Standard Handbook of Hazardous Waste Treatment and Disposal, New York: McGraw-Hill Book Company, 1989.

4. Yen-Hsiung Kiang, and A. A. Metry, Hazardous Waste Processing Technology,Boston: Butterworth Publishers, 1982.

5. E. C. Garcia, Mixed Waste Treatment Options for Wastes Generated at the Idaho National Engineering Laboratory, EGG-WM-9451, January 1991.

6. Tieatment of Low-and Intermediate-Level Liquid Radioactive Wastes, Technical Reports Series No. 236, Vienna: International Atomic Energy Agency, 1984.

7. R. L. Black, Radioactive Liquid Waste Treatment Facility, ANL-84-59, July 1984

8. R. H. Perry and C. H. Chilton, Chemical Engineers' Handbook, 5th Edition, New York: McGraw-Hill, 1973. 


\section{SEPARATION (TT6000)}

This section contains information on technologies that can be used to separate metals, suspended solids, or organics from aqueous waste streams. Reverse osmosis, ion exchange, and precipitation are used to remove metals from aqueous stieams. Centrifugation, drying, and dewatering are used to separate and concentrate the solids from an aqueous stream. Carbon adsorption, distillation, and steam stripping are use to separate organics from an aqueous stream. These technologies have been used in industry, and many have been used with radioactive wastes. follows:

Each separation technology and their applicability to particular waste types are discussed as

Section Technology

$5.1 \quad$ Reverse Osmosis

$5.2 \quad$ Ion Exchange

5.3 Carbon Adsorption

$5.4 \quad$ Precipitation

$5.5 \quad$ Centrifugation

$5.6 \quad$ Drying (Thermal)

$5.7 \quad$ Dewatering (Filtration)

$5.8 \quad$ Distillation

$5.9 \quad$ Steam Stripping

\subsection{Reverse Osmosis \\ (TT6050) $)^{1,2,3,4,5,6,7,8,9,10,11,12,13,14,15,16,17,18,19,20,21}$}

When a semipermeable membrane separates two concentrated solutions of different dissolved solids, pure solvent (usually water) will flow through the membrane into the concentrated solution until an equilibrium is reached in chemical potential on both sides of the membrane. The pressure at which equilibrium is established is known as the osmotic pressure. In reverse osmosis, pressure greater than the osmotic pressure ( 300 to $1500 \mathrm{psig}$ ) is applied to the concentrated solution to cause the solvent to flow from the concentrated side of a semipermeable membrane to the dilute side. The high pressure counteracts the osrotic pressure of the dissolved waste and acts as a driving force to concentrate the solution. The clean solution (the permeate) passes through the membrane leaving a concentrated waste stream (the retentate or concentrate), which must be further treated or disposed. In most cases, when the solids concentration reaches about 5 to $10 \mathrm{wt} \%$, osmotic pressure becomes too high to continue the treatment. Reverse osmosis removes 90 to $95 \%$ of total dissolved inorganic solids, 95 to $97 \%$ of most dissolved organics.

Pretreatment of waste should be accomplished prior to reverse osmosis systems because these systems are susceptible to chemical attack, fouling, and plugging; all of which interfere with effective water treatment. The most important factor that affects a reverse osmosis system performance is membrane fouling. Unfortunately, the extent of membrane fuuling cannot be determined during pilot tests but must be analyzed during onsite "slipstream" evaluation. Fouling can be inhibited by pretreatment that should include (1) removing suspended solids by using coagulation followed by 
filtration or by using $5 \mu \mathrm{m}$ prefilters, (2) prefiltering feed with activated carbon to remove all oil and similar organics. (3) adding dispersants to inhibit or control the formation of compounds that will precipitate, coat the membrane, and block water passage, (4) adjusting and controlling temperature and $\mathrm{Ph}$, and (5) chlorinating (followed by dechlorinating the aromatic polyamide membrane systems) to disinfect and prevent slime growths or contamination of the equipment. Fouling can also be decreased by maintaining turbulent flow or using nonferrous materials to decrease the amount of iron-corrosion products in the feed. Although membranes in desalination service may have lifetimes of over five years, membrane life in waste-treatment applications is probably much shorter.

The basic components of a reverse osmosis unit are membrane elements, a membrane support structure, a containing vessel, feed and collection tanks, a high-pressure pump, and instrumentation. A system to periodically clean the membranes will also be required and consists of a cleaning solution tank, pump, and receiving tank for the cleaning waste stream.

Membranes are assembled into modules for use in a treatment system. The modules come in several forms: (1) tubula:, (2) spiral wound, (3) hollow fiber, and (4) plate and frame. Each type has advantages and disadvantages in processing efficiency, equipment size, operating temperatures, chemical resistance, and water pretreatment requirements. Some advantages of the different types of treatment systems are listed in Table 5-1 below.

The most commonly used membrane materials are cellulose acetate, aromatic polyamides, and thin film composites. The process limitations of each material are listed below.

Table 5-1. Advantages of reverse osmosis modules.

\begin{tabular}{|c|c|c|}
\hline Module Type & Advantages & Disadvantages \\
\hline Tubular & $\begin{array}{l}\text { - Easiest iype to clean chemically or mechanically if } \\
\text { - Can process high-suspended-solids feed with } \\
\text { minimal pretreatment } \\
\text { - Good hydrodynamic control } \\
\text { - lindividual lubes can be replaced } \\
\text { - High Pressure (1500 psig) equipraent available }\end{array}$ & $\begin{array}{l}\text { - Relative high solume required per unit membrane } \\
\text { area } \\
\text { - Relatively expensive }\end{array}$ \\
\hline Spiral wound & $\begin{array}{l}\text { - Compact } \\
\text { - Excellent membrane suifacenolume ratio } \\
\text { - Less expensive than tubular and hollow fiber } \\
\text { modules }\end{array}$ & $\begin{array}{l}\text { - Susceptible to plugging by particulates } \\
\text { Badly fouled membranes are difficult to clean- } \\
\text { basically limiled to chemical cleaning }\end{array}$ \\
\hline Hollow liter & $\begin{array}{l}\text { - Compaci } \\
\text { - Good membrane surfacevolume ratio } \\
\text { - Economical }\end{array}$ & $\begin{array}{l}\text { - Susceptible to plugging by particulates } \\
\text { - Badly fouled membrane modules are hard to } \\
\text { clean-iimited to chemical and mechanical methods }\end{array}$ \\
\hline Plale and frame & $\begin{array}{l}\text { - Good membrane surtacenolume ralio } \\
\text { - Well-developed equipment }\end{array}$ & $\begin{array}{l}\text { - Susceptible to plugging al fiow-stagnation points } \\
\text { - Potentially difficult to clean } \\
\text { - Expensive }\end{array}$ \\
\hline
\end{tabular}


Membrane Material

Cellulose acetate

Aromatic polyamides

Thin-film composites
Temperature

pH Limits Limits ${ }^{\circ} \mathrm{C}\left({ }^{\circ} \mathrm{F}\right)$

2.5.7

4.11

$0-50(32-122)$

$0.46(32-115)$

$<1-13$

$0.79(32-175)$
Other Limitations

Biologically degradable

Cannot tolerate chlorine

Can tolerate moderate chlorine levels (100 ppm)

\section{Input Streams}

Input streams for reverse osmosis are primarily feed streams containing dissolved inorganic solids of 0.5 to $50 \mathrm{~g} / \mathrm{L}$ or water with a low suspended solids content. Below this range, ion exchange is more effective; above this range, evaporation is preferred. Typical membranes can treat most inorganic species and some organic compounds (in the molecular weight range of 500 to 1500). However, the membrane and process conditions must be chosen for the specific application. Reverse osmosis will not reliably treat wastes with high organic contents because they may dissolve the membrane and prevent separation of toxic contaminants. Usually, organics require filltration as an extra treatment step to achieve better decontamination of organics.

\section{Output Streams}

The output steams from the process include (1) a relatively pure permeate (usually water) stream generally suitable for recycling, (2) a concentrated waste stream that can range from 10 to $70 \%$ of the influent stream volume. (3) Solutions from cleaning the membranes, and (4) discarded membranes from periodic replacement to maintain process efficiency.

\section{Advantages}

General advantages of reverse osmosis include (1) the separation process does not require an energy-intensive phase change as required for distillation of evaporation. Therefore, operating costs associated with energy consumption are relatively low, (2) capital costs are also relatively low, (3) reverse osmosis equipment does not require a large amount of space, and (4) because reverse osmosis is a straight-forward mechanical process, it requires a low degree of operator skill.

\section{Disadvantages}

General disadvantages of reverse osmosis include (1) the mernbrane systems require a liquid that has a low level of particulate contamination since in most types of systems, the particulates will plug pores and reduce the efficiency, and (2) many membranes are susceptible to chemical attack by materials dissolved in the water being treated.

\section{Technology Status}

Proven: Reverse osmosis is a well-developed technology. Systems have been used in industrial settings for many years with applications to separation, concentration of product streams, and waste water treatment. Most applications for reverse osmosis have been in the electroplating industry for 
removal and recovery of metals, in the wastewater treatment for removal of metals and hazardous materials for discharge or recycle of water, and in conversion of brine water to potable water.

The technology has also been applied in nuclear conditions to a more limited extent. Reverse osmosis has been used for removal of the radionuclides from low-level aqueous wastes, such as laundry and general process streams. Other radionuclide applications have used precipitation methods to form complex nuclides of uranium, plutonium, americium, strontium, and cesium. The waste is then passed through reverse osmosis or ultrafiltration modules for removal of the nuclides. Some adaptation will be required for liquids containing alpha contamination.

\subsection{Ion Exchange \\ (TT6100) $^{1,2,3,4,5,6,7,9,10,12,18,22,23,24,25,26,27,28,29,30,31}$}

The ion exchange process consists of a reversible interchange of ions of the same sign between a solution containing dissolved solids and a solid phase ion exchange media (resins or zeolites). Hence, ion exchange differs from other systems of waste treatment as it is a process for substituting other ions for certain ions in the waste stream.

Ion exchange media are relatively insoluble granular materials that have acid or basic radicals exposed on parts of their surface. These radicals can be exchanged for ions of the same positive or negative sign in the solution in contact with the granular materials. This exchange is done without any physical change in the granular material other than a possible increase in volurne. The same number of ions will be removed from the ion exchange media as are removed from the solution and added to the ion exchange media. Therefore, the capacity of the media to exchange charged radicals is based on the number of ion radicals available on the exposed granular surtace.

Both common and synthetic ion exchange media are ayailable. However, the synthetic resins make large scale ion exchange practical and leasible. Common materials that act as ion exchangers include natural zeolites (clinoptilolite or greensand), clay (montmorillonite), sulfonated coal (crushed anthracite treated with concentrated sulfuric acid, and peat). The most common synthetic resins are polystyrene-based. Divinylbenzene (DVB) is used as a crosslinking agent with the styrene. Higher DVB crosslinkage levels provide a more stable resin, but result in slower ion-exchange kinetics. leading to lower flow rates and larger resin inventories. A newer resin structure, called macroporous, was designed to retain some advantages of the more highly crosslinked gel resin while minimizing its disadvantages. The structure of synthetic ion-exchange resins used in nuclear power plants is based on styrene-divinylbenzene copolymers. Common types of synthetic exchangers are listed in Table 5-2.

Sometimes, the beds are regenerated with strong acids (typically sulfuric acid) and strong bases (typically sodium hydroxide). The strong resins require extensive regeneration, and the weak resins are slow in dissociating weakly ionized or neutral salts. When the resin bed becomes depleted, the resins are treated as radioactive waste. The average life of the resin ranges from about a week for radioactive waste to a year for primary coolant. Condensate resin has an average life of one to two months, or longer when the system is cleaned ultrasonically. 
Table 5-2. Common types of synthetic exchangers.

\begin{tabular}{|c|c|c|c|c|c|c|}
\hline Type of Resins & Functional Group & $\begin{array}{c}\text { Drained } \\
\text { Density } \\
1 \mathrm{~b} / \mathrm{ft}^{3}\end{array}$ & $\begin{array}{l}\text { Operaling } \\
\text { pH Range }\end{array}$ & $\begin{array}{c}\text { Max } \\
\text { Exchange } \\
\text { Capacity } \\
\text { Meq/g }\end{array}$ & $\mathrm{Meq} / \mathrm{ml}$ & Regeneration \\
\hline Strong acid & $\begin{array}{l}-\mathrm{SO}_{3} \cdot \mathrm{H}^{+} \\
\text {Sulfonic acid }\end{array}$ & $49-53$ & $0-14$ & 4.8 & 2.0 & $\begin{array}{l}\text { Excess strong } \\
\text { acid }\end{array}$ \\
\hline Weak acid & $\begin{array}{l}. \mathrm{COO}^{-} \mathrm{H}^{+} \\
\text {Carboxylic acid }\end{array}$ & 45 & $7-14$ & 11 & 4.0 & $\begin{array}{l}\text { Weak or } \\
\text { strong acid }\end{array}$ \\
\hline Strong base type I & $\begin{array}{l}-\mathrm{CH}_{2} \mathrm{~N}\left(\mathrm{CH}_{3}\right)_{3}{ }^{+} \mathrm{OH}^{-} \\
\text {Quaternary ammonium }\end{array}$ & 45 & $0-14$ & 4.3 & 1.3 & $\begin{array}{l}\text { Excess strong } \\
\text { base }\end{array}$ \\
\hline Strong base type II & $\mathrm{CH}_{2} \mathrm{~N}\left(\mathrm{CH}_{3}\right)_{2} \mathrm{CH}_{2} \mathrm{CH}_{2} \mathrm{OH}^{+} \mathrm{OH}^{-}$ & 45 & $0-14$ & 3.4 & 1.4 & $\begin{array}{l}\text { Excess strong } \\
\text { base }\end{array}$ \\
\hline Weak base & $\begin{array}{l}-\mathrm{N}\left(\mathrm{CH}_{3}\right)_{2} \mathrm{H}^{+} \mathrm{OF}^{-} \\
\text {Tertiary ammonium }\end{array}$ & 32 & $0-6$ & 9 & 2.5 & $\begin{array}{l}\text { Weak or } \\
\text { strong base }\end{array}$ \\
\hline Intermediate base & Mix of above two & 43 & $0-14$ & 8.8 & 2.7 & Strong base \\
\hline
\end{tabular}

Ion exchange resins and zeolites have a selective affinity for the removal of specific ions from the solutions. This selectivity varies with ionic strength, relative amounts of ions present, the kind of resin and temperature.

Basic equipment requirements for this process are columns with liquid distribution internals and pumps. A nonregenerated system will require a sluicing system or another method for removal of the resin. Regenerated systems require t.nks lor the regenerant and other support systems for volume reduction of the liquid waste such $;$; evaporation. Several ion-exchange equipment designs are currently employed including the follor ng:

Fixed-bed concurrent - The operation cycle of a fixed bed concurrent demineralizer consists of (1) service: removal of the polluting ions from the feed solution passing down through the column, until leakage of the ion being removed reaches an unacceptable level, (2) backwash: upflow through the column at a flow sufficient to fluidize the resin bead 50 to 100\% to avoid channeling, and to remove any suspended solids what may have tiltered out on the resin bed during service, (3) regeneration: passing either acid (for cation) or caustic (for anion) down through the column to displace the pollutant ions, and (4) displacement and rinse: displacement of regenerant from the column with a water rinse.

Fixed-bed counter current - The countercurrent method uses a service tlow in the opposite direction to the regeneration. This provides higher uptake and regeneration efficiencies and produces less chemical waste and more concentrated recovered products upon regeneration.

Short-bed - This system uses short beds of tine-mesh ion-exchange resin, low exchanger loadings, fast cycle times, and countercurrent regeneration. The significant advantages are claimed for this system include (1) compact size, (2) efficient regeneration. (3) decreased regenerant wastes. (4) short 
off-stream times, and (5) the ability to treat and produce relatively concentrated, as well as dilute, solutions.

Mixed-bed - This system uses two type of resins, usually a mixture of strong-acid cation and strong base anion, to produce an exceptionally high purity effluent. However, the regeneration is inefficient and time-consuming process. Regeneration requires that resins to be separated during the backwash cycle using density differences of the resins prior to regeneration. A sequence of a cation bed in front of an anion bed can replace the mixed bed system. This mode offers better removal of specific radionuclides and makes regeneration easier.

Moving-bed - This is a continuous countercurrent ion-exchange system where a portion of the resin is continuously removed, regenerated, and returned to the process during operation. This has the advantage of maintaining a consistent effluent water quality and eliminating long periods of down time for regeneration.

The performance of the resin is measured by the decontamination factor (DF) that is used as the main guideline for efficiency. Some major factors that effect DF are (1) operation temperature (selectivity generally decreases with increasing concentration and temperature), (2) decrease in capacity of the resin, (3) residence time, (4) flow distribution, (5) contaminant concentration, (6) insoluble particulates, colloids, high silica content, and neutral molecules such as $\mathrm{I}_{2}$, and (7) contamination from organics or biological growth.

The mixed-bed demineralizer is the primary choice for treating radioactive waste. A welldesigned ion-exchange system can reduce the level of radionuclides (in the ionic form) by factors of 10 to 100 . Ion exchangers used in the nuclear industry reduce both corrosion and neutron-induced activities. Operating temperatures are maintained below $60^{\circ} \mathrm{C}$. The bed contains stationary anion and cation resins, with particle sizes ranging from 0.4 to $0.7 \mathrm{~mm}$, and dimensions ranging from 0.6 to $2.4 \mathrm{~m}$ in diameter, 0.9 to $1.8 \mathrm{~m}$ in depth, and volunes of 0.8 to $5.1 \mathrm{~m}^{3}$ of resin. Anion and cation reactions occur simultaneously. The $\mathrm{H}^{+}$and $\mathrm{OH}^{-}$ions removed from the resin react with each other, reducing the concentration of the electrolyte.

Ion exchange rarely represents an option for the ultimate disposal of hazardous wastes since the process generates chemical wastes, and discarded ion-exchange media wastes that usually require further treatment. Its role is usually to reduce the magnitude of a problem by converting a hazardous waste into a form that can be reused, reducing the residual waste stream bearing the toxic substance for disposal.

\section{Input Streams}

Ion-exchange can be used to treat aqueous solutions containing (1) soluble metal species, (2) inorganic anions (sulfates, nitrates, cyanides, etc.), (3) organic acids (carboxlics, phenols, etc.), and

(4) salt from organic amines formed at high $\mathrm{pH}$. Liquid radioactive waste contaminants treated by ion-exchange include iodine (I-131), lithium, cesium (Cs-137), cobalt (Co-60), manganese (Mn-54), zinc $(\mathrm{Zn}-65)$, chlorine, and boron. 


\section{Output Streams}

The outputs produced from ion-exchange include (1) relatively pure treated wastewater, (2) discarded ion-exchange media, and (3) chemical regenerative solutions containing radionuclides and other metal ions extracted from the treated waste. Treatment of radioactive mixed and low-level wastes creates a liquid radioactive waste of high salt content and spent resin in the form of a sludge of low-level or mixed waste.

\section{Advantages}

Advantages to ion exchange include (1) process is able to achieve higher purity for treated water than other processes, (2) can often remove unwanted ions preferentially, (3) numerous manufacturers of ion-exchange equipment, which keeps costs competitive, (4) processes and equipment have been tested over many years, (5) manual and completely automatic units are available, (6) temperature effects from 0 to $35^{\circ} \mathrm{C}$ are negligible, and (7) the process can easily treat both large and small quantities.

In addition, portable and disposable ion-exchange units are available that permit treatment at facilities with a low annual volume of liquid wastes that gives this method an advantage over other transfer technologies.

\section{Disadvantages}

Disadvantages associated with ion-exchange include (1) chemicals for regeneration may be expensive, corrosive, or dangerous, (2) large quantities of chemical waste are produced if excess regenerant is required, (3) there are limitations on the concentrations that can be treated, (4) down time is required for regeneration (semibatch), (5) resins are not completely specific to a particular substance, (6) resins are prone to fouling by some organic substances, (7) biological growth can contaminate the bed, (8) insoluble particulates, colloids, and high silica content cause plugging (suspended solids should be kept below $50 \mathrm{mg} / \mathrm{L}$ ), and (9) automated plants require expert maintenance, and nonautomated plants require knowledgeable operation and frequent attention.

\section{Technology Status}

Proven: Ion exchange has been used (1) to clean up radionuclides in Boiling Water Reactors (BWRs) and Pressurized Water Reactors (PWRs), (2) as polishing step for reverse osmosis treated radioactive wastewater, (3) to treat large volumes of liquids with low concentrations of radioactivity to reduce radioactivity to a level within established standards for release of the treated waste to the environment, and (4) to purify low- to intermediate-level liquid waste solutions generated in processing operations.

\subsection{Carbon Adsorption (TT6150) $)^{5,10,32,33}$}

Carbon adsorption is used to remove organic, and sometimes inorganic, compounds from liquid or gas streams. The EPA recommends carbon adsorption as a Best Demonstrated Available Technology for wastewaters to remove dissolved organics at concentrations less than about $5 \%$ and, to a lesser extent, dissolved metal and other inorganic contaminants. 
The basic principle of operation for carbon adsorption is the mass transfer and adsorption of a molecule from a liquid or gas onto a solid surface. Activated carbon is manufactured in such a way as to produce extremely porous carbon particles whose internal surface area is large (500 to $1400 \mathrm{~m}^{2} / \mathrm{g}$ of carbon). This porous structure attracts and holds (adsorbs) organic molecules as well as certain metal and inorganic molecules.

Adsorption occurs because (1) the contaminant has a low solubility in the waste, (2) the contaminant has a greater affinity for the carbon than for the waste, or (3) a combination of the two occurs. The actual mechanisms for adsorption include physical adsorption, produced by van der Waals forces; chemical adsorption, produced by the formation of chemical bonds; and electrostatic adsorption, resulting from Coulombic forces between ions and charged functional groups. The amount of contaminants that can be adsorbed by activated carbon ranges trom 0.10 to 0.95 gram per gram of carbon.

The adsorbate can be exposed to the activated carbon in a number of different ways. Contacting schemes for aqueous waste streams include mixed-batch, mixed-flow, packed columns, or pulsed/moving beds. Packed columns are most common for treating wastewaters, where granular activated carbon is packed into the column, and the wastewater flows through the stationary bed. The flow can be either down or up through the vertical columns. Typical residence times range from 30 to $100 \mathrm{~min}$. The contaminants in the wastewater are adsorbed most rapidly and effectively by the upper layers of carbon during the initial stages of operation. These upper layers are in contact with the wastewater at its highest concentrations of contaminants. The small amounts of contaminants that are not adsorbed in the first few layers of the activated carbon bed are removed from solution in the lower or downstream portion of the bed. Initially, essentially none of the contaminants escape from the carbon bed.

As the wastewater flows through the column and the adsorption capacity is reached in the initial layers, the adsorption zone (the location in the column where the majority of adsorption is occurring) moves down the column. As the adsorption zone reaches the end of the carbon bed, the concentration in the effluent rapidly approaches the influent concentration. This point in the process is referred to as breakthrough. At breakthrough, the adsorptive capacity of the carbon bed is exhausted, and little additional removal of contaminants occurs.

Once the carbon bed is spent and can no longer remove contaminants from the waste, it is taken offline. The activated carbon is then either regenerated by thermal or chemical methods for further use or treated by incineration and disposed of. If carbon adsorption is used to treat toxic or hazardous materials, the spent carbon is usually incinerated.

Regeneration is accomplished thermally by heating the carbon to a temperature between 816 and $927^{\circ} \mathrm{C}\left(1500\right.$ and $\left.1700^{\circ} \mathrm{F}\right)$ at which most of the adsorbed contaminants are volatilized and destroyed but that is not high enough to burn the surface of the carbon. About 4 to $9 \%$ of the carbon is lost in this process. Steam can also be used to regenerate carbon by volatilizing adsorbed organics. Chemical regeneration involves the use of an acid, alkali, or organic solvent to redissolve contaminants for further treatment and disposal. A loss of performance occurs with each regeneration of spent carbon because metals (such as calcium, magnesium, and iron) plug small pores in the carbon and prevent some organic contaminants from being desorbed at the thermal regeneration temperature. In each thermal regeneration process, some carbon becomes spent, 
requiring treatment and disposal. As a result, makeup carbon has to be added to the regenerated arbon being placed back in service.

\section{Input Streams}

Inputs are aqueous or gaseous waste streams contaminated with organics. Activated carbon can adsorb most RCRA hazardous organics. Carbon adsorption should be considered as a potential removal process for organic contaminants that are nonpolar, have low solubility, or have high molecular weight. Classes of organic compounds amenable to adsorption on activated carbon include aromatic solvents, polynuclear aromatics, chlorinated aromatics, phenolics, high-molecular-weight aliphatic amines, aromatic amines, surfactants, soluble organic dyes, automotive fuels, chlorinated solvents, and aliphatic and aromatic acids. Some inorganic compounds will also adsorb to activated carbon, but the technology is not widely used for this application. This is caused by problems in the regeneration process when high levels of adsorbed inorganics are present.

\section{Output Streams}

Outputs are aqueous or gaseous waste steams with reduced levels of organic contaminants and discarded activated carbon media.

\section{Advantages}

Advantages of carbon adsorption include (1) carbon adsorption is effective for removing organic compounds otherwise untreatable by biological methods and (2) most organics can be reduced to concentrations in the 1 to $10 \mu \mathrm{g} / \mathrm{L}$ level.

\section{Disadvantages}

Suspended solids, oil, and grease can reduce the effectiveness of carbon adsorption by clogging and coating the pores, as well as by competing for adsorption sites, thereby interfering with the treatment of contaminants of concern. This treatment interference occurs with suspended solids at levels greater than about $50 \mathrm{mg} / \mathrm{L}$, and with oil and grease at or above $10 \mathrm{mg} / \mathrm{L}$. Aqueous waste streams may require pretreatment to address hard-water, or precipitation problems. Frequently, excessive head loss will occur in adsorption columns due to suspended-solids accumulation, biological growth in the bed, or fouling of the influent screen. For hazardous waste streams, extensive application specific, bench-scale testing is usually required to implement carbon adsorption and regeneration processes.

\section{Technology Status}

Proven: Carbon adsorption has been used for treatment of commercial hazardous waste, as well as in the radioactive waste treatment industry.

\subsection{Precipitation (TT6200) $)^{1,3,7,8,9,12,34,35,36,37,38,39,40,41,42}$}

Precipitation is a process where all or some of a substance dissolved in a liquid is removed from a waste stream by chemical coprecipitation or by adsorption to form small particles containing the 
substance suspended in the liquid. Chemical coprecipitation is a process where either a soluble substance is converted into an insoluble form by a chemical reaction or by changes in the composition of the solvent to diminish the solubility of the dissolved substance. Adsorption takes place when small amounts of precipitate are added that have an affinity for the dissolved species to be removed. Cyanides need to be removed prior to precipitation because cyanide complexes are formed that keep the metals in solution.

Hydroxide precipitation is effective in removing $\mathrm{As}, \mathrm{Cd}, \mathrm{Cr}(\mathrm{III}), \mathrm{Cu}, \mathrm{Fe}, \mathrm{Mn}, \mathrm{Ni}, \mathrm{Pb}$, and $\mathrm{Zn}$. The process converts soluble metal ions into less soluble hydroxide compounds. When the hydroxide compounds are added to the waste stream, the $\mathrm{pH}$ is raised to a suitable level for optimum precipitation of the hydroxides. Unfortunately, each metal has its own optimal solubility curve. For most cases, treatment at a pH between 9 and 11 will result in precipitation of most metals from solution in sufficient quantities to meet regulatory limits. The most common precipitating agents are calcium hydroxide (lime), sodium hydroxide (caustic), and magnesium oxide or magnesium hydroxide. Common chemicals used for metals precipitation along with many advantages and disadvantages are listed in Table 5-3.

Sulfide precipitation converts soluble metal ions into insoluble metal sulfides. This can be done by using soluble sulfides (sodium sulfide or sodium hydrosulfide) or insoluble sulfides (ferrous sulfide). Soluble sulfides produce relatively high concentrations of dissolved sulfide resulting in a rapid precipitation of dissolved metals. By using insoluble sulfides, the sulfide is released when in the presence of other metals to form metal sulfides. The excess ferrous sulfide is filtered or settled with the metal sulfide precipitates.

Carbonate precipitation has been used to precipitate some metals from wastewaters. The effluent metal concentrations are comparable to hydroxide precipitation, with the benefits of lower $\mathrm{pH}$ and denser, more filterable sludge.

Some metals such as aluminum, iron, and chromium, have unique characteristics that make their removal more difficult. Aluminum and iron become highly soluble if the $\mathrm{pH}$ is raised too high. Chromium can be present in either a hexavalent form $\left(\mathrm{Cr}^{+6}\right)$ or a trivalent form $\left(\mathrm{Cr}^{+3}\right)$. Hexavalent chromium is toxic and will not precipitate at alkaline $\mathrm{pH}$ as chrome hydroxide, whereas $\mathrm{Cr}^{+3}$ will. Therefore, $\mathrm{Cr}^{+6}$ must be reduced to $\mathrm{Cr}^{+3}$ prior to precipitation. This can be done with acid and a strong reducing agent, such as sulfur dioxide or sodium thiosulfate. Once this reduction is completed, the chromium can be removed along with the other metals present. Discussions of the individual characteristics of various metal ions and their removal from water are presented in several EPA publications.

Other reactions of interest are the redox reactions that typically occur in aqueous metal wastes that are relatively devoid of organic compounds. The most common redox reaction is the use of sulfur-based reduction techniques for chromium using soluble sultite salts (sodium bisulfite, metabisulfite, or hydrosulfite). 
Table 5-3. Common precipitation processes.

\begin{tabular}{|c|c|c|c|c|}
\hline $\begin{array}{l}\text { Precipitation } \\
\text { Chemical Used }\end{array}$ & $\begin{array}{c}\text { Metals } \\
\text { Precipitated }\end{array}$ & $\begin{array}{c}\text { Process } \\
\text { pH }\end{array}$ & Advantages & Disadvantages \\
\hline $\begin{array}{l}\text { Calcium hydroxide } \\
\text { (Lime) }\end{array}$ & \begin{tabular}{|} 
As, $\mathrm{Cd}, \mathrm{Cr}(\mathrm{III}), \mathrm{Cu}, \mathrm{Fe}$ \\
$\mathrm{Mn}, \mathrm{Ni}, \mathrm{Pb}$, and $\mathrm{Zn}$ \\
Removal Efficiency \\
$>99 \%$ for $\mathrm{Cr}, \mathrm{Cu}, \mathrm{Pb}$, \\
and $\mathrm{Fe} ; 98.6 \%$ for $\mathrm{Zn} ;$ \\
and $97 \%$ for $\mathrm{Ni}$
\end{tabular} & 9.4 & $\begin{array}{l}\text { Commonly used } \\
\text { Effective } \\
\text { Economical to use } \\
\text { Sludge dewaters easily }\end{array}$ & $\begin{array}{l}\text { Generates largest sludge volume } \\
\text { Interterences with complexing } \\
\text { agents when stabilizing metal } \\
\text { hydroxide sludges } \\
\text { Overdose can result in poor } \\
\text { effluent quality } \\
\text { Sludges generally not desirable for } \\
\text { reclamation }\end{array}$ \\
\hline $\begin{array}{l}\text { Sodium hydroxide } \\
\text { (Caustic) }\end{array}$ & $\begin{array}{l}\text { As, } \mathrm{Cd}, \mathrm{Cr}(\mathrm{III}), \mathrm{Cu}, \mathrm{Fe} \\
\mathrm{Mn}, \mathrm{Ni}, \mathrm{Pb} \text {, and } \mathrm{Zn} \\
\text { Removal Efficiency } \\
>99 \% \text { for } \mathrm{Cd}, \mathrm{Cr}, \mathrm{Pb}, \\
\mathrm{Ni} \text {, and } \mathrm{Zn} ; 98 \% \text { for } \\
\mathrm{Cu} \text {; and } 76 \% \text { for } \mathrm{Ag}\end{array}$ & $9-11$ & $\begin{array}{l}\text { Generates smaller hydroxide } \\
\text { sludge volume } \\
\text { Provides excellent neutralization } \\
\text { efficiency } \\
\text { Sludges suitable for reclamation }\end{array}$ & $\begin{array}{l}\text { More expensive than lime } \\
\text { Requires larger settlers and } \\
\text { dewatering apparatus because } \\
\text { finer solids are formed }\end{array}$ \\
\hline $\begin{array}{c}\text { Magnesium oxide } \\
\text { or } \\
\text { Magnesium hydroxide }\end{array}$ & $\begin{array}{c}\text { As, } \mathrm{Cd}, \mathrm{Cr}(\mathrm{lll}), \mathrm{Cu}, \mathrm{Fe}, \\
\mathrm{Mn}, \mathrm{Ni}, \mathrm{Pb} \text {, and } \mathrm{Zn}\end{array}$ & 8.9 & $\begin{array}{l}\text { Effective in treating waste } \\
\text { streams containing lower } \\
\text { concentrations of metals ( } \leq 50 \\
\text { mg/L) } \\
\text { Lower sludge volumes } \\
\text { Ease of dewalerability } \\
\text { More effective in batch treatment } \\
\text { systems }\end{array}$ & $\begin{array}{l}\text { High reagent costs (Must add } \\
\text { three to four times the } \\
\text { stoichiometric amount to increase } \\
\text { the pH to } 8-9 \text { ) }\end{array}$ \\
\hline $\begin{array}{l}\text { Soluble sulfides } \\
\text { (Sodium sulfide) } \\
\text { (Sodium hydrosulfide) }\end{array}$ & $\begin{array}{c}\text { As, } \mathrm{Cd}, \mathrm{Cr}(\mathrm{III}), \mathrm{Cu}, \mathrm{Fe} \\
\mathrm{Mn}, \mathrm{Ni}, \mathrm{Pb}, \text { and } \mathrm{Zn} \\
\\
\text { Removal Efficiency } \\
82 \% \text { for } \mathrm{Pb} ; 88 \% \text { for } \\
\mathrm{Cr} ; 93 \% \text { for } \mathrm{Zn} ; 95 \% \\
\text { for } \mathrm{Cd} \text {; and } 98 \% \text { for } \\
\mathrm{Cu} \text { and } \mathrm{Ni}\end{array}$ & $>9$ & $\begin{array}{l}\text { Solubilities of metal sultides are } \\
\text { lower than metal hydroxides } \\
\text { Chromates do not require the } \\
\text { additional reduction step } \\
\text { Not sensitive to most chelating } \\
\text { agents } \\
\text { Effective treatment at lower } \\
\text { concentrations } \\
\text { Sludges suitable tor reclamation }\end{array}$ & $\begin{array}{l}\text { Generation of hydrogen sulfide } \\
\text { gas at acidic conditions } \\
\text { Potential of having excess sulfide } \\
\text { remaining in solution after } \\
\text { treatment } \\
\text { Rapid formation of precipitate is } \\
\text { hard to filter }\end{array}$ \\
\hline
\end{tabular}


Table 5-3. (continued).

\begin{tabular}{|c|c|c|c|c|}
\hline $\begin{array}{l}\text { Precipitation } \\
\text { Chemical Used }\end{array}$ & $\begin{array}{c}\text { Metals } \\
\text { Precipitated }\end{array}$ & $\begin{array}{c}\text { Process } \\
\mathrm{pH}\end{array}$ & Advantages & Disadvantages \\
\hline $\begin{array}{l}\text { Insoluble sulfides } \\
\text { (Ferrous sulfide) }\end{array}$ & $\begin{array}{c}\text { As, } \mathrm{Cd}, \mathrm{Cr}(\mathrm{II}), \mathrm{Cu}, \mathrm{Fe}, \\
\mathrm{Mn}, \mathrm{Ni}, \mathrm{Pb} \text {, and } \mathrm{Zn} \\
\text { Removal Efficiency } \\
\text { better than soluble } \\
\text { sulfides for } \mathrm{Cu}, \mathrm{Cd}, \mathrm{Ni} \text {, } \\
\text { and } \mathrm{Zn}\end{array}$ & $8.5-9$ & $\begin{array}{l}\text { Solubilities of metal sulfides are } \\
\text { lower than metal hydroxides } \\
\text { Effective lieatment at lower } \\
\text { concentrations } \\
\text { Removal efficiencies are greater. } \\
\text { in multi-metal systems than in } \\
\text { single-metal systems } \\
\text { Sludges suitable for reclamation }\end{array}$ & $\begin{array}{l}\text { Generation of hydrogen sulfide } \\
\text { gas at acidic conditions }\end{array}$ \\
\hline $\begin{array}{l}\text { Carbonates } \\
\text { (Calcium carbonate) } \\
\text { (Sodium carbonate) } \\
\text { (Carbon Dioxide) }\end{array}$ & $\begin{array}{l}\text { As, } \mathrm{Cd}, \mathrm{Cr}(\mathrm{III}), \mathrm{Cu}, \mathrm{Fe}, \\
\mathrm{Mn}, \mathrm{Ni}, \mathrm{Pb} \text {, and } \mathrm{Zn} \\
\text { Removal Efficiency } \\
\text { comparable to } \\
\text { hydroxide precipitation }\end{array}$ & & denser, more filterable sludge & $\begin{array}{l}\text { Less effective in removal of } \mathrm{Ni} \\
\text { and } \mathrm{Zn} \text { than hydroxide } \\
\text { precipitation }\end{array}$ \\
\hline $\begin{array}{l}\text { Soluble sulfites } \\
\text { (Sodium bisulfite) } \\
\text { (Metabisulfite) } \\
\text { (Hydrosulfite) } \\
\text { (Sulfur dioxide) }\end{array}$ & $\begin{array}{c}\mathrm{Cr}(\mathrm{VI}) \cdot>\mathrm{Cr}(\mathrm{III}), \mathrm{Ba} \text {. } \\
\mathrm{Se}, \text { selenides and } \\
\text { selenates } \\
\text { Removal Efficiency } \\
>98 \% \text { when followed } \\
\text { by addition of } \\
\text { hydrazine and sodium } \\
\text { hydroxide }\end{array}$ & $2 \cdot 3$ & $\begin{array}{l}\text { Reduces } \operatorname{Cr}(\mathrm{VI}) \text { to } \mathrm{Cr}(\mathrm{III}) \text { to } \\
\text { allow } \mathrm{Cr} \text { to be precipitated with } \\
\text { hydroxide solutions }\end{array}$ & $\begin{array}{l}\text { Process uses excess reducing } \\
\text { agents due to the presence of } \\
\text { dissolved oxygen } \\
\text { May not get complete chromate } \\
\text { reduction since process depends } \\
\text { on reaction time, pH, } \\
\text { concentration and type of agent }\end{array}$ \\
\hline
\end{tabular}

The precipitated solids are typically removed by flocculation followed by sedimentation, filtration or centrifugation. Filtration and centrifugation are discussed elsewhere and will not be covered by this section. Flocculation agents are typically added to cause small, unsettleable particles suspended in a liquid medium to agglomerate into larger, more settleable particles, thus increasing sedimentation efficiency. Only radioactivity associated with the small, suspended particles is removed from the liquid waste by flocculation.

Sedimentation is the physical process in which particles suspended in a liquid settle out through the action of gravity. Sedimentation is used to treat a variety of aqueous radioactive wastes by removing existing settleable particles.

Although flocculation, precipitation, and sedimentation are individual process steps, they are interrelated and are often combined into a single overall treatment process. This process can be operated in a batch or continuous mode. For batch systems, a feed system, pumps, and reaction tank for mixing and settling are required. Filters may also be needed if the precipitant is amenable to filtration. Continuous operations are also available, but the equipment is more complex. 


\section{Input Streams}

Inputs are liquid wastes containing arsenic, barium, cadmium, chromium, copper, iron, lead, manganese, mercury, nickel, selenium, silver, thallium, zinc, fluoride, phosphate, sulfate, organic fatty acids, and dissolved radioactive wastes. They can also be used on liquids with dissolved radioactive waste, colloidal and suspended radioactive particles. Discussions of the individual characteristics of various metal ions and their removal from water are presented in several EPA publications.

\section{Output Streams}

The output streams produced by this process are (1) liquid with a reduced metal content, and (2) a two-phase liquid-solid stream with the majority of the waste concentrated in the solid phase. Precipitation removes only radioactivity contained in the dissolved solids amenable to precipitation.

\section{Advantages}

The advantages of precipitation include (1) process is applicable to wastewaters containing a wide range of dissolved metals, as well as other inorganic substances, (2) process is applicable to mixed waste for separating radionuclides from other hazardous constituents in wastewaters, and (3) specific conditions of $\mathrm{pH}$, temperature, and precipitating reagent addition will allow selective removal of part or essentially all of the radioactive component as a precipitate.

\section{Disadvantages}

The disadvantages of precipitation include (1) precipitation/flocculation/sedimentation is generally limited to dilute solutions, (2) the precipitate, or agglomerate, must be separated from the liquid, (3) sedimentation can be slow, and the clarified liquid must generally be treated by filtration to remove unsettled precipitate, and (4) continuous sedimentation equipment involves more maintenance than simple sedimentation in the precipitation process tank.

\section{Technology Status}

Proven: Precipitation/flocculation/sedimentation is a conventional, operational technology. Chemical additives have been identified for removal of numerous radioactive species and also for removal of hazardous metals. The process has been used successfully at Rocky Flats for the removal of TRU from process wastes. Lab and pilot scale additions of ferric hydroxides to waste streams containing dissolved TRU have shown even better results. These methods have been used for treatment of DOE facility liquid wastes at NFS Reprocessing Plant in West Valley, New York, and at Oak Ridge National Laboratory.

\subsection{Centrifugation (TT6300) $)^{1,3,7,8,9,43}$}

Centrifugation is a unit system for separation of light and heavy phases where the heavy phase, usually a solid, is separated from the lighter liquid by spinning such that the force of gravity, used in sedimentation processes, is replaced by centrifugal force. Centrifuges can be roughly divided into low-speed bulk units that separate large quantities of solids from the liquid phase, and high-speed separators for small quantities of solids or liquid-liquid extractions. The designs vary, but generally 
involve a waste feed to a bowl filled with a stack of spinning funnels. The tunnels are inverted, and as they spin the lighter phase migrates toward the center while the heavier phase is thrown to the wall of the bowl.

\section{Input Streams}

Inputs are two-phase aqueous wastes. The second phase may be liquid or may be solid. Centrifugation is a process that may be used to remove suspended solids from liquid radioactive waste streams.

\section{Output Streams}

Two primary outputs produced by this process are (1) a liquid phase containing little of the second liquid or solid phase and (2) a solid or second liquid phase that normally contains the bulk of the waste as a concentrate. Generally, dilute slurry of 2 to $5 \%$ solids can be processed by centrifugation into a slurry of from 15 to $50 \%$ solids.

\section{Advantages}

Advantages of centrifugation include (1) the separation of two-phase mixtures that are close in density is greatly enhanced by centrifugation as opposed to gravity settling, (2) centrifugation can dewater sticky, gelatinous slurries, (3) it is useful for solids contents greater than 0.5 wt $\%$ and is suitable for pretreatment before filtration or treatment of filter backwash solutions, and (4) the bulk centrifuges work with solutions in the range of 10 to $75 \mathrm{wt} \%$ solids while the high-speed units work well with 0.5 to $20 \mathrm{wt} \%$ solids.

\section{Disadvantages}

Disadvantages of centrifugation include (1) plugging of centrifuges and resulting maintenance is a drawback, (2) below 0.5 wt\% solids, separation is ineffective, and (3) the liquid eftluent from centrifuges require secondary treatment.

\section{Technology Status}

Proven: Centrifugation is a conventional, operational technology with application to waste processes.

\subsection{Drying (Thermal) $(T T 6350)^{1,3,44}$}

Drying can be accomplished by either passive or active systems.

Passive systems, such as drying beds or ponds, function by spreading the sludge over a relatively large area and removing water by (1) drainage through a porous support layer below the sludge, and (2) surface evaporation. Variations from the basic concept include decanting liquid from the top to hasten evaporation from the solids or placing a cover over the bed to prevent intrusion of rain. These beds are typically allowed to sit until the sludge begins to cake and crack. The cake, containing as much as $40 \%$ solids, is then removed for further treatment or disposal. 
Active systems, such as evaporators, crystalizers, rotary dryers and spray dryers, operate by applying a heat source to remove water. This unit operation is typically used as a part of an integrated treatment system, such as with a fluidized bed dryer. However, in-drum drying is in use, and a spray dryer is being developed at DOE facilities.

\section{Input Streams}

Inputs are wet solids, sludges, and slurries.

\section{Output Streams}

Outputs from drying include (1) heavy stream contains concentrated sludges or solids with residual liquid; and (2) a light stream containing expelled gases, vapors, and possibly particulates.

\section{Advantages}

Passive systems have the following advantages: (1) low capital cost, (2) low energy consumption, (3) relatively insensitive to sludge variability, (4) higher solids content in cake than mechanical methods, and (5) requires little or no operator attention.

Active systems have the following advantages: (1) high level of system control, and (2) system can be engineered to hasten processing for a particular waste.

\section{Disadvantages}

The disadvantages of a passive system include: (1) larger land requirement than mechanical methods, (2) climatic changes must be considered in design, (3) cake removal is usually labor intensive, (4) possible seepage beyond pond, (5) may be unsightly or odors could permeate to surrounding area, and (6) higher potential for environmental exposure.

The disadvantages of an active system include: (1) capital equipment cost is relatively high, (2) maintenance can be significant, (3) high energy consumption, and (4) higher level of operator interaction is required.

\section{Technology Status}

Proven: Passive systems have been used successfully for many years. Evaporators, crystalizers, rotary dryers, spray dryers, etc., have been used extensively by the chemical industry for many years. Applications of active systems at DOE sites include: (1) an in-drum method consisting of an immersed heating element to promote evaporation from a wet solid waste (Hanford), (2) a spraydryer for the disposal of waste salt solutions (Rocky Flats), and (3) a disposable hot-air evaporator (INEL). Additionally, a method of using a microwave heat source for drying radioactive waste is being investigated for commercial application. 


\subsection{Dewatering (Filtration) (TT6400) $)^{1,3,9,44}$}

Dewatering is distinguished from drying in that dewatering involves pumping and/or gravitationally draining water from wet solids with higher solids content, possibly after centrifuging. Several type of dewatering equipment are available, including: (1) strainers - metal or fiber screens set across a duct or pipe to catch larger solids, (2) belt filter presses - two porous conveyer belts that are pressed together to squeeze the water out of the sludge, (3) rotary vacuum filters - vater drawn by 10 to $20 \mathrm{in}$. of mercury vacuum through the cloth-or metal-mesh-covered drum to leave a cake build up on the outside of the drum, (4) sludge clarifiers - used to filter the tiner particles through a sludge bed to produce a fluid stream essentially free of all tramp material, and (5) centrifuges and other types of filtration that are covered in other sections of this document.

\section{Input Streams}

Inputs are any pumpable streams composed of solids suspended in a fluid, e.g., slurries, sludges, and suspensions.

\section{Output Streams}

Outputs are solids with retained liquid; fluid with reduced amount of suspended solids. Degree of separation dependent on solid and lluid properties and on the type of tiltration system.

\section{Advantages}

The advantages of strainers include (1) low equipment cost, (2) low power requirements, and (3) does not require skilled personnel to operate.

The advantages of belt filter presses include (1) high pressure machine is capable of producing dry cake, and (2) low power requirements.

The advantages of rotary vacuum filters include (1) does not require skilled personnel, (2) has low maintenance requirements for continuous operating equipment, and (3) provides a filtrate with a low suspended solids concentration.

The advantages of sludge clarifiers include (1) capable of reducing the solids content of the filtrate by filtering through the sludge bed, (2) does not require skilled personnel to operite, (3) low equipment costs, and (4) low power requirements.

\section{Disadvantages}

The disadvantages of strainers include (1) requires frequent cleaning, and (2) requires down time to clean strainers.

The disadvantages of belt filter presses include (1) sensitive to incoming feed characteristics, (2) machines hydraulically limited in throughput, and (3) short media life as compared with other devices using cloth media. 
The disadvantages of rotary vacuum filters include (1) consumes the largest amount of energy per unit of sludge dewatered in most applications, (2) requires continuous operator attention, and (3) auxiliary equipment (vacuum pumps) are loud.

The disadvantages of sludge clarifiers include (1) subject to carryover if design flowrates are exceeded.

\section{Technology Status}

Proven: Various configurations are readily available. Disposable units are also marketed.

\subsection{Distillation $(T T 6550)^{1,4,5,7,9,45}$}

Distillation involves application of heat to a liquid mixture, vaporization of part of the mixture and removal of heat from the vaporized portion. The resulting condensed vapor, called the distillate, is richer in the more volatile components, and the residual unvaporized bottoms are richer in the less volatile components. Most cornmercial distillations involve some form of multiple staging to obtain a greater enrichment than is possible by a single-stage vaporization and condensing operation. In simple distillation, a single equilibrium stage is used to obtain a desired separation, and the operation may be either batch or continuous. Simple continuous distillation (flash distillation) has a continuous feed to an equilibrium stage; the liquid and vapor leaving the stage are in equilibrium. Flash distillation is used in applications where a crude separation is adequate. The component separation in simple distillation is limited by thermodynamic partitioning constraints; therefore, multiple staging must be used to increase the separation efficiency. Multiple staging in a column design is achieved by returning part of the condensed overhead vapors to the top of the column, thereby bringing this reflux liquid into intimate contact with the rising vapors. Either a tray or a packed column is normally used to provide the necessary gas-liquid intertacial area for mass translier. The degree of component separation for a given system configuration is dependent upon the operating conditions, the number of stages, and the amount of reflux.

Batch (pot) distillation is applied to spent solvent wastes where a crude separation is acceptable, and the wastes are highly concentrated and yield significant amounts of recoverable material upon separation. For wastes with constituents having a large relative volatility, batch distillation is capable of providing a good separation. Batch distillation is particularly applicable for wastes with high solids concentrations since the more volatile constituents are separated leaving the solids in the still bottoms. In this way, the quantity of waste requiring subsequent land disposal or incineration may also be effectively reduced.

A batch distillation unit consists of a boiler, a condenser, and a product receiver. The boiler is a device that provides the heat required to vaporm: the liquid fraction of the waste. The rising vapor is collected at the top of the column, cooled, and condensed. The liquid product stream is then routed to a product receiver.

Continuous distillation differs from batch distillation in that it is designed to achieve a higher degree of distillate purity. It can be operated to produce multiple product streams for recovery of more than one solvent constituent from a waste, while generating minimal amounts of residue to be 
land disposed. In general, this technology is used where recovery of multiple constitutes is desired and where the waste contains minimal amounts of suspended solids.

A continuous unit consists of a boiler, a stripping section, a rectification section, a condenser, a reflux system, and a product receiver. The boiler is the device that provides the heat required to vaporize the liquid fraction of the waste. The stripping section is composed of a set of trays or packing in a vertical column. In the stripping section, vapor rising from the boiler is brought in contact with the downflowing liquid feed. Through this contacting, the lower boiling point constituents are concentrated in the vapor. In the rectification section, the vapor rising above the feed tray is contacted with the downflowing condensed liquid product (reflux). The rising vapor is collected at the top of the column, cooled, and condensed. The liquid product stream is then routed to a product receiver.

Column internals are designed to accommodate the physical and chemical properties of the wastewater to be treated. Two types of internals may be used in steam stripping: trays or packing. Each tray represents one equilibrium stage. In the packed steam stripping column, the individual equilibrium stages are not discernible, but the number of equivalent trays can be calculate. from mathematical relationships. Tray types include bubble cap, sieve, valve, and turbok-grid. Trays have several advantages over packing including (1) trays are less susceptible to blockage by solids, (2) they have a lower capital cost for large diameter columns $\geq 1 \mathrm{~m}(\geq 3 \mathrm{ft})$, and $(3)$ they accommodate a wider range of liquid and vapor flow rates. Packing types include raschig rings, pall rings, saddles, and sulzer-structures. Compared to trays, packing has the advantages of (1) having a lower pressure drop per theoretical stage, (2) being more resistant to corrosive materials, (3) having a lower capital cost for small diameter column $<1 \mathrm{~m}(<3 \mathrm{ft})$, and (4) being less susceptible to foaming because of a more uniform flow distribution.

\section{Input Streams}

The incoming streams would be wastewater with volatile organic compounds (VOCs) (batch or continuous) or solids and sludges with VOCs (batch only). Radioactively contaminated mixed wastes with metals and organics can te treated as well to remove the organic constituents from the rest of the waste.

\section{Output Streams}

The output streams to the distillation system are the overheads that contain a mixture of the organic phase and water rich in organics, and the bottoms that are wastewater having little organics. In addition to the VOCs, if the wastewater stream contained dissolved metals and radionuclides [both an EPA toxic metal (Dxxx) and solvent waste] distillation would separate the organic material from the rest of the waste.

\section{Advantages}

Distillation is preferred over steam stripping if the concentration of VOCs and toxic organics are greater than $10 \%$ by weight. 


\section{Disadvantages}

The disadvantages of distillation are that the capital and operating costs are larger than that lor air and steam stripping. In comparison with other treatments for organics, distillation is considered a complex system due to the complex process controls, such as temperature, pressure, and reflux ratios. Also, since the packing depth and tower diameter are functions of the incoming feed concentrations, the required removal, the vapor loading and liquid loading rate, the packing characteristics, temperature, and pressure, the distillation tower may be confined to specific waste stream conditions.

\section{Technology Status}

Available: Distillation has been successfully demonstrated in the petroleum industry to separate crude oil into fractions of varying volatilities for use as gasoline, diesel, heating oil, motor oils and asphalt.

Currently this process is not being used for mixed wastes. Future plans to use this process for mixed wastes are uncertain.

\subsection{Steam Stripping (TT6600) $)^{1,4,5,7,9,45}$}

Steam stripping is a distillation process that provides for the separation of constituents based on differences in volatility. More volatile constituents are separated from less volatile constituents by vaporization by means of steam heat. This treatment is applicable to wastewaters that contain BDAT organics that are sufficiently volatile so they can be removed by the application of steam. These BDAT organics include 1,1,1-trichloroethane, 1,1,2-trichloro-1,2,2-trilluoromethane, acetone, n-butyl alcohol, cyclohexanone, ethyl acetate, ethyl ether, methanol, methyl isobutyl ketone, carbon disulfide, isobutanol, and methyl ethyl ketone. The basic principle of operation for steam stripping is the volatilization of hazardous constituents through the application of heat. The constituents that are volatilized are then condensed and either reused or further treated. The integral part of the theory of steam stripping is the principle of vapor-liquid equilibrium. If the difference between the vapor pressure is extremely large, a single separation cycle or single equilibrium stage of vaporization and condensation may achieve a significant separation of the constituents. If the difference between the vapor pressures is small, then multiple equilibrium stages are needed to achieve effective separation. The parameter that is used to determine the extent of the vapor pressure differential between constituents is relative volatility, expressed as the ratio of the vapor-to-liquid concentration for one constituent divided by the ratio of the vapor-to-liquid concentration of the other constituent.

In a continuous stream stripping unit, some pretreatment may be needed for the wastewater. If suspended solids exist in the wastewater, they should be removed from a waste stream by filtration prior to steam stripping in order to avoid fouling the packing or plugging tray towers.

A steam stripping unit consists of a boiler, a stripper section, a condenser, and a collection tank. The boiler provides the heat required to vaporize the liquid lraction of the waste. The stripping section is composed of a set of trays or packing in a vertical column. The leed (waste intluent) enters at the top. The stripper process uses multiple equilibrium stages, with the initial waste $r$ ixture entering the uppermost equilibrium stage. The boiler is located below the lowermost equilibrium 
stage so that the vapor generated moves upward in the column, coming into contact with the falling liquid. As the vapor comes into contact with the liquid at each stage, the more volatile components are removed or "stripped" from the liquid by the vapor phase. The concentration of the emerging vapor is slightly enriched.

Column internals are designed to accommodate the physical and chemical properties of the wastewater to be stripped. Two types of internals may be used in steam stripping: trays or packing. Each tray represents one equilibrium stage. In the packed steam stripping column, the individual equilibrium stages are not discernible, but the number of equivalent trays can be calculated from mathematical relationships. Tray types include bubble cap, sieve, valve, and turbok-grid. Trays have several advantages over packing, including (1) trays are less susceptible to blockage by solids, (2) they have a lower capital cost for large diameter columns $\geq 1 \mathrm{~m}(\geq 3 \mathrm{ft})$, and (3) they accommodate a wider range of liquid and vapor flow rates. Packing types include raschig rings, pall rings, saddles, and sulzer-structures. Compared to trays, packing has the advantages of (1) having a lower pressure drop per theoretical stage, (2) being more resistant to corrosive materials, (3) having a lower capital cost for small diameter column $<1 \mathrm{~m}(<3 \mathrm{ft})$, and (4) finally being less susceptible to loaming because of a more uniform flow distribution.

\section{Input Streams}

Steam stripping is most applicable for (1) the removal of small amounts of VOCs in large amounts of water, (2) components that form low boiling point azeotropes with water, (3) compounds that are thermally unstable or reactive at high temperatures, (4) compounds that cause excessive fouling, and (5) compounds that present explosion or ignition hazards in direct-fired heaters.

\section{Output Streams}

Output streams from steam stripping include stripped waste and condensed volatile constituents based on the process inputs as discussed below.

If the inputs to this process are wastewater with VOCs and steam, the outputs would be a stripped waste (bottoms), which consists of water nearly depleted of organics, and the volatilized constituents (overheads), which consist of organics and water. If the waste is wastewater with organics, metals, and radionuclides, the bottoms would consist mostly of water with all metals and radionuclides, while the overheads would consist of organics and water. In addition to the VOCs, if the wastewater stream contained dissolved metals and radionuclides [both an EPA toxic (Dxxx) metal and solvent wasie] steam stripping would separate the organic material away from the rest of the waste.

\section{Advantages}

The advantages of steam stripping as compared to air stripping include (1) ability to separate aqueous wastes contaminated with more soluble, less volatile compounds, not readily air-strippable, including acetone, methanol, and pentachlorophenol, (2) ability to handle higher concentrations, up to several percent by weight, of volatile organic compounds in an aqueous waste, and (3) ability to treat nonaqueous wastes such as spent solvents contaminated with nonvolatile impurities. 


\section{Disadvantages}

The disadvantages of stream stripping include (1) the capital and operating costs for steam stripping are larger than those for air stripping, (2) in comparison with other treatments for organics, steam stripping is considered a complex system due to the complex process controls, such as temperature, pressure, and reflux ratios, and (3) since the packing depth and tower diameter are functions of the incoming feed concentrations, the required removal, the steam loading ratio, the liquid loading rate, the packing characteristics, temperature, and pressure, the stripping tower may be confined to specific waste stream conditions.

\section{Technology Status}

Proven: Steam stripping has been successfully demonstrated for the decontamination of a groundwater containing ketones and alcohols as well as chlorinated solvents at 1,000 ppm. BaronBlakeslic and the USEPA are promoting characterization of specific steam stripping processes. 


\subsection{References}

1. S. D. Clinton, Low-Level Radioactive Waste Treatment Technology, DOE/LLW-13Tc, July 1984.

2. Remedial Technology Information System (RTIS) Database, Idaho Falls, Idaho: EG\&G Idaho, Inc., 1991.

3. W. S. Roesener, Unit Systems for the Treatment of TRU Contaminated Waste, WM-PD-92-002, December 1991.

4. A. A. Moghissi, H. W. Godbee, and S. A. Hobart, Radioactive Waste Technology, New York: American Society of Mechanical Engineers, 1986.

5. H. M. Freeman, Editor, Standard Handbook of Hazardous Waste Treatment and Disposal, New York: McGraw-Hill Book Company, 1989.

6. Yen-Hsiung Kiang, and A. A. Metry, Hazardous Waste Processing Technology, Boston: Butterworth Publishers, 1982.

7. E. C. Garcia, Mixed Waste Treatment Options for Wastes Generated at the Idaho National Engineering Laboratory, EGG-WM-9451, January 1991.

8. Treatment of Low- and Intermediate-Level Liquid Radioactive Wastes, Technical Reports Series No. 236, Vienna: International Atomic Energy Agency, 1984.

9. R. A. Corbitt, Standard handbook of Environmental Engineering, New York: McGraw-Hill Book Company, 1989.

10. D. W. Major, J. Fitchko, Emerging On-Site and In Situ Hazardous Waste Treatment Technologies, Northbrook: Pudvan Publishing Co., Inc., 1990.

11. L. E. Applegate, "Membrane Separation Processes;" Chemical Engineering, June 11, 1984.

12. K. R. Muller (ed.), Chemical Waste Handling and Treatment, New York: Springer-Verlag, 1989.

13. W. T. Bourns, "Reverse Osmosis Plant to Process CRNL Low Level Radioactive Liquid Wastes," Canadian Nuclear Society 2nd Annual Conference, June 10, 1981.

14. M. Kikuchi, "Development of a Laundry Waste Treatment System," Nuclear Engineering and Design, 44, 1977.

15. R. G. Gutman, et al., Active Liquid Treatment by a Combination of Precipitation and Membrane Processes, AERE-G-3777, August 1986.

16. M. K. Askim, and C. M. Janacek, "Reverse Osmosis Can Increase Water Supply and Quality of Potable Water," Waste and Sewage Works, 123, October 1976.

17. C. P. Shields, "Reverse Osmosis for Municipal Water Supply," Water and Sewage Works, 119. January 1972. 
18. K. Wagner, et al., Remedial Action Technology for Waste Disposal Sites, Park Ridge: Noyes Publications, 1986.

19. P. S. Cartwright, "An Update on Reverse Osmosis for Metal Finishing," Plating and Surface Finishing, 71, April 1984.

20. McCoy and Associates, Inc., "Membrane Separation Technology: Applications to waste Reduction and Recycling," The Hazardous Waste Consultant, 3, May-June 1985.

21. U.S. Environmental Protection Agency, Treatment of Electroplating Wastes by Reverse Osmosis, EPA 600/2-76-261, September 1976.

22. D. De Renzo (Ed.), Unit Operation for Treatment of Hazardous Wastes, Park Ridge: Noyes Publications, 1978.

23. H. Kuribayashi, et al., "Radionuclide Separation Process (RASEP)," Waste Management '87 Meeting, Tucson, Arizona, March 15, 1987.

24. K. Suzuki, "Selective Separation Process of Radionuclides in Liquid Wastes," 1988 DOE Model Conference Proceedings, Volume 1, Oak Ridge, Tennessee, October 3-7, 1988, CONF-881054Vol. 1.

25. M. A. Ebra, et al., "New Treatment Facility for Low Level Process Elfluents at the Savannah River Site," Waste Management '87 Meeting, Tucson, Arizona, March 1-5, 1987.

26. R. L. Sanks (ed.), Water Treatment Plant Design, Ann Arbor: Ann Arbor Science Publishers, 1978.

27. K. H. Lin, Use of Ion exchange for the Treatment of Liquids in Nuclear Power Plants, ORNL 4792, 1973.

28. W. E. Clark, The Use of Ion exchange to treat Radioactive Liquids in Light-Water-Cooled Nuclear Reactor Power Plants, NIIREG/CR 0143, ORNL/NUREG/TM 204,1978.

29. I. M. Abrams, "New Developments In Counter-Current Fixed Bed Ion Exchange," Proceedings of the 24th International Water Conference, Pittsburgh, 1973.

30. C. J. Brown, et al., "Water and Chemical Recovery by Reciprocation Flow Ion Exchange," Proceedings of the 24th International Water Conference, Pittsburgh, 1973.

31. M. Howden and J. Pilot, "The choice of Ion Exchanger for British Nuclear Fuels Ltd's Site Ion Exchange Effluent Plant," Ion Exchange Technology, 1984.

32. L. Rosengrant, Treatment Technology Background Document, U.S. Environmental Protection Agency Office of Solid Waste, EPA/530-SW-90-059Z. January 1991.

33. J. R. Berlow, Best Demonstrated Available Technology (BDAT) Background Document for F001F005 Spent Solvents, Volume 2, U.S. Environmental Protection Agency Office of Solid Waste, EPA/530-SW-86-056(b), November 1986. 
34. Treatment of Alpha Bearing Wastes, Technical Reports Series No. 287, Vienna: International Atomic Energy Agency, 1988.

35. D. Grosse, Managing Hazardous wastes Containing Heavy Metals, New York: Scitech Publishers, Inc., 1990.

36. Safety Analysis Report, NFS Reprocessing Plant, West Valley, New York, Docket No. 50-201, 1973.

37. R. J. Braatz and R. A. Robinson, Safety Analysis Report--Building 3544, Processing Waste Treatment Plant, ORNL/TM-5444, 1976.

38. U.S. Environmental Protection Agency, Guidance for Sewer System Evaluation, 1974.

39. U.S. Environmental Protection Agency, Chemical Aids Manual for Wastewater Treatment Facilities, EPA 430/9-79-018, MO-25, 1979.

40. U.S. Environmental Protection Agency, In-Process Pollution Abatement: Upgrading Metal Finishing Facilities to Reduce Pollution, EPA 625/3-73-002, 1973.

41. U.S. Environmental Protection Agency, Environmental Pollution Control Alternatives: Economics of Wastewater Treatment Alternatives for the Electroplating Industry, EPA 625/5-79-016, 1979.

42. U.S. Environmental Protection Agency, Control and Treatment Technology for the Metal Finishing Industry, EPA 625/8-82-008, 1982.

43. United States Environmental Protection Agency, Office of Research and Development, Technological Approaches to the cleanup of Radiologically Contaminated Superfund Sites, EPA/540/2-88/002, August 1988.

44. P. N. Cheremisinoff, Editor, Pollution Engineering Flow Sheets Hazardous Wastes Treatment and Unit Operations, USA: Cahners Publishing Company, 1988.

45. J. R. Berlow, Best Demonstrated Available Technology (BDAT) Background Document for F001-F005 Spent Solvents, USEPA, EPA/530-SW-86-056(a) (PB87-120267), November 7, 1986. 


\section{VOLUME REDUCTION (TT8000)}

The volume reduction technologies discussed in this section are used to reduce the total volume of waste prior to disposal. This is accomplished by applying high pressures to the waste, which reduces void space. The technologies presented, compaction and baling, are both used by the nuclear industry. Specific types of volume reduction processes and their applicability to particular waste types are discussed as follows:

Section Technology

6.1 Compaction

$6.2 \quad$ Baling

\subsection{Compaction $(T 18100)^{1,2,3}$}

Compaction is a mechanical volume reduction process by which waste material is compressed in disposal containers. The process achieves volume reduction by removing void space. Compaction is a well-proven treatment technology.

Compactor systems consist of a press, using horizontal or vertical rams to apply pressure to the waste in a drum or box-type container. Volume reduction achieved during compaction is a function of void space in the waste, the force applied by the press, the bulk density of the material, and its springback characteristics. The volume reduction factors are generally between 3 and 10 . Parameters that determine the size and power requirement of a compactor include the throughput, type of waste, size of items to be compressed, disposal container size, and desired volume reduction.

The most common system used in the nuclear industry is the 55-gal drum compactor, which contains a power unit, a hydraulic or mechanical drive, a platen, a base plate, structural supports, a drum-positioning platform, and a control panel. Waste is loaded into the drum, and the power unit is activated to bring the platen down onto the material in the drum. The platen is then raised, the drum recharged, and the process repeated.

Compactors can be divided into two main categories: low-pressure and high-pressure units. Low pressure systems typically have ram pressures of around $35 \mathrm{psig}$, and are used to reduce general combustible and compactible trash. High-pressure compactors (supercompactors) have ram pressures ranging from 5,200 to $11,400 \mathrm{psig}$, and are capable of volume reduction with both noncombustible and traditionally noncompactible waste. Supercompactors can achieve a 2 to 4 volume reduction factor for noncompactible waste, and a 6 to 7 factor for compactible trash.

The volume reduction achieved by a compactor can be improved by preshredding the waste, using antispringback devices, and increasing the power of the unit (supercompactor). 


\section{Input Streams}

Input consists.primarily of dry solid wastes, with sufficient void space to achieve a useful volume reduction factor. For low-pressure systems, the typical feedstream consists of clothing, laboratory equipment, paper, and plastics.

\section{Output Streams}

The output is a volume reduced waste, consisting of the input strean pressed into the final disposal container, usually a 55-gal drum. The compacting process usually generates airborne particulates, that can be removed by a conventional exhaust system using HEPA filters.

\section{Advantages}

Advantages of compaction include (1) compaction is a proven process used throughout the world in the nuclear industry, (2) compaction systems are simple, and tend to be reliable and troublefree, (3) waste compaction is relatively inexpensive, and (4) the process is simple to operate.

\section{Disadvantages}

Disadvantages of compaction include (1) most commercial compactor systems are not available with adequate exhaust equipment and must be modified, (2) compactors cannot reduce the hazard of the incoming waste, and are therefore not appropriate for treating waste streams with hazardous constituents, (3) compaction is not recommended for wastes containing free liquids, or with wastes containing explosives, and (4) compaction should not be used on dense or bulky items where minimum volume reduction would be achieved.

\section{Technology Status}

Proven: Compaction has been used throughout the world in both nuclear and nonnuclear industries. Supercompactors have not been used extensively in the United States, but international applications have demonstrated their usefulness and reliability. They have been used in the Netherlands, France, Germany, and Japan.

\subsection{Baling $(T \mathrm{~T} 8200)^{1,3}$}

Balers compress waste material into bales that are then secured with bands in order to maintain the established volume and shape before being placed into disposal containers. The main difference between baling and compaction is that the waste is compressed inside the disposal container during compaction. Compaction and baling are often accomplished as a sequence of operations. 
Most balers are designed to produce rectangular bales because of the handling, packagin's, and stacking advantages. Typical volume reduction factors are from 1.5 to 3 . Bailing systems are available in a variety of sizes, pressure ranges, and designs. Five types of balers are commercially available:

- A horizontal continuous-extrusion baler operates by compressing one bale against another. Feed is usually restricted to heavy cloth and paper that is shredded before processing.

- The horizontal multiple-stroke baler uses a horizontal, hydraulically operated platen to introduce waste into the compression chamber. The platen is then retracted, and the process repeated until the desired bale length is obtained. The unit can process all types of wet and dry material, but is used primarily for scrap metal. This type of baler is available with one or more compression stages.

- The horizontal multiple-platen baler uses two horizontal platens, at right angles to one another, to compress the waste by applying a single stroke. Waste is fed from a curved skip pan, operated in sequence with a compression door that positions and contains the waste prior to baling.

- The vertical upstroke baler operates in a pit that has a depth equal to the stroke length. Waste is placed in a hopper at floor level, and hydraulic rams push the material upward against the stationary platen. The cycle is repeated until a desired bale length is obtained. The unit is capable of processing wet or dry material.

All commercially available balers require modification or enclosures for contamination control.

\section{Input Streams}

Input streams may consist of wet or dry material with sufficient void space to achieve a useful volume reduction.

\section{Output Streams}

The output stream will be a volume reduced rectangular waste form, suitable for packaging or storage.

\section{Advantages}

The rectangular waste form produced by balers has improved hardling, packaging, and stacking advantages over those produced by compactors, which usually compact the waste into 55-gal drums.

\section{Disadvantages}

The primary problem with balers is the generation of radioactive and particulate matter during operation. Commercial balers require modification to control contamination. The bales require and additional handling step, over compaction processes, for placement into a final container for shipment. 


\section{Technology Status}

Proven: Balers have been used at DOE sites including Argonne, IL.; Oak Ridge, TN.; and Idaho. The technology has been used in both the nuclear and nonnuclear industries. 


\subsection{References}

1. R. L. Jolley, L. R. Dole, H. W. Godbee, A. H. Kibbey, L. C. Oyen, S. M. Robinson, B. R. Rodgers, and R. F. Tucker, Jr., Low-Level Radioactive Waste From Commercial Nuclear Reactors - Treatment, Storage, Disposal, and Transportation Technologies and Constraints, ORNL/TM-9846-Vol. 2, May 1986.

2. A. A. Moghissi, H. W. Godbee, and S. A. Hobart, Radioactive Waste Technology, New York: Alnerican Society of Mechanical Engineers, 1986.

3. R. E. Berlin and C. C. Stanton, Radioactive Waste Management, New York: John Wiley \& Sons, 1989. 


\section{INCINERATION $(\text { TT9000) })^{1,2}$}

Incineration is widely used to thermally destroy the organic constituents of a waste, to reduce the waste volume, and to produce more easily-handled ash products. Waste constituents that can be efficiently destroyed by incineration include organic or combustible substances that are hazardous, toxic, carcinogenic, or infectious. The remaining ash products are more compact, inert, homogeneous and more readily immobilized for disposal. Incineration will not destroy radioactive elements, but may change the molecular structure or the physical form of radioactive constituents.

Many different types of incineration processes can be used for treating municipal wastes, liquid and gaseous industrial wastes, sludges, agricultural wastes, and hospital wastes. Incineration has also been used in many countries to treat low-level radioactive mixed wastes. For mixed wastes, incineration destroys the combustible and hazardous constituents, but does not destroy the radioactive elements. Incineration can, however, reduce the volume of mixed wastes and rnake the resulting ash more homogeneous and easily treated using immobilization processes for final disposal. Indeed, some incineration processes produce relatively inert slag, glass, or vitrified ash products that are stable and easily disposed.

Most incinerator processes include a main or primary chamber, a secondary chamber, and air pollution control equipment. In the primary chamber, solid, liquid and/or gaseous wastes are heated either directly or indirectly. Upon heating, volatile compounds are devolatilized. The amount of air present in the main chamber determines the classification of the process. In starved or controlled air units, the amount of air available for combustion is at or below the stoichiometric level. A portion of the combustible wastes are oxidized to provide heat for the devolatilization step. When the main chamber is operated with more than the stoichiometric level of air, the unit is operated in the excess air mode.

Two eftluent streams from the main chamber are (1) devolatilized gases, combustion products and entrained particulate (fly ash), and (2) the remaining inert and uncombusted material, which may be dry or water-quenched bottom ash, slag, glass, or vitritied ash. The composition and form of the incinerator bottom ash, fly ash, and flue gas depends on the waste feed characteristics, and the design and operating conditions of the incinerator.

Incinerator off-gases generally require secondary combustion in a secondary combustion chamber or afterburner to achieve more complete destruction of devolatilized organic compounds and combustion byproducts. The off-gases are also typically vented to pollution control equipment to remove entrained particulate and acid gases. Eflluent streams from the pollution control equipment include the treated flue gas (vented to the atmosphere) and may include (depending on equipment used) dry fly ash, particulate-laden filter elements, used filter bags, and scrubber liquor that contains absorbed acid gases and scrubbed particulate. The solid and liquid effluent streams, like the incinerator ash, must be treated and suitably disposed. In some incinerator processes, these streams are recycled back to the incinerator. or otherwise suitably treated.

In many routine applications, the heat content of the waste can be recovered in waste heat boilers that are used to cool the off-gases prior the gases arriving at the pollution control equipment. For mixed waste applications. waste heat recovery is usually secondary in importance to maintenance. 
free operation and containment of radioactive materials, so waste heat recovery is not emphasized beyond the cooling required for protecting the air pollution control equipment.

Advantages common to most incinerator processes include:

- Destruction of combustible hazardous materials

- Size and volume reduction of the waste

- Production of more easily-handled effluents

- Ability to process various waste forms and flowrates

Many incinerator processes have common disadvantages. Specific advantages of certain technologies may include the lack of any of the following disadvantages:

- Inability to destroy radioactive elements of mixed waste

- Required preparation of the waste prior to incineration

- Occasional-to-frequent maintenance

- Leaks of ambient air into the process, or process materials into the surroundings (secondary and tertiary containment requirements)

- Required further processing of various bottom ash, fly ash, scrubber liquor, filter elements, and other products of operation and maintenance

- Lag time between emergency incinerator shutdown and final burnout and processing of waste charged at the time of shutdown

- Sensitivity to problems from out-of-design temperature or other operating conditions (slagging, particulate carryover, incomplete combustion, etc.)

- Buildup of residual slag, dust, and other materials that require manual cleanout

- Buildup of adsorbed radioactive nuclides in refractory

- Dependence on the air pollution control system to control gaseous and pariculate emissions, even in the event of catastrophic failure of system components (required backup systems)

Incineration terhnologies that may be considered for mixed and low-level waste treatment are discussed in this section. Other waste treatment technologies that are classified as thermal degradation/volatilization processes are discussed in Section 8. Processes classified as vitrification processes are discussed in Section 9. However, many processes can both oxidize or incinerate wastes and glassify or vitrify the inorganic ash. These processes, such as the slagging furnace and the plasma 
heated meiter, are less easy to categorize strictly as incineration, vitrification, or other thermal degratation processes. Therefore, these have been grouped according to their perceived primary function, even though they can serve combined functions in many applications.

Off-gas pollution control equipment and treatment systems can usually be considered separate unit operations, even though most incinerator processes require inclusion of pollution control systems. These are discussed in more detail in Section 14.

Specific types of incineration processes and their applicability to particular waste types are discussed as follows:

$\begin{array}{ll}\text { Section } & \text { Technology } \\ 7.1 & \text { Multiple Hearth (TT9025) } \\ 7.2 & \text { Controlled Air (TT9075) } \\ 7.3 & \text { Fluidized Bed (TT9125) } \\ 7.4 & \text { Rotary Kin (TT9175) } \\ 7.5 & \text { Slagging Furnace (TT9200) } \\ 7.6 & \text { Infrared Electric Furnace (TT9225) } \\ 7.7 & \text { Molten Salt Combustion (TT9250) } \\ 7.8 & \text { Liquid Waste Cornbustor (TT9325) } \\ 7.9 & \text { Catalytic Incineration (TT9350) } \\ 7.10 & \text { Cyclone Furnace (TT9375) } \\ 7.11 & \text { Blast Furnace (TT9400) } \\ 7.12 & \text { Industrial Boiler (TT9425) } \\ 7.13 & \text { Industrial Kiln (TT9450) }\end{array}$

\subsection{Multiple Hearth (TT9025) $)^{1,3,4,5,6,7,8,9,10,11,12}$}

A multiple-hearth incinerator consists of a refractory-lined steel shell with a series of circular hearths arranged in a vertical design. A schematic of the hearth system is shown in Figure 7-1. ${ }^{12}$ Waste is introduced at the top of the furnace and drops to lower levels by gravity as it burns. The waste is plowed around on each hearth by steel fingers attached to long booms. The booms, known as rabble arms, are in turn connected to a central, air-cooled shaft that rotates to agitate the burning waste. Normally, 2 to 4 rabble arms per hearth are available. As the waste is plowed around a hearth, it eventually falls through holes to the next hearth. Successive hearths are used for drying, heating, combustion, burnout, and cooling of the waste.

Auxiliary fuel burners are mounted on the side of the vessel in the hearths where combustion and burnout occur. The temperature in these zones ranges between 760 to $982^{\circ} \mathrm{C}\left(1400\right.$ to $\left.1800^{\circ} \mathrm{F}\right)$. The auxiliary burners may be designed for injecting high heating value hazardous liquids. A secondary chamber may be required for complete transi.urmation of hazardous wastes. The secondary chamber temperature is maintained at least $982^{\circ} \mathrm{C}\left(1800^{\circ} \mathrm{F}\right)$.

Air pollution control equipment is also required for removing tly ash and acid gases from the flue gas. This type of incinerator has been used principally for sludges, tars, or other low-heating 


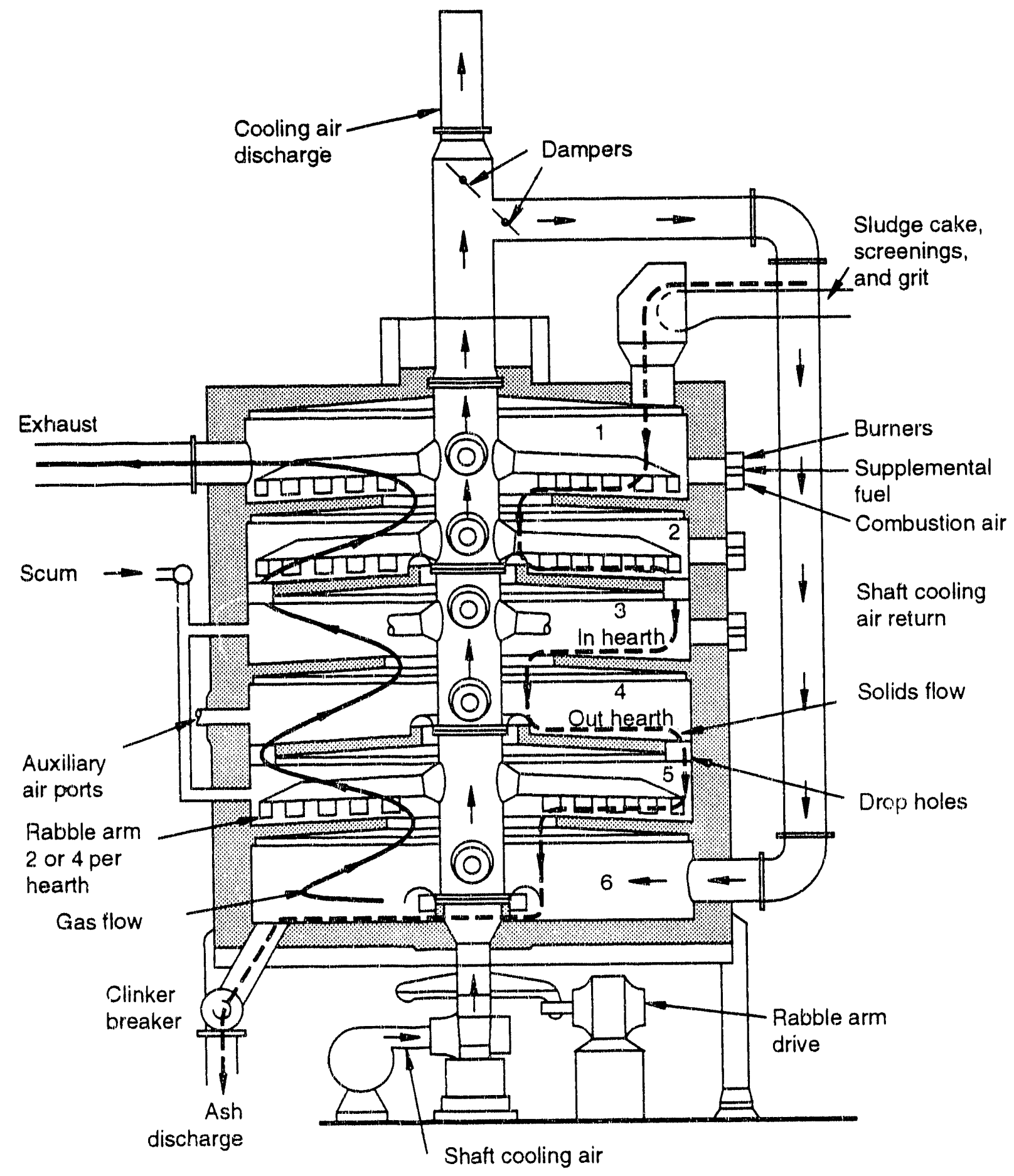

Mэ2. 0199

Figure 7-1. Schematic of a multiple hearth furnace. 
value solids requiring long retention times and has been commonly used for disposal of dewatered activated waste.water treatment sludges. Use of this type of incinerator has been largely abandoned. This category includes agitated hearth incinerators.

\section{Input Streams}

Feedstreams can include sludges, low and high heating value organic liquids, solid combustibles and solid inert wastes. Auxiliary gas or other fuel is required.

\section{Output Streams}

Output streams include (1) bottom ash, including tramp metal and other noncombustibles not removed from the feed, and (2) treated tlue gas and solid/liquid products from the air pollution control system.

\section{Advantages}

Advantages of Multiple Hearth incineration include (1) a wide range of supplementary fuels can be used to provide heat, (2) it accepts a wide variety of input streams and is particularly well suited for evaporating large amounts of water from sludges, and (3) the stationary refractory can have a long life.

\section{Disadvantages}

Disadvantages of Multiple Hearth incineration include (1) pretreatment and sorting of wastes is required, (2) the unit is not well suited for wastes containing fusible ash, large bulky wastes, or large quantities of noncombustible wastes, (3) the refractory is subject to buildup of gamma emitting Americium, (4) the rabble arms, fingers and other moving parts are high maintenance items, and (5) wear, erosion and corrosion of other components, especially seals and the air-cooled central shaft, is likely.

\section{Technology Status}

Available: Multiple-hearth incineration is an operational and conventional technology for nonradioactive waste treatment. Approximately fifty commercial facilities are applying the technology. No DOE facilities have used the technology in the multiple-hearth configuration, but Rocky Flats Plant built a single-hearth variant (agitated hearth) to process TRU waste. For reasons unrelated to the technology, it was never tested.

\subsection{Controlled Air (TT9075) $)^{1,3,5,6,7,8,9,10,11}$}

Controlled air (starved air) incinerators are those that are designed for substoichiometric conditions in the primary zone (main, or pyrolysis chamber). A generic schematic is shown in Figure 7.2. ${ }^{10}$ The hearth is typically stationary, especially in batch processes. In continuous processes, the number of moving parts may be limited, as in the "pulse hearth." A pulse hearth is 


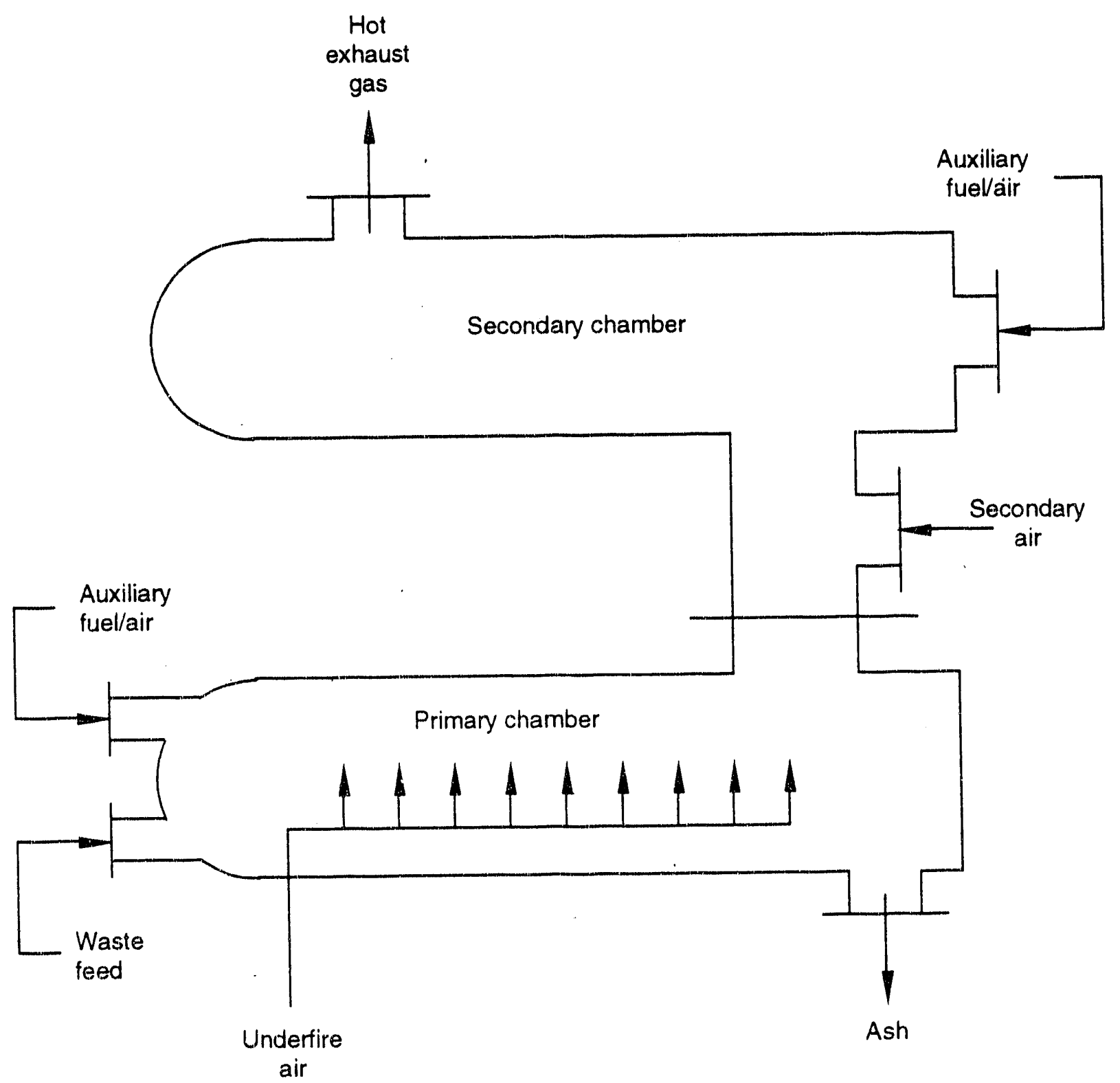

M920203

Figure 7-2. Schematic of a controlled-air incinerator. 
pneumatically jolted horizontally a distance of a few inches several times per minute. This agitates the waste bed, exposing more new surface area for combustion, and gradually pushes the bottom ash into the ash recovery system.

Other incinerator designs, such as the rotary kiln, are typically operated in a starved air mode. The primary feature of controlled air incinerators is low volumes of air and gas flow (and low velocities, usually around $1 \mathrm{fps}$ ) to reduce entrainment of particulate from the waste bed. Controlled air incinerators usually have at least one secondary (afterburner) section or chamber for more complete combustion of the off-gases.

Solid waste is fed into the refractory-lined primary chamber, which is controlled at temperatures ranging between 510 to $816^{\circ} \mathrm{C}\left(950\right.$ to $\left.1500^{\circ} \mathrm{F}\right)$. The combustible and volatile fractions in the waste devolatilize, pyrolize, and partially combust with air provided at 30 to less than $100 \%$ of the stoichiometric air requirement. Often the stoichiometry increases toward the far end of the waste bed to encourage more complete burnout of the remaining char. The combustion reactions provide the necessary heat for devolatilization and pyrolysis. The soot and gaseous combustion and pyrolysis products are vented to refractory-lined secondary chamber, which is controlled at $982^{\circ}$ to $1482^{\circ} \mathrm{C}$ $\left(1800\right.$ to $\left.2700^{\circ} \mathrm{F}\right)$ using auxiliary gas burners. Excess air is provided in the secondary chamber to ensure complete combustion. Liquid waste can be incinerated in either the primary or secondary chambers. The bottom ash is not intended to be slagged or fused. An off-gas treatment system is required to provide emission control.

\section{Input Sireams}

Feedstreams can include low and high heating value wastes, packaged or dispersed solids, sludges, low and high heating value organic liquids. Auxiliary gas or other fuel is required.

\section{Output Streams}

Output streams include (1) bottom ash, including tramp metal and other noncombustibles not removed from the feed, and (2) treated flue gas and solid/liquid products from the air pollution control system.

\section{Advantages}

Advantages of controlled air incineration include (1) a wide range of solid, liquid, sludge, and gaseous wastes may be treated, (2) a variety of supplementary fuels can be used for auxiliary fuel, (3) the low air velocity in the primary chamber minimizes the particulate entrainment, (4) the low stoichiometry in the primary chamber helps limit excessive temperatures, thermal and fuel $\mathrm{NO}_{\mathrm{x}}$ formation, wall cooling requirements, and thermal stress, and (5) the stationary refractory has a long life.

\section{Disadvantages}

Disadvantages of controlled air incineration include (1) some pretreatment and sorting of wastes is required, (2) more extensive sizing and sorting will improve operation, (3) the unit is not well suited for wastes containing fusible ash, large bulky wastes, or large quantities of noncombustible 
wastes, (4) the refractory is subject to buildup of gamma emitting Americium, and (5) wear, erosion and corrosion of some system components, especially the feed system, the ash removal system, and seals, is likely.

\section{Technology Status}

Proven: Controlled-air incineration is an operational and conventional technology for nonnuclear applications. Hundreds of commercial controlled air incinerator facilities are available. Four DOE facilities have used the technology to process low-level radioactive waste. Some have also used it for TRU incineration.

\subsection{Fluidized Bed (TT9125) ${ }^{1,3,5,6,7,8,9,10,11,12}$}

In fluidized bed incinerators, mixing and combustion is enhanced by using upflowing combustion air in a vertical vessel containing a mixed bed of sized inert granular material and the combusting waste. A schematic of a fluidized bed for sludge incineration is shown in Figure 7-3. ${ }^{12}$ The velocity of the upflowing combustion air is adjusted and controlled to fluidize the bed by entrainment, at or near the stagnation velocity of the majority particles in bed. The particles are turbulently mixed and in intimate contact with the passing air, which greatly improves heat and mass transfer of the devolatilization and combustion reactions.

For incinerating solid wastes, sized waste is fed to the top of the fluidized bed, where, initially larger and more dense than burned out particles, it falls lower in the bed. As the waste burns, the particle size and density will change. The smaller, lighter particles of waste and bed material are entrained with the upllowing gases to a high temperature cyclone, which captures the majority of entrained material and recycles it back to the bed. In "recirculating" fluidized bed systerns, the r sycle rate is a significant fraction of the bed material. The recirculation enhances complete combustion.

Auxiliary fuel is often used to maintain the bed temperature between 537 to $760^{\circ} \mathrm{C}(1000$ to $\left.1400^{\circ} \mathrm{F}\right)$. A secondary chamber $\left[>982^{\circ} \mathrm{C}\left(1800^{\circ} \mathrm{F}\right)\right]$ may be required to ensure complete combustion of hazardous wastes. One design uses a second fluidized bed filled with a catalyst that allows the temperature in this chamber to be limited to $537^{\circ} \mathrm{C}\left(1000^{\circ} \mathrm{F}\right)$. Sized limestone (calcium carbonate, $\left.\mathrm{CaCO}_{3}\right)$ or sodium carbonate $\left(\mathrm{Na}_{2} \mathrm{CO}_{3}\right)$ is often used as the bed material to provide in-bed acid gas scrubbing (no scrubber required). Fresh bed material is added as spent bed material is removed with the bottom ash. Off-gas particulate removal is required in addition to the recirculation cyclone.

\section{Input Streams}

Feedstreams can include low and high heating value organic liquids, shredded and sized solid combustibles, sludges and aqueous organics. Other input streams included makeup bed material, auxiliary fuel, and possibly expensive makeup catalyst.

\section{Output Streams}

Output streams include (1) bottom ash and spent bed material, including tramp metal and other noncombustibles not removed from the feed, and (2) treated tlue gas and fly ash (typically dry and 


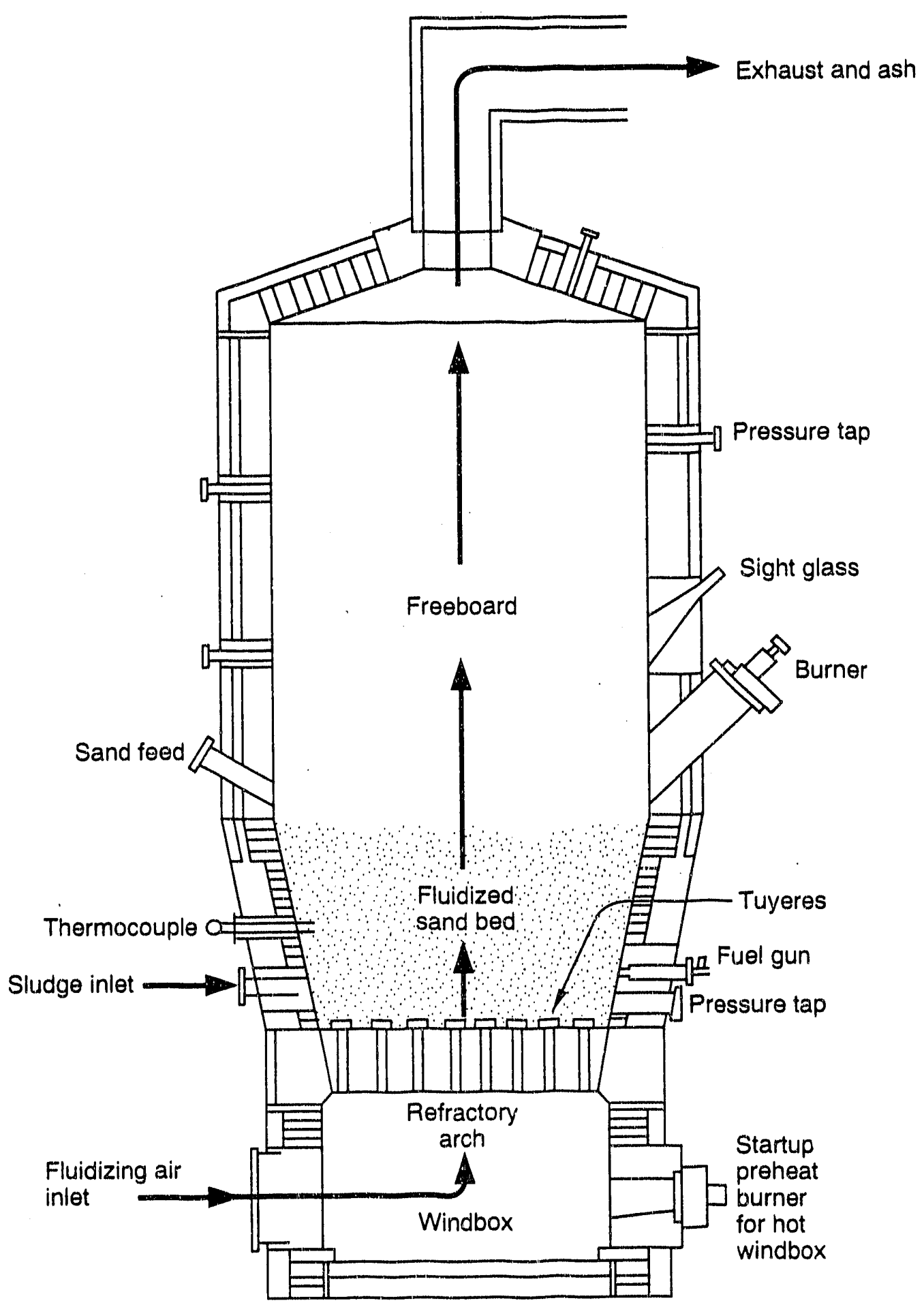

$\times 920055$

Figure 7-3. Schematic of a fluidized bed furnace. 
homogeneous since wet scrubbing is not necessary) from the air pollution control system. The fly ash may consist mostly of dust from fractured bed material, and may have atypical $\mathrm{Ph}$, chemical reactivity, or other properties.

\section{Advantages}

Advantages of fluidized bed incineration include (1) the primary advantage may be that a separate off-gas system scrubbing system is not required, (2) the design is relatively simple, has few moving parts and can be smaller than other incinerators of the same throughputs, (3) the incinerator is long lived, simple to operate and requires little internal maintenance as long as it is designed well and operated within design limits, (4) it can accept a wide variety of input streams with prior sizing, and may be more suitable for high activity mixed wastes, (5) lower operating temperatures result in less $\mathrm{NO}_{x}$ formation and lower emission rates for low-volatility metals and actinides, (6) in some cases a refractory lining is not required, and (7) combustion efficiency is improved by fluidization of the waste bed.

\section{Disadvantages}

Disadvantages of fluidized bed incineration include (1) pretreatment of wastes is required, (2) solids have to be shredded, metal and large noncombustibles need to be removed, and sludges may need to be partially dried, (3) particulate entrainment rates can be high requiring a more extensive off-gas system, (4) erosion rates may be high due to large amounts of moving particles, (5) for higher temperature operation, the refractory is subject to buildup of gamma emitting Americium, (6) the volumes of bottom ash and fly ash will increase since the majority of these streams may be spent bed material, (7) the chernical/physical makeup of the bottom ash and fly ash may also be altered, (8) makeup catalyst may be an added operating expense, and spent catalyst may be an added waste stream, (9) feed requires for feed; feed requires freedom from all except trace amounts of metals to eliminate unnecessary loading of fluidized bed, (10) expensive catalyst needed for off-gas burning, and (11) some insoluble ash in catalyst.

\section{Technology Status}

Available: Fluidized-bed incineration is an operational and conventional technology for nonnuclear waste treatment applications. Over 25 commercial facilities are using the technology. Rocky Flats Plant has operated an incinerator for TRU and low-level waste.

\subsection{Rotary Kiln (TT9175) ${ }^{1,3,5,6,7,8,9,10,11,13,14,15}$}

The rotary kiln is a cylindrical refractory-lined shell mounted on a slight (1 to 5-degree) incline. An example schematic is shown in Figure 7-4. ${ }^{10}$ Waste is fed into the high end, and ash falls from the low end. Rotation of the kiln tumbles the waste in the kiln for better mixing and combustion, and provides for gradual movement of bottom ash through the kiln to the outlet. Rotary kilns normally require a secondary combustion chamber to ensure complete transformation of hazardous constituents.

Devolatilization and pyrolysis of the combustible waste occurs in the kiln section under starved air conditions at temperatures ranging from 593 to $816^{\circ} \mathrm{C}\left(1100\right.$ to $\left.1500^{\circ} \mathrm{F}\right)$. The gas-phase 


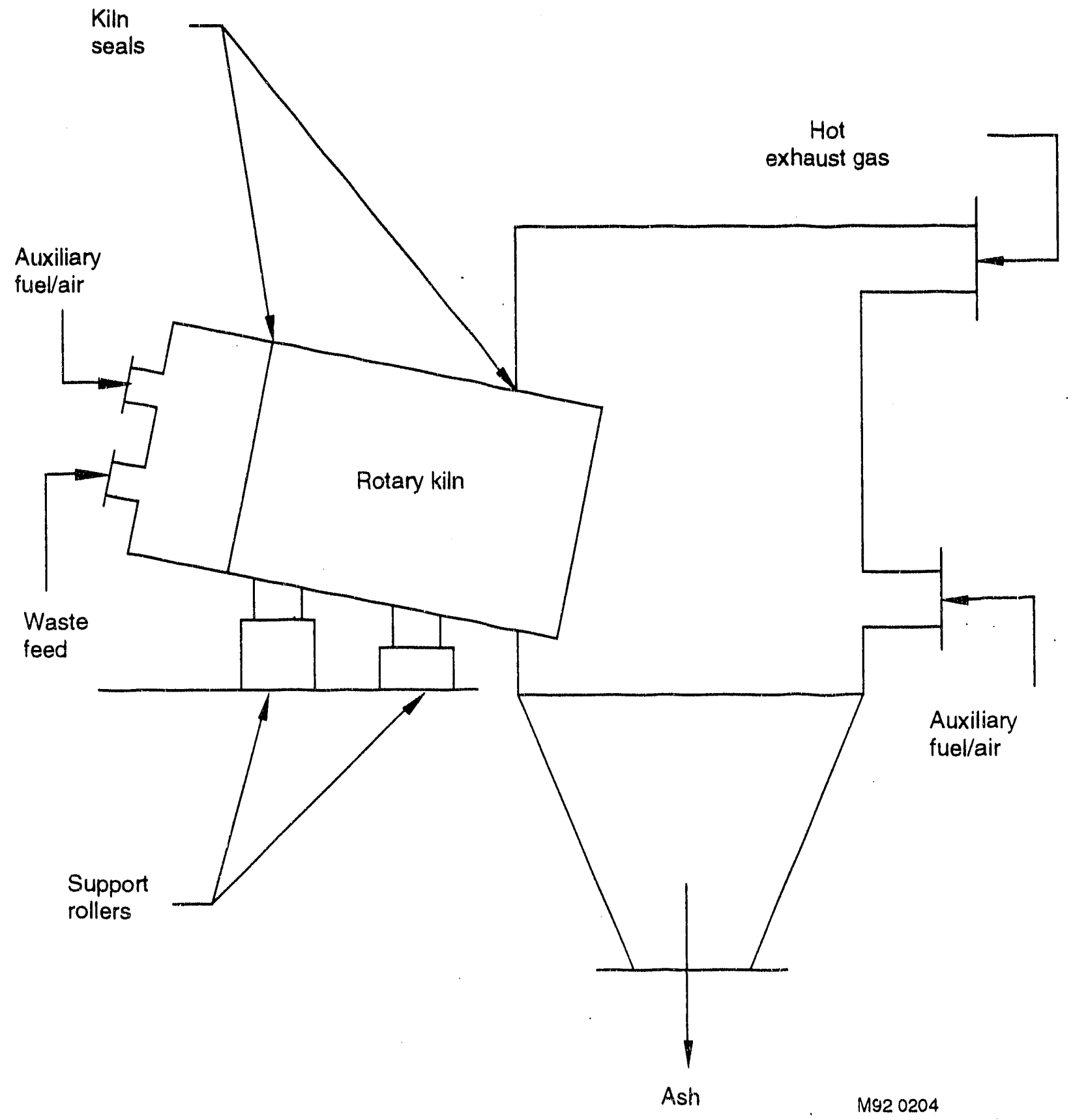

Figure 7-4. Schematic of a rotary kiln incinerator. 
combustion reactions are completed in the secondary section at temperatures of $982^{\circ} \mathrm{C}\left(1800^{\circ} \mathrm{F}\right)$ or higher. Both primary and secondary chambers are generally supplied with auxiliary fuel systems.

\section{Input Streams}

Waste feedstreams can include coarse inert solids, combustible solids, low and high heating value organic liquids, sludges, ion exchange resins, mixed and low-level wastes, and aqueous organic wastes. Auxiliary gas or other fuel is required.

\section{Output Streams}

Output streams include (1) bottom ash, including tramp metal and other noncombustibles not removed from the feed, and (2) treated flue gas and solid/liquid products from the air pollution control system.

\section{Advantages}

Advantages of rotary kiln incineration include (1) the design is relatively simple, with all the motive equipment located outside the incinerator for ease of maintenance, (2) the incinerator accepts essentially all input streams, including liquids and high level fissile material, (3) pretreatment of waste can be limited to coarse shredding to render the inerts small enough to tlow into the waste container with the ash, (4) a minimal amount of hand sorting is required, (5) the ash discharge is continuous, minimizing criticality problems, and (6) the tumbling action enhances combustion.

\section{Disadvantages}

Disadvantages for rotary kiln incineration include (1) particulate loadings in the off-gas may be high due to the turbulent waste mixing in the kiln, (2) drying of some aqueous sludges or melting of some solids can result in ring formation on the refractory or in formation of clinkers, (3) spherical or cylindrical objects may roll through the kiln before completing combustion, (4) the refractory is not as long-lived as that of a stationary hearth, (5) thermal cycling is limited by the refractory concern, (6) seal design is still a possible problem although new technology believed to overcome this problem is ready for testing, and (7) the refractory is subject to buildup of gamma emitting Americium.

\section{Technology Status}

Available: Rotary kiln incineration is an operational and conventional technology for nonnuclear waste incineration. Approximately 75 commercial facilities are using the technology. Rocky Flats Plant built and tested a $45 \mathrm{~kg} / \mathrm{h}$ rotary kiln, but it was never operated due to problems associated with the design of the facility that housed the kiln. Idaho National Engineering Laboratory also built and tested a rotary kiln; the testing was conducted for thousands of hours and indicated the likely success of the technology. The kiln was never operated with radioactive waste due primarily to problems associated with the upgrade of the facility to meet new DOE requirements. 


\subsection{Slagging Furnace (TT9200) $)^{1,3,5,6,7,8,9,10,11,16}$}

A slagging incinerator is designed to operate at sufficiently high temperatures so that all of the inert material left after combustion melts into a slag. A schematic of one type of slagging incinerator is shown in Figure 7-5. ${ }^{16}$ Many slagging incinerators are based on an improved rotary kiln incinerator design. Other incinerator types may be designed to slag, include cyclone incinerators and vertical furnaces. For slagging operation, incinerators must be designed for much higher temperature operation and for slag removal and handling. Example designs include the German multichamber slagging kiln and the high temperature slagging incinerator operated by the Belgians. Slagging incinerators normally require a secondary combustion chamber with temperatures at least $982^{\circ} \mathrm{C}$ $\left(1800^{\circ} \mathrm{F}\right)$ to ensure complete transformation of hazardous constituents.

Temperatures in the primary (slagging) zone may range from 1093 to $1648^{\circ} \mathrm{C}\left(2000\right.$ to $\left.3000^{\circ} \mathrm{F}\right)$. Volatile and combustible components of the waste are devolatilized in the primary zone, leaving a melted slag residue of the noncombustible components (e.g., alumina and silica compounds, metal, and glass). The slag melt progresses through the incinerator into a receiver or a water quench, where it solidifies and thermally fractures into small pieces, and is then drawn from the process. Both primary and secondary chambers are generally supplied with auxiliary fuel systems that can be used for liquid waste incineration.

The vertical furnace design has a primary stage gasifier and a secondary-stage combustion chamber. Solid waste is charged through a hopper at the top and fed to the gasifier through an air lock. As the waste progresses down through the gasifier, it passes through three zones: drying, pyrolyzing, and combustion/melting. Because of the relatively low heat content of typical LLW feeds, supplementary heat must be added to the gasifier to produce melting. This heat could be produced by adding coal and bark to the feed and by using combustion air preheated up to $1038^{\circ} \mathrm{C}\left(1900^{\circ} \mathrm{F}\right)$. The product slag is removed and quenched in water. The gases formed in the main unit are sent to an oxygen-rich afterburner for complete combustion. Operating temperatures in the primary pyrolysis burner range from $816^{\circ} \mathrm{C}$ to $1371^{\circ} \mathrm{C}\left(1500\right.$ to $2500^{\circ} \mathrm{F}$ ), and range from $1204^{\circ} \mathrm{C}$ to $1426^{\circ} \mathrm{C}(2200$ to $2600^{\circ} \mathrm{F}$ ) in the afterburner. The maximum temperature in the combustion/melting zone is $1648^{\circ} \mathrm{C}$ $\left(3000^{\circ} \mathrm{F}\right)$.

\section{Input Streams}

Feedstreams can include combustible solids, high and low heating value organic liquids, sludge, and inert solid wastes.

\section{Output Streams}

Output streams include (1) solidified slag, including glassified or vitrified oxidized metals, any unoxidized tramp metal, and any other noncombustible or nonvolatile materials that were not melted in the process, and (2) treated flue gas and solid/liquid products from the air pollution control system.

\section{Advantages}

Advantages of slagging furnace incineration include (1) the incinerator accepts essentially all ir ut streams, (2) pretreatment is minimal; drums of waste can be led intact, (3) collection of 


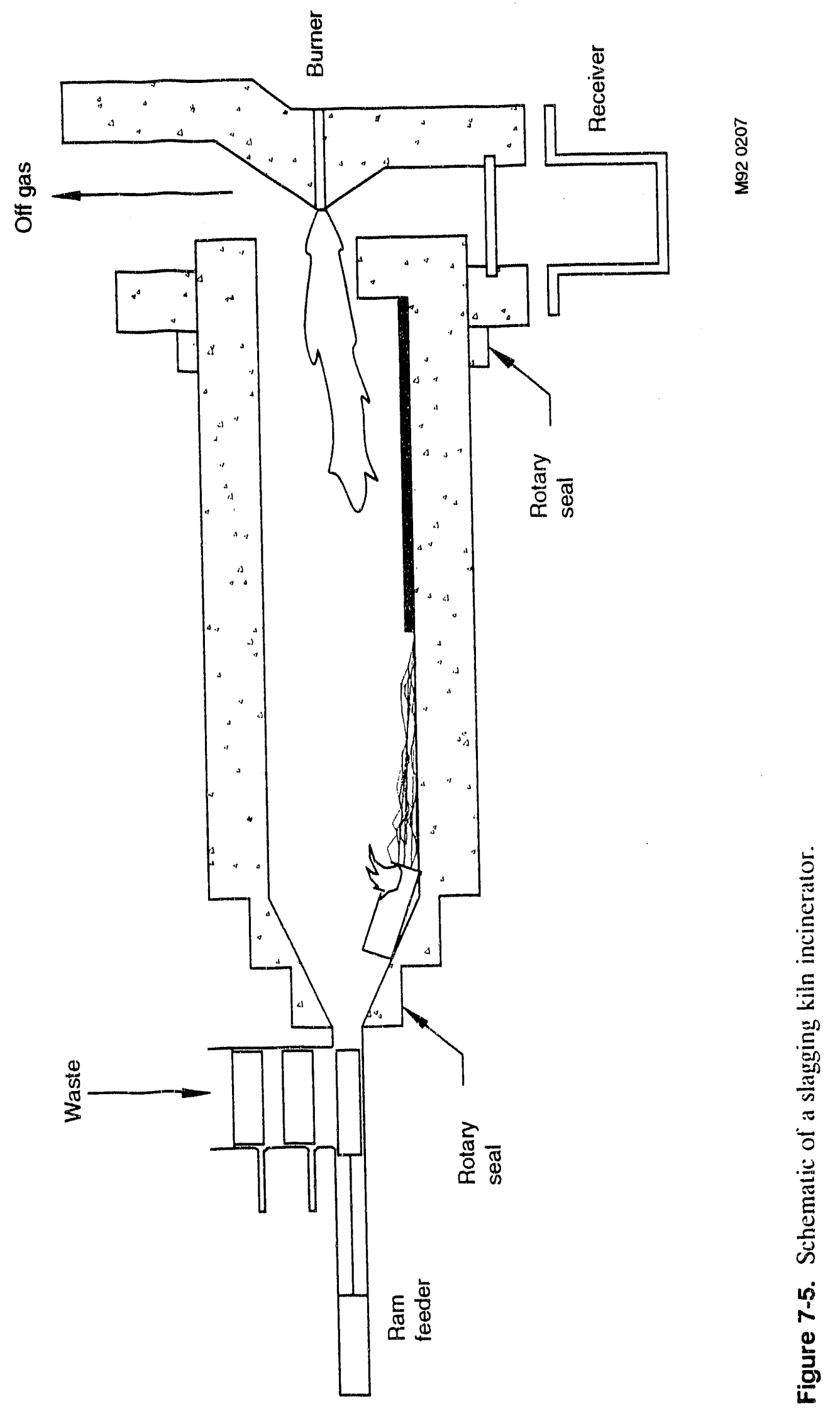


particulates into the slag reduces ofl-ges cleaning requirements, and (4) depending on makeup of the waste feed and operating conditions, the resultant slag may be an acceptable waste form and pass toxicity characteristic leaching procedure (TCLP) limits.

\section{Disadvantages}

One major disadvantage is the increased fractions of metals and metal compounds in the fly ash, due to the higher operating temperatures. Not only will inherently volatile metals partition more to the gas phase, but higher temperatures increase the potential for oxidation and other reacticis that will change the volatility properties of normally less volatile metals. These can include the more volatile nuclides. Fouling of off-gas downstream equipment can also be expected when the vapor forms condense on cooler surfaces. Since higher main chamber temperatures are required, greater volumetric heat throughput is needed, which may increase particulate-entraining gas velocities. The refractory is not as long-lived as that of a stationary hearth. Thermal cycling is limited by the refraciory concern. The refractory is subject to buildup of gamma emitting Americium. Out-of-spec slag may not pass leachability tests or may be unacceptable for actinide recovery, and require reprocessing. Large volumes of waste high level waste in unit could cause criticality concerns. Additives may be required for slag formation.

\section{Technology Status}

Available: Slagging incineration is an operational and conventional technology for nonnuclear applications. Approximately ten commercial facilities are using the technology. Idaho National Engineering Laboratory seriously considered a variant lechnology called the slagging pyrolysis incinerator, but abandoned it when tests by a Florida uility indicated that the particular design would be difficult to operate and maintain in an alpha environment.

\subsection{Infrared Electric Furnace (TT9225) $3,7,8,10,17$}

Infrared electric furnaces employ radiant heat from electrical heating elements to incinerate organic-contaminated wastes. This design has been developed primarily for sludges and soils. A schematic is shown in Figure 7-6. ${ }^{12}$ The furnace is a horizontally oriented, rectangular, ceramic fiber blanket lined steel shell containing a moving horizo.ttal woven wire belt and electric radiant heating elements. The heating elements are construct of silicon carbide to be able generate thermal radiation beyond the red end of the visible spectrum. Waste is carried through the furnace on the moving belt. An internal roller spieads and tlattens the waste layer to approximately $25 \mathrm{~mm}(1$-in.) thick, spanning the width of the belt. Ash is discharged from the end of the belt to the ash handling system. Normally, no rabbling or plowing of the slurige occurn as it is conveyed through the furnace. The primary chamber may include several heating zones of incressing iemperature to iritially dry an finally combust the waste. The primary chamber may be operated either in a pyrolysis :iuel-rich) or combustion mode.

Residence times and temperatures may be adjusted over a wide range to optimize the incineration process. Operating temperatures can range from 427 to $816^{\circ} \mathrm{C}\left(800\right.$ to $\left.1,500^{\circ} \mathrm{F}\right)$. The system is optimally designed for a throughput of 100 ton/day of waste feed. Residence time is controlled by belt speed. In combustion mode, the excess air rate is low (20\%). Off gases flow to a secondary combustion chamber to ensure complete destruction. The secondary combustion 


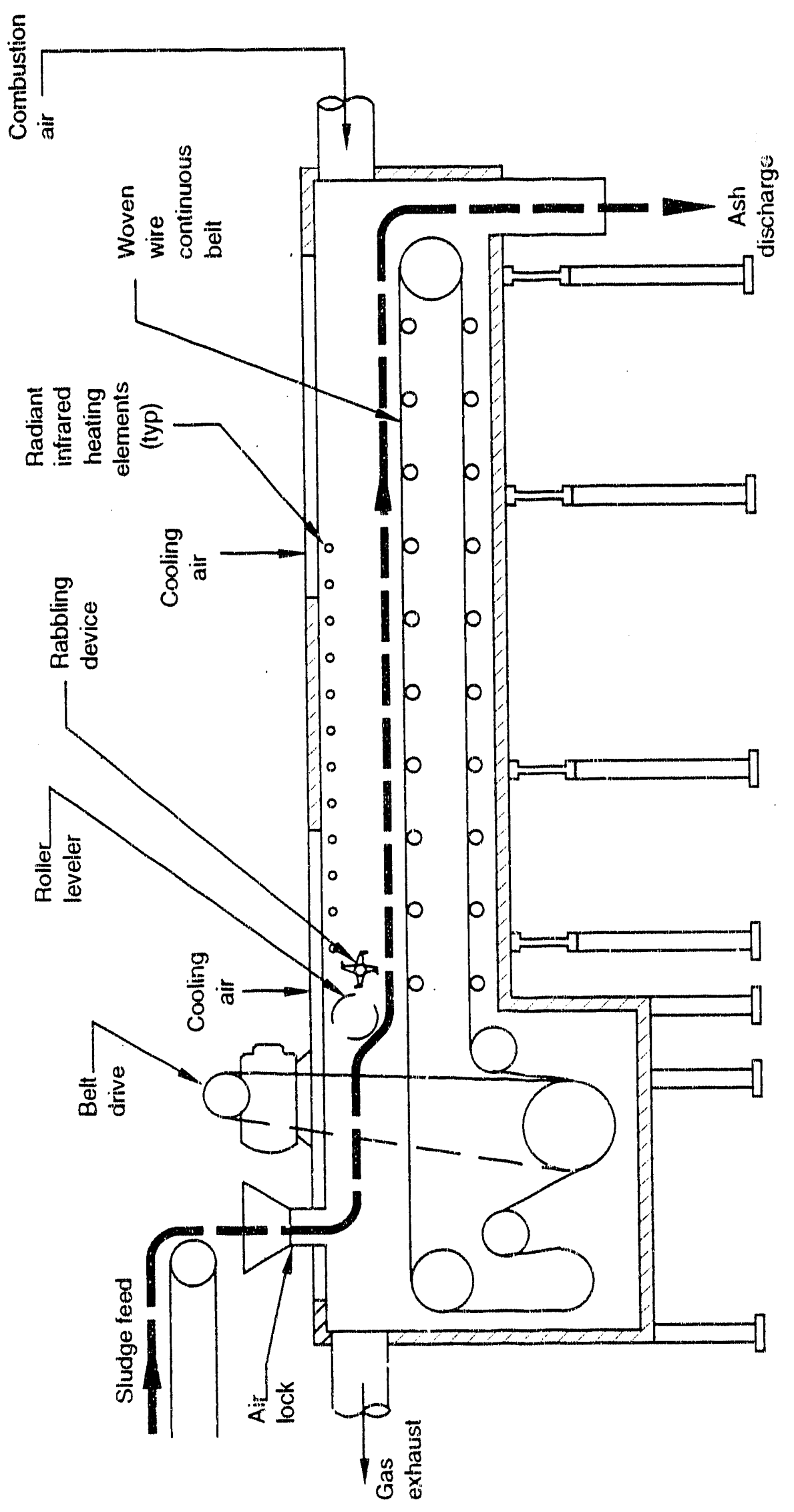

웡
ฟิ
ํ. 
chamber can be either a gas-fired or infrared unit. Flue gas treatment is accomplished by any conventional off-gas cleanup system. Since the air and gas flows are generally low, (no fossil fuel combustion for heating), the gas velocities and entrained fly ash are quite low.

Infrared thermal units use silicon carbide elements to generate Materials to be treated pass through the combustion chamber on a belt and are exposed to the radiation. Waste materials should be less than $50 \mathrm{~mm}(2 \mathrm{in}$.) in diameter for optimal efficiency. In the combustion chamber, wastes can be either incinerated or pyrolyzed at $760^{\circ} \mathrm{C}\left(1400^{\circ} \mathrm{F}\right)$ or $427^{\circ} \mathrm{C}\left(800^{\circ} \mathrm{F}\right)$, respectively.

Several variaiions to this technology are available. One variation termed "conventional temperaire pyrolyzer" allows for feeding liquids, solids or sludges in open containers. A schematic of the convertional temperature pyrolyzer is shown in Figure 7-7.10 Another design is based on an indirectly heated, inclined rotating drum, and is called a "low temperature thermal separator." The waste is feed through the drum. the drum is heated externally in a gas-tired furnace. A variation of this design includes a screw conveyor that is externally heated by hot oil. The waste is heated, vaporized and devolatilized as it is conveyed by the screw through the system.

\section{Input Streams}

Slagging incinerators can process soils, semisolids, oily sludges, and sludges. Pure liquids can also be processed if blended with a suitable carrier, such as soil or veriniculite, to form a semisolid waste matrix. Contaminants include mixed low-level waste, 0 to $100 \mathrm{wt} \%$ organics (including principle organic hazardous constituents). 0 to $5 \mathrm{wt} \%$ chlorine, 0 to $5 \mathrm{wt} \%$ sulfur, 0 to $300 \mathrm{ppm}$ phosphorous, 0 to $1 \mathrm{wt} \%$ alkali metals, 0 to $1 \mathrm{wt} \%$ heavy metals (determined by preoperation testing). Other contaminants include creosote, pentachlorophenol (PCP), 2,3,7,8-tetrachlorodibenzo-p-dioxin (TCDD); organics such as PCBs, dioxins, polynuclear aromatic hydrocarbons (PAH), organochlorinated pesticides (OCP). Wastes must be at least $22 \%$ solids in the feed, and solids should be at a maximum size of 2.5 to $3.8 \mathrm{~cm}(1.0$ to $1.5 \mathrm{in}$.) for efficient operation.

\section{Output Strearns}

Output streams include (1) clean, dried, incinerated solid material from the belt, and (2) treated flue gas anci solid/liquid products from the air pollution control system.

\section{Advantages}

The advantages of slagging incinerators include (1) the energy requirements of the electric furnace may be lower than for fossil fuel-fired units, since the llowrate of combustion air is much smaller, (2) the fan horsepower requirements are lower, and less heat loss occurs from latent heat of the combustion gases, (3) due to the smaller volumes of combustion air and off-gases, the air pollution control equipment can be smaller and less costly. (4) the furnace may be shut down or heated up with fewer refractory problems, (5) the unit has short startup and shutdown time periods, and is easily shut down during ernergencies, and (6) since the operation is at lower, more controlled temperatures, less potential exists for undesirable slagging or melting of inerts and volatilization of metals. 


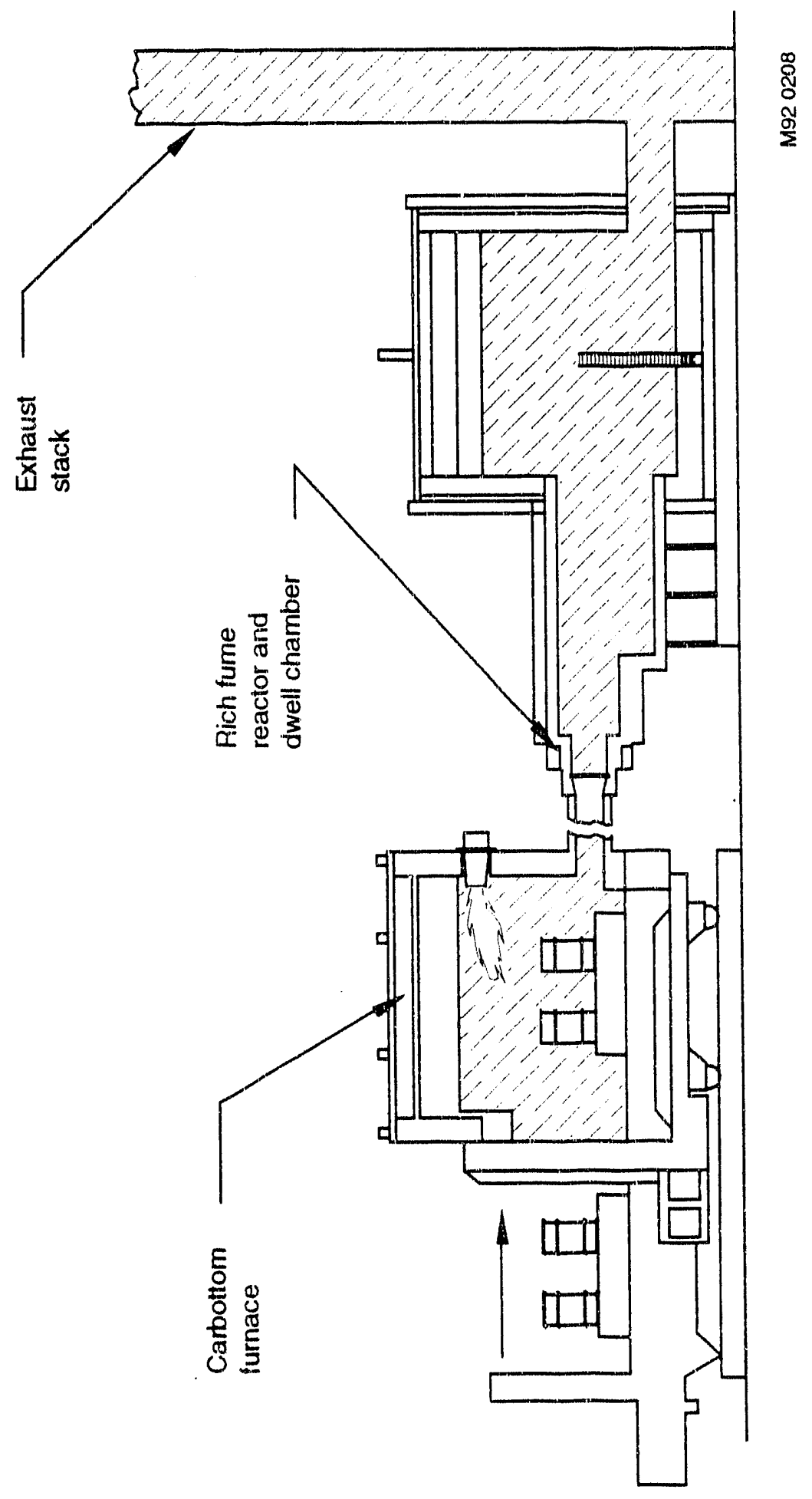

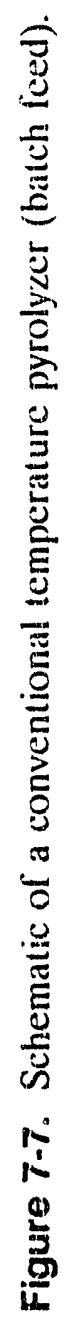




\section{Disadvantages}

Disadvantages of slagging incinerators include (1) connected horsepower, even if the energy is not used, may increase electric utility demand charge in some areas, whether for heating or motive power, (2) each restart after a shutdown requires auxiliary energy since no heat sink is available, such as in the sand bed of the fluidized bed furnace, (3) the furnace requires considerably more floor space as opposed to other furnaces that are vertically oriented, (4) the system can only process solid wastes or sludges with a minimum particle size of $5 \mu \mathrm{m}$ and a maximum particle size of $3.8 \mathrm{~cm}(1.5 \mathrm{in}$.) which may require extensive waste preparation, including sorting, mixing, sizing, and shredding, and (5) this unit cannot process liquids without preprocessing.

\section{Technology Status}

Available: The infrared electric furnace is commercially available, and has been proven reliable at industrial facilities and at onsite remedial actions. Electric furnace incineration has been used at Sydney Mine (near Tampa, Florida), at Peak Oil (in Brandon, Florida), at Florida Steel, at Cornhusker, Nebraska, and at Delray Beach, Florida. Over 40 infrared electric furnaces have been installed in the United States between 1976 and 1985. No application to radioactive waste has been made yet.

Some performance testing has been conducted at infrared electric lurnaces. The Resource Conservation and Recovery Act (RCRA) destruction and removal efficiency (DRE) standard is $99.99 \%$, and the Toxic Substance Control Act (TSCA) standard is $99.9999 \%$. The Shirco unit achieved a DRE for PCBs ranging from $99.9972 \%$ to $99.9988 \%$ at the Peak Oil Superfund Site. DREs for PCBs at the Florida Steel Pilot Scale tests were greater than $99.9999 \%$.

\subsection{Molten Salt Combustion (TT9250) $3,5,18,19,20$}

In molten salt incineration, wastes in the form of liquids, sludges, or shredded solids are fed directly into a molten salt bath. A schematic of the process is shown in Figure $7-8 .^{10}$ Organic materials are rapidly and essentially completely oxidized. The salt, maintained at $1000^{\circ} \mathrm{C}$, is usually sodium carbonate or a eutectic mixture of sodium and potassium carbonate, with a catalytic oxidizing agent. The molten salt traps the chlorine, sulfur, and phosphorus compounds and the remaining inert ash. Excellent contact occurs between the waste and the salt bath to minimize acidic off-gases. The spent salt can be recycled to remove ash and absorbed materials. Catalysts can be added to better treat certain waste components and cleanse off-gases.

A molten salt incinerator consists of a metal containment vessel containing sodium carbonate salts. The exterior of the containment vessel has a gas burner or another suitable heat source to establish the temperature of the molten salt bath. Liquid or solid waste, along with combustion air, are injected into the salt bath through a downcomer. The off-gas and combustion products bubble through the molten salt and are decomposed. Acid gases are scrubbed in the bath, eliminating the need for a downstream scrubbing system. The ash particles are retained within the melt. 


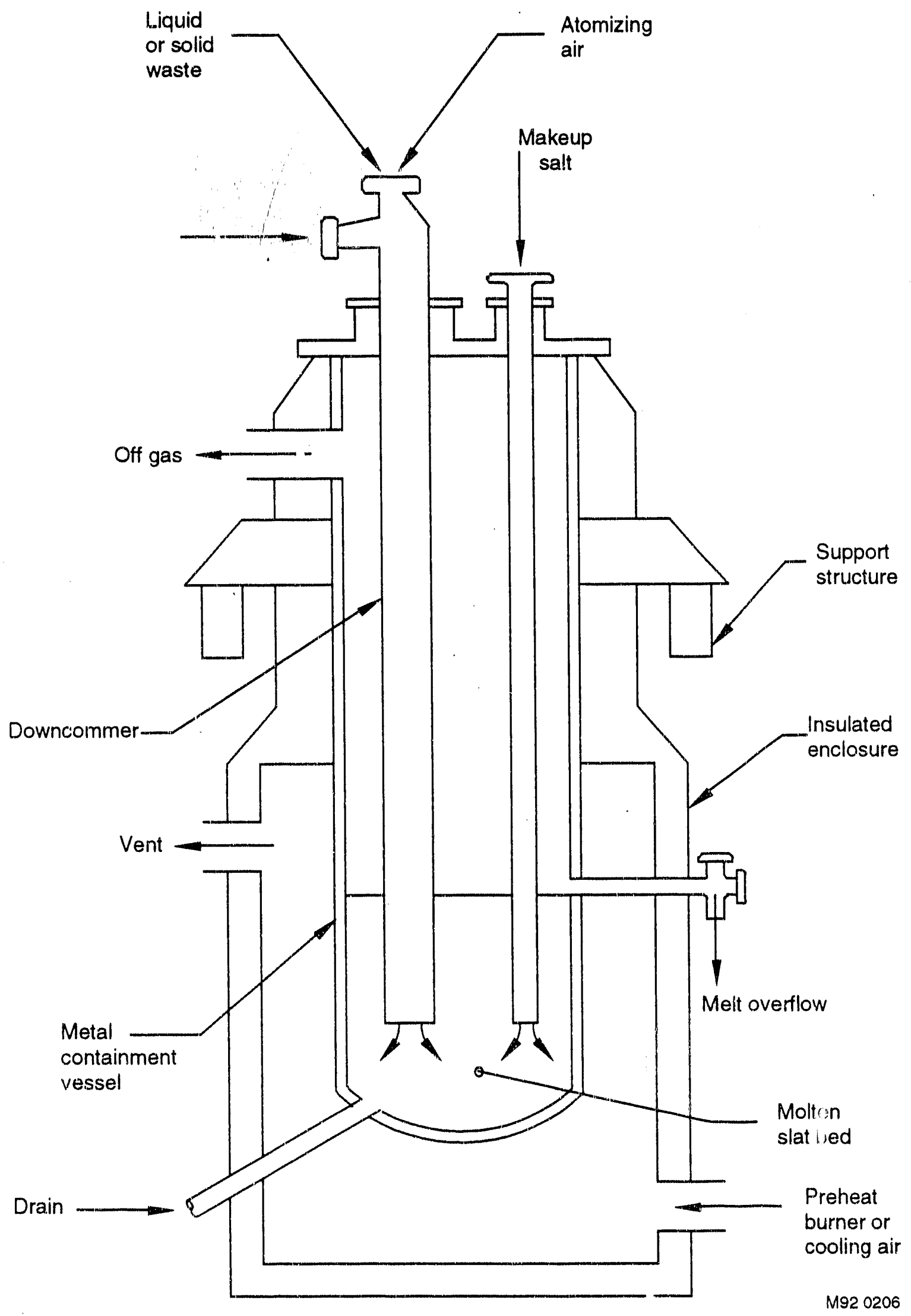

Figure 7-8. Schematic of a molten salt furnace. 


\section{Input Streams}

Input streams can include organics, halogenated organics, inorganics, and metals. Contaminants treated by the Rockwell process include halogenated organics such as PCB, chlordane, HCV, chemical warfare agents such as VX, GB, and mustard gas, pesticides such as DDT and malathion, mixed solids, and aqueous slurries ( $\mathrm{NaNO}(3), \mathrm{NaOH}, 3.4 \% \mathrm{TBP}, \mathrm{PVC}$ resins), concentrated organic solvents and polymers (including fluorinated and chlorinated hydrocarbons), combustible laboratory solids (e.g., activated charcoal, HEPA filters, paper products, ion exchange resins), aqueous streams containing combustibles, and oxidizable metals. The media state can be water, liquid, sediment, sludge/slurry, shredded solids, soil, sized construction materials, refuse, or biota.

\section{Output Streams}

Output streams include clean off-gas, salt (processed and recycled) mixed with inert ash materials, including radionuclides and heavy metals. Condensed particulate in the off-gas may include $\mathrm{NaCl}$ and physical entrainment of droplets into the sparge gas.

\section{Advantages}

The advantages of molten salt combustion include (1) molten salt helps to stabilize temperatures throughout the furnace, to ensure adequate local temperatures for efficient combustion, and limit hot spots where slagging or refractory damage may occur, (2) the salts also scrub the acid gases from the combustion products, and retains the majority of what would otherwise be tly ash, (3) high destruction efficiencies have been achieved for many wastes, including highly toxic and highly halogenated wastes, and (4) low $\mathrm{NO}_{x}$ and heavy metal emissions occur.

\section{Disadvantages}

The disadvantages of molten salt combustion include (1) the process is generally restricted to certain types of organic hazardous wastes, (2) the process is not suitable for high ash content waste because the fluidity of the melt will be adversely affected when it reaches $20 \%$ ash content, (3) molten salt is corrosive to all but specific metal alloys, (4) material and construction costs are high, (5) management of spent salt beds may be difficult, and (6) inorganic reaction products build up in the melt and must be removed.

\section{Technology Status}

Emerging: Rockwell has conducted extensive testing in the bench-scale $4.54 \mathrm{~kg} / \mathrm{h}(10 \mathrm{lb} / \mathrm{h})$ and pilot-scale $113 \mathrm{~kg} / \mathrm{h}(250 \mathrm{lb} / \mathrm{h})$ units. They are currently discussing demonstration and commercialization of the process with potential licensees. Currently, Rockwell International has a molten salt process that uses mixed halide/carbonate melts at 700 to $900^{\circ} \mathrm{C}$ on a wide range of combustible and radioactive wastes. The process has been demonstrated in 1 ton/day pilot plants. The destruction efficiency generally meets or exceeds regulatory emission standards, including those for TSCA regulated materials. The process never found widespread commercial success due to failure to compete economically with incineration. 
Lawrence Livermore National Laboratory (LLNL) and Rockwell International have begun a joint undertaking to develop a process for the rapid, safe, and economical destruction of radioactive toxic wastes by controlled oxidation within beds of molten salts. The proposed system will convert combustible mixed and hazardous wastes into concentrated forms that are free of organics and suitable for either further processing of actinide and toxic metal recovery, or for immobilization treatment for burial. The process will be operated as a closed system. Product gases will be liquified and retained and later discharged or reprocessed. LLNL and Rockwell International are proposing a two stage process. The first stage promotes waste pyrolysis together with acid gas neutralization and ash retention. The second stage completes oxidation of pyrolysis gases in an ash-free melt at $700^{\circ} \mathrm{C}$. The existing process developed by Rockwell International uses mixed halide/carbonate melts at 700 to $900^{\circ} \mathrm{C}$ and has been demonstrated in 1 tonne/day pilot plants on a wide range of combustible and radioactive wastes. The system co, ffiguration used in the existing Rockwell technology is not applicable to mixed waste processing without significant engineering advances requiring increased technical understanding.

\subsection{Liquid Waste Combustor (TT9325) ${ }^{3,7,8,10}$}

Liqui waste combustors can dispose of any combustible liquid with a viscosity of less than 10,000 SSU, or combustible waste gases. They are commercially available in horizontal and vertical configurations. In example schematic is shown in Figure 7-9.10 Waste is injected into the combustion che abe through a dispersing nozzle where it quickly vaporizes and ignites. Like other incinerators, this incinerator system is preheated using natural gas or other conventional fuel before injection of the liquid waste. Typical residence times are 0.5 to $2 \mathrm{~s}$, but up to $12.05 \mathrm{~s}$ is possible. Combustion temperature ranges from $704^{\circ} \mathrm{C}$ to $1648^{\circ} \mathrm{C}\left(1300^{\circ} \mathrm{F}\right.$ to $\left.3000^{\circ} \mathrm{F}\right)$.

At constant residenee time and temperature, the combustion elliciency is improved by rectucing the atomized droplet size to $40 \mu \mathrm{m}$ or less. Rotary cup and pressure atomization are used. The main components of a typical liquid waste combustor are the waste burner system, auxiliary fuel system, air supply system, combustion chamber, and air pollution control device system.

Test burns were conducted by Marquarot Corporation of Van Nuys, California, on ethylene manufacturing waste and hexachlorocylopentadiene (C-5,6). Destruction and removal efficiency (DRE) of $99.999 \%$ at $1,400^{\circ} \mathrm{C}$ was reported.

\section{Input Streams}

Feedstreams can include organic vapor laden gases, liquid wastes, liquid halogenated organics (chlorine, bromine, iodine), organic liquids containing either nitrogen, sulfur, fluorine, phosphorus, silicon, or sodium. Media state includes liquid, sludge/slurry. Depending on the viscosity, the allowable maximum solids concentration may vary from zero to $70 \%$ (by weight). For rotary cup atomization, up to about $20 \%$ solids loading is allowed in the waste stream. Essentially zero solids content is required for single-fluid pressure atomization and internal low pressure atomization types. About $30 \%$ solids concentration is the limit for external low pressure air atomization. Up to $70 \%$ solids concentration is acceptable for external high pressure air and steam atomization types. 

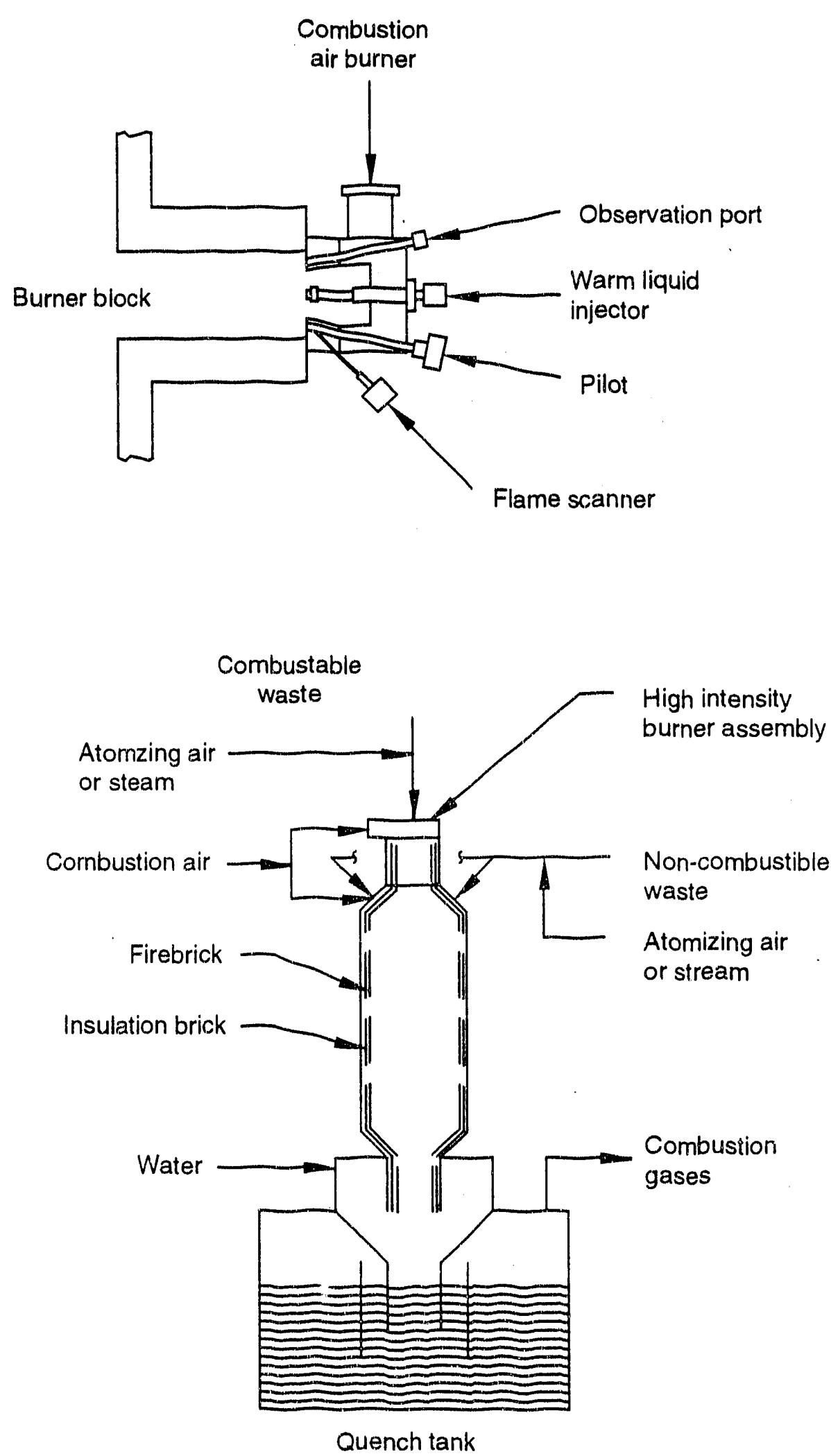

M92 0224

Figure 7-9. Schematic of a liquid-injection incinerator and burner. 


\section{Output Streams}

Output streams include (1) bottom ash, which will be fairly homogenous, and (2) treated flue gas and solid/liquid products from the air pollution control system.

\section{Advantages}

The advantages of liquid waste combustion include: (1) this unit is capable of incinerating a wide range of liquid wastes, (2) continuous bottom ash removal system is not required, (3) there are virtually no moving parts, (4) the use of preheated air in a vertically tired liquid waste incinerator significantly increases decomposition efficiency and economy of operation, (5) the air cone in the vertically fired unit serves as a fuel saver and increases decomposition efficiency by increasing heat retention, (6) lower maintenance costs are incurred than for other units, (7) fast temperature response occurs to changes in the waste fuel flowrate, (8) short residence times ranging from 0.5 to $1.0 \mathrm{~s}$ are possible, (9) the design and operation is simple, and (10) the refractory has a long life.

\section{Disadvantages}

The disadvantages of liquid waste combustion include (1) if the heat content of the waste is inadequate for ignition and incineration temperatures, a supplementary luel must be provided, (2) liquid burners require considerably more turbulence and time to complete combustion as opposed to gas burners, (3) only wastes that can be atomized through a burner nozzle can be incinerated, (4) the atomization process may require preheating and mixing of the waste stream. This preheating must be done within temperature limits to prevent undesirable chemical reactions such as polymerization, nitration, oxidation, coking, etc., (5) the variable flow range is limited at low pressures, (6) atomization tip problems can include high erosion, coking, plugging, and thermal damage, (7) the atomizing nozzles must be removed or blown clear and then cooled with atomizing fluid and secondary air whenever tlow is stopped, to prevent thermal damage or coking and plugging of material in the tip.

\section{Technology Status}

Available: Liquid incineration is a developed and proven commercial technology for nonnuclear applications. Over 200 commercial facilities are applying the technology. Test burns have been conducted by Marquarot Corp. of Van Nuys, California on liquid ethylene waste and hexachlorocyclopentadiene (C-5,6). Hazardous components were benzene, toluene, and chlorinated hydrocarbons. Liquid waste combustors should be considered for waste handling at the source of liquid waste generation.

\subsection{Catalytic Incineration (TT9350) 21,22}

Catalytic incinerators are effective at reducing vapor phase organics, $\mathrm{NO}_{\mathrm{x}}$ and sulphur compounds. The catalyst accelerates the reactions and allows reactions to occur at a lower temperature than would be possible without the catalyst. Gases are passed through a catalyst bed at $316^{\circ} \mathrm{C}$ to $649^{\circ} \mathrm{C}\left(600^{\circ}\right.$ to $\left.1200^{\circ} \mathrm{F}\right)$. Catalysts include noble metals, copper chromite, oxides of copper, chromium, manganese, nickel, and cobalt. Catalytic incinerators are well suited for treating incompletely combusted products from other incineration/combustion processes. Catalytic 
incineration is also useful for primary treatment of hydrocarbon gas streams containing miscellaneous alcohols, amines, acids, esters, aldehydes and other compounds. Catalysts are also effective in reducing oxides of nitrogen and burning sulfur-bearing compounds such as hydrogen sulfide and carbon bisulfides. The off-gases may require venting to acid gas scrubbing equipment.

The five basic steps in catalytic incineration are (1) diffusion of the reactants through the stagnant fluid around the surface of the catalyst, (2) adsorption of the reactants on the catalyst surface, (3) reaction of the adsorbed reactants to form products, (4) desorption of the products from the catalytic surface, and (5) diffusion of the products through the pores and surface film of the bulk vapor phase.

The catalyst flue gases may pass through the primary heat exchanger to recover heat from hot exhaust gases. If required, the waste stream may also be preheated to catalytic oxidation temperatures in a natural gas-fired or electric preheater before passing into the catalyst bed. The bed is generally a ceramic honeycomb or other matrix structure designed to maximize catalyst surface area. The bed can consist of finely divided platinum or other metal deposited on a ceramic or metal support structure.

Catalytic incinerators are effective on a wide range of vapor phase hydrocarbons at low concentrations. Destruction efficiency depends on the specilic hydrocarbon, the catalyst, and the presence of contaminants, which poison or inhibit catalyst operation. Process is sensitive to heavy metals (lead, zinc) and halogens, especially chlorine.

For a fixed residence time in the catalyst bed, increasing the operating temperature at the inlet of the bed increnirs the destruction and removal efliciency (DRE). Alternatively, increasing the residence time white maintaining constant operating temperature will also increase the DRE. Overall, the DRE for volatile organic compounds (VOCs) of $98 \%$ is readily achievable. The DRE for individual difficult to treat compounds up to $95 \%$ can be achieved. The DRE for a given compound may vary depending on whether the VOC is the only one in the emission stream or part of a mixture.

\section{Input Streams}

Input streams can include Vapor phase organics, volatile organic compounds (VOCs), chlorinated solvents, alcohol, unburned natural gas, hydrocarbon solvents, silicones, chlorinated hydrocarbons such as vinyl chloride, and catalyst and catalyst bed material.

\section{Output Streams}

Output streams include (1) scrubbed off-gases, (2) liquid or solid scrubbing products, (3) spent catalyst, and (4) used catalyst bed material.

\section{Adr antages}

Advantages of catalytic incineration include (1) catalytic incineration is excellent for lower temperature combustion and destruction of gaseous materials, and (2) the utility requirement is less than other incinerator processes. 


\section{Disadvantages}

Disadvantages of catalytic incinerator include (1) the combustible waste concentration in the stream should never exceed the lower flammability limit in order to guard against explosion and fire, (2) some materials including phosphates and compounds of metals such as arsenic, mercury, zinc, and lead can poison the catalyst, (3) the pressure drop through some catalyst beds may limit the throughput, (4) if the stream contains high particulate loadings, prefiltration or electrostatic precipitation is required, (5) cleaning and eventual replacement of the catalyst are required, (6) replacement catalyst may be expensive, (7) other contaminants may foul or suppress catalyst operation, and (8) during system operation, high preheat temperatures accompanied by the increase in temperature (due to combustion) may result in high operating temperatures in the catalyst bed causing overheating of the bed and loss of bed activity.

\section{Technology Status}

Available: Catalytic incineration has been used for groundwater stripping operations, graphic art facilities, flexographic printing plants, and latex monomer production.

One catalytic incinerator located at the U.S. Coast Guard Base in Traverse City, Michigan began operation in 1985. It was included in the initial design of the air stripping system. The catalytic incinerator was installed to treat benzene, toluene, and xylene stripped from the groundwater.

A metal oxide catalyst in a fluidized bed configuration has been used in a flexographic printing plant in Massachusetts. The exhaust fumes from 10 tlexographic printing drying ovens containing $120 \mathrm{lb} / \mathrm{h}$ of volatile organic compounds (VOCs), $2.3 \mathrm{~kg} / \mathrm{h}(5 \mathrm{lb} / \mathrm{h})$ ol silicones, and trace amounts of chlorinated hydrocarbons are treated with catalytic incineration. The system was installed in October 1986. Destruction and removal efficiencies (DREs) are in excess of $99 \%$, attributed to operating at $73 \%$ of design air flowrate.

ARI Technologies has a catalyst system that operates at $370^{\circ} \mathrm{C}\left(700^{\circ} \mathrm{F}\right)$ and has a $99.99 \%$ efficiency for destroying chlorinated hydrocarbons from latex monomer production. At present, five plants are successfully operating using catalytic incineration as the control technology.

B. F. Goodrich Chemical Company has developed a catalytic oxidation process known as Catoxid. Chlorinated hydrocarbons from vinyl chloride monomer and chlorinated solvent production are oxidized to produce carbon monoxide, carbon dioxide, hydrochloric acid, and water. The hydrochloric acid reacts with a feedstock to form a useful product; whereas the remaining gases are vented to the atmosphere. This unit treats the chlorinated hydrocarbon waste output of a $10^{9} \mathrm{lb} / \mathrm{yr}$ vinyl chloride monomer plant at Calvert City. This process has replaced a high-temperature, atmospheric pressure incineration unit. This process can handle a wide range of contaminants including solvents and combustible materials. Energy is recovered by steam generation and heat exchange.

\subsection{Cyclone Furnace $(T 9375)^{3,5,6,7,8,9,10,11,23,24,25,26,27}$}

Cyclone furnaces are cylindrically shaped, refractory lined steel shells that can have a vertical or horizontal orientation. The primary feature of cyclone furnaces is cyclonic flow action of the 
combustion gases in the cylindrical main chamber, to promote gas-phase mixing and remove inert ash by impaction on the chamber wall. Contrary to controlled air incinerators, which are designed for low gas velocities in the main chamber, cyclone incinerators are designed for high velocity tangential gas flow. Particle entrainment into the off-gas treatment system is reduced by centrifugal impaction onto the main chamber wall. The main chamber may be operated with excess air to maximize heat release, increase temperatures, and improve combustion and destruction efficiency of organics. Under such high temperature operation, the ash particles are melted, and tend to agglomerate into a molten slag layer on the inside wall of the main chamber. With excess air operation in the main chamber, the secondary (afterburner) section may be eliminated.

Features of the main or combustion chamber may include tangential or radial waste feed, tangential natural gas burners, and tangential primary, secondary and tertiary air ports. The combustion chamber may be oriented horizontally or vertically. In larger designs air is added in substoichiometric amounts with the waste feed.

Several variations of cyclone turnaces are available. One design (Figure 7-10), ${ }^{12}$ tor sludge incineration, has one rotating hearth and a fixed plow that moves the combustible material from the outer edge of the hearth to the center. Sludge is deposited near the periphery of the rotating hearth. Solid waste can be fed by a screw feeder.

Promising designs include B\&W's cyclone furnace for vitrification of contaminated soil. This design was adapted from B\&W's cyclone furnace for coal combustion in utility boilers, developed in the 1940 s to reduce the amount of fly ash entrainment from high ash coals. The single combustion chamber, pilot-scale test unit used to vitrify soil is horizontally oriented. The vitrified slag resulting from these tests passed EPA TCLP tests, and was signiticantly reduced in volume compared to the original soil.

Other designs include a "Cyclone Melting System" developed by Vortec Curporation. This "Counter-Rotating Vortex" combustor was originally developed for melting glass. The CYCLIN ${ }^{\text {TM }}$ incinerator was developed by the Institute of Gas Technology (IGT) and York-Shipley, Inc. This high-intensity, cyclonic incinerator has been tested on liquid wastes.

In the small, unique design used at Mound Laboratory, a portable "lid" that contains a burner, combustion air feed, and an exhaust vent is attached to an open 55-gal waste drum. Combustion air is introduced tangentially to induce cyclonic low, which aids in mixing, improves combustion performance and also aids in the cooling of the chamber walls. The waste in the drum is burned from the top down. The combustion gas swirls up the center of the drum and is vented to an ofli-gas treatment system.

\section{Input Streams}

The various cyclone incinerator designs may treat contaminated soils, organic and mixed waste liquicis, gas, slurries and sludges. Auxiliary tuels include natural gas, and the combustion air is often preheated. Other feedstreams for some models include glass-making raw materials. 


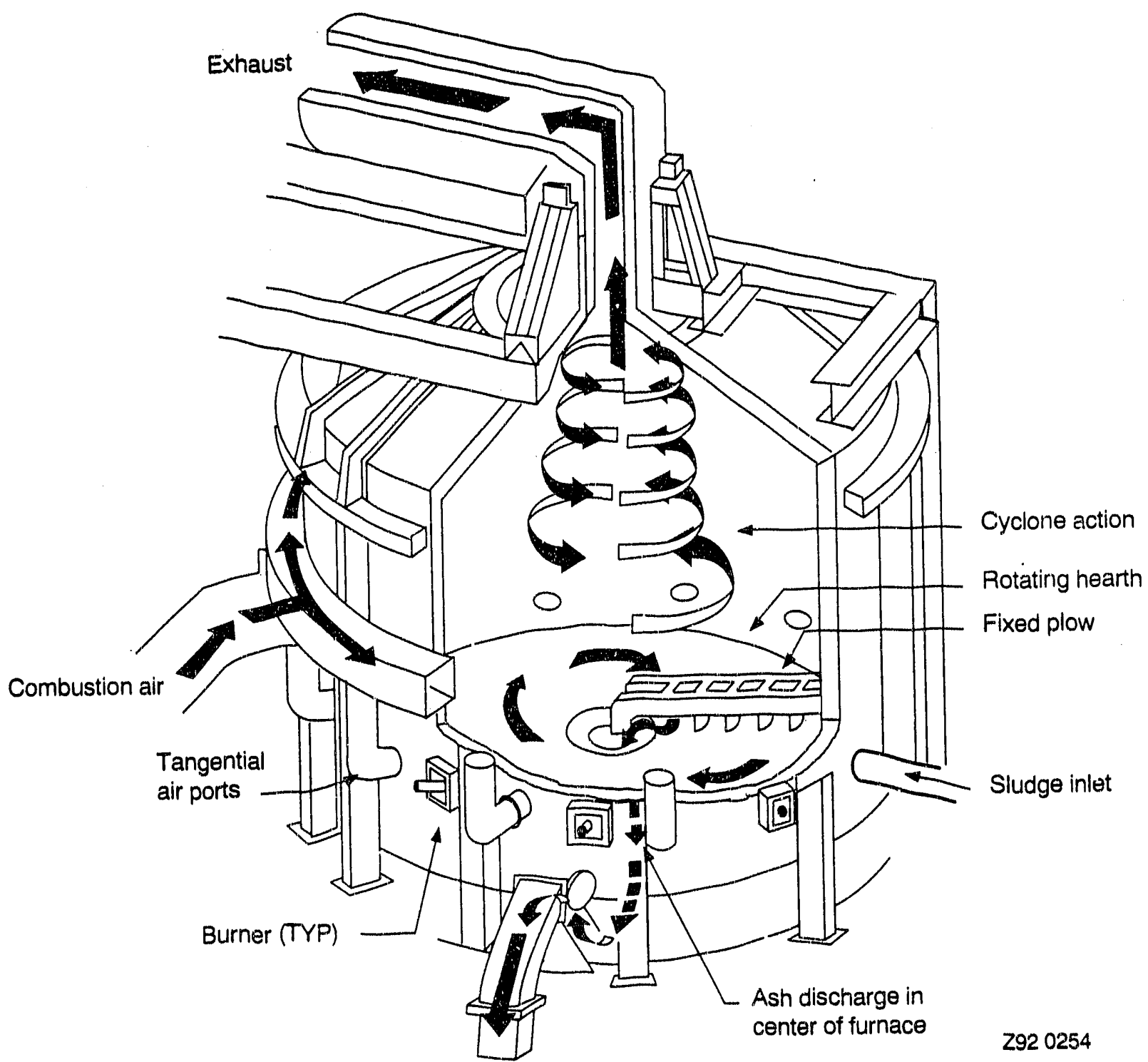

Figure 7-10. Schematic of a cyclone furnace. 


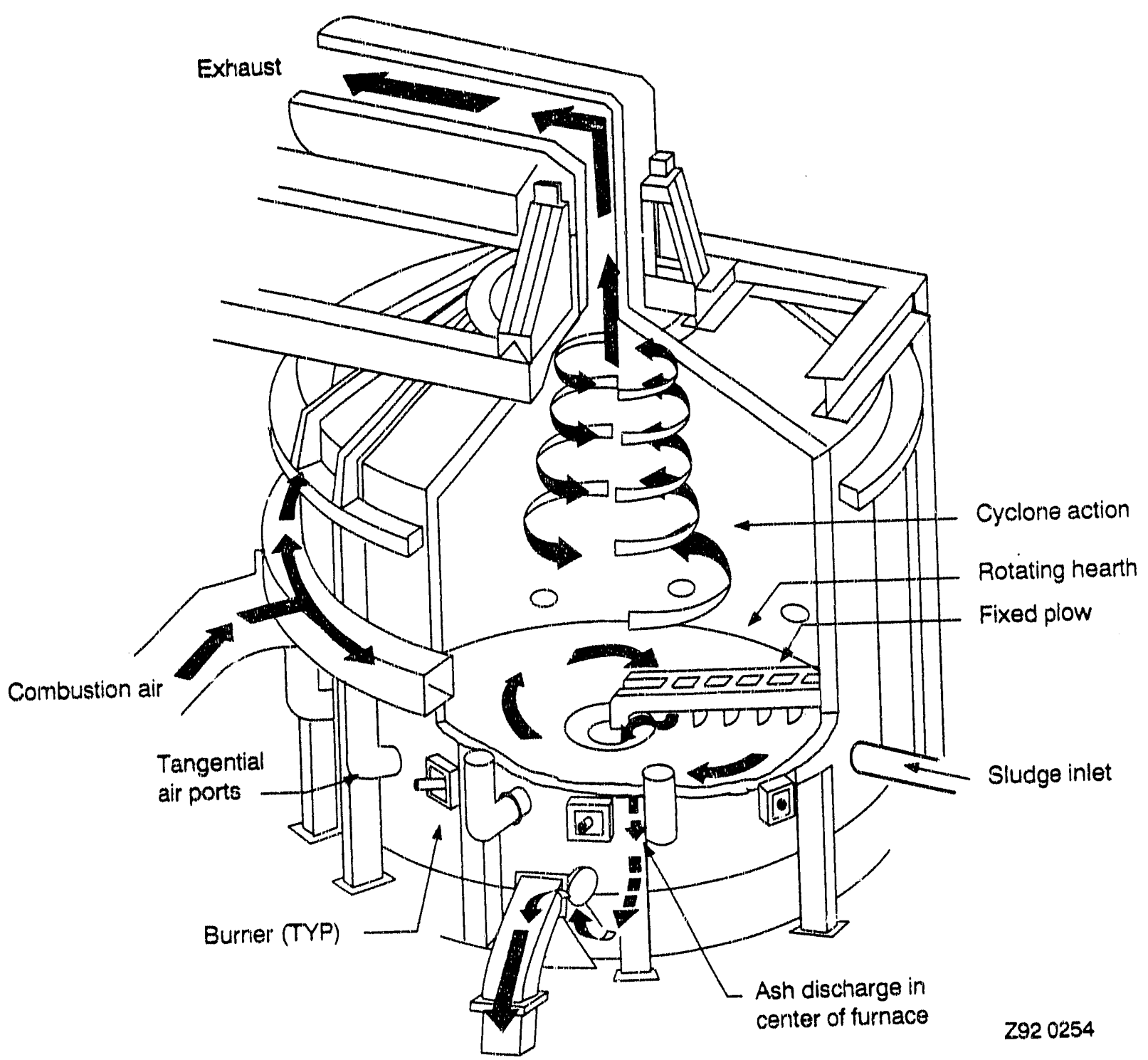

Figure 7-10. Schematic of a cyclone furnace. 


\section{Output Streams}

Output streams may include (1) solidified, slagged bottom ash, which will be fairly homogenous or glassified, and (2) treated flue gas and solid/liquid products from the air pollution control system.

\section{Advantages}

Advantages of cyclonic incinerators include (1) they are typically simple to operate, with low capital cost and low fuel requirements, (2) because of the high combustion chamber temperatures and excess air conditions, an afterburner may not be required, (3) the resultant solidified, slagged bottom ash is leach resistant and may be a suitable final waste form, (4) various cyclonic incinerator designs may efficiently destroy hazardous organic contaminants in high-ash wastes.

\section{Disadvantages}

Disadvantages of cyclonic incinerators include (1) high combustion chamber temperatures will tend to devolatilize metals and increase metal reactions to more volatile forms resulting in significant metals partitioning to the off gas, even when the majority of ash is slagged and collected on the wall of the main chamber, (2) even during cyclonic flow conditions, entrainment incompletely burned waste and/or fly ash may be higher than for other incinerator systems, (3) pretreatment of wastes may be required, and (4) the refractory of the slagging excess-air incinerator will be subject to buildup of gamma emitting Americium.

\section{Technology Status}

Available: Cyclonic furnaces are an operational and conventional technology. Installations of B\&W slagging cyclone coal-fired furnaces combine for over $26,000 \mathrm{MW}$ electrical capacity. This technology is available for hazardous and mixed waste incineration. Several designs have been tested for waste incineration, including B\&W's cyclone furnace, the Vortex Corporation "Cyclone Melting System," and the IGT/York-Shipley liquid waste incinerator. B\&W's cyclone furnace has successfully vitrified an EPA Synthetic Soil Matrix (SSM) for the Superfund Innovative Technology (SITE) Program. The IGT/York-Shipley incinerator has been tested for several liquid wastes.

The DOE has tested a small scale version for mixed wastes at Mound Laboratories. The Japanese make extensive use of this technology for low-level radioactive waste. Research is in progress in the United States on a high temperature version that slags the waste.

\subsection{Blast Furnace $(T T 9400)^{10}$}

This is an application of cofiring hazardous waste in Boilers and Industrial Furnaces (BIF). This approach has been developed in recent years because some industrial furnace and boiler applications have the desired characteristics for treating certain hazardous waste streams. New BIF regulations are currently being promulgated by the EPA to allow (and regulate) permitted hazardous waste cofiring in industrial furnaces and boilers. In blast furnaces, liquid hazardous organic waste is blended with No. 6 fuel oil and fired as the furnace fuel. Hazardous organic compounds are effectively destroyed in the combustion zone of the blast furnace, where temperatures exceed $1649^{\circ} \mathrm{C}\left(3000^{\circ} \mathrm{F}\right)$. 
A blast furnace produces molten iron from iron ore and other iron bearing leed materials. A schematic of a blast furnace is shown in Figure 7-11. ${ }^{10} \mathrm{CO}$ and $\mathrm{H}_{2}$ travel upward through the molten bed and react with the iron oxide to produce iron. The molten iron and slag are tapped from separate taps at regular intervals. Excess $\mathrm{CO}$ and $\mathrm{H}_{2}$ are produced to drive the iron oxide reduction reaction to completion. This gas with excess $\mathrm{CO}$ and $\mathrm{H}_{2}$ is tired in a set of three stoves used to heat the blast air. The stoves cycle between combusting blast furnace gas, and heating blast air so that one stove provides hot blast air while the other two stoves heat up. Dust is removed from the blast furnace gas before the gas enters the stoves.

\section{Input Streams}

Feedstreams can include liquid and gaseous wastes. Contaminants have included 1,1-dichloroethene, chloroform, 1,1-trichloroethane, trichloroethene, benzene, tetrachloroethene, toluene, $\mathrm{m} / \mathrm{p}$-xylene, o-xylene, naphthalene, and total chlorine.

\section{Output Streams}

Output streams include combustion gases, fly ash, and solidified molten iron and slag.

\section{Advantages}

Advantages of blast furnace include (1) the energy from the ofl-gases, having a heating value of about $90 \mathrm{Btu} / \mathrm{scf}$, is used to produce steam for air compression and other process steam requirements, and (2) the high temperature blast furnace can efficiently destroy hazardous organic compounds.

\section{Disadvantages}

Disadvantages of blast furnace include (1) the potential for leaks, especially for $\mathrm{CO}, \mathrm{H}_{2}$, and other incompletely burned byproducts, requires specilic safety precautions during operation, (2) the waste feed cannot be shut off without upsetting the blast furnace carbon and heat balances, (3) radionuclides and heavy metals would probably remain in the ore melt, which may preclude many uses of the iron product, and may require other treatments, and (4) since rlast furnaces would typically be located away from mixed/low-level waste generating facilities, the waste would require shipment to the blast furnace for treatment adding another dimension of difliculty for regulated shipment and temporary storage of such wastes.

\section{Technology Status}

Available: Tests were recently conducted at a large steel mill that colired waste with the abovelisted compounds. The above compounds were efticiently destroyed. The steel company routinely burns hazardous wastes in their blast furnace. No tests on mixed wastes were conducted.

\subsection{Industrial Boiler (TT9425) ${ }^{10}$}

This is another application of coliring hazardous waste in Boilers and Industrial Furnaces (BIF). This approach has been developed in recent years because some industrial furnace and boiler 


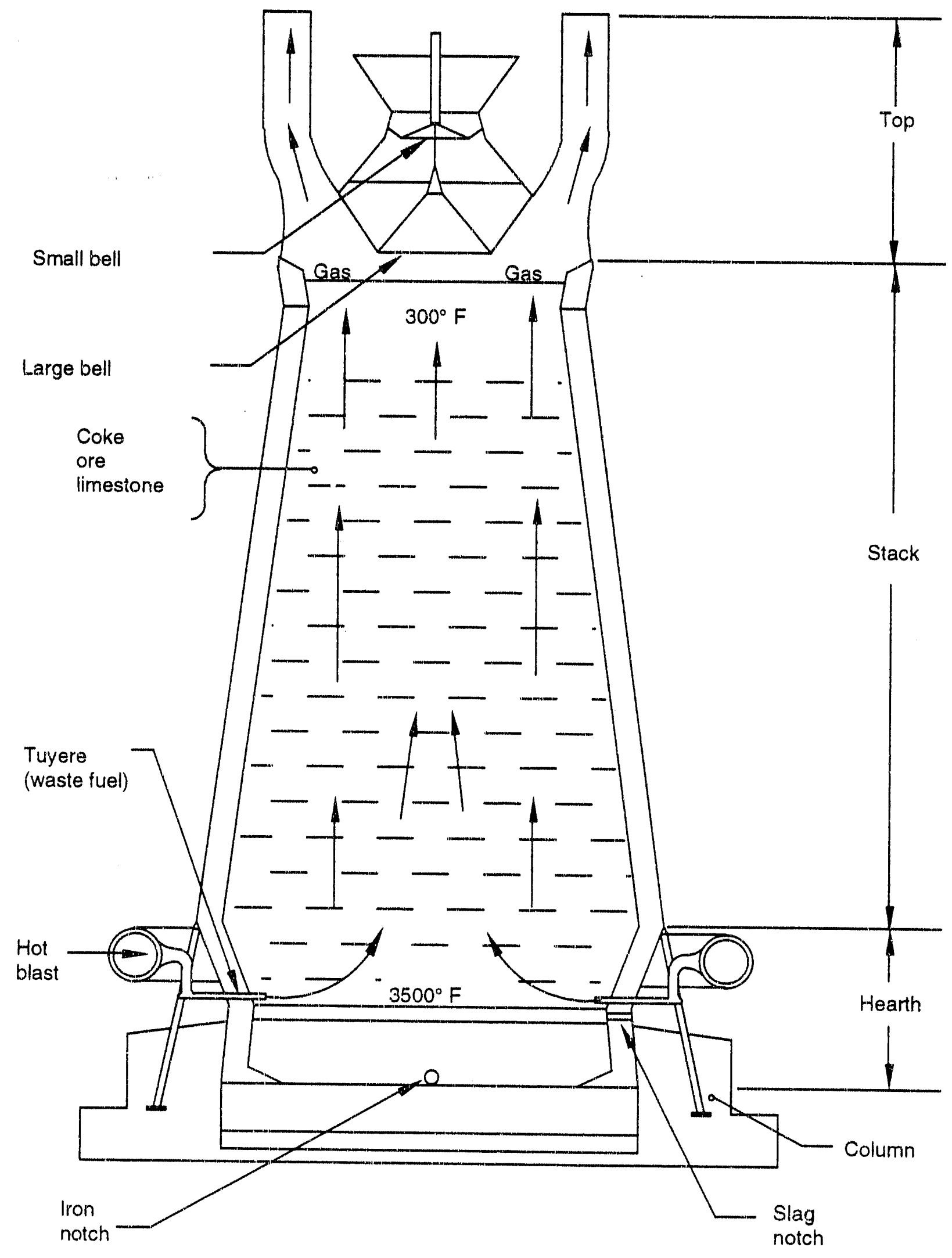

Figure 7-11. Sctiemátic oil an ind ustrial blast furnace. 
applications have the desired characteristics for treating certain hazardous waste streams. New BIF regulations are currently being promulgated by the EPA to allow (and regulate) permitted hazardous waste cofiring in industrial furnaces and boilers.

In industrial boilers, hazardous waste may be colired by special permil with the routinely used fuel (typically oil, gas, or coal) for that specific boiler. Since the waste is cotired with other highheating value fuels, high temperatures and long residence times are often feasible to achieve high destruction efficiencies of hazardous organic components. The heating value of the waste stream is recovered in the boiler steam generation process, and fuel requirements for the boiler are reduced. The actual waste injection design and operation for the boiler depends on the characteritics of the waste.

\section{Input Streams}

Input streams consist of liquid or gaseous wastes, sludges, or slurries. Constituents may include practically any organic materials such as solvents, aromatics, halogenated compounds, or oxygenated compounds.

\section{Output Streams}

Output streams will include (1) bottom ash, which will be fairly homogenous, and (2) treated flue gas and solid/liquid products from the air pollution control system.

\section{Advantages}

Advantages of industrial boiler include (1) the high temperature llame region in the burner zones is efficient in destroying hazardous organic materials, (2) the heating value of the waste stream is recovered in the boiler steam generation process, and (3) luel requirements for the boiler are reduced.

\section{Disadvantages}

Disadvantages of industrial boiler include (1) atomizer upsets and other upset conditions such as low oxyger or low temperature firing can produce significantly degraded combustion efficiency. (2) hazardous compounds in the waste may not be elficiently destroyed, or significant formation of hazardous products of incomplete combustion (PICs) may occur during upset conditions or due to the cooling effect of water walls or banks steam tubes where combustion reactions may still be occurring, (3) few industrial boilers are equipped with sulficient air pollution control equipment to suitably treat and dispose of the increased amounts ol acid gases, devolatilized metals, or particulate, (4) since the primary purpose of industrial boilers is steam (or hot water) generation, they are not designed or operated for suitable containment of radioactive materials. (5) the levels and flowrates of hazardous cunstituents into the boiler is limited by permit conditions to those levels where suitable process operation and allowable emissions are proven by trial burns, (6) emissions of surrogate indicators [CO and total hydrocarbons (THC)] must be continuously monitored, and (7) the firing of hazardous wastes must be suspended during any process upsets or when emissions exceed allowable limits. 


\section{Technology Status}

Available: The technology is available, although not proven for mixed waste applications. Among other trial burns and test programs, the EPA Hazardous Waste Engineering Research Laboratory has performed a boiler cofiring field test program in which eleven test boilers showed high levels of thermal destruction for principal organic hazardous constituents (POHCs). Further tests were done using a forced draft Combustion Engineering (CE) type watertube boiler.

\subsection{Industrial Kiln (TT9450) ${ }^{10}$}

This is another application of cofiring hazardous waste in Boilers and Industrial Furnaces (BIF). This approach has been developed in recent years because some industrial furnace and boiler applications have the desired characteristics for treating certain hazardous waste streams. New BIF regulations are currently being promulgated by the EPA to allow (and regulate) permitted hazardous waste cofiring in industrial furnaces and boilers.

Industrial kilns that are particularly adapted for coliring hazardous wastes include cement kilns, lime kilns, and aggregate kilns. A schematic of an industrial kiln is shown in Figure 7-12. ${ }^{10}$ Cement kilns are used to calcine a mixture of clay, limestone and other raw materials to cement clinker for grinding into cement. Lime kilns are used to dehydrate and oxidize limestone $\left(\mathrm{CaCO}_{3}\right)$ to quicklime $(\mathrm{CaO})$. Aggregate kilns are used to heat and expand dense raw materials into light-weight bulk materials.

Hazardous waste may be cotired by special permit with the routinely used fuel (typically oil, gas, or coal) for that specific kiln. Kilns are typically refractory-lined rotary tunnels, ranging up to $7.62 \mathrm{~m}$ (25 it) in diameter, and hundreds of feet long. Kilns are designed for especially high temperature and long residence time processing of solids. Combustion gas temperatures maly exceed $1648^{\circ} \mathrm{C}$ $\left(3000^{\circ} \mathrm{F}\right)$ for cement and lime kilns, and $1093^{\circ} \mathrm{C}\left(2000^{\circ} \mathrm{F}\right)$ for aggregate kilns. Combustion gas residence times may range from 2 to $10 \mathrm{~s}$, and the residence time for solid materials may be hours. Such long residence limes and high temperatures are ideal for high efficiency destruction of hazardous organic compounds. The presence of acid gas scrubbing calcium, magnesium and sodium compounds is an added feature of cement kilns.

\section{Input Streams}

Feedstreams can include liquid or gaseous wastes, sludges, slurries, or solid materials. Constituents may include practically any organic materials such as solvents, aromatics, halogenated compounds, or oxygenated compounds.

\section{Output Streams}

Output streams include (1) bottom ash, mixed with the kiln product (cement clinker, quicklime, or aggregate), and (2) treated flue gas and solid/liquid products from the air pollution control system. 


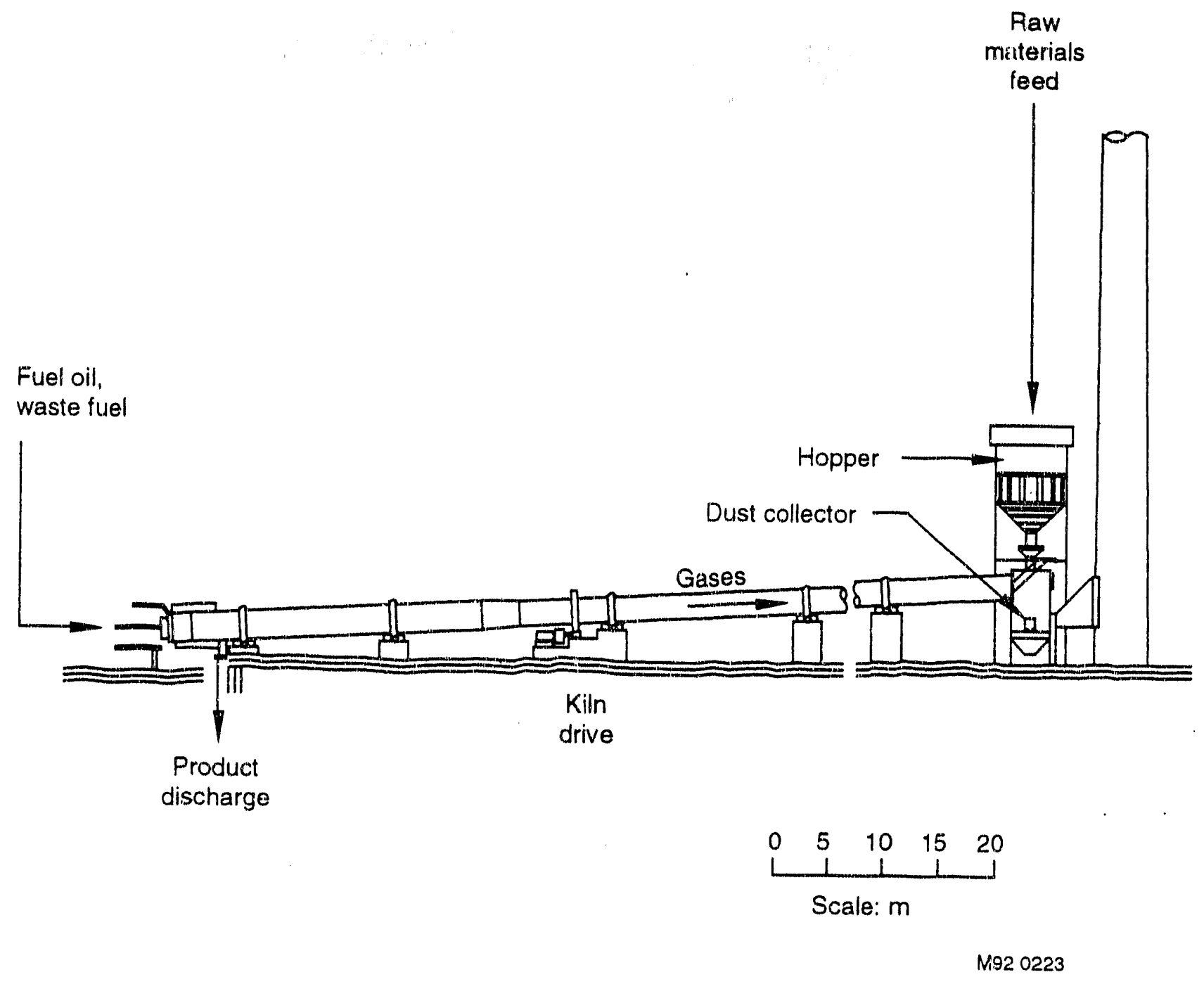

Figure 7-12. Schematic of an industrial kiln (typical for cement, lime, and aggregate kilns). 


\section{Advantages}

Advantages of industrial kiln include (1) the long residence times and high temperatures are ideal for high efficiency destruction of hazardous organic compounds, (2) the presence of acid gas scrubbing calcium, magnesium and sodium compounds eliminates the need for acid gas scrubbing equipment on cement kilns, (3) all kilns are equipped with fly ash emissions control equipment, and (4) the heating value of the waste stream is recovered in as heat generation for the kiln process, and fuel requirements for the kiln are reduced.

\section{Disadvantages}

Disadvantages of industrial kiln include (1) atomizer upsets and other upset conditions such as low oxygen or low temperature firing can produce significantly degraded combustion efficiency, (2) hazardous compounds in the waste may not be efficiently destroyed, or significant formation of hazardous products of incomplete combustion (PICs) may occur during upset conditions, (3) few lime kilns and aggregate kilns are equipped with sufficient air pollution control equipment to suitably treat and dispose of the increased amounts of acid gases, (4) the high temperatures result in increased partitioning of metals and metal compounds to the llue gas, were the more volatile compounds may remain as difficult-to-control vapor, (5) the less volatile metal compounds may condense into such small particle sizes that these too may be difficult to collect, (6) the inorganic waste constituents and acid gases adsorbed into the process material may adversely aflect the product quality, (7) industrial kilns are difficult to hermetically seal and chronically have significant fugitive dust emissions, (8) kilns are not designed or operated for suitable containment of radioactive materials, (9) the levels and flowrates of hazardous constituents into the kiln is limited by permit conditions to those levels where suitable process operation and allowable emissions are proven by trial burns, (10) emissions of surrogate indicators ( $\mathrm{CO}$ and total hydrocarbons (THC)) must be continuously monitored, (11) the firing of hazardous wastes must be suspended during any process upsets or when emissions exceed allowable limits, and (12) since industrial kilns would typically be located awaly trom mixed/low-level waste generating facilities, the waste would require shipment to the blast furnace for treatment adding another dimension of difficulty for regulated shipment and temporary storage of such wastes.

\section{Technology Status}

Available: The technology is available, altholigh not proven for mixed waste applications, and still emerging for hazardous waste treatment. Several trial burns and other tests and operations have been performed and are planned for coliring materials such as waste tires in cement kilns. 


\subsection{References}

1. W. S. Roesener, Unit Systems for the Treatment of TRU Contaminated Waste, WM-PD-92-002, December 1991.

2. L. Rosengrant, Treatment Technology background Document, U.S. Environmental Protection Agency Office of Solid Waste, EPA/530-SW-90-059Z, January 1991.

3. EG\&G Idaho, Inc., Environmental Technologies Information System, Computer Database, Developed October 1990 for DOE/ID.

4. R. L. Jolley, L. R. Dole, H. W. Godbee, A. H. Kibbey, L. C. Oyen, S. M. Robinson, B. R. Rodgers, and R. F. Tucker, Jr., Low-Level Radioactive Waste From Commercial Nuclear Reactors - Treatment, Storage, Disposal, and Transportation Technologies and Constraints, ORNL/TM-9846-Vol. 2, May 1986.

5. DOE National Low-Leve! Radioactive Waste Management Program Handbook Series, Low-Level Radioactive Waste Treatment Technology, DOE/LLW-13c, July 1984.

6. A. A. Moghissi, H. W. Godbee, and S. A. Hobart, Radioactive Waste Technology, New York: American Society of Mechanical Engineers, 1986.

7. H. M. Freeman, Editor, Standard Handbook of Hazardous Waste Treatment and Disposal, New York: McGraw-Hill Book Company, 1989.

8. Yen-Hsiung Kiang, and A. A. Metry, Hazardous Waste Processing Technology, Boston: Butterworth Publishers, 1982.

9. R. E. Berlin and C. C. Stanton, Radioactive Waste Management, New York: John Wiley \& Sons, 1989.

10. Hazardous Waste Remedial Actions Program, An Assessment of Thermal Destruction Technologies for Application to Department of Enerxy Mixed Wastes, DOE/HWP--106-Vol. 1 and 2, August 1991.

11. T. G. Hedahl, R. L. Benedetti, C. H. Cargo, R. J. Carpenedo, W. H. Landman, and J. E. Langford, Intinerator Unit Process Evaluation, WM-F2-81-002, May 1981.

12. P. N. Cheremisinoff, Pollution Engineering Flowsheets, Hazardous Material, United States: Cahners Publishing Co., 1988.

13. J. A. Peters, "Effects of Disposal of Hazardous Wastes in Cement Kilns on Conventional Pollutant Emissions," Incineration and Treatment of Hazardous Waste, EPA/600/9-84/022, Proceedings of the Annual Research Symposium (10th) at Fort Mitchell, KY, April 1984 , pp. 38-47.

14. D. R. Day, "Evaluation of Hazardous Waste Incineration in a Lime Kiln," Incineration and 
Treatment of Hazardous Waste, EPA/600/9-84/022, Proceedings of the Annual Research Symposium (10th) at Fort Mitchell, KY, April 1984, pp. 48-56.

15. Vic Cundy et al., "Rotary Kiln Incineration IV. An Indepth Study--Kiln Exit, Transition and Afterburner Sampling During Liquid $\mathrm{CCl}_{4}$ Processing," Journal of Air Pollution control Association (JAPCA), pp. 1073-1085.

16. R. Geimer, T. Hertzler, R. Gillins, and G. L. Anderson, "Assessment of Incineration and Melting Treatment Technologies for RWMC Buried Waste," EGG-WTD-100035, February 1992.

17. USEPA, "Shirco Infrared Incineration System," Applications Analysis Report, EPA/540/A5-89/010, June 1989.

18. John F. Cooper, Joseph C. Farmer, Oscar H. Krikorian, "Molten Salt Processing of Mixed and Hazardous Wastes," A Proposal to the Office of Technology Development Department of Energy, ADS No. SF-1506-01 (Formerly ADS No. SF-1608-02), Lawrence Livermore Laboratory, Livermore, CA, September 4, 1990, pp. iii-x.

19. DOE Office of Technology Development (OTD), "TD Monthly Progress Report--Molten Salt Processing of Mixed Waste," October 1990.

20. Environmental Technology Program Annual Repoit FY 90, Program Leader: Jesse L. Yow, Jr., UCRL-LR-105199, Lawrence Livermore National Laboratory, January 2, 1991, pp. 36-39.

21. Michael Kosusko, Carlos Nunez, "Destruction of Volatile Organic: Compounds Using Catalytic Oxidation," Air \& Waste Management Assoc., Volume 40, No. 2, February 1990, pp. 254-259.

22. M. S. Jennings, N. E. Krohn et al., Catalytic Incineration for Control of Volatile Organic Compound Emissions, Noyes Publications, Library of Congress 85-4923, 1985.

23. C. Eid and A. J. Van Loon, Incineration of Radioactive Waste, Graham and Trotman, Ltd., London, 1985, pp. 48-57.

24. S. S. Freeman, et al., "The Mound Laboratory Cyclone Incinerator for Radioactive Waste," Management of Low-Level Radioactive Waste, Volume I, Pergamon Press, 1979.

25. J. Batdorf, R. Gillins, and G. Anderson, Detailed Technology Assessments for Thermal Waste Treatment Processes, EGG-WTD-10036, January 1992.

26. D.W. Major, and J. Fitchko, Emerging On-Site and In-Situ Hazardous Waste Treatment Technologies, Northbrook, IL: Pudvan Publishing Co., Inc., 1990.

27. J. M. Czuczwa, H. Farzan, S. J. Vecci, and J. J. Warchol, "Cyclone Furnace tor Vitrification of Contaminated Soil and Wastes," 1991 Incineration Conference, Knoxville, TN, May 13-17, 1991. 


\section{THERMAL DEGRADATION/VOLATILIZATION (TT10000)}

Waste thermal treatment systems may be grouped according to their design and function. Treatment systems whose primary function is to destroy the organic waste components by combustion are generally classified as incinerator processes, and are discussed in Section 7. The primary function of some other thermal treatment processes is to stabilize the solid, inert waste components by vitrification. These processes are discussed in Section 9. Some technologies, such as the cyclonic incinerator and the plasma arc melter, can both incinerate organic waste components, and also vitrify or glassify the inert waste components. Such combined functions can make these technologies attractive for treating certain wastes, but less easy to categorize. These have been grouped as incineration or vitrification systems according to their perceived primary function, even when they can serve combined functions.

Other technologies are available that are significantly different from those classified as incinerators or vitrification systems. These are grouped separately as thermal degradation and or volatilization systems, and are discussed in this section. Technologies that seem to fit best into this classification include the following:

$\begin{array}{ll}\text { Section } & \text { Technology } \\ 8.1 & \text { Calcination } \\ 8.2 & \text { Acid Digestion } \\ 8.3 & \text { Chemical Oxidation/Reduction } \\ 8.4 & \text { Wet Air Oxidation } \\ 8.5 & \text { Supercritical Fluid Oxidation }\end{array}$

These systems are thermal waste treatment technologies. They include thermal degradation and/or oxidation reactions, but they are not typically classified as incineration systems because they are different from most incinerator systems.

\subsection{Calcination $(\pi 10100)^{1,2,3,4,5,6}$}

Calcination is a thermal process that evaporates water from waste material, and thermally decomposes nitrate and fluoride salt solutions to metallic oxides and lluorides, waste vapor, and nitrogen oxides. The calcination process itself does not include combustion of organic compounds that occurs during incineration. Calcination occurs at temperatures ranging from 427 to $1093^{\circ} \mathrm{C}$ $\left(800\right.$ to $\left.2000^{\circ} \mathrm{F}\right)$ and requires either indirect electrical or fossil fuel-lïred heating, or direct heating from fossil-fired burners.

Calcination may occur in fluidized beds, rotary drum systems, or other systems that enable rapid and complete heat and mass transfer between the solid and gas phases. For example, a calciner that has been operated at the INEL is a specialized application of a tluidized bed incinerator. A schematic of this calciner is shown in Figure 8-1.6 Calcium nitrate is needed as a raw material when waste containing fluorides is processed. Off-gas filtration equipment is required for particulate collection, and acid gas scrubbing may be required if halogenated or sulfur-bearing compounds are present in the waste. 


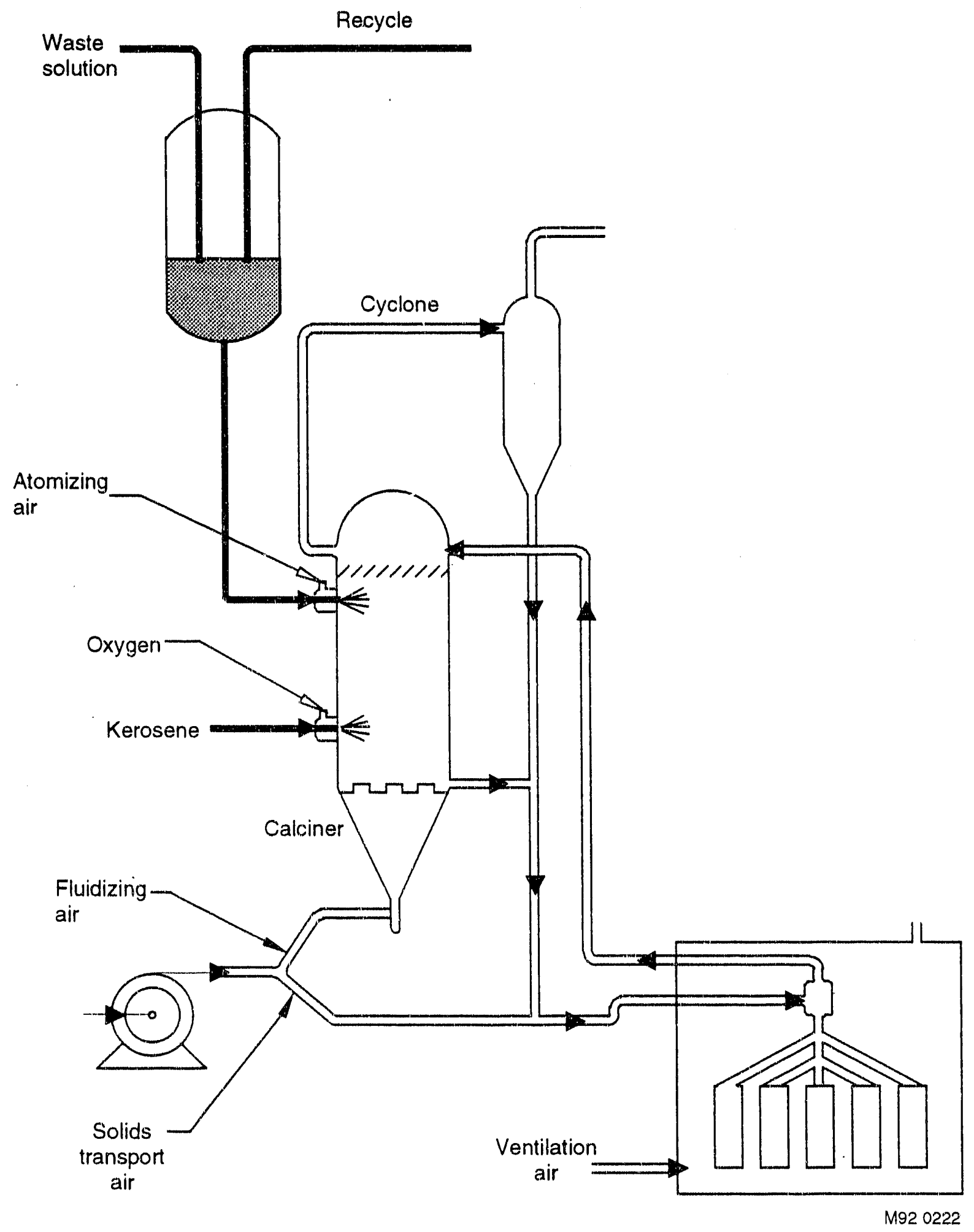

Figure 8-1. Schematic of a calciner. 


\section{Input Streams}

Input streams can be aqueous wastes, incliding high level liquid wastes and sludges; raw materials such as calcium nitrate for Huoride-containing wastes.

\section{Output Streams}

Output streams may include calcined ash, bed matcrial (for fluidized beds), coarse inert waste solids, and combustion gas (from fossil-tired systems), solit or liquid products from air pollution control equipment.

\section{Advantages}

Advantages of calcination include (1) the design can be simple and have lew moving parts, and may not require refrarto.y liners, and (2) calcination of high level liquid wastes results in volume reduction and change of physical form to a more immobilized, calcined waste form.

\section{Disadvantages}

Disadvantages of calcination include (1) only aqueous waste can be handled in the INEL fluidized-bed calcine;, although other calciner designs are available (e.g., the rotary calciner) that readily accept sludges, (2) particulate entrainment rate san be high requiring special attention in offgas system design, (3) the INEL calciner operates at moderate temperatures $482^{\circ} \mathrm{C}\left(900^{\circ} \mathrm{F}\right)$ resulting in the formation of significant $\mathrm{NO}_{x}(4)$ the INEL calciner is not designed to burn hazardous organics, and (5) the addition of an afterburner and more significant scrubber equipment would likely be required for mixed waste treatment.

\section{Technology Status}

Proven: This technology is proven in nonwaste treatment applications, and in limited radioactive waste treatment. Calcination is a commonly used commercially for heating such materials as limestone, gypsum, clay, and coke to decompose, dehydrate, oxidize, and/or drive off volatiles.

Idaho National Engineering Laboratory has been operating a lluidized bed calciner for years to treat high level liquid waste from the reprocessing of nival nuclear reactor fuel. This design is relatively simple in that it has few moving parts. Spent scrub liquid from the off-gas system is reprocessed in the calciner. This calciner does not require refractory lining.

\subsection{Acid Digestion (TT10200) $)^{1,7}$}

In this process, organic materials are digested and oxidized in hot concentrated sulfuric and nitric acids. Carbon compounds are dehydrated (carbonized) by the sulturic acid, and then oxidized by the nitric acid. The end products are gases and insoluble salt residues. This concept for processing combustible waste was developed and lested at Hantord Engineering Development Laboratory. 
The Hanford facility includes a feeder, tigester, calciner, and off-gas treatment unit. Shredded combustible wastes are added to a hot $\left(250^{\circ} \mathrm{C}\right)$ concentrated sulfuric acid solution that carbonizes the waste. Nitric acid is added to complete the carbon oxidation to carbon dioxide. Hydrogen peroxide has $i$. en testud as a replacement for nitric acid. This reduces the formation of $N O_{x}$ emissions. T'empe stures ranged from 171 to $182^{\circ} \mathrm{C}\left(340\right.$ to $\left.360^{\circ} \mathrm{F}\right)$ for cellulosic wastes to $221^{\circ} \mathrm{C}\left(430^{\circ} \mathrm{F}\right)$ for PVC wa:tes.

The generat $u d$ vapor and gas, including $\mathrm{SO}_{x}$ and $\mathrm{NO}_{x}$, require treatment in an off-gas system. At the Hanford facility, the gases are vented through a demister, adsorbents, and a scrubber. The absorbed $\mathrm{I}_{2} \mathrm{SO}_{4}$ and $\mathrm{HNO}_{3}$ are distilled and reused in the digestion process.

The residue from the digestion process also requires further processing. At the Hanford facility, the residue is drained from the bottom of the digester and is calcined at about $500^{\circ} \mathrm{C}$. The sulfuric acid generated from the residue during calcination is reused in the process after passing through the condenser. The calcined residue is mixed with the ash of combustible wastes, converted into ceramiclike blorks, and then melted for immobilization in a microwave melting process. Engineering feasibility has heen demonstrated at Hanford. Plutonium, if present in the waste feed, remains with the inorganic sulfate and oxide salts residue, and ean be recovered by leaching with a dilute nitric acid solutions. Acids are recovered and recycled.

\section{Input Streams}

Input wastes can include organics, and inorganics. Physical forms can include sludges, liquids, solids (shredded), and sediments. Teflon and organic liquids do not process well.

\section{Output Streams}

Output streams include insoluble oxides, sulfate salts, carbondioxide, water, acid gases, scrubber water, and particulate residue as discussed below. The nonvolatile inorganics form insoluble oxides or sulfate salts, while the organics are converted to carbon dioxide, water, and other gaseous products. The gaseous products may include acid gases such as $\mathrm{HCl}$ (from PVC and other plastics), and entrained particulate residues. The acid gases and particulates require treatment such as scrubbing with an aqueous alkaline scrubbing solution. The scrubber liquid becomes a secondary waste that can be processed to recover the nitric and sulfuric acids for recirculation back to the digester. leaving any remaining particulate residue for further treatment/disposal.

\section{Advantages}

Advantages of acid digestion include (1) the nitric and sulfuric acids in the off-gas can be recovered and recycled for reuse. (2) virtually any waste form can be handled, (3) little particulate fines are generated. adapting this technology to processing wastes (e.g., ion exchange resins) that would generate large quantities of fine particulate, and (4) other suitable applications may include processing explosive wastes and high level Pu-containing wastes that would contaminate refractory. 


\section{Disadvantages}

Some disadvantages include (1) low processing rates, (2) acid makeup requirements, (3) acid handling requirements, (4) removal of the radionuclides after digestion, and (5) disposal of the acid after depletion.

\section{Technology Status}

Available: Although this technology is used in many industrial and laboratory applications, and is available for mixed waste applications, it is not proven for mixed wastes. No significant work has been done on this concept since 1982. The state of developrent for this process is low and has been limited to small bench scale equipment. Process rates have been limited to 8 to $10 \mathrm{~kg} / \mathrm{h}$ of feed material.

\subsection{Chemical Oxidation-Reduction (TT10300) $2,3,4,10$}

Chemical oxidation-reduction is used to destroy, reduce the toxicity or reduce the solubility of pollutants. Oxidation is used for organic and inorganic materials while reduction is used mainly for inorganic materials. The basic process involves mixing liquid waste with a chemical or group of chemicals that promote destruction or oxidation. Variations include using heat, ultraviolet light and/or catalysts to increase the efficiency or rate of reaction. The process is operated in either a batch or continuous mode, depending on reaction rates and volumes to be processed. Standard mixing equipment such as tanks, agitators, and pumps are used. Catalysts used are typically recycled.

\section{Input Streams}

Feedstreams can include aqueous liquid wastes, chemical reactants, and catalysts.

\section{Output Stream}

Output streams include gases, aqueous liquid containing salts or less toxic ions of the original toxic waste constituents, and spent catalyst.

\section{Advantages}

Advantages include (1) simplicity and (2) minimal energy requirements.

\section{Disadvantages}

Chemical oxidation-reduction is limited to dilute aqueous liquid wastes and moderate pressure and temperature conditions.

\section{Technical Status}

Available: Chemical oxidation-reduction is a conventional and well developed technology for treating dilute aqueous solutions of some toxic compourds. Los Alamos National Laboratory has built a system to treat PCB-contaninated groundwater. This system uses titanium dioxide as a 
catalyst, and uses solar mirror reflectors to focus sunlight onto clear plastic piping through which the contaminated groundwater flows for treatment.

\subsection{Wet Air Oxidation (TT10500) $)^{2,3,4,6,8,9}$}

Wet air oxidation is the oxidation of dissolved or suspended organic substances in an aqueous system at elevated temperatures and pressures. A schematic of this process is shown in Figure 8-2. Oxygen (air) and a dilute organic/water mixture are introduced into a reactor vessel at subcritical conditions 177 to $343^{\circ} \mathrm{C}\left(350\right.$ to $\left.650^{\circ} \mathrm{F}\right)$ and 20 to 200 atm where oxidation of the organics occurs.

The process, once started, is thermally self-sustaining provided that the waste input stream has a heating value of at least $1,800 \mathrm{Btu} / \mathrm{lb}$. The heat of combustion for the waste mixture provides the necessary heat to maintain the reaction temperature and replace system heat losses. For waste streams with lower heating values, supplemental, indirect heating may be necessary. The pressure is maintained above the vapor pressure of water to prevent boiling. The process oxidizes the organics to water, carbon dioxide, and various acids. Acids may be subsequently neutralized or orherwise treated and disposed. Reaction times of $60 \mathrm{~min}$ are typical.

\section{Input Streams}

Input streams include dilute aqueous organic wastes, air (or oxygen), and acid neutralizing agents (if used).

\section{Output Streams}

Output streams include aqueous acidic (or neutralized) wastes, dissolved or suspended inorganic solids, gases from oxidation reactions.

\section{Advantages}

Advantages of wet air oxidation include (1) the process does not have large energy requirements, and does not require large vessels or equipment, (2) the off-gas volumes are small, and the off-gas is free of $\mathrm{NO}_{\mathrm{x}}, \mathrm{SO}_{\mathrm{x}}$, other acid gases and particulates, (3) the process is uniquely suited for difficult-to-incinerate, dilute waste streams, and (4) the process temperature of less than $343^{\circ} \mathrm{C}$ $\left(650^{\circ} \mathrm{F}\right)$ is much cooler than typical incineration temperatures that range from $482^{\circ} \mathrm{C}$ to over $1093^{\circ} \mathrm{C}$ (900 to over $2000^{\circ} \mathrm{F}$ ).

\section{Disadvantages}

Disadvantages of wet air oxidation include (1) wet air oxidation is not effective for treating halogenated species, (2) it is not highly predictable and usually requires facility design and operation in accordance to the specific compounds being treated, (3) it is limited to weak aqueous organic solutions, (4) high pressure system hardware is required, (5) reaction times (residence times) are not fast, (6) off-gas scrubbing may be required, and (7) special alloys and materials may be necessary to prevent corrosion. 


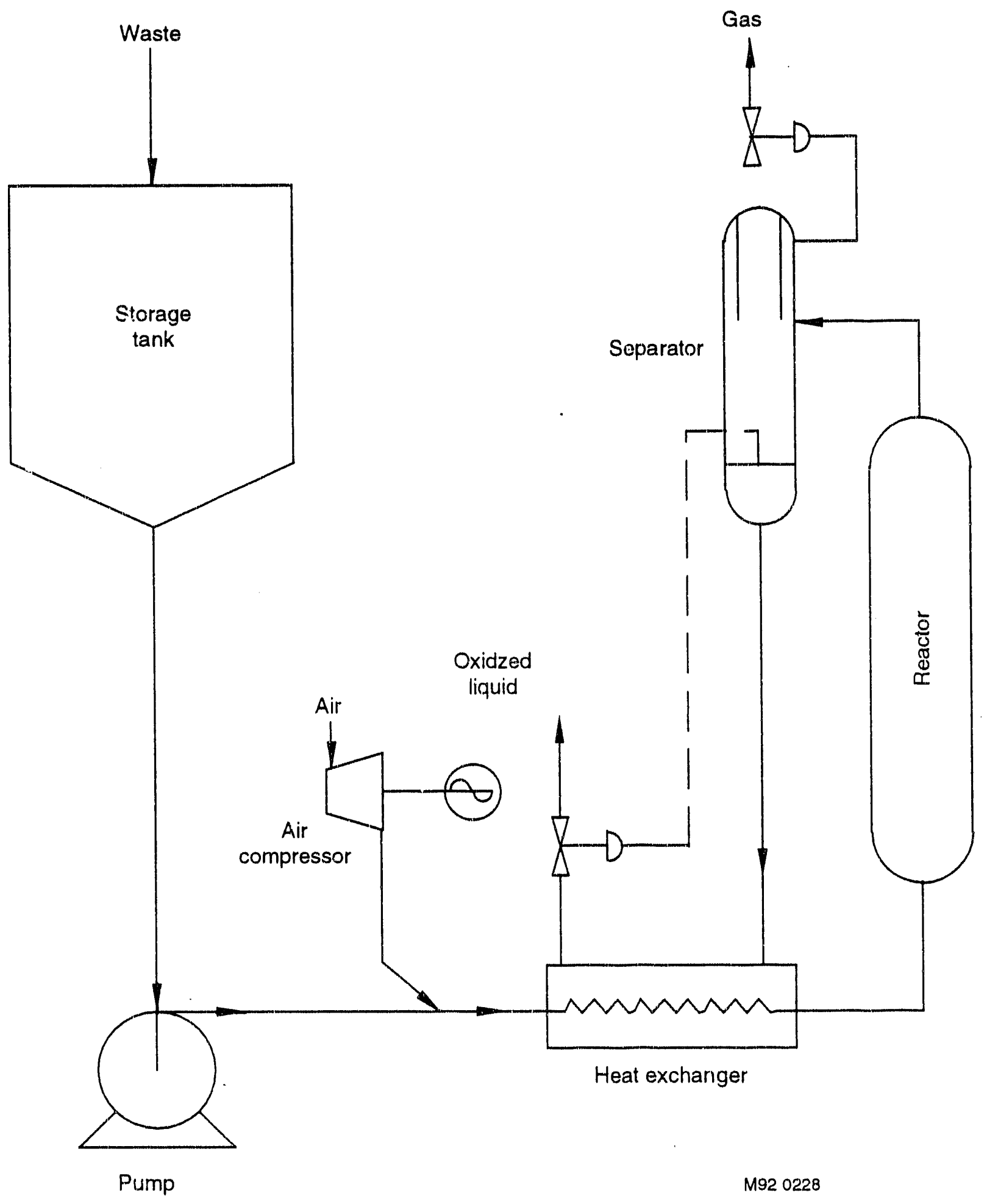

Figure 8-2. Schematic of a wet air oxidation process. 


\section{Technology Status}

Emerging: Wet air oxidation is an operational technology, and it may have uniq 1 e applications to hazardous waste treatment. Applications to radioactive waste may be more limite 1.

\subsection{Supercutical Fluid Oxidation (TT10600) $2,3,6,9,10,11$}

Supercritical fluid oxidation takes advantage of the unique physical properties of water at its supercritical state. At normal temperatures and pressures, water behaves as a dense liquid and is a solvent for polar and ionic compounds. Most organic compounds are not soluble in water. However, above $374^{\circ} \mathrm{C}\left(705^{\circ} \mathrm{F}\right)$ and $218 \mathrm{~atm}$, water is supercritical. The densities of the liquid and vapor phases become identical and the two phases become indistinguishable. In supercritical water, hydrogen bonding is eliminated and the water becomes an excellent solvent for organics. Oxygen and organics are totally miscible, and ionic, inorganic compounds precipitate out of solution. Since oxygen and organics are soluble in supercritical water, it is an excellent medium for fast, homogeneous oxidation reactions.

Aqueous-phase oxidation of dissolved or suspended organic substances occurs spontaneously when oxygen (or air) and a dilute organic/water mixture are introduced into a reactor vessel at supercritical conditions. A process flow diagram of the Modar oxidation system is shown in Figure 8-3. ${ }^{10}$ Inorganic compounds (salts and metals) are nearly insoluble and precipitate out. If the heating value of the waste feed is greater than about $1800 \mathrm{Btu} / \mathrm{lb}$, then the process, once started, is thermally self-sustaining. The process reduces the organics to wate: carbon dioxide, and various acids. Reaction times of less than a minute are typical.

\section{Input Streams}

Feedstreams include aqueous organic wastes. Organic contaminants may include PCBs, dioxins, solvents, pesticides, still bottoms, and tank bottoms. These may be diluted or concentrated to adjust the heat content and contaminant concentrations prior to supercritical oxidation.

\section{Output Streams}

Products of the process include aqueous acidic wastes, carbon dioxide, precipitated inorganic materials, and salts.

\section{Advantages}

Advantages of supercritical tluid oxidation include (1) once initiated, the process is thermally self-sustaining provided waste with sufficiently high heat content of around $1800 \mathrm{Btu} / \mathrm{lb}$ or higher is treated, (2) since reaction times are relatively fast, residence times of around one minute allow small equipment and high throughput rates, (3) little off-gas is generated, and it is free of $\mathrm{NO}_{x}, \mathrm{SO}_{x}$, and particulates, (4) the process is uniquely suited for nonincinerable, dilute waste streams, (5) oxidation of organics can be efficient, and inorganics are precipitated out of solution. (6) some of reactions, specifically the dehydration of alcohols to alkenes, are catalyzed by the presence of trace amounts of acids, (8) for most oxidation reactions, the reaction rate dues not depend on the concentration of oxygen, and (9) the oxidation process occurs at relatively low temperatures of around $374^{\circ} \mathrm{C}\left(705^{\circ} \mathrm{F}\right)$, 


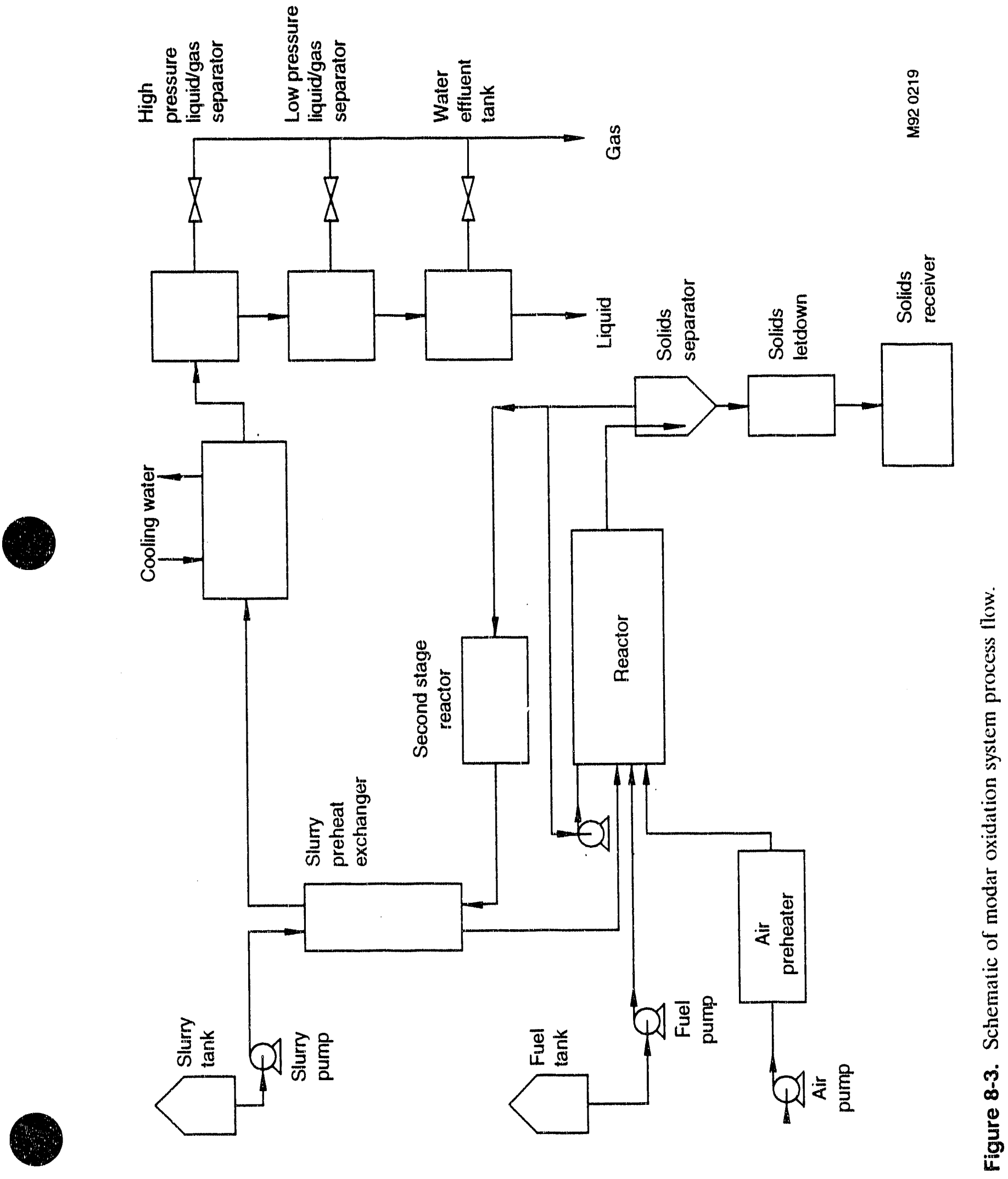


compared to temperatures ranging from 482 to above $1093^{\circ} \mathrm{C}$ (900 to above $2000^{\circ} \mathrm{F}$ ) for most other incineration processes.

\section{Disadvantages}

The greatest disadvantage is corrosiveness of supercritical water at such high pressures and temperatures, especially when treating halogenated compounds. Not only is destruction of the main reactor body, piping, pumps and other equipment a problem, but also corrosion products tend to plug piping and openings even before the equipment becomes unusable. Special alloys, materials and procedures may be required to limit corrosion problems.

Other disadvantages include (1) supercriticat fluid oxidation is limited to weak aqueous organic solutions. (2) the safe containment of high pressures of at ound 218 atmospheres mandates special equipment and procedures, (3) present scientitic knowledge is limited about how reactions take place in supercritical water, nd (4) reactions, products and byproducts for the enormous variety of possible waste contaminants is not known.

\section{Technology Status}

Emerging: Supercritical fluid oxidation has no current applications to radicactive waste. No universal, commercial reactor designs are available yet. Operating experience has been limited to bench-scale and pilot-scale systems. One system by Oxidyne Inc. uses a deep-well oxidation process to provide the necessary high pressure from static water pressure head. A transportable, skidmounted pilot unit has been developed and is available from Modar. 


\subsection{References}

1. DOE National Low-Level Radioactive Waste Management Program Handbook Series, LowLevel Radioactive Waste Treatment Technologies, DOE/LLW-13c, July 1984.

2. EG\&G Idaho, Inc., Environmental Technologies Information System, Computer Database, Developed October 1990 for DOE/ID.

3. Yen-Hsiung Kiang, and A. A. Metry, Hazardous Waste Processing Technology, Boston: Butterworth Publishers, 1982.

4. E. C. Garcia, Mixed Waste Treatment Options for Wastes Generated at the Idaho National Engineering Laboratory, EGG-WM-9451, January 1991.

5. R. E. Berlin and C. C. Stanton, Radioactive Waste Management, New York: John Wiley \& Sons, 1989.

6. Hazardous Waste Remedial Actions Program, An Assessment of Thermal Destruction Technologies for Application to Department of Energy Mixed Wastes, DOE/HWP-106-Vol. 1 and 2, August 1991.

7. William Gilmore, Radioactive Waste Disposal Low and High Level, Noyes Data Corporation, Library of Congress 77-085656, 1977, pp. 114-116.

8. A. A. Moghissi, H. W. Godbee, and S. A. Hobart, Radioactive Waste Technology, New York: American Society of Mechanical Engineers, 1986.

9. H. M. Freeman, Editor, Standard Handbook of Hazardous Waste Treatment and Disposal, New York, McGraw-Hill Book Company, 1989.

10. D. W. Major and J. Fitchko, Emerging On-Site and In-Situ Hazardous Waste Treatment Technologies, Northbrook, Ill: Pudvan Publishing, 1990.

11. R. W. Shaw, R. B. Brill, A. A. Clifford, C. A. Eckert, And E. U. Franck, "Supercritical Water, A Medium For Chemistry," Chemical and Engineering News, December 23, 1991. 


\section{VITRIFICATION (TT11000)}

Vitrification systems are designed primarily to immobilize hazardous or radioactive substances within a nonleachable, long-life solid glassy or rock-like form that can meet acceptance criteria for shipping and/or storage. Some technologies, such as the slagging furnace and the plasma heated melter, can both incinerate organic waste components, and also vitrify or glassify the inert waste components. Such combined functions can make these techrologies attractive for treating certain wastes, but less easy to categorize. These have been grouped according to their perceived primary function, even when they can serve combined functions. Treatment systems whose primary function is to destroy the organic waste components by combustion are generally classified as incinerator processes, and are discussed in Sertion 6. Technologies primary designed for vitrification are discussed in this section. Some other technologies that are sufficiently different from those classified as incinerators or vitrification systems are grouped separately as thermal degradation and or volatilization systems, and are discussed in Section 8.

Vitrification design technologies that are discussed in this section are as follows:

$\begin{array}{ll}\text { Section } & \text { Technology } \\ 9.1 & \text { Glass Furnace (Joule-Heated Melter) } \\ 9.2 & \text { Plasma Arc Heated Melter (transferred Arc) } \\ 9.3 & \text { Plasma Torch Heated Melter (Nontransferred Arc) } \\ 9.4 & \text { Shaft Furnace (Cupola) } \\ 9.5 & \text { Microwave Melter } \\ 9.6 & \text { Flame Reactor }\end{array}$

\subsection{Glass Furnace (Joule Heated Melter) $(T \text { 11100) })^{1,2,3,4,5,6,7,8,9,10,11,12,13,14}$}

A glass furnace is a refractory-lined reactor containing a pool of molten glass. The glass is initially melted by auxiliary heating and then maintained in a molten state 927 to $1538^{\circ} \mathrm{C}(1700$ to $2800^{\circ} \mathrm{F}$ ), depending on the glass chemistry) by joule heating. A simplified schematic of one design is shown in Figure 9-1.' Using joule heating, an electric current is passed through the molten material between submerged electrodes. Energy is imparted to the material according to the current and the resistance of the material. Depending on temperature, the electrodes may be inconel or high-molybdenum steel.

Waste may be introduced into one end of the furnace above the molten glass along with combustion air. Liquid and gaseous wastes may be introduced through injectors. Shredded solids and sludges may be introduced through a screw conveyor system, and containerized waste may be fed by a ram feeder. Radiant and contact heat from the molten glass provicles the necessary heat to devolatilize and combust organic waste materials above and on the glass pool. Air jets located at different heights on opposing sides of the furnace wall create turbulence for mixing above the molten glass and provide oxygen for combustion. 


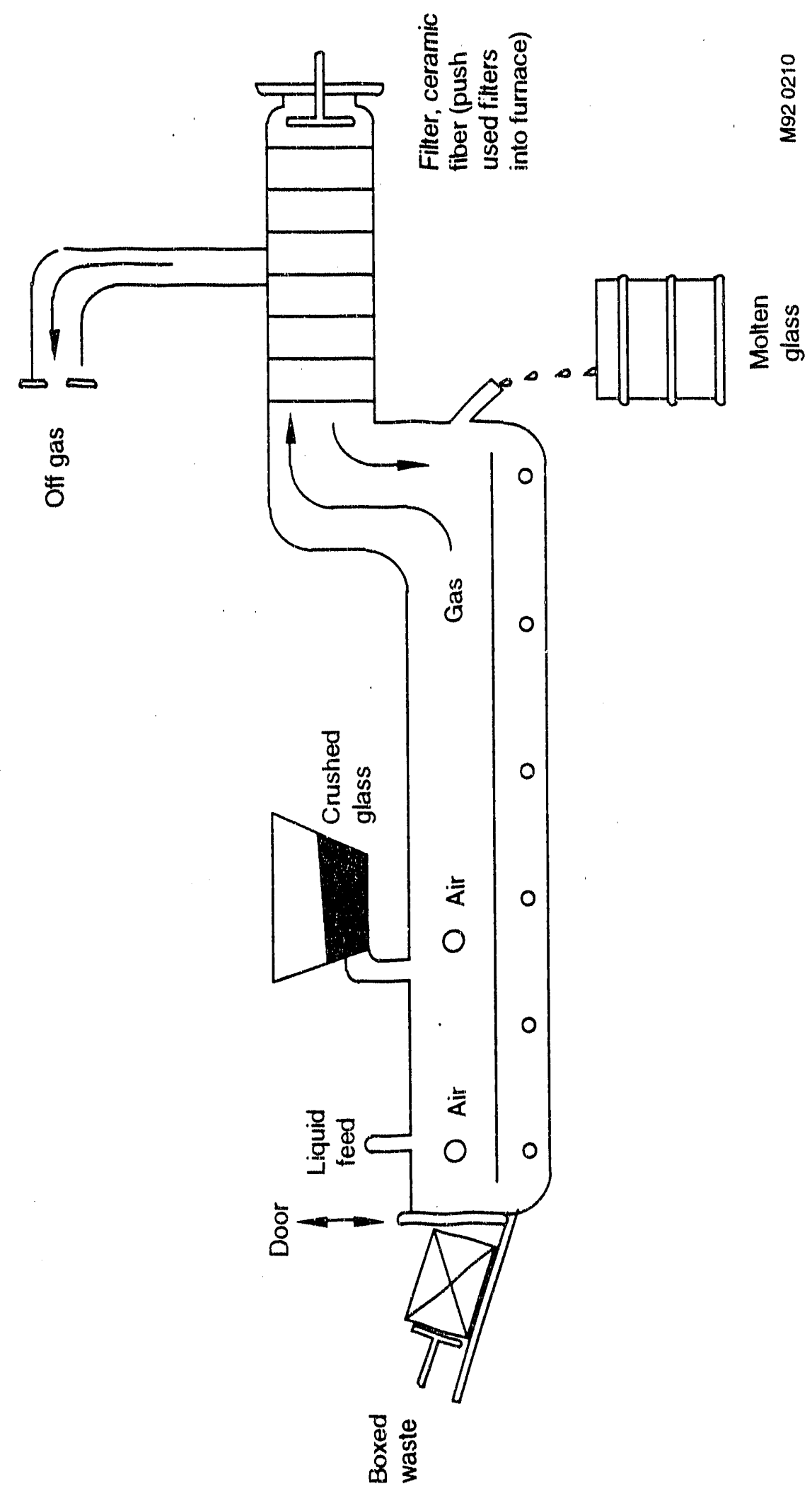

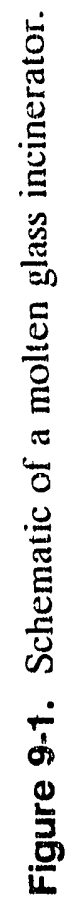


Exhaust gas is vented out the opposite end of the furnace. In one design, the exhaust is passed through disposable filters. As the filters become loaded with particulate, they are pushed forward into the glass melt by new replacement filters. This recycles the entrained particulate captured on the filters back into the melt and eliminates the filter waste stream. The exhaust gas will generally require acid gas scrubbing in addition to the particulate removal.

Depending on the glass chemistry and the waste makeup, some of the solid products of combustion and inert materials are melted and dissolved into the glass inatrix. Materials that are either too refractory to melt or that cannot chemically bond into the glass matrix are physically encapsulated in the glass. The glass-waste mixtu, $\eta$ be continuously removed or batch discharged to solidify into a hard, glassy waste form that can oe nonlcachable.

In one variation, the waste feed and combustion air are introduced into the pool of molten glass via a drop tube. This confines more of the combustion reactions below the surface of the pool, enhances intermixing of the waste and combustion gases with the glass, and promotes higher particulate retention.

\section{Input Streams}

Input strearns consist of combustible solids, inert solids, fow and high heating value organics, aqueous organics, and sludge wastes. Raw materials include those necessary for glass-making, and filters that are disposed of into the glass melt.

\section{Output Streams}

Output streams consist of solidified glass, treated combustion gas, and solid or liquid wastes from the off-gas ccrubbing system. depending on the chemistry and operating temperatures, the solidified glass may be aluminosilicate (low temperature) or borosilicate (medium temperature) glass.

\section{Advantages}

The advantages of glass furnaces include (1) glass furnaces will produce a lairly stable output that may readily meet waste acceptance criteria for shipping and/or storage, (2) the operating temperatures result in high efficiency transformation of organics, while still being lower than the temperatures in other melters (reducing $\mathrm{NO}_{x}$ and volatile metals emissions), (3) off-gas processing residues can be recycled through the furnace, and (4) since the heat is maintained by joule heating, the volumes of off-gas are smaller, resulting in smaller sized air pollution control equipment and lower capital costs.

\section{Disadvantages}

The disadvantages of glass furnaces include (1) high moisture content waste may require pretreated to minimize moisture, (2) waste feed variation is limited, and the waste must be well characterized, to prevent variations (such as in metals content) that may affect the electrode operation, (3) low melt resistivity will cause increased current (shorting), and high resistivity will limit the current, (4) dense solids such as metals may form a separate phase and tend to settle out of the glass, (5) liquid pools of metals on the bottom of the chamber (called salamanders) may also cause 
electrode shorting, (6) glass chemistry is dependent on waste composition, (7) due to the addition of glass raw materials, operating costs are higher, and waste volume reduction is less significant, and (8) depending on operating conditions, the electrodes may be rapidly consumed.

\section{Technology Status}

Emerging: Glass furnaces are an operational but unique technology. The technology as applied to hazardous and mixed waste treatment is emerging. Pacific Northwest Laboratory has used a glass furnace for the treatment of defense waste. Battelle is developing a joule-heated glass melter that would be applicable to contaminated soils.

The Electromelt Pyroconverter developed by Penberthy Electromelt is built upon basic technology that has been in existence for $30 \mathrm{yr}$. The Penberthy system has not been specifically permitted as a hazardous waste incinerator, but the technology is promising. The Electromelt Pyroconverter is commercially available as a chemical processor for a variety of nonhazardous solids (e.g., plastics, resins, trash, filter sludges, and radioactive metal oxides), and liquids (organics, wastewaters). It is being tested for use on hazardous wastes but high ash wastes such as soils may pose treatment problems.

Other promising melter designs include a proposal by Associated Technical Consultants (ATC) to develop mechanically stirred melters analogous to those originally investigated by Owens-Illinois Company. ATC and Glasstech are currently building a refractory lined version of its Stir-Melter ${ }^{\mathrm{TM}}$ with a temperature capability of $1500^{\circ} \mathrm{C}$ for melting scrap tiberglass and vitrification of municipal waste in incinerator ash.

\subsection{Plasma Arc Heated Melter (Transferred Arc) $(\pi 11200)^{7,10,12,15,16,17,18,19,20,21}$}

A plasma arc melter uses the energy from a thermal plasma arc to combust organics and melt inert waste components. The plasma arc is generated within the furnace primary chamber by multiple electrodes above a molten bath of material, which could be inert waste or other material. The arc occurs between the electrodes and the melt (or the chamber, in some cases, during heatup) and is called a transferred arc. The electrodes may be graphite or some other material, and may be cooled or noncooled (consumable). In some variations, the electrodes may be submerged under a cold cap or into slag or metal melt phases.

Temperatures of up to $1648^{\circ} \mathrm{C}\left(3000^{\circ} \mathrm{F}\right)$ in the furnace chamber enable combustion or pyrolysis of organics, and melt inert materials into the bath. Volatile organics are further treated in a secondary combustion chamber. Molten solid material can be removed continuously by overflow or poured by batch and can form a leach-resistant, vitrified waste form.

One process variation of the plasma torch is called the Plasma Centrifugal Reactor (PCR). The reactor is a two-chamber furnace that operates semicontinuously. A schematic is shown in Figure 9-2. ${ }^{12}$ Waste material is fed to a rotating primary chamber (rotating reactor well) where substoichiometric operation results in pyrolysis of the organic waste while rotation at $50 \mathrm{rpm}$ forces the slagged waste liquid toward the outer walls. Gaseous products are lully combusted in a secondary 


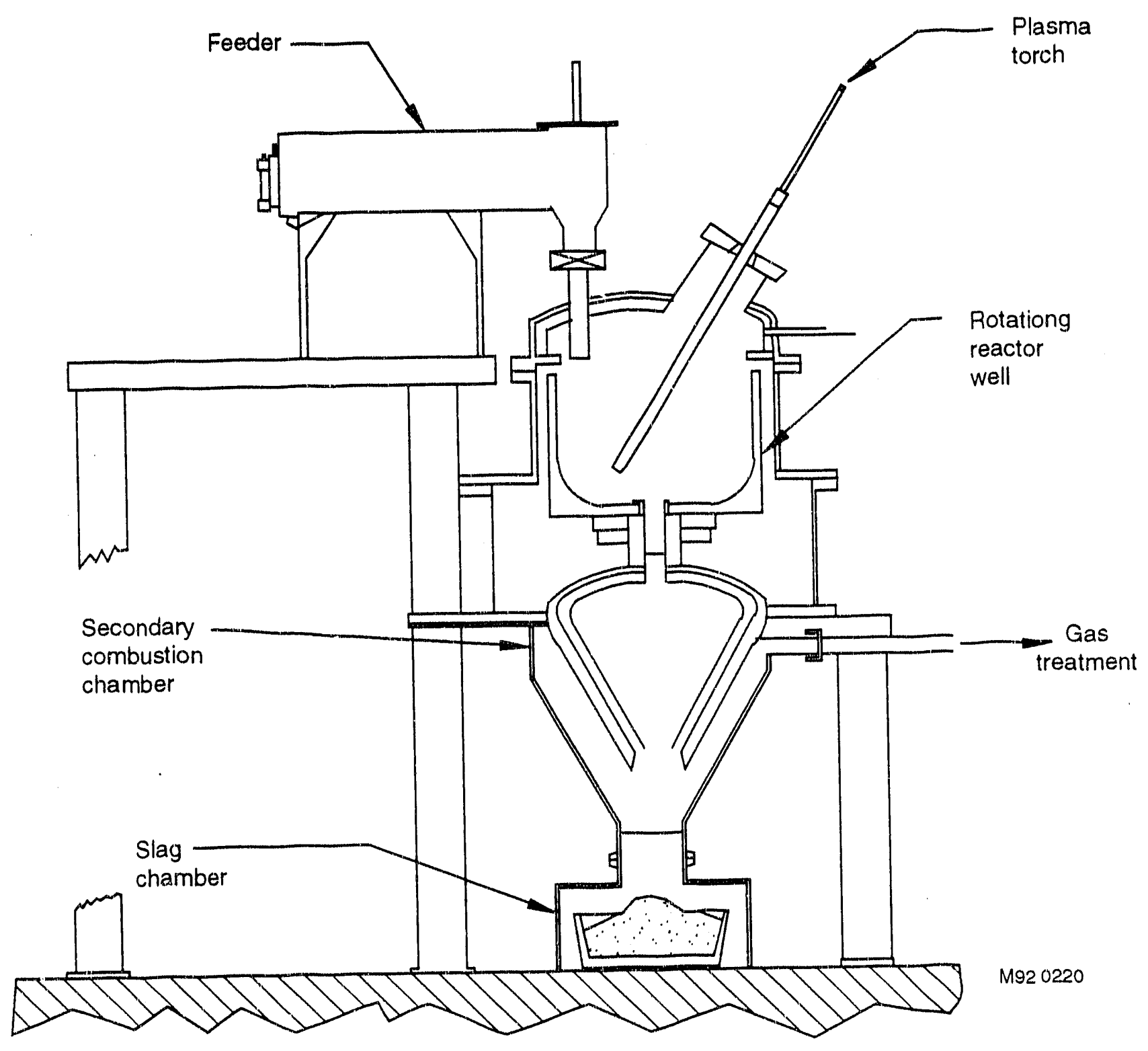

Figure 9-2. Schematic of the plasma centrifugal reactor. 
combustion chamber. The use of an air plasma in the primary chamber, and pure oxygen for combustion in the secondary chamber, results in low off-gas volumes. After treating a batch of waste material, the primary chamber rotational speed is decreased, which allows the molten slag to flow to the center of the chamber. The slag pours through a hole in the center of the primary chamber and falls through the secondary chamber into a mold below the secondary chamber.

\section{Input Streams}

Input streams consist of combustible solids, inert solids, sludges, low and high heating value organic liquids, and aqueous liquid wastes. Raw materials may include those necessary for glass or basalt making.

\section{Output Streams}

Output streams depend on the operating temperatures and the chemistry in the melt. The vitrified waste form can be low-temperature aluminosilicate glass, medium temperature borosilicate glass, or high temperature iron-enriched basalt. Vitrilied glass or iron-enriched basalt, treated combustion gas, and solid or liquid wastes from the ofl-gas scrubbing system. Waste streams from the off-gas system nay be recycled back into the melter.

\section{Advantages}

Advantages of plasma arc heated melters include (1) plasma arc melters can accept a wide variety of inputs and produce a fairly stable output that may readily meet waste acceptance criteria for shipping and/or storage. (2) the high temperatures result in high etticiency transtormation of organics. (3) off-gas processing residues can be recycled through the furnace, (4) since the heat is maintained by plasma arc heating, the volumes of ofl-gis are smaller, resulting in smaller sized air pollution control equipment and lower capital costs. (5) using electrodes that are not gas-cooled, the off-gas volume is even smaller, and (6) the operation is more quiescent than other melter types. resulting in less potential for particulate carryover in the off-gas.

\section{Disadvantag s}

Disadvantages of plasma arc heated melters include (1) in an oxidizing environment. carbon electrodes will be consumed rapidly, and (2) at the typically higher operating temperatures, the more reactive and volatile metals will be devolatilized or react to form more volatile compounds, and will partition significantly to the otl-gas.

\section{Technical Status}

Available: The process has been used in the metals industry for many years, and is emerging for mixed waste treatmen:. The Centrifugal Plasma Furnace has been accepted for treatability studies under Superfund Innovative Technology Evaluation (SITE) at the DOE's Research Facility in Butte, Montana. The research is concentrated on organically contaminated and simulated Radioactive Waste Management Complex (RWMC) soils. The unit uses a transterred-arc torch arc-melter with an enclosed rotating drum. 
Research and development is needed in the areas of (1) plasma science in regards to electrical, thermodynamic, transport, chemical reactivity, and physical properties, (2) energy transfer to improve energy efficiency, (3) plasma process chemical reactions to enhance destruction efficiencies, (4) electromagnetic effects to reduce energy losses, enhance mixing, and promote selective chemical reactions, and (5) development of auxiliary equipment specifically tailored for plasma processing applications.

\subsection{Plasma Torch Heated Melter (Nontransferred Arc) $(\mathrm{TT} 11300)^{7,10,12,14,22}$}

This process uses a cooled torch that includes both positive and negative electrodes. The arc is formed within the torch, and is used to ionize a gas stream that becomes a high temperature plasma. A simplified schematic is shown in Figure 9.3. ${ }^{12}$ The plasma torch is installed into a primary process chamber where waste materials are fed. The high temperature plasma stream provides the heat to combust or pyrolize organic waste materials (depending on the oxygen stoichiometry) and melt inert materials into a bath. The molten material is discharged from the chamber and lorms a leach-resistant vitrified waste form when cooled. Typically, an afterburner section would be inciuded to ensure complete burnout and destruction of organic materials.

One variation of this technology is called a plasma pyrolysis reactor. The plasma pyrolysis reactor is a horizontal chamber in that liquid waste is pyrolyzed by injection through a thermal plasma plume. The plume is generated by passing an electric charge through an air stream. which ionizes the gas molecules and generates temperatures up to $9982^{\circ} \mathrm{C}\left(18,000^{\circ} \mathrm{F}\right)$. The collinear electrodes of the plasma device act as a plug-tlow atomization zone for the liquid waste leed, and the pyrolysis chamber serves as a mixing zone where the atoms recombine to form hydrogen, carbon monoxide. hydrochloric acid and particulate carbon. Temperature in the recombination zone is maintained at 1200 to $2400^{\circ} \mathrm{C}$. An off-gas scrubbing system is required.

\section{Input Streams}

Input streams consist of liquids, inert solids, sludges, and combustible solid wastes.

\section{Output Streams}

Output streams consist of vitrified slag, combustion product gases, and solid/liquid materials from the off-gas system. Waste materials from the off-gas systern may be recycled into the main chamber.

\section{Advantages}

The advantages of plasma torch heated melters include (1) the vitrified slag is expected to be highly leach-resistant and excellent for stabilization of toxic metals and radionuclides, and (2) use of pure oxygen for combustion results in lower off-gas loads. 


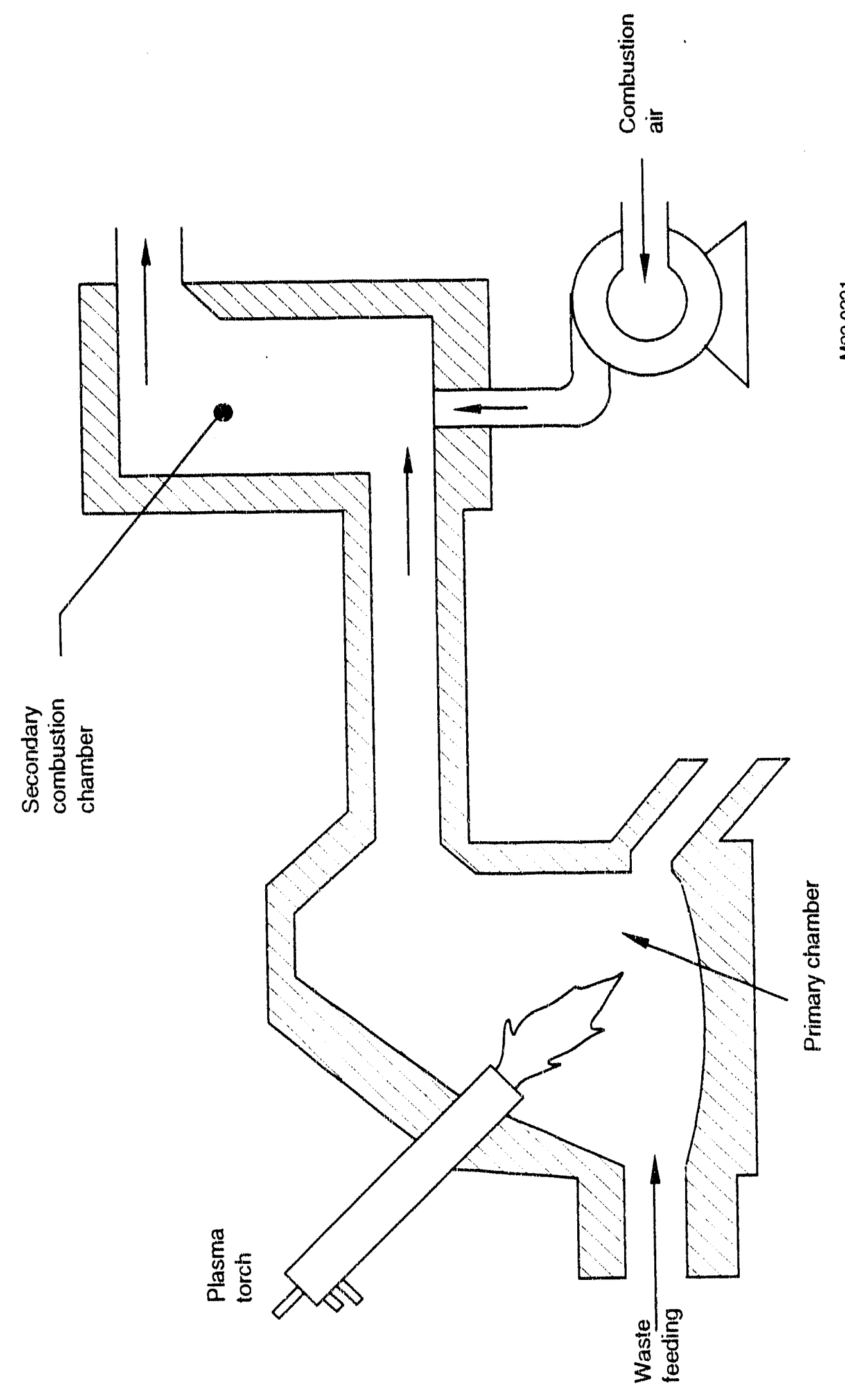

$\bar{N}$
N
N
之̇

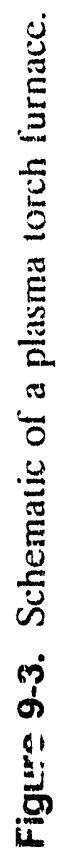




\section{Disadvantages}

The disadvantages of plasma torch heated melters include (1) complex equipment may require significant and difficult to perform maintenance, (2) consumable torches require frequent replacement, (3) volatile metals will partition with the gas stream under the typically high operating temperatures, and (4) the high temperatures are also conducive to significant $\mathrm{NO}_{\mathrm{x}}$ formation.

\section{Technology Status}

Available: The plasma torch furnace is an emerging technology with no current applications to radioactive wastes. This process is well developed for the metals industry, but is emerging and unproven for hazardous waste or mixed waste processing.

\subsection{Shaft Furnace (Cupola) $(\pi 11400)^{14}$}

Cupolas are vertical, cylindrical shatt furnaces used in the metals foundry industry to process scrap iron and steel. Figure $9-4^{23}$ shows two designs of shaft furnaces. The cupola is operated in a reducing atmosphere to reduce metal oxides back to the elemental lorm. Heat is conventionally provided in the process through combustion of coke, which is added to the batch charge with limestone, and scrap iron/steel. The coke provides not only heat (from combustion) but also is a source of carbon for the addition to the steel. The limestone is used as a flux for the inert coke ash and metal slag. Combustion "blast" air is provided either preheated or as unheated "cold-blast" air through tuyeres at the base of the cupola. Off-gas particulate and acid gas control are required.

Alternative heat sources include using other fossil fuels such as natural gas, oil, and anthracite coal. Electrical heat sources include plasma torches located symmetrically around the base of the cupola, or graphite electrodes to generate a plasma arc. One variation is called the Skygas process. An electric arc ionizes water in the feedstream to create high temperature, gaseous $\mathrm{H}_{2}$ and $\mathrm{OH}$ radicals. These radicals heat the waste and initiate chain reactions and propagation of other free radicals. Organic compounds are pyrolized to form $\mathrm{CO}$ and $\mathrm{H}_{2}$.

\section{Input Streams}

Input streams consist of process scrap iron, steel, hazardous wastes.

\section{Output Streams}

Output streams consist of iron and steel products, slag, combustion product gases, and solid/liquid materials from the off-gas system. Waste materials from the off-gas system may be recycled into the main chamber.

\section{Advantages}

Advantages of shaft furnace include (1) the vitrified slag is expected to be highly leach-resistant and excellent for stabilization of toxic metals and radionuclides, and (2) use of pure oxygen for combustion results in lower off-gas loads. 

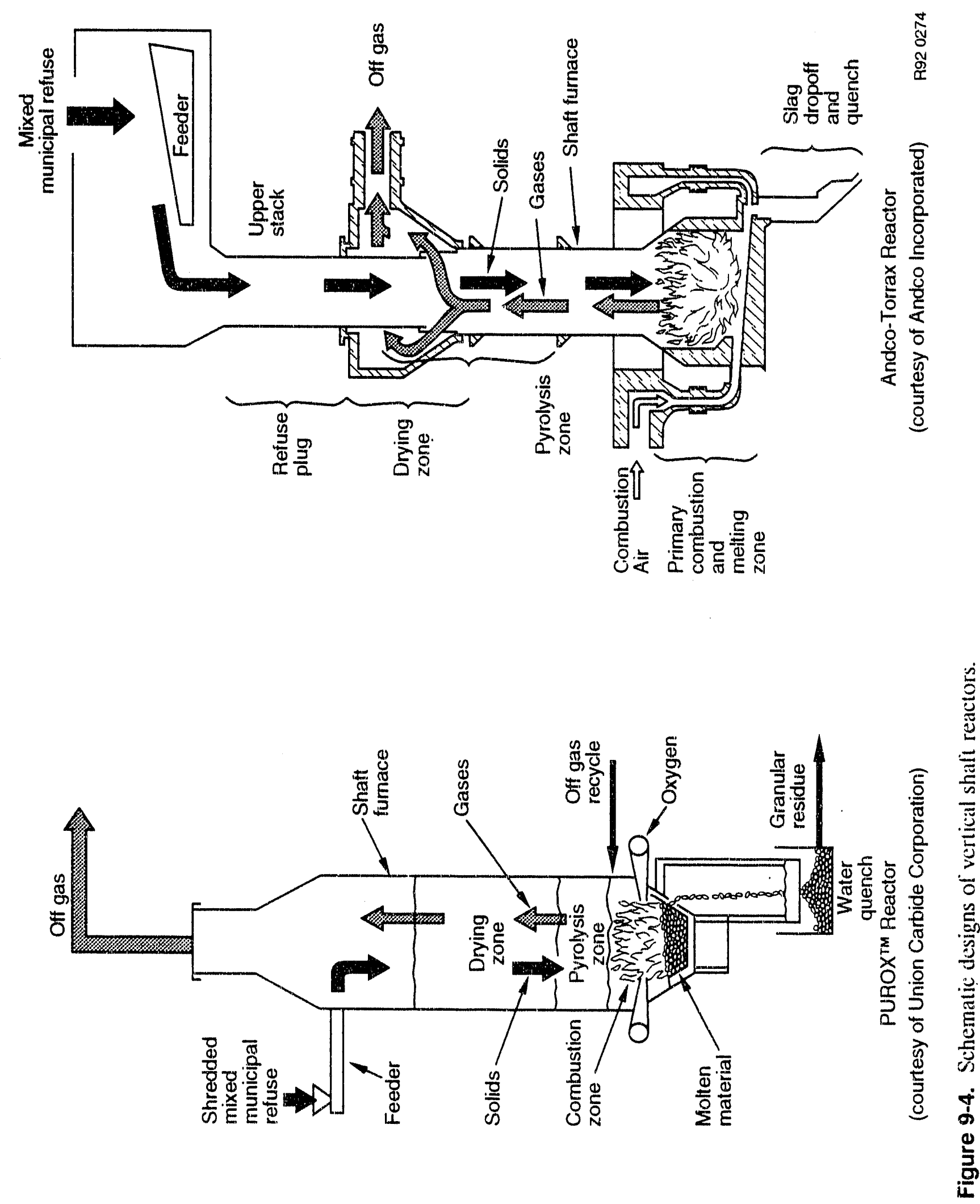


\section{Disadvantages}

Disadvantages of shaft furnace include (1) complex equipment may require significant and difficult to perform maintenance, (2) torch requires frequent replacement, (3) volatile metals will partition with the gas stream under the typically high operating temperatures, and (4) the high temperatures are also conducive to significant $\mathrm{NO}_{\mathrm{x}}$ formation.

\section{Technology Status}

Available: The coke-tired and plasma-tired cupolas have been used in the foundry industry. Companies that use plasma-fired cupolas include General Motors and Pcugot. Westinghouse Electric is researching the use of this technology for hazardous waste treatment. This process is still emerging as a technology for treatment of mixed wastes. A Karlsruhe type shaft furnace was constructed in 1976 at the Seibersdorf Research Center, which is part of the Austrian National Radwaste Management System. This unit fired solids that contained PVC.

\subsection{Microwave Heating (T10500) ${ }^{7,12,22,24,25,26,27,28}$}

Microwave heating can be used for two purposes: destruction of organics or melting of inorganics. A schematic of the Tokai microwave melter is shown in Figure 9-5. ${ }^{12}$ Microwave heating occurs through the internal friction produced inside a dielectric material when its molecules vibrate in response to an oscillating microwave field. Microwave penetration depth is a lunction of material composition, temperature, and frequency of the microwave energy. Tests were conducted using FCCapproved microwave frequencies for industrial, scientilic, and medical use, 915 and $2450 \mathrm{MHz}$. Several microwave penetration depth experiments were conducted with wet and dry sludges to understand where the microwave heat is deposited. The economic application in hazardous waste reduction, detoxification, and reccvery for microwave heating is still being investigated.

Microwave technology can also treat soil in situ. This process is known as in situ radio frequency (IRF) heating. IRF consists of a microwave oven built around a block of contaminated soil.

\section{Input Streams}

Input streams are organics, inorganics, radionuclides, and TRU waste. Media state include sediment, refuse, sludge/slurry, soil.

\section{Output Streams}

Output streams are inorganics, ceramic-like blocks, sludge/slurry, and soil.

\section{Advantages}

Advantages of microwave heating include (1) toxic organics are decomposed in much the same way as in incineration but at lower temperatures, (2) microwave technology may be able to more easily treat small quantities of highly toxic materials that cannot be handled by other means, (3) moving parts are limited, (4) the waste may be processed in the final storage container, thus 


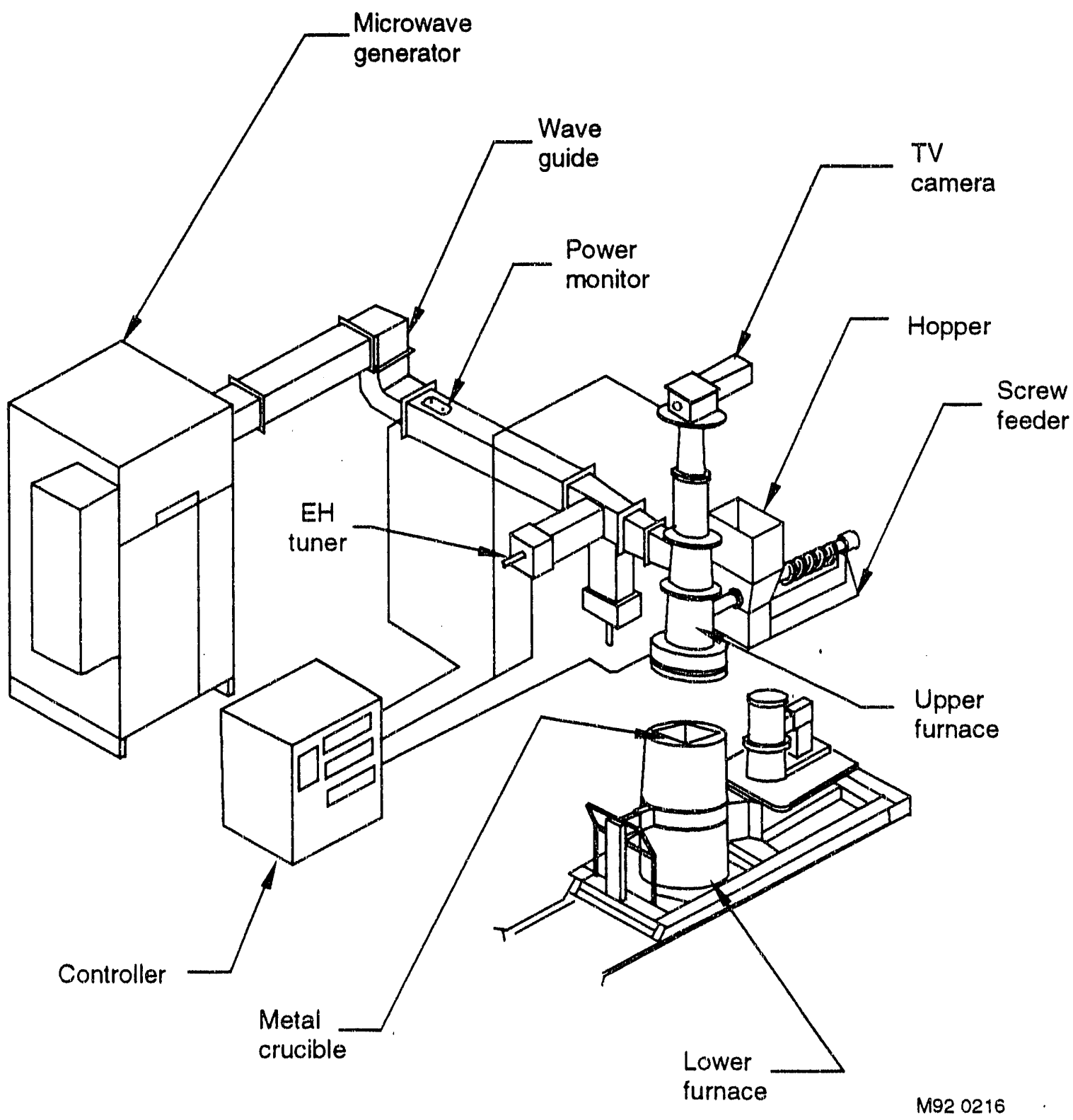

Figure 9-5. Schematic of the Tokai microwave melter. 
eliminating the need to handle and transport hot chemicals from heated casings of the wiped-film evaporator or extruder into the storage container, (5) microwave heating of radioactive dielectric materials requires no local heating elements because the microwave heat is absorbed directly, (6) less waste is usually generated than from other incineration processes, thus minimizing storage and transportation costs, (7) this technology is effective for both wet and dry materials and has the potential to replace evaporation steps for slurries, and (8) microwave energy can be transmitted through waveguides from generators that can be safely located outside a radioactive hot cell where routine maintenance can be performed.

\section{Disadvantages}

The disadvantage of microwave heating include (1) the possibility for thermal runaway exists if the local heating rate of the material exceeds the rate of heat diffusion through the material, (2) when equipment is operating at the highest powers, microwave arcing must be prevented by minimizing sharp metallic edges and points in the microwave cavity that attract arcs, (3) uneven melting has not been resolved, (4) melting of the containers is also a problem. (5) the tinal waste form is not as robust as from other incineration and vitrification technologies, and (6) the ability of the final waste form to meet waste acceptance criteria is not known.

\section{Technology Status}

Available: This technology is still being tested and is under development for application to mixed wastes. Argonne National Laboratory (ANL) has reported $80 \%$ destruction of trichloroethene (TCE) in a commercial oven with an activated charcoal lilter. The Tokai works (Japan) has used a microwave melter to transform incinerator ash and acid residues into ceramic-like blocks. This melter was used to treat surrogate material at a rate of $5 \mathrm{~kg} / \mathrm{h}$. Bench-scale tests of in-drum vitrification of TRU-contaminated wastes have been performed at DOE's Rocky Flats Plant.

The Oak Ridge National Laboratory (ORNL) Waste Handling and Packaging Plant (WHPP) is proceeding with the development of a microwave process to the pilot-scale level so that fair comparisons can be made vs. other processes such as the wiped-film evaporator and the extruder. The ORNL is also developing a process that uses microwaves to solidify liquid radioactive wastes in the 55-gal metal drums in which they are stored. The process boils the waste dry and melts the salt residue. The waste contains elements with atomic numbers heavier than that of uranium (e.g., TRU waste). They have also developed a method to eliminate microwave arcing. This process can solidify the waste into salt cakes; The salt cakes meet the available or expected criteria for ultimate disposal of TRU waste at the Department of Energy's (DOE's) planned Waste Isolation Pilot Plant (WIPP) in New Mexico. ORNL researchers are currently operating a one-third scale microwave applicator. They plan to build a $60 \mathrm{~mW}$ pilot scale system to demonstrate processing in a 55-gal drum.

\subsection{Flame Reactor $(\pi T 10600)^{29}$}

The flame reactor process is a hydrocarbon lueled, Mash smelting system that treats wastes containing metals at temperatures exceeding $\left.1982^{\circ} \mathrm{C}(360) 0^{\circ} \mathrm{F}\right)$ in oxygen enriched air. Organic waste components are combusted, while inert waste components are vitrified. Metals are oxidized. This process was designed for granular solids, soils, slags, and sludges. The process is patented by Horsehead Resource Development (HRD) Company. 
The flame reactor was designed for treating heavy metal contaminated soils and sludges. To date, wastes containing up to $40 \%$ zinc, $10 \%$ lead, $3 \%$ cadmium, $3 \%$ chromium, and small amounts of nickel, copper, cobalt, and arsenic have been treated. The process reduces the volume and mobility of heavy metals. After treatment, metals are primarily in a recyclable metal oxide layer. Offgas particulate cleaning and acid gas scrubbing may be necessary.

\section{Input Streams}

Input streams consist of sediment, sludge/slurry, soil, refuse, biota. Contaminants include organics and heavy metals.

\section{Output Streams}

Output streams consist of (1) glass-like vitrified solid, (2) heavy metal enriched slag, and (3) off-gas requiring treatment.

\section{Advantages}

Advantages of a flame reactor include (1) the reactor can be compact and low capital cost, (2) the residence time is rapid, and (3) at such high temperatures, destruction of organic compounds is expected.

\section{Disadvantages}

The disadvantages of a flame reactor include (1) large wet agglomerated waste particles (up to 20 mesh) can be processed, yet a decrease in the efliciency of metals recovery usually results, and (2) pretreatment may be required to produce a dryer leed and to reduce the particle size.

\section{Technology Status}

Emerging: The demonstration plant is being readied for a Superfund Innovative Technology Evaluation (SITE) demonstration at HRD's facility at Monaco, Pennsylvania. 


\subsection{References}

1. International Atomic Energy Agency, Treatment of Off-Gas from Radioactive Waste Incinerators, Technical Report Series No. 302, Austria: IAEA, 1989, p. 23.

2. Harry Freeman, Innovative Thermal Hazardous Organic Waste Treatment Processes, Park Ridge NJ: Noyes Publication, 1985.

3. Dennis F. Bickford, "Advanced Radioactive Waste-Glass Melter (U)," Westinghouse Savannah River Company, April 22, 1990.

4. Ray S. Richards, Dennis F. Bicktord, "Small High-Speed Glass Melter for Waste Vitrification," Associated Technical Consultants Inc., Toledo, OH, Westinghouse Savannah River Co., Savannah River Laboratory, Aiken, SC, April 23, 1990.

5. Hazmat World, Volume 4, No. 2, February 1991, p. 29.

6. J. A. Batdorf, "Research and Development Support for Plasma Destruction of Solid Hazardous Waste," EG\&G Idaho, Inc., June 1989.

7. EG\&G Idaho, Inc., Environmental Technologies Information System, Computer Database, Developed October 1990 for DOE/ID.

8. DOE National Low-Level Radioactive Waste Management Program Handbook Series, LowLevel Radioactive Waste Treatment Technologies, DOE/LLW-13c, July 1984.

9. A. A. Moghissi, H. W. Godbee, and S. A. Hobart, Radioactive Waste Technology, New York: American Society of Mechanical Engineers, 1986.

10. H. M. Freeman, Editor, Standard Handbook of Hazardous Waste Treatment and Disposal, New York: McGraw-Hill Book Company, 1989.

11. R. E. Berlin and C. C. Stanton, Radioactive Waste Management, New York: John Wiley \& Sons, 1989.

12. Hazardous Waste Remedial Actions Program, An Assessment of Thermal Destruction Technologies for Application to Department of Energy Mixed Wastes, DOE/HWP-106-Volumes 1 and 2, DE91 018445, August 1991.

13. T. G. Hedahi, R. L. Benedetti, C. H. Cargo, R. J. Carpenedo, W. H. Landman, and J. E. Langford, Incinerator Unit Process Evaluation, WM-F2-81-002, May 1981.

14. R. Geimer, T. Hertzler, R. Gillins, and G. L. Anderson, "Assessment of Incineration and Meiting Treatment Technologies for RWMC Buried Waste," EGG-WTD-100035, February 1992.

15. "Incineration and Treatment of Hazardous Waste," Proceedings of the 10th Annual Research Symposium, JACA Corp., Ft. Washington, PA, September 1984, pp. 124-128. 
16. J. A. Batdorf, "Research and Development Support for Plasma Destruction of Solid Hazardous Wastes," EG\&G Idaho, Inc., June 1989.

17. M. Breton et al., "Technical Resource Document Treatment Technologies for Solvent Containing Wastes," GCA Corp., Bedford, MA, EPA/600/2-86/095, October 1986.

18. L. J. Staley, "Hazardous Waste Decontamination With Plasma Reactors," Hazardous Materials Control, March/April 1990, pp. 67-71.

19. T. L. Eddy, D. Parker, A. D. Donaldson, G. A. Reimann, "Plasma Destruction of Hazardous Mixed Waste," EG\&G Idaho Inc., January 1990.

20. Remedial Technology Information Management System (RTIMS I) Database, Ebasco Services, Inc., Rocky Flats, Colorado, 1990.

21. Yen-Hsiung Kiang, and A. A. Metry, Hazardous Waste Processing Technology, Boston: Butterworth Publishers, 1982.

22. W. S. Roesener, Unit Systems for the Treatment of TRU Contaminated Waste, WM-PD-92-002, December 1991.

23. P. N. Cheremisinoff, Pollution Engineering Flow Sheets, Hazardous Material, United States: Cahners Publishing Co., 1988.

24. E. C. Garcia, Mixed Waste Treatment Options for Wastes Generated at the Idaho National Engineering Laboratory, EGG-WM-9451, January 1991.

25. T. L. White, E. L. Youngblood, J. B. Berry, A. J. Mattus, "Status ol Microwave Process Development for RH-TRU Wastes at Oak Ridge National Laboratory," Proceedings of the Waste Management '90 Conference, February 25-March 1, 1990.

26. T. L. White, "Microwave Processing of Remote-Handled Transuranic Wastes at Oak Ridge National Laboratory," Proceedings of the Waste Management 89 Conference, February 26-March 2, 1989, pp. 263-267.

27. R. D. Petersen, A. J. Johnson, S. D. Swanson, "Application of Microwave Energy for Solidification of T'RU Waste." Proceedings of the Waste Management '85 Conference, pp. 325-330, 1985.

28. Y. Ogata, J. Ohuchi, E. Inada, N. Tsunoda, "Processing at the Plutonium-Contaminated Waste Treatment Facility," proceedings of the Management of Low and Intermediate Level Radioactive Wastes Symposium, 1988, pp. 325-339.

29. Superfund Innovative Technologies Program: Technology Profiles, EPA/540/5-89/013, November 1989. 


\section{IMMOBILIZATION/STABILIZATION (TT12000)}

The technologies presented in this section are designed to immobilize chemical or radioactive hazards by providing a solid waste form, limiting surface area available for leaching, and limiting the solubility or detoxifying the constituents of the waste. All of these processes use either inorganic or organic additives, which serve as chemical bonding agents, waste form or process performance enhancers, and/or containment. The application and selection of an immobilization technology is often driven by EPA's hazardous waste treatment standards, waste handling concerns, or the waste acceptance criteria of a disposal facility.

Specific types of immobilization/stabilization processes and their applicability to particular waste types are discussed as follows:

$\begin{array}{ll}\text { Section } & \text { Technology } \\ 10.1 & \text { Portland Cement Systems } \\ 10.2 & \text { Bitumen } \\ 10.3 & \text { Vinyl Ester, Organic Polymers } \\ 10.4 & \text { Lime Fly Ash Pozzolan Process } \\ 10.5 & \text { Sulfur Polymer Cement } \\ 10.6 & \text { Encapsulation } \\ 10.7 & \text { Amalgamation }\end{array}$

\subsection{Portland Cement Systems (TT12100) $)^{1,2,3,4,5,6}$}

These systems use Portland Cement as a solidification/stabilization agent for immobilization of wastes. In this type of system, cement and an aqueous waste, or cement, water, and a waste are mixed to form a solid waste form. Other solid materials such as ion-exchange resin, filter sludges or mechanical assemblies are either added to the mixture or are encapsulated in the cement.

Portland cement is a mixture of powdered oxides of calcium, silica, aluminum, and iron, produced by kiln burning of materials rich in calcium and sili a at high temperatures 1400 to $1500^{\circ} \mathrm{C}$. When the anhydrous cement powder is mixed with water, hydration occurs and the cement begins to set. Additives, such as lime $(\mathrm{CaO})$, soluble silicates, clays, emulsifiers, etc., are often used to improve process or waste form performance. The chemistry involved is complex because many different reactions occur depending on the composition of the cement mixture.

As the cement begins to set, a colloidal gel of indefinite composition and structure is formed. Over time, the gel swells and forms a matrix composed of interlacing, thin densely packed silicate fibrils. Constituents present in the waste slurry (e.g., hydroxides and carbonates of various metals) are incorporated into the interstices of the cement matrix. The high $\mathrm{pH}$ of the cement mixture tends to keep metals in the form of insoluble hydroxide and carbonate salts.

Two types of systems have been used in the past for solidification of wastes. The first type uses "in-drum" mixing. The solidification agent and solid wastes are mixed and placed into a disposal container. Liquids are then added and either the container is rotated or a mixer placed into the 
container to mix the wastes. The second type mixes wastes, cement and linely sized solids in an external mixer. The wastes are then placed into containers through hoses or chutes. Mechanical assemblies can be placed into a container prior to adding the waste.

\section{Input Streams}

Cement systems have been used to solidify a wide variety of wastes such as dilute aqueous liquids, evaporator concentrates, filter sludges, soils, and ion-exchange resins. The wastes typically have a large fraction of water to add to the cement. Cement systems can also be used to encapsulate larger wastes.

\section{Output Steams}

The output from this type of system is a solidified waste form, usually contained in 55-gal drums.

\section{Advantages}

Advantages of Portland Cement Systems include (1) this type of solidification has been used extensively for treatment of LLW in the nuclear power industry, (2) the material and technology are well known and available, (3) most aqueous wastes chemically bond to matrix, (4) compared to other solidification and stabilizaiion technologies, the cost is relatively low, (5) the waste form provides good self shielding, (6) the process does not cause vapor problems, (7) the cement powder has a long shelf life, (8) the waste form has good impact and compressive strength, low leachability for some radionuclides, and does not leave free water if properly formulated. (9) the process can provide rapid controllable setting, without differential setting, and (10) in-container and in-line mixing processes are available.

\section{Disadvantages}

Oil and grease in both cement-based and lime/pozzolan-based systems result in the coating of waste particles and the weakening of the bond between the particle and stabilizing agent, thereby decreasing the resistance of the naterial to leaching. Organic compounds in the waste interfere with the stabilization chemical reactions and bond formation, thus inhibiting the curing of the stabilized material. Sulfate and chloride compounds intertere with the stabilization chemical reactions, weakening bond strength and prolonging setting and curing times. Sulfate and chloride compounds may reduce the dimensional stability of the cured matrix, thereby increasing leachability potential.

Systems with external mixers require cleanup immediately after completion of solidification. Failure to clean can result in solidification of the solidification system. Systems with mixing inside the disposal container can have regions of undetected nonsolidification of the waste. In some cases, solids can be produced that do not meet the leachability (i.e., EPA's Toxicity Characteristic Leaching Procedure) or strength requirements for disposal. Recovery from these types of upsets is difficult.

Often, cement based systems significantly add to total waste volume. Solidified waste forms have high densities that can complicate handling and transportation of the waste. 


\section{Technology Status}

Proven: Portland cement has been used extensively for treatment of LLW in the nuclear power industry. Portland cement based systems are frequently used to satisfy RCRA hazardous waste treatment standards, where stabilization has been determined to be the Best Demonstrated Available Technology (BDAT).

\subsection{Bitumen $(T 12400)^{1,2,7}$}

Bitumen (or asphalt) processes solidify the waste by bringing hot asphalt into direct contact with the waste, which evaporates any moisture present. Then the asphalt is blended to coat the waste particles, and allowed to cool, trapping the waste in the asphalt matrix. Unlike portland cement systems, where some chemical bonding may take place between the waste and solidification matrix, the stabilization mechanism for bitumen is physical entrapment. Bitumen (or asphalt) is a mixture of asphaltene and malthene hydrocarbons obtained generally from the "bottoms" of the crude oil distillation process used by petroleum refineries. The use of asphalt requires that the asphalt be heated to over $150^{\circ} \mathrm{C}$ to soften the materiai and drive off any water in wet wastes.

\section{Input Streams}

Bitumen processes can accept both organic and inorganic solids. Since contact with the hot asphalt will cause moisture to evaporate, solids and sludges with water content can also be tolerated.

\section{Output Streams}

The output stream is a solidified waste form.

\section{Advantages}

Advantages of bitumen processes include (1) technology and material are well known and available, (2) the process is compatible with a wide range of wastes, and results in a concurrent volume reduction of aqueous wastes, (3) the process does not leave free standing water, (4) individual waste particles are coated, (5) bitumen is a low cost material, (6) unlike cement-based and lime/pozzolan-based systems, the setting process is not as sensitive to the waste media or contaminants present, since the setting process is not based on a chemical reaction, and (7) typically, the final waste form has a low leachability.

\section{Disadvantages}

Disadvantages of bitumen process include (1) bitumen is tlammable and burns spontaneously at temperatures as low as $390^{\circ} \mathrm{C}$, (2) the process can not tolerate a significant loading of salts because of hardening effects, (3) the waste may swell in water, leading to increased leachability and product degradation, (4) potential for radiolytic gas generation exists, (5) exposure to heat may cause melting or phase separation of waste form, (6) the process requires the use of elevated temperatures, (7) heating must be well controlled and spread evenly, (8) storage of asphalt before use requires 
elevated temperatures to maintain fluidity of material, (9) capital equipment costs are relatively high, and (10) emissions during processing of hot bitumen may clog off-gas system filters.

\section{Technology Status}

Proven: Bitumen solidification has been used principally in the European countries, where it has been popular for several decades. The fire hazard associated with bitumen processing has primarily prevented its widespread use in the United States.

\subsection{Vinyl Ester, Organic Polymers (T12500) $)^{1,2,6,7}$}

Several types of organic polymer solidification systems have been used or proposed in the past. These systems include Urea-formaldehyde (UF), Vinyl ester styrene (VES), polycster, polyethylene, and other similarly based sustems. Only the UF and VES based systems have been used routinely for treatment of LLW. The UF based systems had significant amounts of liquid remaining after treatment and are no longer used. Therefore, the only polymer system in current use is the VES based system. VES immobilizes the waste by encapsulating it in a plastic matrix. When liquid waste is processed. it is dispersed in the binder and, when the binder hardens, the waste becomes trapped in the small cells that are formed. These polyester-type resin based polymers are particularly attractive because of their ability to immobilize free water in the cell structure of the matrix.

In the VES sysiem, a waste container is partially lilled with vinyl ester resin binder. Liquid waste is mixed with styrene catalyst and a promoter. The mixture is added to the container and mixed. The mixture solidities in about one hour.

\section{Input Streams}

VES systems can be used to solidity a wide variety of wastes such as dilute liquids, evaporator concentrates, filter sludges, and ion-exchange resins.

\section{Output Streams}

The output from this type of system is a soliditied waste form. usually contained in 55-gal drums.

\section{Advantages}

Advantages ol VES include (1) the process is adaptable to many liquid and solid wastes, (2) the process does not leave free standing water, (3) the linal waste form has a relatively low leachability, high compressive and impact strength, and good radiation stability. (4) the process is appealing due to the ease of working with liquid components, and (5) in-container mixing is available.

\section{Disadvantages}

Disadvantages of VES include (1) binder shelf life is limited, (2) hazards are associated with monomer, catalyst, and promoter handling. (3) some wastes may interact chemically and prevent or affect polymerization. (4) the materials are relatively expensive, and (6) the mixing method is critical for success. 


\section{Technology Status}

Proven: VES systems have been used in commercial LLW systems for several years.

\subsection{Lime Fly Ash Pozzolan Process (TT12700)}

This process is referred to not only as the pozzolanic process but also as either a silicate-based or lime-based process. Pozzolanic materials (siliceous materials such as sodium silicate, potassium silicate, fly ash, ground blast furnace slag, cement kiln dust, volcanic ash, etc.) are those that set to a solid mass when mixed with hydrated lime (calcium hydroxide). An aqueous reaction occurs between the fine-grained siliceous material and the lime to produce a hardened product that physically traps the contaminants in the cured pozzolan matrix. In general, lime stabilization is similar to cement-based techniques. However, the waste form will have a slower setting time.

In practice, the pozzolanic material is blended with the waste to form a sludge. A metered amount of lime is added to the mixture, which is then routed through a blender then to casting/curing equipment. The most commonly available pozzolan in the United States is fly ash from pulverized coal-fired electrical generating stations. Volcanic ash is also used, where available. The silica and alumina in the fly ash chemically react with the calcium hydroxide and other calcium compounds in the lime-based reagent to form strength-gaining compounds, such as ettringite and tobermorite.

The pozzolanic reaction is time and temperature dependent, requiring curing temperatures in excess of $4^{\circ} \mathrm{C}\left(40^{\circ} \mathrm{F}\right)$. The higher the temperatures, the more quickly the reaction occurs. Typically, pozzolanic reactions are more slowly developing than cementitious reactions (from the hydration of portland cement) that are thought to develop ultimate strength within several months to a year, compared to many years for pozzolanic reactions. The relative proportions of fly ash and lime reagent also effect the rate of strength development in the stabilized mixture, as does the pozzolanic activity of the fly ash. Some fly ashes are more pozzolanically reactive than others or react better with certain reagents than other fly ashes. Typically, 20 to $30 \%$ lime is required to produce acceptable strength, but this varies with the type of fly ash used.

Unlike pozzolanic stabilization of soils and aggregates, the solidification/stabilization of waste sludges by means of pozzolanic reactions can be affected by the chemistry of the material being stabilized. Possibly, acidic, organic, or metal constituents in some sludges could inhibit or otherwise interfere with the normal development of chemical reactions in solidified/stabilized sludges. Consequently, a comprehensive mix design program (treatability study) is ordinarily required to properly design an effective stabilized sludge mix, especially because most sludges by their nature are not homogeneous in composition or solids content.

\section{Input Streams}

Lime/fly ash is used on inorganics, contaminated water, sediments, sludges/slurries, soils, structures, or refuse. 


\section{Output Streams}

The product of lime/fly ash is a castable solid waste form. Little chemical change occurs to the waste; however, it is solidified.

\section{Advantages}

Advantages of lime fly ash pozzolan processes include (1) pozzolanic systems are relatively inexpensive, and (2) metals in the waste are converted to insoluble silicates or hydroxides and are incorporated into the interstices of the binder matrix, thereby inhibiting leaching.

\section{Disadvantages}

Disadvantages of lime fly ash pozzolan processes include (1) the lime-pozzolan reactions are sensitive to the presence of sodium borate, calcium sulfate, carbohydrated and potassium bichromate, and others, (2) oils and greases can prevent bonding, (3) to incorporate ash, combustion should be complete, (4) system is highly alkaline, and with certain wastes this can cause release of undesirable gas or leachate, (5) hazardous waste treated by lime-lly ash will probably not pass EPA's Toxicity Characteristic Leaching Procedure (TCLP), and (6) waste form may not be as durable or control contaminate leaching as well as portland cement systems.

\section{Technology Status}

Available: Lime/fly ash is used to treat metal plating wastes on a production basis. It has also had limited use at waste cleanup sites. VFL Technolo;y Corporation performed a bench scale mix design testing and demonstration at the Saco Tannery jite. It has also heen demonstrated for use with low-level waste incinerator ash and ion exchange resins.

\subsection{Sulfur Polymer Cement (TT12800) ${ }^{6,11,12}$}

Use of Sulfur Polymer Cement (SPC) in racioactive waste disposal is a recent extension of development work that was begun in the 1970 s by the U.S. Bureau of Mines. When a small quantity of dicyclopentadiene and oligomers of cyclopentadiene are added to elemental sulfur, a thermoplastic polymer is the result. The SPC may be used for solidification of a number of waste streams that may not be solidified using other techniques. It is most applicable to high concentrations of mineral acids, corrosive electrolytes, and salt solutions. SPC is a thermoplastic, requiring no chemical reaction for solidification. Laboratory testing has shown that SPC is resistant to leaching of both radionuclides and hazardous metals. SPC has excellent mechanical stability and corrosion resistance to most materials.

Recovery from inadvertent stoppages is easier with SPC than other waste forms. For example, interruptions in flow from an externally mixed Portland cement system has caused solidification and subsequent disposal of process equipment. With SPC recovery from such an interruption may only require reheating the equipment.

This process is still in the developmental stage and systems to process radioactive and mixed waste have not been developed. However, a process would probably involve mixing dry wastes. 
elemental sulfur, and additives together and heating the mixture to about $132^{\circ} \mathrm{C}\left(270^{\circ} \mathrm{F}\right)$. The waste form has successfully passed EPA TCLP testing for toxic heavy metals and most NRC testing under 10 CFR 61.

\section{Input Streams}

Inputs consist of a variety of materials such as incinerator ash, sludges, evaporator concentrates, adsorbed liquids, and dirt. However, the wastes either must be dried prior to entry into this system, or dryers must be provided within the system, to treat the waste. Contaminants passing EPA's TCLP standards were zinc, lead, sodium, potassium, calcium, copper, iron, and cadmium. Contaminants passing NRC tests were boric acid salts, incinerator hearth ash, fly ash, and dehydrated sodium sulfate salts that have not been successfully solidified or stabilized in concrete in signiticant quantities.

\section{Output Streams}

The output from this process will be a solidified waste form, which has been cast into 55 -gal drums, or other appropriate containers.

\section{Advantages}

Advantages of SPC include (1) SPC is predicted to last twice as long as portland cement products, (2) because it is a thermoset, waste composition does not hinder or prevent solidification, (3) SPC has the same density as portland cement, which gives similar radiation shielding properties to the waste form, and (4) SPC will contain a greater weight percent of most waste materials than will portland cement.

\section{Disadvantages}

SPC has some limitations on the t? les of materials that can be treated. If SPC is cooled too quickly, it will contain an excess number of voids that can connect with one another. If the aggregate in the SPC contains water, tiny steam vents will develop. Either case will cause both gas and water to penetrate SPC. SPC deteriorates in hot concentrated chromic acid solutions, hot organic solvent solutions, sodium chlorate-hyperchlorite copper slimes, and strong alkali $(>10 \%)$. SPC is not recommended for use with strong bases and oxidizing agents, aromatic or chlorinated hydrocarbons, or oxygenated solvents. Treatment of nitrate salts with SPC needs to be carelully reviewed since significant chemical reactions could occur. Dried materials that expand when wet will rupture the solidified waste. Two examples of this type of waste include ion-exchange resins and bentonite clays.

\section{Technology Status}

Available: SPC is used commercially in the construction industry. Its use for disposal of radioactive waste is currently in a laboratory developmental stage. Results to date are lavorable. 


\subsection{Encapsulation $(\pi 12900)^{4,5,10}$}

Encapsulation processes can take the form of macroencapsulation. microencapsulation, or both. Microencapsulation is the containment of individual waste particles in a polymer or asphalt matrix. Macroencapsulation is the encasement of a mass of waste in a thick polymer coating. The waste mass may have been microencapsulated prior to macroencapsulation. Several polymeric matrices are available for use in these encapsulation processes. These include asphalt, polyethylene, thermosetting plastics (such as urea formaldehyde type resins), sulfur polymer cement, and resins that can be polymerized under ambient temperature in the presence of a catalyst. The EPA believes that encapsulation technologies are primarily applicable to wastes containing hazardous metal constituents. The Agency has established a treatment standard of macroencapsulation for radioactive lead solids.

Microencapsulation processes typically involve the following unit operations in series:

- $\quad$ Predrying of the waste to remove entrained moisture.

- Mixing of the heated waste with molten encapsulating agent (asphalt, polyethylene, thermosetting resins).

- Cooling of the hot mixture to allow the mixed mass to harden into a solid mass.

Generally, ratios of matrix to waste used are high compared to those of pozzolanic stabilization processes (i.e., the ratio is in the 1:1 to 1:2 range for encapuslation). Mixing is generally done at 120 to $130^{\circ} \mathrm{C}$ depending on the melting characteristics of the matrix and the type of equipment used for mixing. A few processes differ from the above description in that polymerization of monomers mixed with waste is conducted at ambient or near ambient temperatures in the presence of catalysts. The monomer (or monomeric mixture) then polymerizes at room temperature, coating the individual particles.

The macroencapsulation process of hazardous waste solids usually involves two steps. In the first step, the hazardous wastes may be chemically treated by using low-cost dehydrating agents such as lime, kiln dust, or Portland cement. This operation does not increase volurne of the solids significantly because only a small amount of dehydrating agent is needed to dewater the solids. The resulting mixtures are friable, and they can easily be ground. In the second step, the dehydrated sludges are ground and the particles may be microencapsulated. typically by a polybutadiene binder. Then the mass is macroencapsulated, or coated, typically by high-density polyethylene. The typical apparatus for macroencapsulation processes features heated or cooled molds, a method of waste and hardened product manipulation, and hydraulics for mold actuation. The molds typically contain electrical band heaters and water cooling channels. Alter the polymer coating hardens, the mold is split to facilitate product demolding.

\section{Input Streams}

Encapsulation technologies are primarily applicable to wastes containing hazardous metals, such as lead solids, heavy metal sludges, and incinerator ash. 


\section{Output Streams}

Encapsulation processes produce a solid waste form.

\section{Advantages}

Advantages of encapsulation include (1) the process can be effective for some soluble and toxic materials not readily treated by other stabilization technologies, (2) for compatible wastes, pollutant containment may be significantly improved over other processes, and (3) high waste-to-polymer volume ratios can be obtained.

\section{Disadvantages}

Disadvantages of encapsulation include (1) the presence of greases, oils, chelating agents, entrained moisture, organic solvents, hydrated salts (sodium sulfate, magnesium sulfate, metal chlorides), or oxidizers (such as nitrites, chlorates, or perchlorates) may interfere with the setting or level of performance of the matrix material, (2) heating of mixtures of waste with polymers or asphalt can cause hydrocarbon emissions, and (3) processing is more difficult (e.g., higher temperatures, specialized equipment) than for pozzolan and pozzolan-portland cements and theretore more expensive.

\section{Technology Status}

Proven: The EPA's Best Demonstrated Available Technology for radioactive lead solids is macroencapsulation. Various encapsulation processes have been used to stabilize commercial hazardous waste, as well as radioactive LLW.

\subsection{Amalgamation $(\pi 12300)^{5}$}

The amalgamation processes depend on the ability of mercury to form low-melting point solid alloys with metals such as copper and zinc, which have the thermodynamic capability of simultaneously reducing mercuric and mercurous salts to elemental mercury. Basically, an excess of the less noble metal (zinc or copper) is contacted with a waste containing mercury or mercury salts. The chemical reaction reducing the mercury in the mercury salts occurs and the elemental mercury liberated forms an alloy with the excess metal added. For zinc and mercuric nitrate, the reaction may be written:

$$
\begin{aligned}
& \mathrm{Hg}\left(\mathrm{NO}_{3}\right)_{2}+\mathrm{Zn}-\mathrm{Zn}\left(\mathrm{NO}_{3}\right)_{2}+\mathrm{Hg} \\
& \mathrm{Hg}+\mathrm{Zn}-\text { mercury zinc amalgam }
\end{aligned}
$$

The amalgamation processes consists of, for example, contacting waste liquid mercury with finely divided zinc powder. The mass rapidly solidifies into a solid amalgam, which is more easily managed and less mobile than liquid mercury.

The EPA has established amalgamation as a method of treatment for mixed wastes containing elemental mercury. These types of wastes are typically found in vacuum pumps and related 
manometers. In the nuclear industry, this form of mercury has been contaminated with radioactive tritium (a radioisotope of hydrogen). The EPA has determined that amalgamation not only provides significant reduction in air emissions of mercury, but also provides a change in mobility from liquid mercury to a paste-like solid, potentially reducing leachability. The required method of treatment, e.g., amalgamation, may be performed using any of the following elements: zinc, copper, nickel, gold, and sulphur.

\section{Input Streams}

The amalgamation process is applicable to elemental mercury and mercury salts.

\section{Output Streams}

The amalgamation process produces a soft metal alloy consisting of mercury and the less noble metal (e.g., zinc, copper, etc.).

\section{Advantages}

Advantages of amalgamation include (1) amalgamation is an inexpensive method for immobilizing and reducing the emissions from elemental mercury spills, and (2) amalgamation improves the handling of elemental mercury, by converting the waste from a liquid to solid form.

\section{Disadvantages}

Disadvantages of amalgamation include (1) amalgamation may not significantly reduce the leachability of mercury, and (2) it may be difficult to achieve adequate mixing of the mercury and zinc power if this process is used on a large scale since historically, amalgams have been made in small quantities at the laboratory scale.

\section{Technology Status}

Available: Amalgamation is recommended by the EPA for treatment of radioactively contaminated elemental mercury. However, whether this process has been used as a waste treatment technology in the nuclear industry is unknown. 


\subsection{References}

1. DOE National Low-Level Radioactive Waste Management Program Handbook Series, LowLevel Radioactive Waste Treatment Technology, DOE/LLW-13c, July 1984.

2. A. A. Moghissi, H. W. Godbee, and S. A. Hobart, Radioactive Waste Technology, New York: American Society of Mechanical Engineers, 1986.

3. Options for the Treatment and Solidification of Organic Radioactive Wastes, Technical Report Series No. 294, Vienna: International Atomic Energy Agency, 1989.

4. H. M. Freeman, Editor, Standard Handbook of Hazardous Waste Treatment and Disposal, New York: McGraw-Hill Book Company, 1989.

5. L. Rosengrant, Treatment Technology Background Document, U.S. Environmental Protection Agency Office of Solid Waste, EPA/530-SW-90-059Z, January 1991.

6. W. S. Roesener, Unit Systems for the Treatment of TRU Contaminated Waste, EG\&G Idaho, Inc.: WM-PD-92-002, January 1992.

7. R. E. Berlin and C. C. Stanton, Radioactive Waste Management, New York: John Wiley \& Sons, 1989.

8. Remedial Technology Information System (RTIS) Database, EG\&G Idaho, Inc., Idaho Falls, Idaho, 1991.

9. R. A. Corbitt, Standard Handbook of Environmental Engineering, New York: McGraw-Hill Publishing Company, 1990.

10. J. E. Alleman, N. A. Berman, M. F. Prouty, "Solidification, Encapsulation, and Stabilization of Industrial Wastes," Proceedings of the 37th Industrial Waste Conference, May 11, 12 and 13, 1982, Purdue University, West Lafayette, Indiana, Ann Arbor, Michigan: Ann Arbor Science, 1983, pp. 803-811.

11. G. R. Darnell, "Sulfer Polymer Cement, A Soliditication and Stabilization Agent for Hazardous, Mixed, and Low-Level Radioactive Waste," Idaho National Engineering Laboratory (INEL), EG\&G Idaho, Inc., P.O. Box 1625, Idaho Falls, ID 83415, DOE Field Office Contract No. DE-AC07-76ID01570, December 17, 1991.

12. P. D. Kalb, J. H. Heiser III, and P. Colombo, "Comparison of Modified Sulfer Cement and Hydraulic Cement for Encapsulation of Radioactive and Mixed Wastes," Waste Management R\&D Group, Department of Nuclear Energy, Brookhaven National Laboratory, Upton, New York 11973, DOE contract No. DE-AC02-76CH00016. 


\section{SIZING (TT14000)}

This section contains various sizing techniques that can be used to prepare the materials for various volume reduction technologies or as a pretreatment for decontamination, treatment, or incineration systems. These operations are typically used to process large metal or plastic items. For many of the methods, cutting can be carried out either in the dry statc or under water.

Specific types of sizing processes and their applicability to particular waste types are discussed as follows:

$\begin{array}{ll}\text { Section } & \text { Technology } \\ & \\ 11.1 & \text { Arc Saw Cutting } \\ 11.2 & \text { Plasma Arc Cutting } \\ 11.3 & \text { Oxygen Burning } \\ 11.4 & \text { Hacksaws and Guillotine Saws } \\ 11.5 & \text { Shredding } \\ 11.6 & \text { Cryogenic Fracturing } \\ 11.7 & \text { Abrasive Cutter } \\ 11.8 & \text { Thermite Reaction Lance } \\ 11.9 & \text { Laser Cutting } \\ 11.10 & \text { Water Jet Cutting } \\ 11.11 & \text { Abrasive Jet Cutting }\end{array}$

\subsection{Arc Saw Cutting (T14100) ${ }^{1}$}

A circular, toothless saw blade is used to cut metals by establishing a high current electric arc between the blade and the material being cut. No physical contact occurs between the blade and the workpiece. The polarity of the current is chosen so that the major material removal occurs to the workpiece, although, the blade is gradually consumed. Rotation of the blade is essential to aid in cooling of the blade and maintenance of its structural integrity. However the rotational speed (300 to $1800 \mathrm{rpm})$ is not a critical parameter. The depth of the cut is limited by the blade diameter.

\section{Input Streams}

The input stream will consist of conductive metals up $100.9 \mathrm{~m}$ (36 in.) thick.

\section{Output Streams}

The output stream will consist of the sized input stream, and small, highly oxidized pellet cuttings of the material that has been cut.

\section{Advantages}

Some advantages of arc saw cutting are (1) arc saw cutting is a "noncontact" cutting process and requires less force to hold the workpiece in place than other mechanical cutting processes, (2) the 
cutting process operates at a much higher energy level, resulting in faster cutting speeds than other process such as oxygen burning, (3) the ability to sever any electrically conductive material makes it especially attractive for cutting nonferrous metals that could not be cut by the oxygen burning process, (4) the process can be started up instantly without requiring preheat system, (5) it can operate under water or in air, and (6) the rotating blade lasts longer than the lungsten electrode use in plasma arc cutting.

\section{Disadvantages}

Some disadvantages of arc saw cutting are (1) increased hazards such as electrical shock, fire, intense light, fumes and gases, and noise that may not be present with mechanical processes, (2) increased difficulty for close tolerance work, (3) equipment tends to be more expensive than oxygen burning equipment, (4) the process requires a large amount of electric power, (5) the process alters the structure of the metal in the cut zone and introduces internal tensile stresses from the rapid expansion, upsetting, and contraction of the metal at the cut surface, and (6) the depth of cut is limited by the blade diameter that gets smaller with increased use.

\section{Technology Status}

Proven: Arc saw cutting has been used in a nuclear environment.

\subsection{Plasma Arc Cutting (TT14200) $)^{1,2,3,4}$}

The plasma arc cutting process severs metal by using a constricted, direct current arc to melt a localized area of a workpiece, removing the molten material with a high-velocity jet of ionized gas (plasma) issuing from the constricting orifice. Plasma arcs operate typically at temperatures of 9983 to $13871^{\circ} \mathrm{C}\left(18000\right.$ to $\left.25000^{\circ} \mathrm{F}\right)$.

Plasma cuts in plates up to approximately $8 \mathrm{~cm}(3 \mathrm{in}$.) thick may have a surface smoothness similar to that produced by oxyfuel gas cutting. On thicker plates, low travel speeds produce a rougher surface and discoloration. On thick stainless steel, 13 to $18 \mathrm{~cm}$ (5 to $7 \mathrm{in}$.) thickness, the plasma arc process has little advantage over oxyfuel gas powder cutting. The cut widths (kerf) of plasma arc cuts are 1.5 to 2 times the width of oxyluel gas cuts in plates up to $5 \mathrm{~cm}(2 \mathrm{in}$.) thick. This width increases as the thickness of the material to be cut increases.

The plasma cutting process is used with either a handheld torch or a mechanically-mounted torch. Several types and sizes of each are available, depending on the thickness of metal to be cut. The equipment includes (1) torch positioning equipment, (2) a torch traveling system, (3) air, starting gas, and plasma gas supplies, (4) a constant-current or drooping volt-ampere characteristic, relatively high-voltage direct-current power supply, and (5) associated automatic controls. Plasma arc equipment normally includes controls to (1) start and stop the equipment, (2) sequence the entire operation, including varying the gas tlow and power level if necessary, (3) shutdown the torch in the event of gas failure since the torch may be damaged by internal arcing without an adequate supply of gas, and (4) control coolant for high-current torches.

Some torches can be dragged aiong in direct contact with the workpiece, while others require that a standoff be maintained between the tip of the torch and workpiece. Usually a standoff is 
maintained between the torch tip and workpiece for best cut quality. The standoff distance must be maintained within fairly close tolerances to achieve uniform results. Some mechanized torches are equipped with an automatic standoff controlling device to maintain a lixed distance between the torch and workpiece. In other cases mechanical followers are used to accomplish this. Mechanized torches can be mounted either on a tractor or on a computer-controlled cutting machine or robot.

\section{Input Streams}

This process was initially used for cutting aluminum but can cut carbon steel, or any other conductive nonferrous metal, including those resistant to acetylene cutting. The maximum cut depth for many materials is $18 \mathrm{~cm}$ ( 7 in.). The process has been used to cut stainless steel up to $13 \mathrm{~cm}$ (5 in.) thick or aluminum alloy up to $15 \mathrm{~cm}(6 \mathrm{in.})$ thick.

\section{Output Streams}

The output will consist of smaller pieces of the input material, small amounts of the cuttings, and small amounts of oxidized andlor devolatilied metals.

\section{Advantages}

Some advantages of plasma arc cutting are (1) the amount of force required to hold the workpiece in place and move the torch (or vice versa) is much lower with the "noncontact" plasma arc cutting process than other mechanical cutting processes, (2) the cutting process operates at a much higher energy level, resulting in faster cutting speeds than oxygen burning, (3) the ability to sever any electrically conductive material makes it especially attractive for cutting nonferrous metals that could not be cut by the oxygen burning process. (4) the process can be started up instantly without requiring preheat system and can operate under water or in air, and (5) the process can be a hand-held operation or automated.

\section{Disadvantages}

Some of the disadvantages of plasma arc cutting are (1) increased hazards such as electrical shock, fire, intense light, fumes and gases, and noise that may not be present with mechanical processes, (2) increased difficulty for close tolerance work. (3) equipment tends to be more expensive than oxygen burning equipment, (4) the process requires a large amount of electric power, (5) the process alters the structure of the metal in the cut zone and introduces internal tensile stresses from the rapid expansion, upsetting, and contraction of the metal at the cut surface, (6) the depth of cut is limited by the blade diameter that gets smaller with increased use, and (7) the tip and electrode wear during cutting that deteriorates cutting performance.

\section{Technology Status}

Proven: Plasma arc cutting has been extensively used on full-scale nonradioactive hardware has confirmed its effectiveness in segmenting bulky metallic waste materials. It has been proven to be successful in decommissioning reactor vessels and segmenting irradiated piping. 


\subsection{Oxygen Burning $(T T 14300)^{1,2}$}

Oxygen Burning, also known as oxyfuel cutting, is a process where the metal is severed or removed by the chemical reaction of oxygen with the metal at elevated temperatures, leaving a clean cut surface. Oxygen burning consists of circulating a mixture of a fuel gas and oxygen at the orifice of an ignited torch. The cutting tip of the torch is at the main oxygen jet orifice. This orifice is surrounded by a ring of preheater jets. The oxygen jet rapidly oxidizes most of the metal in a narrow section to make the cut. Metal oxides and molten metal are expelled from the cut by the kinetic energy of the oxygen stream. In the case of oxidation resistant metals, the reaction is aided by adding chemical fluxes or metal powders to the cutting oxygen stream.

Oxygen burning can be used to cut plates up to $2 \mathrm{~m}$ ( $7 \mathrm{ft}$ ) thick. As material thickness increases, oxygen flow rates must usually be increased. Cutting tips with larger cutting oxygen ports are required to handle the higher flow rates. Consequently, the width of the cut (kert) also increases as the material thickness being cut increases. Varying the cutting speed from those recommended for best quality cuts usually results in irregularities in the kerf.

Two basic types of oxygen burning equipment are available: manual and machine. The manual equipment is used primarily for maintenance, scrap cutting, cutting risers off castings, and other operations that do not require a high degree of accuracy or a high quality cul surface. Machine cutting equipment is used for accurate, high quality work, and for large volume cutting, such as in steel fabricating shops.

The basic equipment needed for manual oxygen burning are (1) one or more cutting torches suitable for the preheat fuel gas to be used and the range of material thicknesses to be cut, (2) cutting tips to cut a range of material thicknesses, (3) oxygen and fuel gas hoses, (4) oxygen and fuel gas pressure regulators, (5) sources of oxygen and luel gases to be used, and (6) flame strikers, eye protection, flame and heat resistant gloves and clothing, and salely devices.

Machine cutting equipment often includes (1) a machine to move one or more torches in the required cutting pattern, (2) torch mounting and adjusting arrangements on the machine, (3) a cutting table to support the work, (4) means for loading and unloading the cutting table, and (5) automatic preheat ignition devices for multiple torch machines.

\section{Input Streams}

This process can only be used on metals that undergo rapid exothermic oxidation; namely, ferrous metals and wrought iron products [up to $2 \mathrm{~m}$ ( $7 \mathrm{ft}$ ) thick]. This process cannot be used on stainless steel, cast iron, aluminum, and nonferrous metals without increasing the cutting temperature above the melting point of the refractory oxides.

\section{Output Streams}

The output will consist of smaller pieces of the input material. 


\section{Advantages}

Some advantages of oxygen burning are (1) steels can generally be cut faster than by mechanical chip removal processes, (2) section shapes and thicknesses that are difficult to produce by mechanical means can be severed economically, (3) equipment costs are low compared to machine tools, (4) equipment is portable and can be used in the field, (5) cutting direction can be changed rapidly on a small radius during operation, (6) large plates can be cut rapidly in place by moving the torch rather than the plate, and (7) the process can be a hand held operation or automated.

\section{Disadvantages}

Some disadvantages of oxygen burning are (1) dimensional tolerances are significantly poorer than machine tool capabilities, (2) The process is essentially limited commercially to cutting steels and cast iron, although other readily oxidized metals, such as titanium, can be cut, (3) the preheat flames and expelled red hot slag present tire and burn hazards to personnel, (4) fuel combustion and oxidation of the metal require proper fume control and adequate ventilation, (5) special process modifications are needed for high alloy steels and cast iron, and (6) hardenable steels may require preheat, posiheat or both to control their metallurgical structures and mechanical properties adjacent to the cut edges. Oxygen burning is not recommended for extensive remote cutting.

\section{Technology Status}

Proven: Oxygen burning has been used in the nuclear industry.

\subsection{Hacksaws and Guillotine Saws (TT14400) $)^{1,5}$}

Hacksaws and guillotine saws are common industrial tools used for cutting all metals. The cutting process results from the reciprocating action of a hardened steel saw blade against the metal being cut. Portable power hacksaws are clamped with a chain to a pipe in a position such that the blade contacts the underside of the pipe. This allows the weight of the motor to advance the blade into the workpiece about the chain mount pivot point. An operator may increase the feed pressure manually by applying downward force on the motor body or by suspending weights from the body. As a general rule an 20-cm (8-in.) diameter Schedule 40 pipe can be cut in 6 to 10 min with a power hacksaw. In general, blade lubrication is not necessary.

A portable guillotine saw also clamps by chain to a pipe but the saw and motor are mounted above the cut allowing the weight of the unit to advance the saw into the workpiece. Cutting speed is approximately $1 \mathrm{~min}$ for each inch of pipe diameter based on Schedule 40 pipe. In general blade lubrication is not necessary.

\section{Input Streams}

Inputs consist of metals, piping [up to $36 \mathrm{~cm}$ (14 in.) diameter for power hacksaws and up to $46 \mathrm{~cm}$ (18 in.) diameter for guillotine saws), wood products, and plastics. 


\section{Output Streams}

Outputs consist of segmented metals, pipes, wood products, and plastics and secondary waste steams from cutting fluids if used.

\section{Advantages}

Some of the advantages of hacksaws and guillotine saws are (1) reduced tire hazards, (2) simpler radioactive contamination control because no fumes or gases ocsur, (3) available in portable or stationary modes, (4) requires minimum operator assistance after positioning thus reducing operator exposures when cutting in high radiation zones, (5) motors powered by air o electricity, (6) automatic feed, measure, and cut off of a series of pieces (production-type machines), (7) easy to change from one job to another, (8) inexpensive alloy and high steel blades have long lives, (9) accepts a wide variety of materials, and (10) low operating costs.

\section{Disadvantages}

Some of the disadvantages of hacksaws and guillotine saws are (1) the process is slow because the stroke of a hack saw is intermittent, (2) the rate a hack saw penetrates the material depends on the feeding force, and (3) cutting fl,ids, if used, will produce a secondary waste stream.

\section{Technology Status}

Proven: Hacksaws and guillotine saws have been used in the nuclear industry.

\subsection{Shredding $(\pi 14500)^{6}$}

Shredding is normally used for processing dry solids before incineration. compaction or other treatment of the solids. Low-speed shredders simultaneously open the waste containers and size the wastes for processing. Shredder operation consists of two counter rotating shafts with cutter wheels attached. The cutter wheels intermesh and tear apart the waste as it is drawn through. The waste material is trapped between the wheels and cut to the size of the clearance between the wheels. A "comb" is used on the noncutting side of the shafts to prevent waste from falling through. The discharged material is dropped into a container that can be processed by incineration or compaction.

A typical shredder contains a number of intermeshing, counter rotating shafts driven by a variable-speed motor. Features such as a motor controller, which reverses the direction of the motor and shaft if jamming occurs, along with various design of cutting teeth, are readily available. The waste is usually fed to the shredder by a conveyer.

\section{Input Streams}

Shredders can be used on all types of dry solids - paper, cloth, plastics, and even some light metal. 


\section{Output Streams}

The output materials consist of pieces of the input material that have been shredded to 3 smaller, more uniform size distribution.

\section{Advantages}

Some advantages of shredding include (1) reliability, (2) low power requirements, (3) unshreddable items left on top of cutters are easily removed when shredder is turned off, and (4) does not pulverize the waste, which would create large amounts of dust.

The advantages of shredding before coinpaction include (1) springback after compaction is reduced, (2) traditionally "noncompactible" waste such as wood can be compacted, (3) the required compaction pressure may be reduced because material deformation is not necessary tor compaction, and (4) mixing of the waste during shredding prevents the generation of "hot spots" during compaction.

\section{Dikadvantages}

Some of the disadvantages of shredding include (1) lugitive dust emissions (2) cleaning of internal hopper area and shredding teeth could aflect overall processing time. (3) potential for fire and explosions due to potential pyrophorics and explosives, and (4) high maintenance.

\section{Technology Status}

Proven: The shredding process is well proven in nonnuclear industries and has been used in the nuclear industry in more recent years.

\subsection{Cryogenic Fracturing $(T 14600)^{7,8,9}$}

In cryogenic fracturing, solid materials are cooled in a liquid nitrogen bath to reduce their temperature to below their nil-ductility temperature. The nitrogen bath temperature is $-196^{\circ} \mathrm{C}$ $\left(-320^{\circ} \mathrm{F}\right)$. At this temperature, the materials are more brittle and easily broken having lost their ability to absorb energy via plastic deformation. Articles are removed from the liquid nitrogen and placed in a hydraulic press to crush the frozen materials. Adequate force applicd to a material below nil-ductility temperature causes the material to britle fracture into shards. A recycle system allows large pieces to recycle back through the cryogenic tracturing process.

The time required to treeze a sealed container can be reduced by puncturing the container. The typical time required to cool a nonpunctured drum can be reduced from approximately $17 \mathrm{~h}$ to 45 min. Typical hydraulic press forces during cryogenic fracturing can ianged from 60 to 900 tons.

Cryogenic fracturing equipment consists of storage tanks for the liquid nitrogen, liquid nitrogen baths, a hydraulic press, and equipment to move the parts from the liquid nitrogen baths to the press. 


\section{Input Streams}

Input streams can include cloth, paper, plastic, wood, carbon steel concrete, asphalt, paper, lifting cables, electrical cables and other materials that become brittle when cooled to $-196^{\circ} \mathrm{C}\left(-320^{\circ} \mathrm{F}\right)$.

\section{Output Streams}

Same wastes as influent except the size is reduced to smaller particles.

\section{Advantages}

Some advantages of cryogenic fracturing include (1) the colder temperatures decrease the average energy of the molecules that will deactivate and desensitize explosives and pyrophorics, (2) cryogenic temperatures freeze bioactivity and significantly reduce chemical reaction rates and volatility, (3) cryogenic fracturing produces small amounts of secondary wastes, (4) the process is suited for fully remote-automated design, and (5) less encrgy is required due $(1)$ the embrittlement of the material to be sized.

\section{Disadvantages}

Some of the disadvantages of cryogenic fracturing include (1) large liquid nitrogen requirements, (2) when cryogenic fracturing soil, concrete, and asphalt, these materials build up under the hydraulic press preventing the crusher from traveling the full stroke. (3) the cooled materials must be processed quickly before the materials can warm up, and (4) some carryout of radioactive materials can occur due to entrainment in the rapidly vaporizing nitrogen gas.

\section{Technology Status}

Emerging: Initially, the cryogenic fracturing process was developed to render inert and destroy chemical weapons. Cryogenic fracturing technology has been tested at NRT in San Diego, California. for treatment of INEL waste using 55-gal steel drums and $0.6 \times 0.6 \times 2 \mathrm{~m}(2 \times 2 \times 8 \mathrm{ft})$ plywood boxes filled with various articles.

\subsection{Abrasive Cutter (TT14650) $)^{1,10}$}

An electrically, hydraulically or pneumatically powered wheel with an abrasive surface of resinbonded particles of aluminum oxide or silicon carbide cuts through the workpicce by grinding the metal away. This produces a clear cut (kerl). Cutling ranges lor stationary abrasive wheels are approximately $6.5 \mathrm{~cm}^{2}\left(1 \mathrm{in}^{2}{ }^{2}\right.$ ) of cut area every ${ }^{-}$. Reported wear rates for wheels average $1 \mathrm{in}^{2}$ of surface area corsumed for each square inch of cut area. Water lubricants can be used to improve wear resistance by $50 \%$. 


\section{Input Strearns}

Inputs consist of metals, piping or stock less than 8 in. in diameter, chord, high-density alloys, nonferrous alloys, and nonmetallic materials such as composites, plastics, natural stone, glass, and refractory products.

\section{Output streams}

The output stream will consist of the sized input materials, cuttings, and secondary waste steams from cutting fluids if used.

\section{Advantages}

Some advantages of abrasive cutters are (1) low cost, (2) usefulness on a wide variety of materials, and ( 3 ) equipment can be portable or stationary.

\section{Disadvantages}

Some disadvantages of abrasive cutters are (1) contamination control is difficult, since the particles are removed in small pieces, (2) water lubricants used to decrease wear on the grinding surface generate secondary wastes, (3) the cutting process creates a noise level of 140 to $160 \mathrm{~dB}$, requiring hearing protection for operators, and (4) the cutting process generates sparks, making is unsafe to operate near combustibles.

Stationary applications require the materials to be cut to be brought to an established workstation. The disadvantages of portable hand-held abrasive cutters include (1) they are relatively slow, (2) require constant operator attention, (3) the reaction force of the workpiece against the operator for long periods of time is tiring, and (4) the applicability of manual cutting is generally limited to pipe and components of less than $5 \mathrm{~cm}(2$-in.) diameter.

\section{Technology Status}

Proven: Abrasive cutting has been used in the nuclear industry.

\subsection{Thermite Reaction Lance $(T T 14700)^{1}$}

A thermite reaction lance is an iron pipe packed with steel. aluminum and magnesium wires with a flow of oxygen gas through it, which cuts by a thermite reaction at its tip that causes the metal to melt. The thermite reaction lance is capable of cutting any metal. The maximum depth of the cut is limited only by the ability to keep the cut (kerf) clear of the molten metal. The rate for metal cutting has been reported as generating approximately $2.5 \mathrm{-m}$ (1-in.) diameter hole at the rate of $30 \mathrm{~cm}$ (12 in.) depth per minute, provided the molten metal is free to flow away from the kert.

The lance is practical only in the manual (hand-held) mode. A typical lance cutting system consists of a lance holder, the lance. and oxygen supply, gas regulator and an oxygen hose. Each lance will burn for approximately $6 \mathrm{~min}$ and consume ahout $6 \mathrm{~m}^{3}\left(60 \mathrm{ft}^{3}\right)$ of oxygen. 


\section{Input Streams}

Input streams are all metals at practically any thicknesses.

\section{Output Streams}

Output streams are molten metals, and smaller pieces of the original metal.

\section{Advantages}

The advantages of a thermite reaction lance include (1) usefulness in air or underwater, (2) relative ly low cost, and (3) can cut all type of metals at any thickness.

\section{Disadvantages}

The disadvantages of a thermite reaction lance include (1) the operator must wear fireproof protective clothing and faceshield, which is difficult to use underwater. (2) the thames and expelled red hot slag present fire and burn hazards to personnel, and (3) hardenable steels may require preheat, postheat or both to control their metallurgical structures and mechanical properties adjacent to the cut edges.

\section{Technology Status}

Proven: The thermite reaction lance has been used in the nuclear industry.

\subsection{Laser Cutting (TT14800) $)^{2,3,11}$}

Laser beam cutting is a thermal cutting process that severs material by locally melting or vaporizing the material using a laser beam. The process is used with or without assist gas to aid the removal of molten and vaporized material. Depending on the material, a jet of reactive gas such as oxygen can be applied coaxially with the beam, improving process speed and cut edge.

Laser cutting equipment consists of a laser, a beam delivery system. supply of assist gases (helium, nitrogen, and carbon dioxide), and the ability to maneuver the workpiece or the cutting beam. For optimum cut quality, the optics should be held motionless, to avoid any vibration or misalignment in the beam delivery system. Fiber optic systems have been developed that allow greater tlexibility in directing the cutting beam.

The $\mathrm{CO}_{2}$ laser is the most powertul and reliable type of laser in general use. The $\mathrm{CO}_{2}$ laser is a gas-discharge device that operates by sending an electric current through a gas. A high-power $\mathrm{CO}_{2}$ laser can cut up to $2.5 \mathrm{~cm}$ (1-in.) thick carbon steel. However, good quality cuts on steel are typically made on metal thinner than $0.9 \mathrm{~cm}(0.375 \mathrm{in}$.) because of the limited depth of locus of the laser beam. Typical cutting speed for $0.9-\mathrm{cm}(0.375$-in.) carbon steel is $1.3 \mathrm{~m} / \mathrm{min}(50 \mathrm{ipm})$ with a power consumption of $1500 \mathrm{~W}$. However, these rates assume the cut quality is of importance. For simple sizing operations, "raw" processing capabilities will need to be investigated to determine the processing rate. 
Laser cutting results are highly reproducible, and laser systems have achieved operating uptimes greater than $95 \%$. Relative movement between the beam and workpiece can be easily programmed. Lasers also have the flexibility for power and time sharing so that cost effectiveness of full-time beam operation can be maximized.

\section{Input Streams}

The laser can cut an extremely wide range of materials (metals, ceramics, inorganics, organics, and composites) without regard to their hardness or electrical conductivity. Inorganic materials, as a class, have low vapor pressures and poor thermal conductivities making them good candidates for laser cutting. Unfortunately, many common varieties have high melting points and poor thermal shock resistance that tends to make them harder to process than metals. Organic materials generally decompose by laser light, which enables cutting to be done at higher speeds or with lower power lasers.

\section{Output Streams}

Output stream consists of smaller pieces of input material.

\section{Advantages}

Laser cutting has the advantages of (1) high culting speeds, (2) narrow cut (kert) widths, (3) high-quality edges. (4) low-heat input, (5) minimal work distortion, (6) easily automated, (7) cut geometry can be changed without the major rework required with mechanical tools, (8) no tool wear, (9) finishing operations are not usually required, (10) minimal job setup time. (11) no mechanical contact between the cutting device and the workpiece, (12) can cut aluminum without leaving any dross, (13) eliminates secondary wastes, and (14) noise, vibration, and lume levels involved are quite low compared to most conventional processes.

\section{Disadvantages}

The disadvantages of laser cutting include (1) high initial costs, (2) exposure to high voltage power supplies, (3) exposure to direct or rellected light, and (4) exposure to fumes from materials being cut.

Fixed beam laser cutting has the disadvantages of (1) complicated systems are required to move large workpieces, (2) the minimum lloor area required is four times the maximum sheet size, and (3) automatic sheet feeding and part removal are difficult, as is accurate contouring with widely varying loads.

Moving optical systems have the disadvantages of (1) beam divergence due to the variance of diameters, focal point, and spot size as a function of both distance from their source, and the location where the laser beam intercepts the lens, (2) beam must be allowed to travel across the entire workpiece without a change in alignment, (3) vibration and deflection are more difficult to suppress, and (4) harder to seal the beam path against dirt on the optical elements since many moving beam systems share enclosures with gears, motors, and other sources of contaminants, shortening the life of the optics. 


\section{Technology Status}

Available: Among the laser material processing applications, cutting is the most common process, and is experiencing an excellent growth rate worldwide. No information was obtainable to indicate that this technology had been used in a nuclear environment.

\subsection{Water Jet Cutting (T14900) ${ }^{3}$}

A wide variety of materials, both nonmetals and metals, can be cut using a high-velocity water jet. The jet is formed by forcing water through a 0.1 to $0.6-\mathrm{min}(0.004$ to 0.024 -in.) diameter orifice in a tungsten carbide or synthetic sapphire nozzle, under high pressure $(30,000$ to $60,000 \mathrm{psig})$ to obtain jet velocities ranging from 518 to $914 \mathrm{~m} / \mathrm{s}$ (1700 to $3000 \mathrm{ft} / \mathrm{s})$. The nozzle is typically $0.3 \mathrm{~mm}$ to $25 \mathrm{~mm}$ ( 0.010 to 1.0 in.) from the work piece, with distances under $6 \mathrm{~mm}(0.25 \mathrm{in}$.) being preferred. At these speeds and pressures, the water erodes many materials rapidly, acting like a saw blade. Metals and other hard materials are cut by adding an abrasive in powder form to the water stream.

Resulting workpiece tolerances depend on the equipment, workpiece material and thickness, but can be as close as $0.1 \mathrm{~mm}( \pm 0.004 \mathrm{in}$.) on dimensions and $0.05 \mathrm{~mm}( \pm 0.002)$ on positioning. In simple water jet cutting, the cut (kert) width is usually $0.13 \mathrm{~mm}(0.005 \mathrm{in}$.) or wider. In abrasive water jet cutting, it is usually $0.8 \mathrm{~mm}(0.032 \mathrm{in}$.) or larger. Kerf tapering may be reduced by adding long chain polymers, such as polyethylene oxide, to the water or by reducing cutting speed.

The water stream, with a flow rate of 0.1 to $5 \mathrm{gpm}$, is usually manipulated by a robot or gantry system, but small workpieces may be guided past a stationary water jet by hand. The key pieces of equipment for a water jet or an abrasive water jet system are (1) the special high pressure pump or intensifier used to provide the stream of water, (2) the plumbing and tank or catcher unit to handle the water, (3) the gantry, robotic, or other delivery system to transverse and guide the water jet, and (4) thr: nozzle assemble unit which forms the jet. In the case of abrasive water jets, an abrasive delivery system includes a hopper, a metering valve, and a mixing unit, which mixes the abrasive particles into the water stream.

\section{Input Streams}

Water jet cutting can be used on a wide range of materials (metals, concrete, leather, cardboard, plastics, and composites). An abrasive jet is particularly good for cutting laminates of different materials including sandwiches of metals and nonmetals.

\section{Output Streams}

Output streams from this process include (1) smaller sized pieces of the material being cut, and (2) contaminated water and abrasive materials.

\section{Advantages}

The advantages of water jet cutting include (1) a wide application range, (2) no predrilling is required to start cutting, (3) cutting may be omnidirectional, (4) minimal or no deburring is required, 
(5) the process is easily adapted to robot control, (6) minimal tool wear out, other than the orifice, nozzle and wear on the robot mechanism. (7) minimal lateral forces are generated simplifying fixturing, and (8) the part being cut does not heat up.

\section{Disadvantages}

The disadvantages of the water jet cutting include (1) low cutting speeds, (2) initial capital costs are high because of the pumps and pressure chamber required to propel and direct the water jet, (3) nozzles must be replaced every two to four hours in abrasive water jet systems, (4) a collection device must be provided to collect the exhaust liquid form the cutting stream, (5) the material to be cut must be softer than the abrasive used, (6) thin ductile metals tend to suffer bending stress from the abrasive jet and show exit burrs, (7) ceramics show decrease in as-fired strength, (8) the abrasive grit wears the carbide nozzles to an out-of-round conditions, and the.jet loses its symmetry, causing cut quality to deteriorate, and (9) secondary wastes are created by this process that must be disposed of properly.

\section{'Technology Status}

Available: Industries that use water jet cutting include automotive, aerospace and defense, building supply, circuit board manufacturing, steel fabrication, foundries, food processing, glass manufacture, mining, oil and gas well equipment, packaging, paper, rubber, shipyards, and steel service centers. Equipment is available in a range from individual components to finished machine tools. More complex systems such as 5-axis robotic system. tend to be custom-built. No information was obtainable to indicate that this technology had been used in a nuclear environment.

\subsection{Abrasive Jet Cutting (TT14900) ${ }^{3}$}

Similar to water jet cutting, high pressure gas or liquid jets containing abrasive materials are used to cut through many materials, ranging from foam rubber to the hardest steels. Air, nitrogen, or carbon dioxide are ordinarily used as carrier gases, and water or light oil as carrier liquids. The abrasive materials most often used are aluminum oxide, silicon carbide, dolomite, sodium bicarbonate, and small glass beads. The technique functions by entraining the abrasive material in the carrier stream, focusing the carrier/abrasive stream through a tungsten carbide or synthetic sapphire nozzle. then impinging that stream onto the workpiece. The abrasive action of the high speed particles cause the cutting action.

The key pieces of equipment lor a abrasive jet cutting system are (1) the special high pressure pump or intensifier used to provide the stream of liquid or supply of high pressure gas, (2) the plumbing and tank or catcher unit to handle the liquid, abrasive material and work piece chips, (3) the gantry, robotic, or other delivery system to transverse and guide the tluid jet, (4) the nozzle assemble unit which forms the jet, and (5) an abrasive delivery system including a hopper, a metering valve, and a mixing unit, which mixes the abrasive particles into the tluid stream. 


\section{Input Streams}

The input stream for this technology can consist of almost any solid material (metals, concrete, leather, cardboard, plastics, and composites). Layered (metallic-nonmetallic) material that can pose problems with thermal cutting techniques can also be cut.

\section{Output Streams}

The output streams consist of the cut work pieces, small particles of the material being cut, contaminated carrier gas or liquid and contaminated abrasive materials.

\section{Advantages}

The advantages of abrasive jet cutting include (1) a wide application range, (2) the ability to cut fragile, brittle, extremely hard or heat-sensitive material, (3) no predrilling is required to start cutting, (4) cutting may be omnidirectional, (5) minimal or no deburring is required, (6) the process is easily adapted to robot control, (7) minimal tool wear out, other than the orifice, nozzle and wear on the robot mechanism, (8) minimal lateral forces are generated simplifying tixturing, and (9) the part being cut does not heat up.

\section{Disadvantages}

The disadvantages of the abrasive jet cutting include (1) low cutting speeds, (2) initial capital costs are high because of the pumps or compressors, and pressure chamber required to propel and direct the water jet. (3) nozzles must be replaced every two to lour hours in abrasive jet systems, (4) a collection device must be provided to collect the exhaust liquid from the cutting stream, (5) the material to be cut must be softer than the abrasive used, (6) thin ductile metals tend to suffer bending stress from the abrasive jet and show exit burrs, (7) the abrasive grit wears the carbide nozzles to an out-of-round conditions, and the jet loses its symmetry, causing cut quality to deteriorate, and (8) secondary wastes are created by this process that must be disposed of properly.

\section{Technology Status}

Available: No information was obtainable to indicate that this technology had been used in a nuclear environment so the term proven could not be applied. 


\subsection{References}

1. A. A. Moghissi, H. W. Godbee, S. A. Hobart, Radioactive Waste Technology, New York: The American Society of Mechanical Engineers, 1986, pp. 499-550.

2. R. L. O'Brien, Editor, Welding handbook, Volume 2: Welding Processes, Miami, FL: American Welding Society, 1991.

3. American Society for Metals, Metals Handbook, Volume 3: Machining, 1967, pp. 252-253, 255-256.

4. R. L. Jolley et al., Low-Level Radioactive Waste From Commercial Nuclear Reactors, ORNL/TM--9846, Vol. 2, May 1986.

5. L. E. Doyle, Manufacturing Processes and Materials for Engineers, New Jersey: Prentice-Hall, Inc, 1969, pp. 655-665.

6. G. R. Darnell, W. C. Aldrich, Low Speed Shredder and Waste Shredability Tests, EGG-22266, April 1983.

7. G. Loomis, D. Osborne, M. Ancho, Executive Summary of the Cryofracture Demonstration Program, EFF-WTD-9916, September 1991.

8. D. Osborne, M. Winberg, Test Plan for Cryofracture Demonstration, Sampling, and Analysis, EFF-WTD-9780, July 1991, pp. 1-2,14.

9. D. Osborne and W. Scheib, Test Report For Cryofinculure DiM Demonstration, NRT 3001-5, Rev. 1, September 1991.

10. W. J. Savage Company, "Turning from water wheels to abrasive saws," Tooling and Production, 56, May 1990, pp. 101-102.

11. Mark Lowell, Jr. "Lasers gain trust," Tooling and Production, 56, August 1990, p. 169. 


\section{METAL RECOVERY (TT15000)}

The mixed and low level wastes at INEL include many streams that include contaminated metal components and metal construction or structural materials. The most common types of contaminated metals include mild steel, stainless steel, aluminum, copper, nickel, and brass. Smaller amounts of heavy metals occur. Metals are undesirable components in the leedstreams of most incinerator processes designed to combust the organic waste components. In some waste streams, metals take up relatively small space compared to combustible or inert materials, but can be a considerable fraction of the total weight of the waste streams. Bulk metals may be relatively unchanged physically in lower temperature nonslagging incineration processes, and exit the process as in-homogeneous components of the bottom ash, which may require further treatment. In higher temperature slagging incinerators, metals may melt, oxidize, devolatilize or remain unchanged, depending on the metal, metal size, and operating temperature and conditions. The degree of metals oxidation and devolatilization that does occur in incineration is not desirable, since the devolatilized metal and metal oxide vapors are generally hazardous and may be radiouctive. These vapors must be removed from the flue gas in the off-gas treatment system.

Some metals in waste streams are worth recovering from waste streams for reuse. However, significant limitations of the feasibility of metals recovery processes exist for low level waste streams. First, the concentrations and physical form of recoverable metals is important. Relatively in homogeneously grouped metals may be physically removed by hand, screens, or gravity from the waste stream. Second, the purity of the recovered metals determines if the metals can be recycled. Recovery purity depends on variables such as the recovery process and concentrations of the desired metals and undesired contaminants. Therefore, effective metals recovery for recycling from low level wastes may be limited.

The most common metals recovery operations include:

- Acid leaching

- Filtration

- High temperature metals recovery

- Ion exchange

- $\quad$ Retorting

Filtration and ion exchange technologies are discussed in Sections 1 and 4 of this report volume. High temperature metals recovery technologies are discussed in Section 9. Acid leaching and retorting technologies are not discussed here because of their limited expected applicability to low level wastes. The following section includes further discussion on high temperature metals recovery.

Section Technology

High Temperature Metals Recovery 


\subsection{High Temperature Metals Recovery $(T T 15100)^{1,2,3,4,5,6,7,8,9}$}

High temperature metals recovery technologies (metal melting) include many different types of processes, some of which are discussed in Section 9 on vitrification. The most commonly recovered metals using melting technologies include cadmium, chromium, lead, nickel, and zinc. Metal melters may be heated by electrical induction heating or by plasma arc. Fossil-fired melters are also used, but are less desirable due to temperature limitations and, especially in low level waste metal melting, due to the increased amounts of off-gas.

When contaminated metal and slagging material is placed in the furnace and melted a slag phase forms and floats on top of the metal phase. Fluxing agents may improve the slag separation. Melter operational variations in temperature, mixing, and oxidizing/reducing conditions will significantly affect the two phases. Radioactive contaminants will tend to oxidize and concentrate in the slag phase, leaving the metal phase relatively free of contamination. The slag and metal phases are removed separately from the melter through separate taps. The metal can be solidilied into a convenient shape for disposal or other use. The slag phase containing the bulk of the contamination, can be cooled into a vitrified slag that may be acceptable for disposal as is, or may be further treated to improve isolation characteristics.

Any combustible and volatile materials, including volatile metals and metal oxides, will enter the off-gas. The off-gases require treatment using systems discussed in Section 14 to remove hazardous and radioactive materials from the off-gas prior to being emitted to the atmosphere.

\section{Input Streams}

Input streams are wastes containing metals (mild steel, stainless steel, aluminum, copper, nickel, brass, etc.), metal oxides, and metal salts. Contaminants can include combustible, hazardous and radioactive materials. Fluxing agents or additives to improve the slag waste form characteristics may also be added.

\section{Output Streams}

Output streams are metals reduced in contamination, contamination rich slag, off-gases formed in the furnace, and byproducts of the off-gas treatment systern.

\section{Advantages}

Advantages include the phase separation of relatively decontaminated metals from the more contaminated, slag-forming nonmetals and metal oxides. For the metal phase, decontamination factors of 100 and TRU levels of less than $10 \mathrm{nCi} / \mathrm{g}$ are possible. The slag can be processed further to concentrate and recycle radioactive elements. Depending on the melting process, the final form of the contaminated slag phase can be a well immobilized, leach-resistant vitritied glass or basaltic material. The metal phase may be readily disposed of or recycled. 


\section{Disadvantages}

Disadvantages include: (1) some waste sorting and size reduction of metal components may be required, (2) large scale tests for low level wastes have not been performed, (3) tiic required treatments for the slag and the final waste form acceptance criteria have not been established, (4) the process operates at extremely high temperatures and volatilization of metals and metal oxides will need to be addressed, (5) materials such as shielding blocks made from contaminated, melted metal scrap are not releasable for unrestricted use because U.S. regulations do not permit free release of this kind of material, (6) purity of the recovered metal is highly dependent upon process variables, and (7) recovered metals that are not of the specified purity are not recyclable without further processing.

\section{Technology Status}

Emerging: Metal melting in the metals industry is a well established, operational and conventional technology. Use for metals recovery and decontamination from low level waste streams has not been extensive.

The Scientific Ecology Group, Inc. (SEG) is building a Metal Melt Facility, commence operation in early 1992. The new Metal Melt Facility is designed to process current and luture inventories of contaminated metals. The 20-ton induction furnace will mold high-density, customized shielding blocks out of contaminated or activated metal for use in major DOE high-energy physics programs. This melting process provides effective decontamination by phase separation, enabling beneticial reuse of the contaminated metal. Presently, surplus nonradioactive steel is used as shielding for radioactive materials at DOE high energy physics facilities. This steel becomes radioactive through its use as shielding. This steel shielding later becomes additional radioactive waste requiring expensive disposal and continued surveillance. Contaminated materials processed in the new SEG melter are considered an attractive source of shielding for the current and next generation of high energy physics facilities.

The SEG facility consists of the preconditioning area, the preheater area, the induction and/or alloying furnace area, the cooling and mold stripping area, and the final treatment and shipping area. In the preconditioning area, scrap metal will sized and sorted to suit the furnace charge. The scrap will be segregated into mild steel, stainless steel, aluminum, copper, nickel, and brass. The purpose of this preconditioning, sizing, and sorting is to permit longer melt campaigns with the same type of material.

The gas fired preheater dries the scrap metal and burns away any oils or other combustible material so it can be placed safely in the induction furnace. The preheater can preheat several tons an hour, reaching a maximum temperature of $538^{\circ} \mathrm{C}\left(1,000^{\circ} \mathrm{F}\right)$.

The 20-ton hydraulically tilted induction furnace is equipped with a refractory lid to reduce heat loss. Feed stock from the preheater is placed in the furnace. Fluxes are added to obtain the desired material quality for the production of the shield blocks or the alloyed material. The metal is then poured into the ingot mold by tilting the furnace hydraulically. 
After the molds are filled, the solidified metal is stripped from the mold with a hydraulic plunger. The samples are assigned unique identification numbers, and the activity in the ingots are verified.

Waste generated during processing will be volume reduced at the SEG-Oak Ridge facility to minimize its final disposal volume (supercompaction, incineration, and solidification). 


\subsection{References}

1. W. S. Roesener, EG\&G Idaho, Inc. Process Engineering, to M. R. Martin. EG\&G Idaho, Inc., "Report On Trip To Oak Ridge, Tennessee To Visit Scientific Ecology Group (SEG) and Toxic Substances Control Act (TSCA) Incinerator", WSR-04-9, March 18, 1992.

2. Treatment of Low- and Intermediate-Level Solid Radioactive Wastes, Technical Reports Series No. 223, Vienna: International Atornic Energy Agency, 1983.

3. B. Heshmatpour and G. L. Copeland, Effects of Slag Composition and Process Variables on Decontamination of Metallic Wastes by Melt Refining, ORNL/TM-7501, January 1981.

4. B. Heshmatpour, G. L. Copeland, and R. L. Heestand, Decontamination of Transuranic Waste Metal by Melt Refining, ORNL/TM-7951, December 1981.

5. B. Hesmatpour, G.L. Copeland, and R. L. Heestand, Decontamination of Transuranic Waste Metals by Melt Refining, Nuclear and Chemical Waste Management, Vol. 4, pp. 129-134, 1983.

6. E. Schuster, K. H. Trummer, G. Hotmann, "Laboratory Scale Melt Experiments with ${ }^{241}$ Am, ${ }^{55} \mathrm{Fe}$, and ${ }^{60} \mathrm{Co}$ Traced Austenitic Steel Scrap," proceedings of the Waste Management '88 Conference, Vol. 2, pp. 859-864, 1988.

7. E. Schuster and E. W. Haas, Behavior of Actinides and Other Radionuclides that are Difficult to Measure in the Melting of Contaminated Steel, EUR-12875, 1990.

8. M. G. Seitz, T. J. Gerding, and M. J. Steindler, Decontamination of Metals Containing Plutonium and Americium, ANL-78-13, June 1979.

9. L. Rosengrant, Treatment Technology Background Document, U.S. Environmental Protection Agency Office of Solid Waste, EPA/530-SW-90-059Z, January 1991. 


\section{PHYSICAL/CHEMICAL TREATMENT (TT16000)}

The technologies presented in this section include those involving some type of chemical reaction as the primary mechanism for treatment and/or separation. This class includes oxidation/reduction reactions, solvolytic reactions (such as hydrolysis), affecting solubility, and acid/base reactions. These technologies cover a wide range of reactions and the underlying principles of many of them are similar.

Specific types of physical/chemical treatment processes and their applicability to particular waste types are discussed as follows:

$\begin{array}{ll}\text { Section } & \text { Technology } \\ 13.1 & \text { Electrolytic Oxidation } \\ 13.2 & \text { Alkali Metal Dechlorination } \\ 13.3 & \text { Alkali Metal/PEG Dechlorination } \\ 13.4 & \text { Neutralization } \\ 13.5 & \text { Oxidation/Reduction } \\ 13.6 & \text { Solvent Extraction } \\ 13.7 & \text { Soil Washing } \\ 13.8 & \text { Controlled Water Reaction } \\ 13.9 & \text { Photochemical Dehalogenation }\end{array}$

\subsection{Electrolytic Oxidation (TT16200) $)^{1,2,3,4}$}

The process is based on the reactions occurring at electrode surfaces. Cathodes and anodes are immersed in a tank containing a waste to be oxidized, and a direct electrical current is imposed on the waste system. The process is particularly applicable to aqueous wastes containing cyanides and dissolved metals. The cyanide ions are electrically decomposed and oxidized to ammonia and/or urea, nitrogen, and carbon dioxide. Metal ions are reduced to the elemental metal and are plated out on the cathodes. Electrolytic oxidation can treat wastes containing up to $10 \%$ cyanide.

The effectiveness of electrolytic oxidation is dependent uron the waste characteristics and the system design and operating characteristics. Waste characteristics affecting performance include the conductivity of the waste, which is dependent upon the liquid solvent and on the concentrations of dissolved cyanide ions, other oxidizable constituents, and reducible metal ions. Furthermore, as electrolysis continues conductivity of the waste decreases as the concentrations of oxidizable and reducible species is reduced. Thus, the electrolycic reaction becomes incrementally less efficient as the retention time increases.

The design and operating parameters that affect performance include operating temperature, residence time, electrode spacing and area, and the degree of mixing. The process is usually operated at elevated temperatures, typically in the range of 52 to $93^{\circ} \mathrm{C}\left(125\right.$ to $200^{\circ} \mathrm{F}$ ). In addition to temperature, both cell current and voltage are measured to monitor process performance. 
Since electrolytic oxidation is typically operated as a batch process, retention time is important to provide sufficient time to effectively destroy the cyanides in the waste. The retention time will depend not only on the initial cyanide concentration but also on the desired final concentration acceptable for discharge. Because the rate of cyanide destruction decreases as the cyanide concentration decreases, retention time is not a linear function of concentration. Typical retention times range from several hours to a week or longer.

The solution must be maintained in the alkaline range, typically $\mathrm{pH} 11.5$ to 12.0 , to prevent conversion of cyanide to hydrogen cyanide that would be liberated as the gas. Addition of caustic or lime can be used to control pH. Also, the electrical conductivity of the solution must be high enough to allow the electrolytic reaction to proceed at an acceptable rate. Conductivity can be increased by addition of a supporting electrolyte, such as salt.

The electrolytic reaction rate increases with higher current density in the cell. Current density is increased by closer electrode spacing, increased electrode surface area, and/or increased voltage.

The process requires good mixing in the reaction vessel to ensure an adequate supply of oxygen for the reaction, enhance mass transfer to promote the oxidation reaction, and keep any suspended solids present in suspension. Mixing can be provided either by mechanical agitation, recirculation, or sparging with air. The latter mechanism has the added advantage of ensuring adequate mass transfer for introducing oxygen.

\section{Input Strearns}

Electrolytic oxidation is used to treat aqueous wastes containing dissolved cyanide and metals. Solids must be dissolved in the liquid waste before undergoing reaction. Suspended solids are acceptable, but they will not undergo reaction.

\section{Output Streams}

Electrolytic oxidation reclaims metals and oxidizes cyanides. When treating aqueous cyanide bearing wastes, output streams include (1) gaseous ammonia, nitrogen, and carbon dioxide, (2) treated aqueous waste, and (3) elemental metals plated onto cathodes.

\section{Adraritages}

Advantages of electrolytic oxidation include (1) the ability to treat a wide variety of aqueous wastes containing high levels of cyanides with destru ction efficiencies of $99.9 \%$ for cyanide and recoveries ranging from $90 \%$ ipwards for common me tals and (2) the process provides the potential for recovery of metals for recycle or disposal.

\section{Disadvantages}

Disadvantages of eletrolytic oxidation include (1) the process is not useful for most dissolved organics, organic wastes, viscous, tarry liquids, or other low conductivity wastes, (2) solids must be dissolved, (3) the process is nonselective so competition with other oxidizable species can occur, (4) the process requires long process times, and (5) process is a batch operation. 


\section{Technology Status}

Available: Electrolytic oxidation has been used in electrolytic regeneration of spent copper plating and pickling solutions. The treatment technology is widely used tor the destruction of high concentrations of cyanides in a variety of wastes from the metals processing industry. Other metals that have been recovered by this process include gold, silver, nickel, zinc, and cadmium.

\subsection{Alkali Metal Dechlorination ( $(T 16300)^{1,5,6,7,8}$}

In alkali metal dechlorination, chlorine is chemically displaced from chlorinated organic compounds contained in oils and organic liquid wastes. The great affinity of alkali metals tor chlorine (or any halide) is the chemical basis of the process. The process can be applied to a variety of chlorinated organics including polychlorinated biphenlys (PCBs), dioxins, solvents, and pesticides. The halogenated compound structure can be either aliphatic or aromatic. Removal of the chlorine lessens the hazardous nature of chlorinated compounds, and can also split chlorinated molecules.

In typical applications, the waste is filtered, dewatered, and dried of moisture if necessary, since alkali metals are highly reactive with water. The prepared waste is introduced into a reactor contacting with the reagent. Usually the reactor is blanketed with an inert gas such as nitrogen because alkali metals are also highly reactive with oxygen. Following treatment, additional tiltration or centrifugation may be required. In addition to use of a reactor system, the process has been modified for in situ or excavation technique applications.

\section{Input Streams}

Alkali metal dechlorination is used on organic liquids, oils, soils, and sludges. Matrices amenable to treatment include mixed waste. However, the process is not applicable to aqueous wastes or wastes containing water or moisture.

\section{Output Streams}

Output streams include alkali metal-chloride salts and the treated waste, which contains dechlorinated aliphatic and aromatic compounds. In some cases, the residues may include polymers and heavy metals as well.

\section{Advantages}

Advantages of alkali metal dechlorination include (1) results in high destruction efficiencies, typically $95 \%$ or higher for PCBs, (2) can be used to treat a varicty of waste matrices, and (3) the process does not necessarily destroy the hydrocarbons, providing the possibility for recycling if appropriate.

\section{Disadvantages}

Disadvantages of alkali metal dechlorination include (1) laboratory-scale tests are required to test reagent/waste compatibility, (2) the potential exists for forming hazardous residues, and (3) a 
potential fire hazard exists because of the reactivity of the alkali metals with air, oxygen, and moisture so the process must be conducted in an inert atmosphere.

\section{Technology Status}

Available: Goodyear Tire and Rubber Company (1980), American Mobile Purification, Sun Ohio, PPM Inc., Acurex, Chemical Waste Management Inc., and Exceltech Inc. are all companies that have systems for dechlorination using an alkali metal.

\subsection{Alkali Metal/PEG Dechlorination (TT16400) ${ }^{1,5,6,7,8}$}

This process is a modification of the alkali metal process, to chemically remove chlorine from chlorinated organics of all types, including PCBs and dioxins. The reagents for this process are a mixture of an alkali metal hydroxide and polyethylene glycol (PEG). Using this process certain classes of chlorinated organics in contaminated organic liquids, sludges, and soils can be successfully dechlorinatec. The process reduces the toxicity of materials but increases the volume.

In the reagent mixture, the alkali metal is present as a cation that is held in solution by the large polyethylene glycol anion. PCBs and other halogenated organics have a high solubility in the reagent mixture, producing a single-phase system in which the anions readily react to displace the chlorine atoms. In the case of chlorinated aromatics, the reaction produces a PEG ether that can subsequently decompose to a phenol.

The reagent reacts with the chlorinated organic and displaces the chlorine to produce a lower toxicity, water-soluble material. The mechanism for dechlorination involves nucleophilic displacement of chlorine atoms by PEG to form an alkali metal chloride (typically $\mathrm{KCl}$ or $\mathrm{NaCl}$ ) and a substituted organic. Use of potassium can improve reactivity in comparison to sodium. Other variations of this basic process are available as well. For instance, dimethyl sulfoxide (DMSO), when added to the potassium polyethylene glycol (KPEG) process, can improve the extraction of dioxin from the organic phase into the immiscible aqueous reagent phase.

The process can be operated either under ambient or elevated temperature conditions. Typically, the mixture is heated to reduce the viscosity of the reagent. The process can be applied using a reactor system similar to that used for the alkali metal process. Reaction times at elevated temperatures, e.g., 50 to $100^{\circ} \mathrm{C}\left(122\right.$ to $\left.212^{\circ} \mathrm{F}\right)$ range from $10 \mathrm{~min}$ to $2 \mathrm{~h}$. Typical process operations include pretreatment, decontamination, and clarification. Pretreatment can include separation of the water and organic phase, if required, and filtration to remove solids. Radio frequency or microwave heating is used for in situ heating. Reagent preheating is typically used for removal, treatment, or disposal processes.

In situ dechlorination should be used in situations with uniform, shallow, soil contamination where conventional agricultural equipment can mix the soil and reagent. If the contaminated soil is deeper than 0.3 to $0.6 \mathrm{~m}$ ( 1 to $2 \mathrm{ft}$ ). or if high concentrations are apparent, the soil can more suitably be excavated and then dechlorinate it after it is made into a slurry. One advantage of removing the soil to dechlorinate it is that unused reagent can be recovered and recycled. This will offset some of the cost of removal, especially if large amounts of reagent are required to dechlorinate the waste stream. 


\section{Input Streams}

Alkali metal combined with PEG can be used to treat a variety of chlorinated organic compounds such as PCBs, dioxins, chlorinated hydrocarbons, chlorinated acids, and thiols. Matrices amenable to treatment include mixed waste, wastewater, sludges, liquids other than water, and soils.

\section{Output Streams}

Output streams include chloride salts, polymers, and lower toxicity, water-soluble materials. Output streams are in the form $\mathrm{f} f$ water, sludges, slurries, and/or soils.

\section{Advantages}

Advantages of alkali metal combined with PEG include (1) the process is quite environmentally safe, (2) transformer oils are cleaned for reuse, not destroyed, (3) the process can be accomplished onsite with a mobile unit, eliminating unnecessary handling of the waste material. (4) a wide range of PCB concentrations can be treated, (5) most systems can be completely enclosed, (6) unused reagents can be recovered and recycled. (7) process costs are significantly less expensive than incineration for disposal of transformer fluids, and.(8) estirnated costs are less than or within the range of costs of chemical waste landfill.

\section{Disadvantages}

Disadvantages of alkali metal combined with PEG include (1) the possibility exists for side reactions to occur that generate hazardous constituents and (2) heat and excess reagents are required for the process to function effectively in matrices containing more than $7 \%$ moisture.

\section{Technology Status}

Available: Chemical Waste Management, Accurex, PPM Inc., and Sun Ohio have mobile treatment systems for PCB contaminated oils. One system has a capacity of up to 10,000 gpd and is used for oils with less than 10,000 ppm PCBs and less than 2000 ppm water.

In situ treatment is developmental. General Electric developed and uses glycol reagent to destroy PCBs in soil. Galson Research Corporation developed alkali polyethylene glycolate (APEG) that can be catalyzed by dimethyl sulfoxide (DMSO) to increase the rate of reaction by increasing the alkalinity (strength) of the potassium polyethylene glycol (KPEG). A bench-scale unit was tested on PCB contaminated soil during August of 1987. A pilot-scale unit was tested in late 1987. These tests were done by Galson Research Corporation.

\subsection{Neutralization $(\mathrm{TT} 16600)^{7,9,10}$}

Neutralization is used to adjust basic or acidic waste to an acceptable $\mathrm{pH}$ range (usually between $\mathrm{pH} 6.0$ and $\mathrm{pH} 9.0$ ). The $\mathrm{pH}$ is adjusted by adding alkaline wastes or chemical reagents to acidic wastes and vice versa. Neutralization is used to treat wastes in order to reduce or eliminate their reactivity and corrosiveness. The process can be operated either batch or in a continuous mode depending upon application. Equipment needs are modest consisting of pumps, tanks, mixers, and 
$\mathrm{pH}$ instrumentation for control. Besides modest capital requirements, operating costs can be inexpensive. The only major requirement is that adequate mixing should be provided to ensure complete reaction. As an option, a second reactor stage may also be provided. Equalization takes place during the second stage where further mixing occurs, allowing time for the neutralization reactions to reach equilibrium. Care must be taken to ensure compatibility of the waste with the treatment chemicals to prevent formation of significant solids or hazardous byproducts. Liquids, slurries, and sludges are all amenable to treatment by neutralization. In situ neutralization involves injecting dilute acids or bases into the ground to either optimize $\mathrm{pH}$ for further treatment or to neutralize plumes so that further treatment is not necessary.

\section{Input Streams}

Neutralization can be used on either organic or inorganic, spent acidic and alkaline wastes. The process can be used on liquids, slurries, sludges, and even gases under appropriate conditions.

\section{Output Streams}

The residual includes a neutralized ( $\mathrm{pH}$ between 6 and 9) effluent containing dissolved salts and possibly suspended solids. Residuals çan be in the form of a liquid, sludge, slurry, or gas.

\section{Advantages}

Advantages of neutralization include (1) the process is simple, using readily available equipment, (2) it is reliable and can be automated, (3) the process can be applied in sitl., (4) it can be applied either continuously or as a batch operation, and (5) overall treatment costs are normally quite modest.

\section{Disadvantages}

Disadvantages of neutralization include (1) construction materials must be resistant to corrosivity of the wastes and reagents, (2) the potential exists for hazardous violent, and or exothermic, reactions to occur in the neutralization process, and to produce air emissions in some cases, and (3) the byproducts can be hazardous.

\section{Technology Status}

Available: Ecolochem, Inc. has developed a mobile water treatment plant for cleanups of up to $600 \mathrm{gpm}$. Rexnord has a system to treat 1 to $10 \mathrm{gpm}$ for groundwater and includes neutralization, clarification, air stripping, filtration, carbon adsorption, reverse osmosis, ion exchange, and sludge dewatering systems. Envirochem Waste Management Services, Inc. has developed a mobile system that includes neutralization, phase separation, heavy metal precipitation, and carbon filtration system capable of treating 4.000 gpd. Chemical Waste Management, Inc., has a mobile system capable of treating up to $100,000 \mathrm{gpd}$ for metals removal. It uses oxidation, precipitation, neutralization, and filtration processes. Detox, Inc. offers custom systems as mobile units. 


\subsection{Oxidation/Reduction (TT16700) $)^{1,11,12,13,14,15,16}$}

Reduction-oxidation (redox) reactions chemically transform reactants to increase the oxidation state of one reactant, and decrease the oxidation state of the other reactant. This process is used to destroy, or at least reduce the toxicity, of many toxic organics and heavy metals. This method can also be done in situ. The use of reducing agents is less common than oxidizing agents because of the high reactivity of the reducing agents.

Redox reactions can be used to detoxify, precipitate, or solubilize metals and decompose, detoxify, or solubilize organics. Oxidizing agents commonly employed include hypochloride or chlorine, ozone, hydrogen peroxide, and permanganate. Commonly employed reducing agents include sulfur dioxide, sodium borohydride, sulfite, ferrous ion, and hydrazine.

The effectiveness of redox processes in treating wastes depends not only upon characteristics of the specific waste but also on system design and operating parameters. Depending on the particular species of interest, the waste characteristics of importance are the cotal concentration of other oxidizable/reducible species present, the concentration of metal salts, and the concentration of oil and grease. The presence of other oxidizable/reducible species will increase the demand for reagents, thus potentially reducing the effectiveness of the process. Likewise, metal salts, particularly lead and silver salts, can react with various oxidizing agents to form insoluble compounds such as chlorides, chlorates, hypochlorites, peroxides, and sulfites. This can cause excessive consumption of the oxidizing agent and reduce the effectiveness of treatment. Finally, oil and grease can potentially cause problems because of fouling of monitoring and control instrumentation such as $\mathrm{pH}$ and oxidation/reduction potential (ORP) probes. For efficient process operation, waste characterization and homogeneity of waste composition are important considerations.

The important system design and operating parameters include residence time, reagent choice and amount, the degree of mixing, system $\mathrm{pH}$, operating temperature and choice of catalyst, if required. The selection of appropriate system residence time is important to ensure complete reaction while minimizing devolatilization of waste components or byproducts.

The choice of reagent and addition rate are influenced by several factors. The amount of reagent required will vary with the agent chosen. Enough reagent must be added to ensure complete reaction with all available species, while the specific amount depends upon the nature of the reactant species in the waste and the detailed redox chemistry involved. In practice, reagent addition is in excess of stoichiometric requirements to account for variability in waste composition and mixing, and ensure complete reaction.

The degree of mixing must be sufficient to prevent stagnation and concentration gradients in the reagent-waste mixture. Proper mixing will ensure maximum contact between reagent and the waste. It can also limit the production of solids from side reactions. These solids could potentially resist further reaction, decreasing the eflectiveness of the process.

The selection of the optimum system operating $\mathrm{pH}$ is important to maximize the effectiveness of the redox chemistry. In addition, selection of the proper $\mathrm{pH}$ can eliminate or minimize unwanted side reactions. Finally, selection of proper $\mathrm{pH}$ may be required to maintain reactant species, such as cyanide, in the proper form and prevent their unwanted release. 
Selection of appropriate operating temperature is important because it affects the rate of the redox reactions and the solubility of the reagent and waste. Reaction rates increase with temperature, and in most cases solubility also increases with temperature. Thus, typically the process is operated at elevated temperature to improve the reaction kinetics and reduce the required system residence time.

In some cases the use of an appropriate catalyst may allow operation at a lower temperature and/or improve the level of destruction of the target waste components. Typical catalysts for oxidation include copper nitrate and copper bromide.

The redox process can be operated in either the batch or continuous mode. Equipment requirements are modest, consisting of standard process equipment. This includes equipment such as chemical feed systems, tanks, pumps, agitators, and instrumentation for control and monitoring. At a minimum, instrumentation will consist of $\mathrm{pH}$ and ORP monitors. The latter would be used to monitor the effectiveness of the process. However, since ORP is nonspecific, waste characterization and homogeneity of waste composition is important to ensure the effectiveness of the process.

For proper treatment and disposal of the waste, additional system operations such as pretreatment and posttreatment may be required. Pretreatment might include size reduction and filtration, while posttreatment might include clarification or filtration. The requirements will depend on the specific waste being treated.

\section{Input Streams}

This process can be used on aqueous wastes, liquids, sludges, and slurries. Contaminants amenable to treatment include cyanide, aldehyde, mercaptans, phenols, benzidine, unsaturated acids, pesticides, benzene, arsenic, iron, manganese, chromium VI, mercury, lead, silver, chlorinated organics, and unsaturated hydrocarbons.

\section{Output Streams}

Efiuents will include liquids, gases, and possibly solids. The gases will include primarily carbon dioxide and water vapor. The liquids will be aqueous systems containing primarily salts and simple inorganic acids or bases. The solids will include precipitates tormed during the process.

\section{Advantages}

Advantages of oxidation/reduction include (1) the process is simple, and uses readily available equipment and reagents, (2) capital, operating, and maintenance costs can be low, (3) the process can be operated either continuously or batch, and (4) is applicable to a wide variety of waste constituents.

\section{Disadvantages}

Disadvantages of oxidation/reduction include (1) implementation is sometimes difficult because the system must be designed for the specific application, (2) laboratory and/or pilot-scale testing is required, (3) the reagents themselves are often hazardous, (4) the possibility exists for undesirable 
side reactions or the production of hazardous byproducts, (5) process control is difficult if waste composition varies significantly, and (6) the process cannot be used to treat solids.

\section{Technology Status}

Available: Rexnord has a system that treats groundwaters with volatile organics, extractable organics, and heavy metals at a rate of 1 to $10 \mathrm{gpm}$. Andco Environmental Processes, Inc. has a 50 gpm system equipped with an electrochemical process to remove heavy metals. Envirochem Waste Management Services, Inc. and Chemical Waste Management, Inc. have a mobile system. ATW Calwelu has in situ systems. REDOX, Inc. has a mobile treatment system. Ensotech, Inc. has a system that processes 20 to $120 \mathrm{gpm}$. The Ensotech system is mobile and includes chemical RESOX, neutralization, precipitation, and immobilization. This process has been effective in treating wastewaters from the pulp industry, food industry, pesticide manufactures, synthetic fibre industries, refining plants and hydrolysis, etc.

\subsection{Solvent Extraction (T16800) $)^{1,17,18,19,20,21}$}

Solvent extraction involves passing a solvent through a mixture that has both soluble and insoluble components. The solvent dissolves and removes the soluble component, leaving behind the insoluble component. Extraction is used primarily to treat wastes containing a variety of organic constituents. The selection of the proper extraction tluid is dependent on the selective solubility of the organic and the other components, such as inorganics and the waste matrix.

Two variations exist for this basic process. The first is liquid extraction (LE) and the second is supercritical tluid extraction (SFE). The primary differences between the two processes are the operating temperatures and pressures used, and whether the solvent is a liquid or a supercritical fluid. The SFE process operates at an elevated temperature and pressure, depending on the choice of tluid, to take advantage of supercritical properties of the solvent.

In the simplest extraction system, the waste and tluid are mixed or otherwise brought into intimate contact to allow mass transter of the solute from the waste to the solvent. For the process to operate effectively, only the solutes must be highly soluble in the solvent. The remainder of the waste must be insoluble in and immissible with the fluid.

In its current stage of development, SFE is a batch process. On the other hand, LE can be operated in either the batch or continuous mode. For LE, standard processing equipment is required consisting of tanks, agitators, pumps, settlers or clariliers, and instrumentation and controls. The simplest LE system is a single stage unit consisting of a mixer followed by a settler. The solvent and waste are mixed together and introduced into the settler to separate the extract (solvent containing the solute) and the residual. More effective treatment can be provided by using multistage units or extraction columns.

For SFE, the waste is contacted by the fluid in a high pressure extraction vessel. The solute is separated from the extract downstream in a separator vessel when pressure letdown reduces the solubility of the solute in the fluid. Extraction is performed in a flow-through mode with solvent recycle. For SFE, equipment requirements include pressure vessels, compressors and instrumentation and controls. 


\section{Input Streams}

Solvent extraction can be used to remove contaminants from wastes ranging from wastewaters and liquids to sludges and soils. The process has been used to extract a wide variety of contaminants including carbon tetrachloride, chloroform, benzene, naphthalene, gasoline, vinyl acetate, furfural, butyric acid, higher organic acids, dichloroethane, oils and grease, xylene, toluene, methyl acetate, acetone, higher alcohols, butanol, propanol, phenol, heptane, PCBs, and other complex organics. It has also been used on creosote-saturated sludge, slop oil emulsion solids, heat exchanger bundle cleaning sludge, API separator sludge, primary and secondary oils/solids/water separation sludges, biosludges, cooling tower sludges, HF alkylation sludges, waste FCC catalyst, spent catalyst, Stretford unit solution, tank bottoms, and treated clays.

\section{Output Streams}

Output streams include (1) treated solids, slurries, wastewater, sediments, sludges, and soils, (2) solvent extract, and (3) solute recovered from the extract.

\section{Advantages}

Advantages of solvent extraction include (1) solvents can be recovered and recycled, (2) this process can remove PCBs, which prevents shipping large quantities of contaminated oil to a destruction site, (3) solvent extraction can reduce the volume of some waste streams, and (4) extraction efficiencies up to $99 \%$ have been obtained in selected cases.

\section{Disadvantages}

Disadvantages of solvent extraction include (1) solvent extraction is not always applicable to a waste stream that has a water soluble component due to reactivity ol components, (2) solids may be retained in the system hardware and foaming may occur in receiving tanks, (3) when using some solvents, such as triethyl amine (TEA), the treatment system must be operated under a nitrogen blanket because of the reactivity with oxygen, (4) when treating large quantities of dilute wastes, solvent extraction can not compete economically with other treatment processes such as biological oxidation or adsorption, and (5) complete separations are rarely achieved, necessitating some type of posttreatment.

\section{Technology Status}

Available: Union Carbide Corporation (Oak Ridge Y-12 Plant) has a system that removes chlorinated hydrocarbons (including PCBs) from transformer oil using dimethyl formamide solvent. Results were obtained from the New Bedford (Massachusetts) Harbor Superfund Site in September 1988 on PCB-laden sediments that used a liquified propane and butane mixture as the extraction solvent.

Clean Harbors (Braintree, Mass); ENSCO (Little Rock, Arkansas); Star Enterprise (Port Arthur, Texas) all have used solvent extraction to treat wastes. The tirst full-scale BEST unit was used at the General Refining Superfund site in Garden City, Georgia. Solvent Extraction is the 
selected remedial action at the Pinnete's Salvage Site in Maine and is the preferred alternative at the F. O'Conner site in Maine.

The Extra kSol process is scheduled to be tested at a U.S. site containing PCBs in April 1991. Testing previously done with the unit has shown it can lower PCB levels in clay-bearing soils by as much as $92 \%$, PAHs in refinery oily sludge by $96 \%$, pentachlorophenol in gravel by $99.7 \%$ and pentachlorophenol in activated carbon by $89 \%$. Numerous other commercial processes are available.

At this time, SFE is still in the developmental stage with no units being available commercially.

\subsection{Soil Washing $(T T 16850)^{22,23,24}$}

This is a solvent extraction process specifically for the removal of inorganic and/or organic contaminants from soils. The process is similar to liquid extraction (LE). Extraction is accomplished by passing the solvent through the soil using a contacting/separation process. Solvents are typically aqueous and include a variety of other constituents such as chelating agents, surfactants, redox agents, and acids or bases. The composition of the solvent is adjusted to optimize extraction efficiency for the constituents of concern. Current commercial applications have been targeted previously for PCBs. The equipment requirements are similar to those of 'LE.

\section{Input Streams}

The input streams are contaminated soils or sludges and the solvent. The solvent is usually water containing additive, such as acid or bases, chelating agents, and surfactants.

\section{Output Streams}

The output streams include the treated soil or sludge, and spent solvent extract, which contains the removed contaminant.

\section{Advantages}

Advantages of soil washing include (1) the process is simple and (2) the process requires only modest capital equipment and operating costs.

\section{Disadvantages}

Disadvantages of soil washing include (1) the process is currently still under development, with commercialization limited to removal of PCBs, (2) the solvents used must have low toxicity and be recoverable/recyclable, and (3) to date the process has proven to be only moderately effective.

\section{Technology Status}

Emerging: Sources include IT Corporation and Critical Fluid Systems. 


\subsection{Controlled Water Reaction (TT16900) $)^{1,24,25,26}$}

Controlled water reaction is a particular application of hydrolysis. Hydrolysis is the use of water as a reagent to destroy, decompose, or alter a chemical species. In general, the reaction involves the displacement of a functional group on a molecule with a hydroxyl group from water. For the specific example of organics, the reaction can be represented as follows:

$$
\mathrm{RX}+\mathrm{H}_{2} \mathrm{O}-\mathrm{ROH}+\mathrm{HX}
$$

$\mathrm{R}$ is the organic group and $\mathrm{X}$ is the leaving group. Hydrolysis of organic compounds can result from a neutral reaction with water or it can be catalyzed in the presence of an acid or a base. For the specific example of reactive metals such as the alkali metals, the reaction can be represented as:

$$
\mathrm{M}+\mathrm{nH}_{2} \mathrm{O} \rightarrow \mathrm{Me}(\mathrm{OH})_{\mathrm{n}}(\mathrm{aq})+\mathrm{n} / 2 \mathrm{H}_{2}(\mathrm{~g})
$$

This is the reaction of an active metal with water under controlled conditions to produce a metal hydroxide with the liberation of hydrogen gas. The EPA considers controlled water reaction or hydrolysis to be the Best Demonstrated Available Technology (BDAT) for the treating waste alkali metals. The process will eliminate the reactive characteristic of these metals. Performance is affected by temperature, $\mathrm{pH}$, the homogeneity of the waste mixture, and the ability to mix the waste with water.

For treating alkali metals, the metal waste will normally be received in some type of sealed containers such as metal cans or drums. These are fed manually onto a conveyor leading to size reduction equipment such as a hammer mill. The hammer mill is contained in a sealed enclosure where water is constantly introduced to initiate reaction as soon as the containers are breached. When the size of the debris is reduced sufticiently, it exits the hammer mill to a sealed reaction tank to complete reaction. Solids and liquids resulting from the process remain in the tank. Off-gas trom the process goes to a treatment system for removal of particulate. The hydrogen can then be flaredoff. Solids are filtered from the aqueous waste and the $\mathrm{pH}$ adjusted by addition of acid prior to discharge.

Typically, the process equipment will be housed in a dedicated facility designed to handle explosions. This includes reinforced walls and provision for safely venting excess pressure. During operation, the process facility is maintained at negative pressure to reduce risks of escape of hydrogen. Exhaust from the facility is vented through the ofl'-gas treatment system.

\section{Input Streams}

The process can be used to treat a wide variety of wastes including mixed waste and was e containing a variety of organics, inorganics, and reactive metals. In the application envisioned, the waste will be in the form of a solid and the reagent will be liquid water.

\section{Output Streams} residues.

The outputs consist of highly alkaline aqueous solutions, hydrogen gas, and possibly solid 


\section{Advantages}

Advantages of controlled water reaction include (1) the process is simple and highly effective, (2) capital and operating costs are modest, and (3) the reagent (water) is abundant and inexpensive.

\section{Disadvantages}

Disadvantages of controlled water reaction include (1) the reaction is highly exothermic, making the process difficult to monitor and control, and (2) production of hydrogen as a byproduct increases the hazards associated with the process.

\section{Technology Status}

Available: This is a common industrial process. The basic methods using hydrolysis to treat hazardous waste have been developed and applied in an industrial setting. However, application for hazardous waste treatment, which can be less controlled due to waste variations, has been limited. The EPA considers hydrolysis to be the BDAT for the reactive metals.

The process has been used at the INEL for the destruction of reactive metals in wastes containing sodium and sodium-potassium ( $\mathrm{NaK}$ ).

\subsection{Photochemical Dehalogenation (T16950) $8,26,27$}

This process is based upon removal of a halogen such as chlorine from a halogenated organic compound by exposure to high intensity illumination of the appropriate wavelength. This process is also discussed as a type of chemical oxidation/reduction in Section 8. The reaction typically proceeds through a free-radical mechanism, producing lree halogen or halogen acid molecules and the corresponding unhalogenated hydrocarbon. The process reduces the toxicity of the treated waste. The waste must have sufficient transparency for the light used so it can penetrate far enough into the waste to provide effective treatment.

Typical process equipment required for this process includes tanks, agitators, and pumps. In addition, a high illumination light source and a photochemical reactor are required. The combination of source and reactor must be coupled in such a way that the light from the source enters the reactor. This implies a window, wall or piping labricated trom some type of transparent material such as glass or quartz. A catalyst such as titanium oxide may be used to increase reaction rates and/or destruction efficiency.

\section{Input Streams}

This process can treat a variety of aqueous wastes containing halogenated organic compounds. Organics amenable to treatment include chlorinated insecticides and herbicides, PCBs, and dioxins. 


\section{Output Streams}

The output streams include the treated liquids, which may contain added amounts of halogen acids, and gaseous halogens. The liquids will be unhalogenated organics or water containing them.

\section{Advantages}

Advantages of photochemical dehalogenation include (1) the process does not destroy but only dehalogenates the organics, and (2) this provides the possibility of recovery and recycle.

\section{Disadvantages}

Disadvantages of photochemical dehalogenation include (1) the process is only applicable relatively transparent liquids because of the limited pathlength of light in opaque or absorbing media, and (2) process efficiency is only on the order of $90 \%$ dehalogenation.

\section{Technology Status}

Emerging: The technology is still in the developmental stage. 


\subsection{References}

1. EG\&G Idaho, Inc., Remu dial Technology Information System (RTIS) Database, EG\&G Idaho, Inc., Idaho Falls, Idaho, 1991.

2. L. Rosengrant and L. Lopez, Treatment Technology Background Document, PB91-160556, NTIS, January 1991, pp. 38-43.

3. E. C. Garcio, Mixed Waste Treatment Options for Wastes Generated at the Idaho National Engineering Laboratory, EGG.WM-9451, EG\&G Idaho, Inc., January 1991, pp. 46-47.

4. U.S. EPA, A Compendium of Technologies Used in the Treatment of Hazardous Wastes, EPA/625/8787/014, U.S. EPA, September 1987, p. 23.

5. Ibid, pp. $23-24$.

6. A. Kornel, "Dehalogenation," in Standard Handbook of Hazardous Waste Treatment and Disposal, edited by H. M. Freeman. New York: McGraw-Hill Book Company, 1989. pp. 7.53-7.63.

7. D. W. Major and J. Fitchko, Emerging On-Site and in Situ Hazardous Waste Treatment Technologies, Northbrook, Illinois: Pudvan Publishing Co., Inc., 1990, pp. 3.45-3.47.

8. R. Rodensky, D. Hammer, and M. Shuck. "Regulatory and Technological Trends in PCB Treatment and Disposal," Hazmat World, February 1992, pp. 56-60.

9. U.S. EPA, A Compendium of Technologies Ised in the Treatment of Hazardous Wastes, EPA/625/8-87/014, U.S. EPF. September 1987, p. 18.

10. E. C. Garcia, Mixed Waste Treatment Options for Wastes Generated at the Idaho National Engineering Laboratory, EGG-WM-9451, EG\&G Idaho, Inc. January 1991, p. 49.

11. Ibid, pp. $44-46$.

12. L. Rosengrant and L. Lopez. Treatment Technology Background Document, PB91-160556, NTIS, January 1991, pp. 17-3\%.

13. E. G. Fochtman, "Chemical Oxidation aid Red ,tion," in Standard Handbook of Hazardous Waste Treatment and Disposal, edited by H. M. Freeman. New York: is"cGraw-Hill Book Company, 1989, pp. 7.41-7.51.

14. D. W. Major and J. Fitchko, Emerging On-Site and In Silu Hazardous Waste Treatment Technologies, Northbrook, Illinois: Pudvan Puhlishing Co., Inc., 1990. pp. 3.39-3.41.

15. W. S. Roesener, Unit Systems for the Tritment of TRU Contaminated Waste. WM-PD-92-002, EG\&G Idaho, Inc., February 1992, p. 68. 
16. U.S. EPA, A Compendium of Technologies Used in the Treatment of Hazardous Wastes, EPA/625/8-87/014, U.S. EPA, September 1987, pp. 20-22.

17. D. W. Major and J. Fitchko, Emerging On-Site and In Situ Hazar:ous Waste Treatment Technologies, Northbrook, Illinois: Pudvan Publishing Co., Inc., 1990, pp. 3.43-3.43b.

18. J. B. Berkowitz, "Solvent Extraction," in Standard Handbook of Hazardous Waste Treatment and Disposal, edited by H. M. Freeman, New York: McGraw-Hill Book Company, 1989, pp. $677-6.89$.

19. L. Rosengrant and L. Lopez, Treatment Technology Background Documert, PB91-160556, NTIS, January 1991, pp. 157-170.

20. E. C. Garcia, Mixed Waste Treatment Options for Wastes Generated at the Idaho National Engineering Laboratory, EGG-WM-9451, EG\&G Idaho, Inc., January 1991, pp. 32-34.

21. U.S. EPA, A Compendium of Technologies Used in the Treatment of Hazardous Wastes, EPA/625/8-87/014, U.S. EPA, September 1987, pp. 11-12.

22. Ibid, p. 11.

23. D. W. Major and J. Fitchko, Emerying On-Site and In Silu Hazardous Waste Treatment Technologies, Northbrook, Illinois: Pudvan Publishing Co., Inc., 1990, pp. 3.43-3.43b.

24. A. Wilds, "Hydrolysis," in Standard Handbook of Hazardous Waste Treatment and Disposal, edited by H. M. Freeman, New York: McGraw-Hill Book Company, 1989, pp. 6.47-6.58.

25. E. C. Garcia, Mixed Waste Treatment Options for Wastes Generated at the Idaho National Engineering Laboratory, EGG-WM-9451, EG\&G Idaho, Inc., January 1991, p. 48.

26. U.S. EPA, A Compendium of Technologies Used in the Treatment of Hazardous Wastes, EPA/625/8-87/014, U.S. EPA, September 1987, p. 20.

27. P. C. Kearney and P. H. Mazzocchi, "Photolysis," in Stundard Handbook of Hazardous Waste Treatment and Disposal, edited by H. M. Freeman, New York: McGraw-Hill Book Company, 1989, pp. 7.33-7.40. 


\section{OFF-GAS TREATMENT (TT23000)}

Incineration or vitrification of mixed and low-level wastes will most gemerally require an exhaust system that can treat off-gases prior to venting those streams to the atmosphere. Essentially all thermal treatment systems may generate dusts, fly ash, gaseous products of combustion, vaporized materials, and acid gases. The volumes and composition off-gas streams will depend on the type of process and the composition and physical form of the waste being processed. For example, fossil fuel fired waste incinerators and afterburners will generate relatively large amounts of flue gas from the combined effects of the fossil fuel and organic waste combustion.

Even processes that are not fossil fuel fired, such as microwave melters, will create off-gases from devolatilization and combustion of the waste materials. These processes include pyrolysis and combustion of organic waste constituents, combustion of auxiliary fuels, generation of entrained fly ash, and devolatiiization of inert materials such as metals. Some processes such as starved-air incinerators, although designed to have low particulate emissions, will still require high efficiency particulate removal from the flue gas to minimize the venting of radioactive materials. When incinerated wastes include plastics and other halogenated materials, the off-gases will include acid gases.

Off-gas streams from thermal waste treatment processes can contain contaminants that are toxic, carcinogenic, radioactive, noxious, or irritating to animals or plants. Also included are those substances that are damaging to the environment, such as acid rain precursors. Some air pollutants also contribute to haze and visible pollution. Entrained particulate (tly ash) can include entrained dust of inert material, incompletely burned solid organics, and devolatilized/recondensed solid and liquid furnes of metals, oxides, acids, and organic material. Acid gases can include oxides of nitrogen $\left(\mathrm{NO}, \mathrm{NO}_{2}\right.$, and $\left.\mathrm{N}_{2} \mathrm{O}\right)$, sultur oxides $\left(\mathrm{SO}_{2}\right.$ and $\left.\mathrm{SO}_{3}\right)$, and halogen acids $(\mathrm{HCl}, \mathrm{HF}, \mathrm{HBr}$ ). Products of incomplete combustion can include a wide variety of hazardous organic compounds, including aliphatic, aromatic, oxygenated, cyclic, and halogenated compounds.

Off-gases must be treated prior to emission to the atmosphere to remove or reduce leveis if these pollutants to meet limits that are (1) within regulatory levels, (2) considered safe for operating personnel, surrounding communities, and the environment, and (3) acceptable to the public.

Even high efficiency air pollution control equipment cannot remove $100 \%$ of air contaminants from air and gas streams. The challenge for designing a suitable system is to determine expected input contaminant levels and acceptable levels of contaminants that can be emitted to the atmosphere. In most cases, any visible emissions (not including steam plumes) are not acceptable, and plume opacity limits are generally $20 \%$ or less. Emission limits for hazardous air pollutants may be determined using risk assessments.

Off-gas treatment operations may include particulate removal, acid gas scrubbing, removal of heavy metals, and possibly removal of products of incomplete combustion. Particulate removal is typically performed by filtration or other physical, mechanical or electrical separaticn processes, such as cyclones or electrostatic precipitators. Acid gases are typically scrubbed using either wet or dry systems. $\mathrm{NO}_{x}$ controls can include design and operational modifications to the thermal systems, or downstream $\mathrm{NO}_{x}$ removal operations such as catalytic reduction or oxidation/chelation and wet scrubbing. Heavy metal removal strategies can include reducing the thermal treatment operating 
temperat ures, reducing entrained particulate, high efficiency filtering, tlue gas cooling, scrubbing, and adsorption.

Many flue gas streams may require cooling or heating to prevent damaging pollution control equipment or to achieve desired operating temperatures. Flue gas cooling may be performed by dilution, quenching, or heat exchange. Flue gases may heated or reheated (to reach desired operating temperatures, prevent corrosion damage from moist gas or eliminate a steam plume) by direct or indirect heating, or by mixing with a hotter stream.

Off-gas treatment systems are discussed in the following sections.

\section{Section Technology}

14.1

Particulate Filtration (TT23100)

14.1.1 Baghouse (TT23120)

14.1.2 Ceramic Filter (TT23140)

14.1.3 Metal Filter (TT23160)

14.1.4 HEPA Filter (TT23180)

14.2 Particulate Separation (TT23200)

14.2.1 Gravity Separator (TT23220)

14.2.2 Cyclone Separator (TT23240)

14.2.3 Electrostatic Precipitator (TT23260)

14.2.4 Mist Eliminator (TT23280)

14.3 Acid Gas Scrubbing (TT23300)

14.3.1 Wet Scrubbing (TT23320)

14.3.2 Dry Scrubbing (TT23340)

14.4 $\mathrm{NO}_{x}$ Control (TT23400)

14.4.1 In-furnace $\mathrm{NO}_{x}$ Controls (TT23410)

14.4.2 Selective Catalytic Reduction (TT23420)

14.4.3 Selective Noncatalytic Reduction (TT23430)

14.4.4 Nonselective Noncatalytic Reduction (TT23440)

14.4.5 Nonselective Catalytic Reduction (TT23450)

14.4.6 Direct Decomposition (TT23460)

14.4.7 Oxidation and Scrubbing (Tr23470)

14.4.8 Chelation and Scrubbing (TT23480)

14.5 Heavy Metals Removal (TT23500)

14.5.1 Activated Carbon Absorption (TT23520)

14.5.2 Sodium Sulfide Injection (TT23540)

14.5.3 Other Mercury Control Processes (TT23560)

14.6 Off-gus Cooling/Heating (TT23600)

14.6.1 Air Dilution (TT23620)

14.6.2 Water Quench (TT23640) 


\subsection{Particulate Filtration (TT23100)}

Filtration is a common and efficient operation for removing particulates from flue gas streams. The most common filtration systems can include fabric filter bags, ceramic "candle" filters, sintered metal filters, and HEPA (High Efficiency Particulate Air) filters.

\subsubsection{Baghouse (TT23120) $)^{1,2,3,4,5,6,7,8,9,10}$}

A baghouse is a large filter housing containing up to several hundred long filter bags. A schematic is shown in Figure 14-1. ${ }^{2}$ Typically, the bags are cylindrical and made of tabric, although flat bags or a pleated filters are also used and ceramic and sintered metal bags are available. The bags normally hang vertically in the bag chambers, suspended from a tubesheet separating the dirty bag chamber from the clean-air plenum. As the gases enter the bag chamber, they pass through a distributor mechanism designed to spread the gas tlow throughout the chamber so a uniform, low gas velocity occurs in the chamber and a uniform dust load occurs on each bag.

In operation, a filter cake rapidly builds up on fabric surface and fills in pores in the fabric. This filter cake is less porous than the filter fabric. The filtration occurs across the filter cake, rather than across the bag material. In the absence of the filter cake, the filtration is much less efficient, because the pores in the fabric are actually bigger than particles being removed.

The bags are periodically cleaned on a cycle using reverse air tlow, mechanical shaker, or pulsejet cleaning. For high temperature continuous duty, a pulsejet baghouse is normally used. A portion of the bags in the baghouse are cleaned continuously, cycling row by row through the baghouse. The slower the cleaning cycle, the higher the overall efficiency, because the bags are in the dirty condition for longer durations. Typical pressure drops across the bags range from 1 in. $-\mathrm{H}_{2} 0$ water for clean bags to 6 in.- $\mathrm{H}_{2} \mathrm{O}$ for dirty bags. Immediately following each cleaning, a few minutes is required to recoat each bag before optimal collection efficiency is attained.

An important parameter for a baghouse is the air-to-cloth ratio, in units of actual flowrate of filtered gas divided by the fabric surface area. In general, lower air-to-cloth ratios result in higher filtration efficiency and less wear on the fabric. Lower air-to-cloth ratios require more space and require higher capital costs.

The type of fabric used impacts the degree of filtration achieved and the maximum temperature at which the baghouse can be operated. Long-term continuous operating temperatures may be as high as $218^{\circ} \mathrm{C}\left(425^{\circ} \mathrm{F}\right)$ (Nomex) to $260^{\circ} \mathrm{C}\left(500^{\circ} \mathrm{F}\right)$ (glass fiber), with somewhat higher short-term (a few hours duration) peak temperatures. Filtration performance can also be affected by whether the fabric is a weave or a felt and whether it has a surface coating or treatment. The weight of the fabric in ounces per square yard also affects bag performance. Heavier bags may haw a higher pressure drop, but will normally last longer when subjected to abrasion and physical stress. With a heavy bag material, baghouse pressure drops in excess of 15 in. $-\mathrm{H}_{2} 0$ can be sustained. 


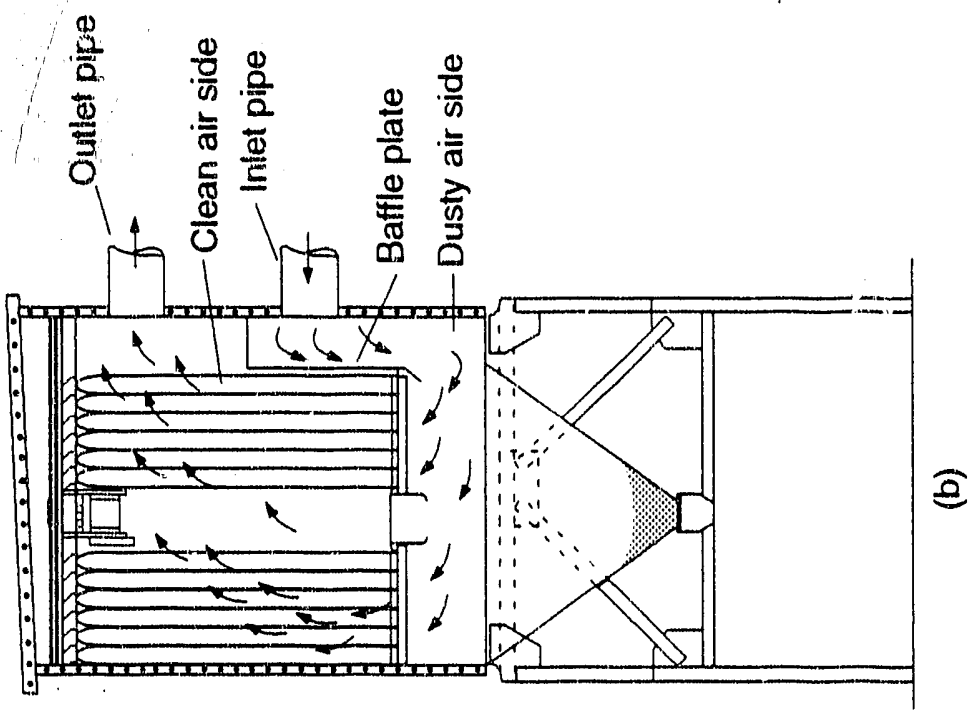

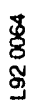
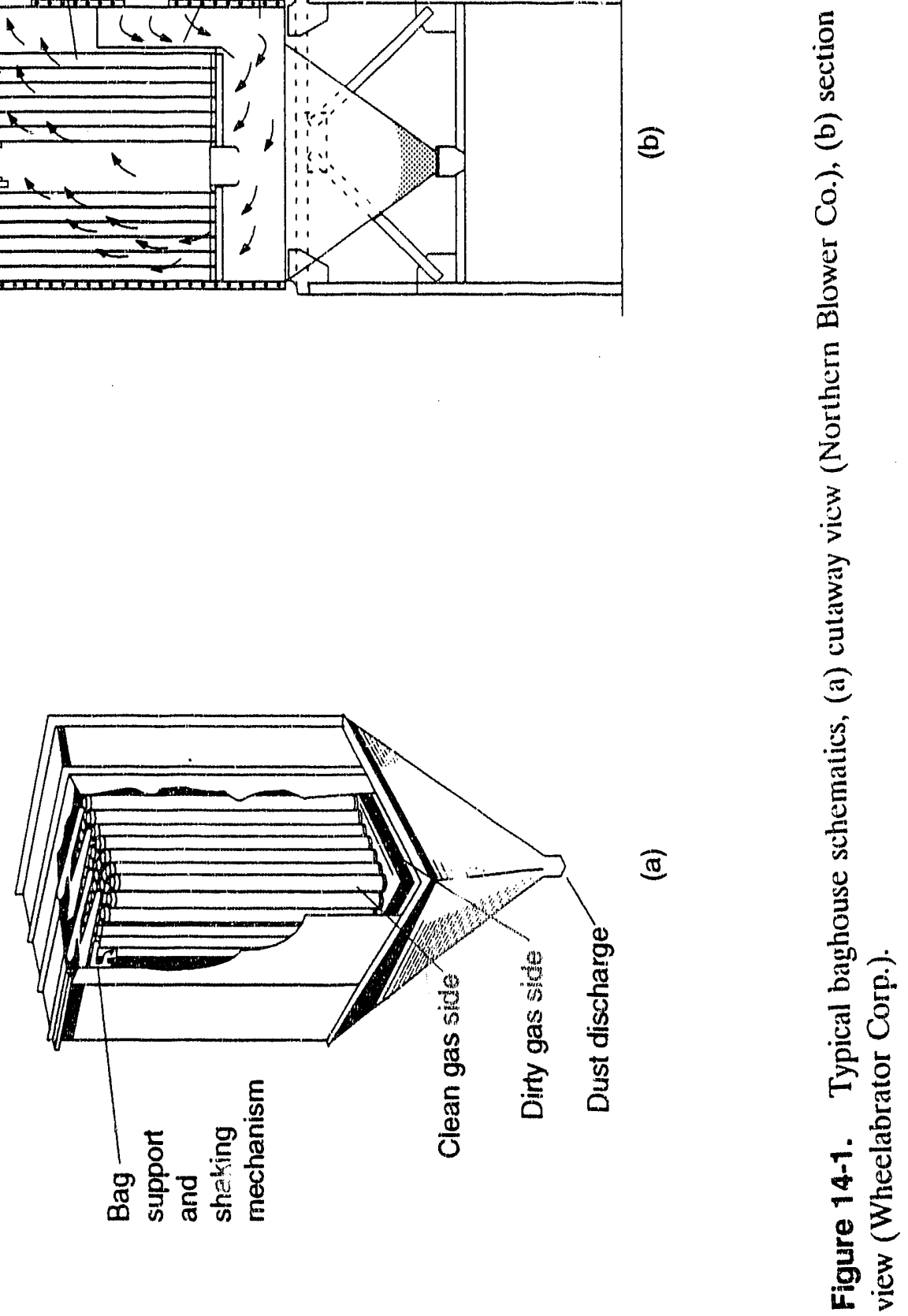


\section{Input Streams}

The input stream is the dry, particulate laden off-gas stream trom any process, including thermal processes.

\section{Output Strearns}

The output streams are the cleaned flue gas, relatively homogeneous tly ash, and periodically, replaced filter bags.

\section{Advantages}

Baghouses are versatile and can be designed to operate under various conditions. Baghouses can have high fractional removal efficiencies. When properly designed, baghouses remove essentially all particulate $>2 \mu \mathrm{m}$ and can remove $>97 \%$ of all particulate larger than $0.5 \mu \mathrm{m}$. With extra care in design and operation, even higher submicron particulate removal efficiencies can be obtained. Baghouses are flexible with essentially an infinite turndown ratio and are capable of handling a great variety of dust loads. In addition, as long as the fabric is intact, the bags present a positive barrier that cannot be penetrated even if other problems arise.

Baghouses are frequently chosen when dry acid gas scrubbing is employed. Unlike wet particulate collectors, a baghouse keeps the acid gas scrubbing residue dry. Baghouses can also improve acid conversion when the gas passes through the filter cake that acts as a sorbent.

\section{Disadvantages}

Baghouses cannot tolerate moisture. In the presence of moisture, catastrophic bag failures, bag blinding and/or severe corrosion may occur. Bag blinding occurs when the pores in the fabric become irreversibly plugged with dust and cause excessive pressure drops. Bag blinding will also result from extremely fine particulate penetrating into the fabric medium and from volatile particulate (such as heavy metals and products of incomplete combustion) condensing on the fabric. Because of physical stress, the bags tend to get holes and tears that release uncontrolled particulate matter. Fine dust is easily reentrained while pulsing; so, the chamber may have to be taken out of service to perform the required cleaning.

\section{Technology Status}

Proven: Baghouses are a well established technology. They are proven and have been used worldwide in at least 6 low level waste incineration facilities.

\subsubsection{Ceramic Filter (TT23140) ${ }^{1,11,12,13,14,15,16}$}

Ceramic filter candles are similar in concept to the fabric filter bags in a baghouse. Ceramic candles are housed in a chamber much like a baghouse, with a hopper beneath the candles and a tube sheet to support the candles and separate the dirty section from the clean. A simplified schematic is shown in Figure 14-2. ${ }^{1}$ The candle filters can be made from a variety of ceramic materials using either ceramic granules or ceramic fibers and may have a soft form or a hard torm. 


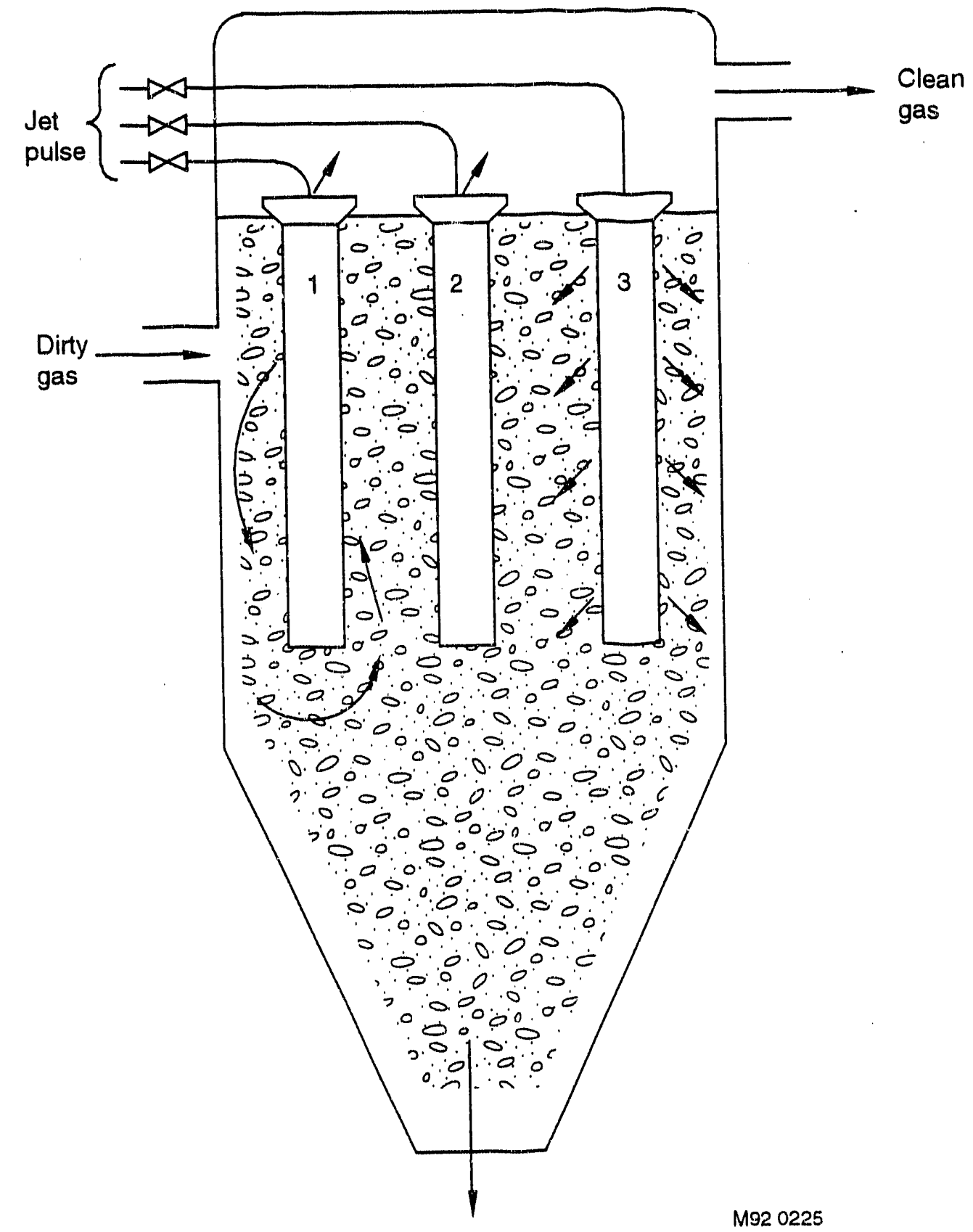

Figure 14-2. Schematic of a ceramic candle filters. 
Dirty flue gas enters near the bottom of the filter housing just above the hopper. The gases pass through the filters depositing particulate on the outside of the ceramic tilters. After a layer of particulate matter builds up on the surface, the filters are cleaned by pulsing with compressed air. For a typical application, the initial pressure drop is approximately 5 in. $-\mathrm{H}_{2} 0$. The maximum pressure drop is 5 psi. Custom designs, however, have specified a 15 psi pressure drop. As with baghouses, only a portion of the filters, approximately $10 \%$, are pulsed at a time to allow the other filters to remain operational. The gas volume used in pulsing is not controlled by valves, as it is in a baghouse, but rather a pulse measuring tank is used, providing more precise control of the amount of air.

The equivalent of an air-to-cloth ratio in the ceramic candle tilters is referred to as face velocity. Ceramic candles are normally designed for face velocities of 3 to $4.5 \mathrm{~m} / \mathrm{min}$ (10 to $15 \mathrm{ft} / \mathrm{min}$ ). For high dust loadings a face velocity of 6 to $1.2 \mathrm{~m} / \mathrm{min}(2$ to $4 \mathrm{ft} / \mathrm{min})$ is used. Alternatively, the high dust loading can be reduced partially with a cyclone so that the higher face velocities can be used. Another important parameter related to ceramic filters is the ratio of the largest pore to the mean pore. A value of two is desired for this ratio.

\section{Input Streams}

Input streams are dry, particulate laden off-gas streams from any process, including thermal processes.

\section{Output Streams}

Output stream are bulk, dry, relatively homogeneous fly ash, and periodically, replaced tilter elements.

\section{Advantages}

Ceramic candles have many of the same advantages as fabric filters. They can be turned down to minimal or no flow with no problems and may perform better at the lower flow rate. They act as a positive barrier to particulate emissions should a failure occur in the system. Ceramic filters are also reported to have high particulate fractional removal efficiencies. More than $99.5 \%$ of the particulate $0.3 \mu \mathrm{m}$ or larger are collected with ceramic candles. This value is one of the highest removal efficiencies available.

Another advantage of ceramic tilters is their ability to operate at high temperatures. Hard ceramic filters can operate at $1038^{\circ} \mathrm{C}\left(1900^{\circ} \mathrm{F}\right)$ and solt ceramic tilters can operate at $1538^{\circ} \mathrm{C}$ $\left(2800^{\circ} \mathrm{F}\right)$. At these temperatures, combustion may still be occurring and the candles can be used to collect and completely burn the soot particles on the candle surface.

\section{Disadvantages}

As with baghouse filters, ceramic filters should be kept dry. If moisture collects on the surface, it can normally be baked off by raising the temperature. This will result in a slight increase in pressure drop. Therefore, the filters should be operated above the dew point. Reentrainment of ultrafine particulate during cleaning may be a problem when using ceramic candles. 
Ceramic candle filters have a few unique problems. At high temperatures, the structural strength of the tube sheet is lowered and thermal expansion may cause some difficulties. To resolve these issues, the tube sheet is cooled with water or steam. In addition, the housing must be refractory lined to prevent thermal damage.

Because ceramic candles are made from the same types of materials as refractories, they are subject to the same types of failures. Frequent thermal cycles cause some wear. Likewise, the ceramic can be attacked by alkali metals, forming eutectics that degrade or ruin the filters. To mitigate this problem, "getters" can be used to precoat the filters. These getters interact with the alkali metals and help protect the ceramic material. In addition, the particle size of the getters can be controlled so that a porous cake forms on the filter surface. As with a baghouse filtration, such a cake provides better filtration at a lower pressure drop over long time periods.

\section{Technology Status}

Proven: Ceramic candle filters have been used in industry for several years now. Approximately 100 of these filters are in service worldwide. Of this number, approximately 10 to 15 units are in service in the U.S. Most of these units are relatively small, and only a few are used on thermal treatment systems such as incinerators. The low number of incinerator installations may be attributed in part to some common problems associated with the original filters. However, recent improvements have corrected many of these problems. For example, the original ceramic candle tilters were easily plugged and required frequent replacement. Current filters use an outer layer that has tine pores and an inner layer with larger pores. The outer layer protects the filter from penetration of fine particulate, therefore minimizing blinding. With this improvement, incinerator operators with ceramic candle filtration are reporting filter life of 6,000 to 8,000 h of service. Some ceramic candle filters in use in France feature disposable outer layers that can be removed and discarded. New outer layers can then be placed on the original base layers. Therefore, filters last longer with reduced disposal volume.

Many improvements in ceramic candle filters are a result of the development of soft tilters. Soft ceramic filters have a maximum operating temperature of $1538^{\circ} \mathrm{C}\left(2800^{\circ} \mathrm{F}\right)$ compared to $1038^{\circ} \mathrm{C}$ $\left(1900^{\circ} \mathrm{F}\right)$ for hard ceramic filters. The soft filters are approximately seven times lighter in weight and cost slightly less than half as much. In addition, soft candles are not subject to thermal shock and result in less waste volume when candles are replaced.

\subsubsection{Metal Filter (TT23160) ${ }^{17}$}

With the exception that the filters are made of metal, these filters are similar to other filtration systems such as baghouses and ceramic candles. Metal filters are made from sintered metal powders, woven wire mesh with fibers sintered together at points of contact, or a combination of these materials. These metal filters are available in different grades ranging from coarse filtration to high efficiency filtration, equivalent to that of HEPA filters, i.e., $99.97 \%$ removal of $0.3 \mu \mathrm{m}$ and larger particles. In one application, these filters were tested at a removal efficiency of $99.999997 \%$ for $0.1 \mathrm{~m}$ particles. Such high efficiency is attainable because of the quality control used during the manufacturing process. The size of particles used to make these filters is carefully controlled to ensure that pore size is constant. 
Metal filters can be pleated to form a high surface area per unit volume and can be made from 316L stainless steel or from a variety of alloys, such as Inconel. The metal filters are contained in housings with support grids that provide for thermal expansion but prevent the filters from rubbing or vibrating against the wall or other filters.

Particulate filtering is accomplished by the porous cake is built up on the outside wall of the filters. In operation the initial pressure drop is typically 2 in. $-\mathrm{H}_{2} \mathrm{O}$. The filters are designed for a maximum pressure drop of 20 psi. The metal filters are normally operated with a face velocity of 5 to $7 \mathrm{fpm}$ but can go up to $20 \mathrm{fpm}$. Metal filters permit a maximum operating temperature of $899^{\circ} \mathrm{C}$ $\left(1650^{\circ} \mathrm{F}\right)$.

Metal filters are cleaned with compressed air similarly to fabric filters and ceramic filters. Even though the metal filters may be rigid, their unique surface characteristics and thin walls provide for excellent cleaning with compressed air.

\section{Input Streams}

Input streams consist of dry, particulate laden ofl-gas streams from any process, including thermal processes.

\section{Output Streams}

Output streams consist of bulk, dry, relatively homogeneous tly ash, and periodically, replaced filter elements.

\section{Advantages}

Because of the similarity in concept, metal filters share the same types of advantages as baghouses However, because of the metallic construction, these filters have other unique advantages. Metal filters are mechanically durable and will withstand a variety of harsh environments. For example, the filters can be wetted and are less damaged by moisture. Metal filters have another advantage over other filters in that they may be cleaned with water or chemical solutions. This cleaning can be done either by removing the filters and cleaning, or the filters can be cleaned in situ using a special design. Metal filters can be operated at high temperatures and high pressure drops. Under these conditions, other filters would be distorted or pore dimensions would be altered.

The high structural integrity of these filters and the cleanable nature of the filters results in longer filter life and smaller waste disposal volumes of spend media. In addition, the tilters can handle high particulate loadings in excess of $1.6 \mathrm{~kg} / \mathrm{m}^{3}\left(0.1 \mathrm{lb} / \mathrm{lt}^{3}\right)$ ol solids in the gas. Metal filters also have a unique fail-safe feature that prevents the escape of particulate should one of the filters fail. A secondary filter element, designed to be plugged off by particulate if the primary element is breached, is placed in the top of each filter. Once plugged, the gas flow through the damaged element is stopped and little or no particulate is carried through the damaged element. 


\section{Disadvantages}

Two primary disadvantages exist to using metal filters. First, these filters have a large initial cost. However, the durability and resulting long life will make up for the higher cost in many cases. The second disadvantage to using metal filters is their weight. Metal filters and the housing are heavy and may need special requirements for a foundation.

\section{Technology Status}

Proven: Despite the proven high particulate removal efficiency, these filters have not been widely accepted in the nuclear industry or in the waste treatment industry. At least five low-level waste incineration sites exist worldwide that use metal filters.

\subsubsection{HEPA Filter (TT23180) $)^{6,18}$}

HEPA (High Efficiency Particulate Air) filters are a standard in the nuclear industry and in other processes requiring extremely high particulate removal. A general schematic is shown in Figure 14-3. ${ }^{18}$ The filtering medium in a HEPA filter is made from glass fibers that are pressed into a high density paper. Waterproof binders are used so that the medium will be able to resist damage from small amounts of moisture. For nuclear applications, a radiation resistant medium can be used and the cell frame and the housing is typically made from stainless steel. The medium is shaped into pleats to increase the filtration surface area per unit of volume. Between the pleats are metal separators that hold the shape of the pleats as well as decrease the resistance to flow.

To prevent leakage, the filter medium is bonded to each wall of the cell frame. The frame, in turn, is mechanically locked in the housing and sealed with either a tirm gel material or a gasket. Individual cells are available in a variety of sizes and are designed for a variety of face velocities and volumetric flow rates. Typical face velocities range from 38.1 to $152.4 \mathrm{~m} / \mathrm{min}$ (125 to $500 \mathrm{fpm}$ ).

HEPA filters consist of one or more HEPA filter cells in a common housing. When more than one cell is used, the cells are arranged in a parallel flow pattern. Because these filters intercept and trap the dust particles on the surface, the filters have a limited capacity in terms of the amount of particulate that can be collected. Typically, about 4.5 to $6.8 \mathrm{~kg}$ (10 to $15 \mathrm{lb})$ of particulates can be collected in a $0.6 \mathrm{~m} \times 0.6 \mathrm{~m} \times 0.3 \mathrm{~m}(24 \mathrm{in} . \times 24 \mathrm{in} . \times 12 \mathrm{in}$.) HEPA tilter before the filter is exhausted and must be replaced.

Because HEPA filters are more expensive than other types of filters, they are normally used in series downstream of one or two lesser grade filtering systems. An initial coarse filtering process may include a cyclone separator. This may be followed by a baghouse, which is followed by the HEPA filters. By using prefiltering and intermediate filtering equipment, the HEPA filters normally receive less than 1 to $10 \%$ of the original particulate loading.

HEPA filters collect essentially all the particulate matter present in a gas stream. Therefore, they are frequently referred to as absolute filters. Four collection efliciencies are available for this type of filter. The standard grade of HEPA filters has a minimum collection efliciency of $99.97 \%$ for $0.3 \mu \mathrm{m}$ and larger particles. The next grade has a $99.99 \%$ collection efliciency for $0.3 \mu \mathrm{m}$ and larger particles. 


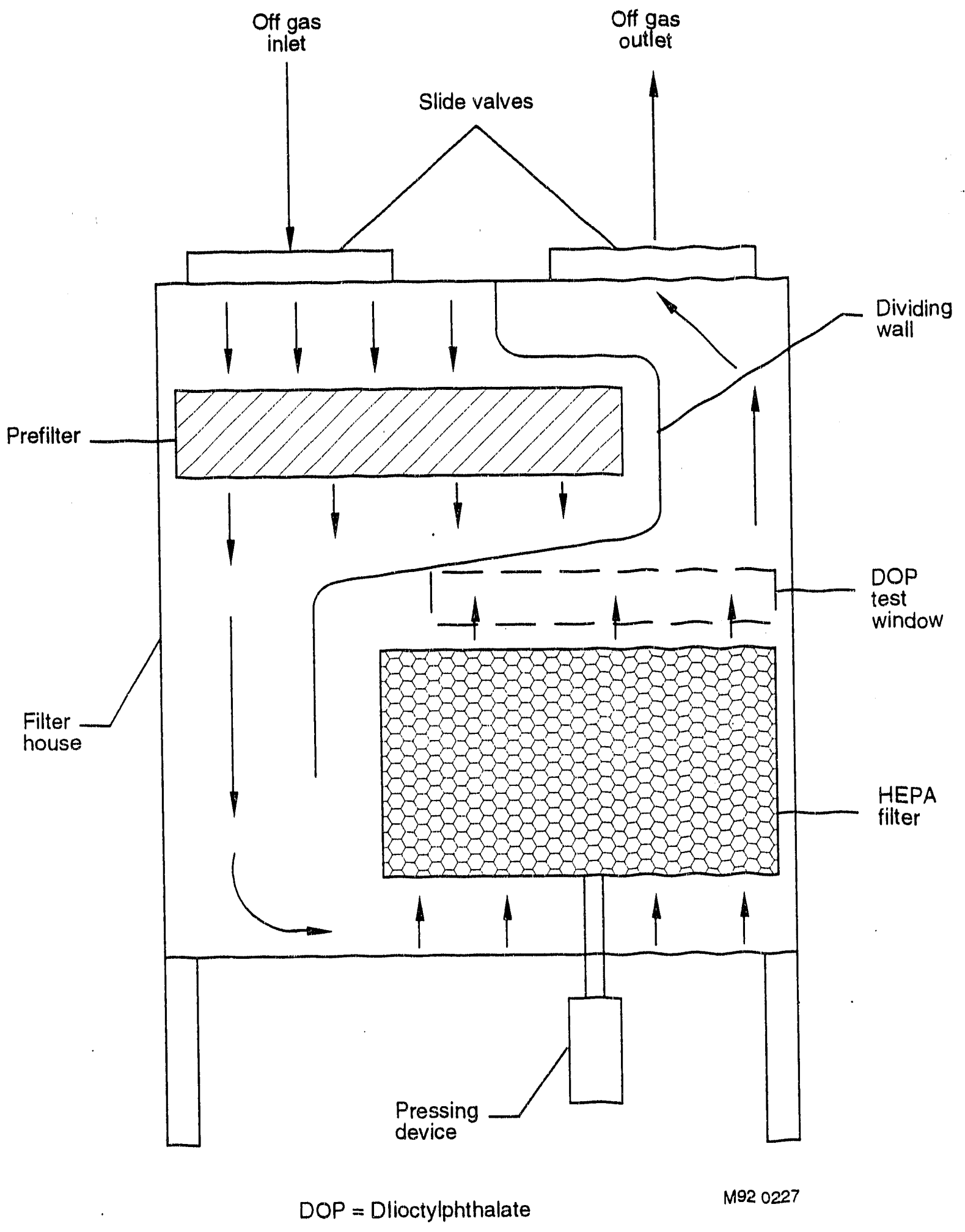

Figure 14-3. Schematic of a HEPA filter house nuclear Karlsruhe type. 
Although normally used in the manufacture of integrated circuits and other "clean room" applications, two high performance filters are available. Ultra low penetration air (ULPA) filters have a minimum removal efficiency of $99.999 \%$ for $0.3 \mu \mathrm{m}$ and larger particles. The highest grade filters available are referred to as laser tested and have a minimum removal efficiency of $99.9995 \%$ for $0.12 \mu \mathrm{m}$ and larger particles.

Using a bank of prefilters, intermediate filters, and standard HEPA lilters, the initial pressure drop across the HEPA filter bank is typically 1 to 1.5 in. $-\mathrm{H}_{2} 0$. The HEPA filters will normally function until the pressure drop exceeds 5 to 6 in. $-\mathrm{H}_{2} \mathrm{O}$.

The normal temperature limit is $121^{\circ} \mathrm{C}\left(250^{\circ} \mathrm{F}\right)$, but high-temperature options of between 500 and $1000^{\circ} \mathrm{F}$ are available. Housings are available with multiple, in situ test ports to individually test each filter in a bank. If desired, factory scan testing can be used to verify that no pinhole leaks occur in the medium. For applications where gas adsorption is desired, the HEPA filter bank housing can be expanded and activated carbon tilters added. One of the options that some HEPA filter vendors can supply is a blowback feature. These HEPA filter housings have compressed air cleaning devices so that the particulate can be cleaned off and the filter may remain in service for a longer period of time. These housings have a hopper for dust collection and are available in modules that can be connected together to handle the required gas volume.

\section{Input Streams}

Input streams consist of dry, particulate laden off-gas streams from any process, including thermal processes. The particulate loading should be light to limit filter element replacement requirements.

\section{Output Streams}

Output streams consist of replaced filter elements laden with particulate, and small amounts of bulk, dry, relatively homogeneous fly ash.

\section{Advantages}

Advantages of HEPA filters include (1) no operational or maintenance costs are incurred other than filter replacement and fan entrgy requirements for the pressure drop across the HEPA filters, (2) the manpower to replace the filters is minimal but leak testing must be done after the installation of a new filter to verify that it is properly sealed and that no leaks exist in the medium, and (3) capital costs are moderate and depend on the options selected.

\section{Disadvantages}

HEPA filters cannot be changed without takin the filter bank off line. Replacement of prefilters can be necessary frequently, so redundant HEPA filter barks are commonly connected in parallel, thereby doubling the cost of the equipment. With this arrangement, one tilter bank is out of service while filters are being changed. Even though the bank may have been out of service for a long time before the filters are changed, the housing may be hot il the llue gases are hot. Therefore, extreme caution must be used while changing lilters. This may be difticult, because the 
worker may need to be fully suited in anticontamination clothing and wear a respirator while changing the filters.

\section{Technology Status}

Proven: HEPA filters are presently in use in 17 low level waste incineration facilities throughout the world.

\subsection{Particulate Separation (TT23200)}

Many other particulate separation procisses are available in addition to filtration systems. These include separation systems that use forces such as gravity, inertia and electrical attraction to separate particles from air and gas streams. The most commonly used and applicable separation technologies are discussed below.

\subsubsection{Gravity Separators (TT23220) $)^{1,2,6}$}

Gravity separators or settling chambers are the simplest particulate removal device available. Settling chambers are empty chambers either vertically or horizontally inserted into the off-gas ducting. As the name implies, gravity settling chambers use the force of gravity to overcome the drag force from the gas flow that keeps particulate matter entrained in the off-gas. Settling chambers have large cross-sectional areas to reduce the gas velocity and entrainment force. The larger and denser particles can fall downward and are collected in a hopper.

The cross-sectional area required is a function of the gas viscosity and density, the particle diameter and density, and the removal efficiency required. Normally. the cross-sectional area is sized to give a gas velocity of less than $3 \mathrm{~m} / \mathrm{s}(10 \mathrm{l} / \mathrm{s})$. However, this size can be inlluenced by other considerations, such as particulate agglomeration, which results in larger diameters and, theretore. better collection.

Cooling the gas stream reduces the gas viscosity, the gas volume and the gas velocity. These factors allow a smaller cross-sectional area to be used. The length of the chamber depends on its horizontal vertical or vertical orientation. Horizontal chambers must provide a sufficient residence time to accommodate the rate of particle drop through the height of the chamber. Vertical cnambers require sufficient length to attain fully developed tlow. However, the gas velocity at fully developed flow must be less than the settling velocity of the particulate.

\section{Input Streams}

Input streams are dry or moist particulate laden off-gas streams from any process, including thermal processes. 


\section{Output Streams}

Output streams are wet or dry bulk particulate with a relatively large mean diameter of 10 to $100 \mu \mathrm{m}$.

\section{Advantages}

Advantages of gravity separators include (1) gravity settling chambers have low capital, installation, operating, and maintenance costs, (2) the pressure drop through settling chambers is low, normally less than 1 in. $-\mathrm{H}_{2} \mathrm{O},(3)$ they can be operated at high temperatures by lining the settling chambers with refractory materials, and (4) because slower velocities produce less frictional drag on the particulate, the removal efficiency is increased with turndown of gas thow rate.

\section{Disadvantages}

Settling chambers only offer high removal efficiencies for large particles, typically greater than $50 \mu \mathrm{m}$. Collection efticiencies for particles $15 \mu \mathrm{m}$ in diameter may be on the order of $20 \%$. Settling chambers are thus not normally used in thermal treatment systems where the majority of the particulate is less than $15 \mu \mathrm{m}$.

\section{Technology Status}

Available: The technology is simple and well developed, but not applicable to mixed and low level waste treatment, because of the size of particulate effectively removed. No low-level waste incineration processes are presently available that specifically use gravity separation.

\subsubsection{Cyclone Separator (TT23240) $)^{1,2,3,4,5,6}$}

Cyclones separate solids from gas streams by centrifugal force. Cyclone separators are vertical, cylindrical vessels with a gas entrance designed to give a spiraling gas-thow around and down the cyclone wall, as shown in Figure 14-4. ${ }^{1}$ This spiraling motion can be created by a tangential entrance, by vanes placed in the entrance, or by an involuted entrance that wraps around the outside circumference of the cylinder before opening up into the vessel.

Once in the cyclone, the downward spiraling llow of the gas stream imparts a centrifugal force on the particulate that is thrown radically outward to the cyclone wall. When the particles hit the wall, much of their monentum is absorbed and they fall through the lower conical section of the cyclone into a hopper. The cleaned gas flow is forced back up through the center of the downward spiraling gas flow, to exit through a tube mounted in the top center of the cyclone. This tube extends down into the center of the cyclone separator so that it is actually below the gas entrance ports so the gas flow cannot short circuit the spiraling flow path.

The cyclone separator diameter, relative to the actual gas flow, has the greatest effect on collection efficiency. Smaller diameters result in higher gas velocities and higher centrifugal force. This, in turn, results in a higher collection efficiency but at a cost of higher pressure drop, energy consumption, and erosion/abrasion. 


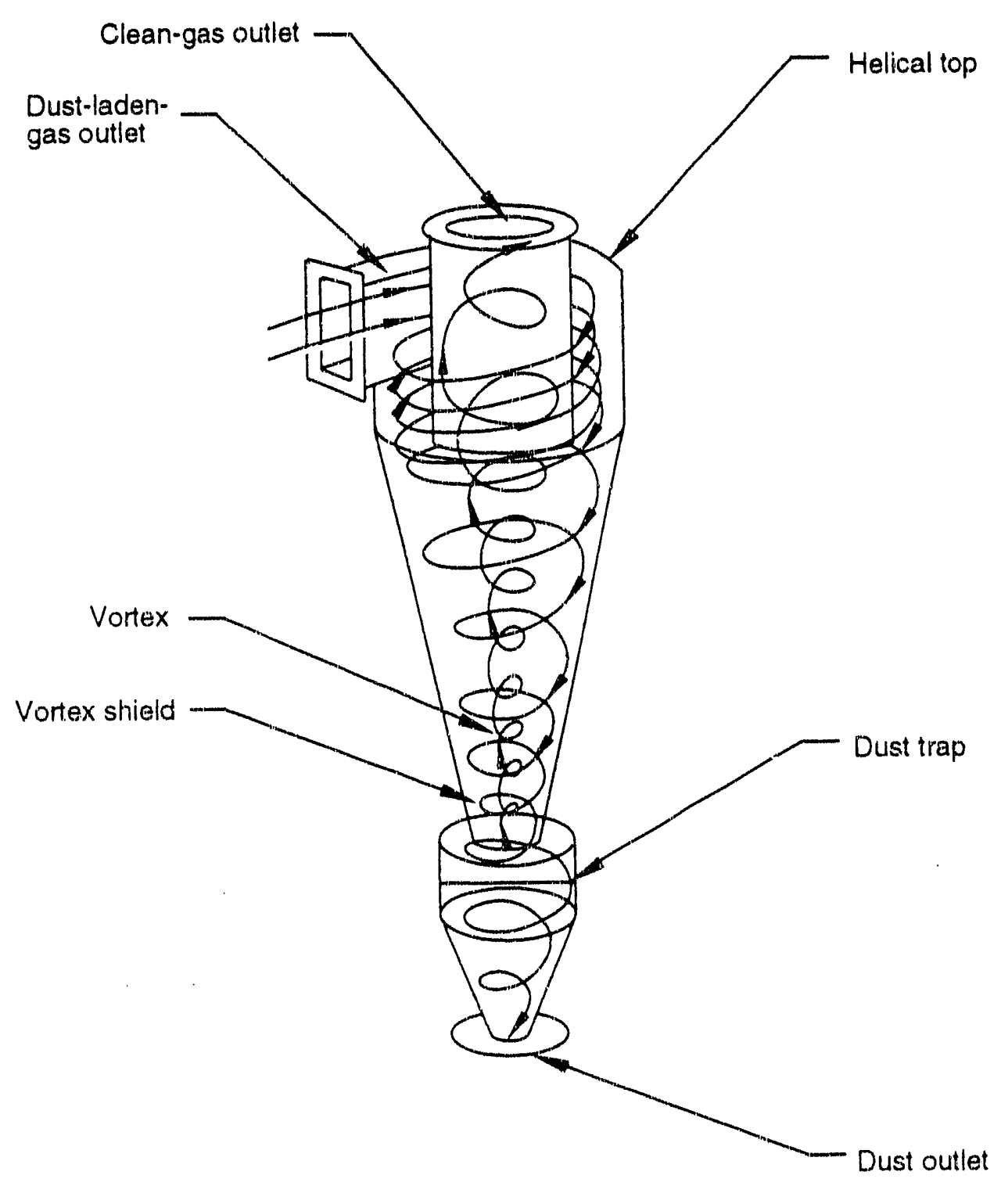

M92 0214

Figure 14-4. Schematic of a cyclone separator. 
Although cyclone separators are fairly simple in concept, a great variety in the models is available. Some have continuously tapered diameters and some have multiple sections, with each section having a different diameter and a small tapered connection between each section. Multiple cyclone separators arranged in parallel or series, called multiclones, are often used with a common housing and shared components such as a gas inlet plenum and a dust collection hopper.

\section{Input Streams}

Input streams are dry or moist particulate laden olf-gas streams from any process, including thermal processes.

\section{Output Streams}

Output streams are the cleaned gas stream and wet or dry bulk particulate.

\section{Advantages}

Cyclone separators have some advantages associated with their simpiicily. They have low capital, installation, operational, and maintenance costs. When relacictory-lined, they can be operated at high temperatures. Cyclone separators can handle high dust loadings and, when compared to other particulate removal devices, have low-to-moderate pressure drops. ranging from approximately 1 to 5 in. $-\mathrm{H}_{2} \mathrm{O}$. They are effective at removing not only solid particulate but also liquid droplets, and can be used in moist gas streams. In fact, their collection efficiency can improve in moist streams due to wetting and agglomeration effects on the particulate.

\section{Disadvantages}

Cyclone separators have two major drawbacks that limit their use in thermal treatment systems. First, cyclone performance depends on gas velocity and are therelore sensitive lo gas flow turndown. Furthermore, even when operated at the proper gas velocity, most cyclone separators are less effective at removing smaller particles. The collection efficiency for well designed cyclones may be on the order of $20 \%$ lor particles $1 \mu \mathrm{m}$ in diameter and $8.5 \%$ lor particles greater than $10 \mu \mathrm{m}$. Most incinerator systems require higher efficiency particulate removal in these size ranges and smaller size ranges.

\section{Technology Status}

Proven: Cyclone separators are simple and well developed, but not used extensively in low level waste treatment processes due to their coarse removal efficiency. They are used in four low level waste incineration processes worldwide and are used combination with other higher efticiency particulate removal devices.

\subsubsection{Electrostatic Precipitator (TT23260) ${ }^{1,2,3,4,5,6,19,20,21}$}

An electrostatic precipitator (ESP) uses electrical attraction lorces on charged particulate to clean off-gas streams. A schematic of an ESP is shown in Figure 14-5. ${ }^{1}$ The main components of a typical ESP include a long, vertical discharge electrodes spaced in a line between two grounded or 


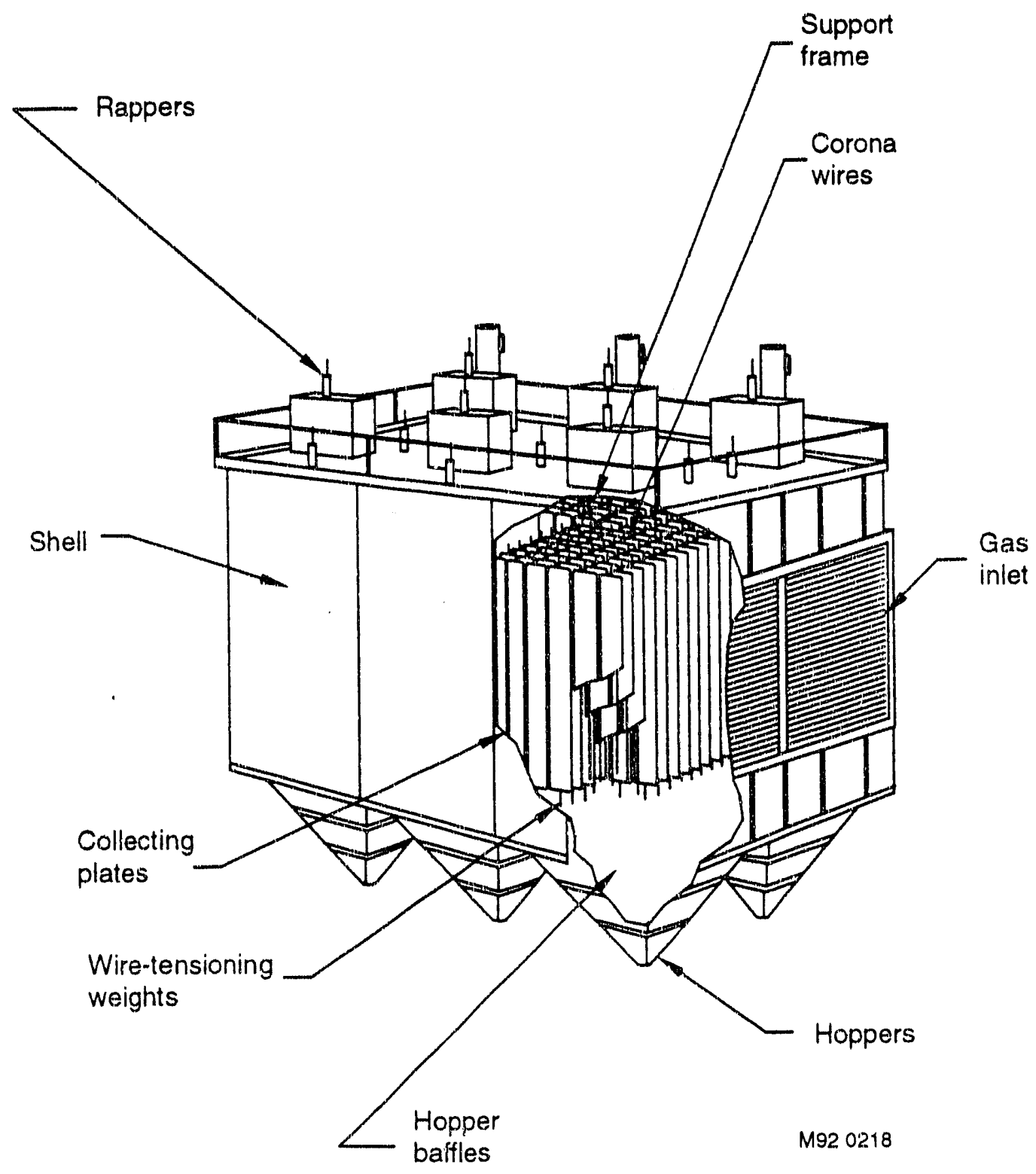

Figure 14-5. Schematic of an electrostatic precipitator. 
oppositely charged collection plates. Particulate removal in an ESP involves two key steps. First, the particles are electrically charged. High voltage on the order of $40,000 \mathrm{~V}$ is applied to the discharge electrodes. This voltage ionizes gas molecules in the region near the electrodes, resulting in gas corona. Ions are driven toward the grounded plates, and impact with and charge the particles in the gas stream. Larger particles charge much more rapidly and can retain a higher charge than small particles.

The second step is particulate migration to the collection plates due to the electrical attraction. The larger, more rapidly and higher charged particles migrate most rapidly to the collection plates, followed by smaller particles. The residence time in the ESP must be sufficient for the particles to reach the collection plates. Gas velocity in an ESP typically ranges between $(0.6$ to $1.5 \mathrm{~m} / \mathrm{s}(2$ to $5 \mathrm{f} / \mathrm{s})$ and gas residence time can be as high as $15 \mathrm{~s}$. To limit the amount of build up on the collection plates, the plates are periodically or continuously cleaned by impact-type or vibratory type rappers, or by water film removal.

Two arrangements of electrodes are used in electrostatic precipitation. In the single-stage arrangement, the discharge electrodes and the collecting plates are located in the same chamber. In the two-stage arrangement, the discharge electrodes are placed in the first chamber where ionization and particulate charging is achieved. The collection plates are placed in the second chamber where removal is achieved.

A tubular precipitator is a concentric cylinder design variation. The collection plates are tubes in a vertical bundle. A single discharge electrode hangs down the center of each tube.

Other design options include cold-side and hot-side precipitations. Cold-side precipitators operate at about 149 to $204^{\circ} \mathrm{C}\left(300\right.$ to $\left.400^{\circ} \mathrm{F}\right)$, while hol-side precipitators are designed for operation at 371 to $427^{\circ} \mathrm{C}\left(700\right.$ to $\left.800^{\circ} \mathrm{F}\right)$.

\section{Advantages}

ESPs have numerous advantages that have established them as a popular particulate removal device. ESPs have a higher removal elfieiency than settling chambers and cyclones, though not as high as baghouses. The typical removal elficiency in an incinerator application is greater than $95 \%$ : however, removal efliciencies $>99.9 \%$ can be obtained. Because the collector does not rely on impaction or filtration, Well designed ESPs with long residence times have proven to be an excellent device for submicron particulate removal. Furthermore, ESPs have an inlinite turndown ratio. ESP performance may improve with turndown. Hot-side precipitators require less tiue gas cooling than do baghouses.

Operating and maintenance costs for ESPs have proven to be low, when compared to other particulate removal devices. The pressure drop across an ESP is typically less than 0.5 in.- $\mathrm{H}_{2} 0$. Therelore, fan power requirements are low. Even though the particulate charging voltage is high, the current used is small, resulting in an overall low power consumplion. Because no lilter medium is used. medium replacement and disposal is avoided. Other maintenance expenses are also normally low, because the only moving parts are the rappers. 


\section{Disadvantages}

Factors that can impair ESP collection efficiency include (1) lower temperature flue gases are more difficult to ionize, (2) gas sneakage results in portions of dirty gas that are not treated, (3) rapping reentrainment and back-corona may drive collected particulate back into the gas tlow, (4) electrical performance is strongly dependent on precise dimensions and spacing, in the ESP. as well as gas temperature, humidity, composition, and resistivity of the ash layer on the collection plates, (5) downstream formation of dioxins and furans may occur in hot-side ESPs under some temperature and residence time conditions if there are unburned hydrocarbon precursors remaining in the flue gas, (6) there is a lack of a physical barrier, between the inlet and outlet, such as tilter medium which prevents a release if a failure occurs in the system, which could result in an uncontrolled particulate release during abnormal operations.

ESPs have high capital costs and can have excessive replacement costs because of damaged electrodes resulting from hammer rapping. ESPs require a large space, which may add to building costs. ESPs provide only particulate control, compared to wet and dry scrubbing systems that provide both acid gas and particulate control.

\section{Technology Status}

Proven: ESPs are commonly used in many industries. They are available, but are in present use at only two low level incineration systems worldwide.

\subsubsection{Mist Eliminator (TT23280 $)^{1,2}$}

Demisters are specifically designed to remove liquid droplets from wet, saturated flue gas streams. Mist collection is based on impingement of the mist onto solid surfaces. They are most commonly used at the outlets of wet scrubbers, and are often an integral part of a wet scrubber system. They most often consist of wire mesh or perforated screens or baltles placed across the gas flow, typically at the top of a scrubber vessel. As the saturated gas passes through voids in the screen, the liquid droplets impact on the screen, coalesce into larger droplets, and drip back into the scrubber or other vessel. Even though the gas must. pass through the screen, pressure drop is minimal, usually less than 0.5 in. $-\mathrm{H}_{2} \mathrm{O}$. Operating temperatures range between $66^{\circ} \mathrm{C}$ to $93^{\circ} \mathrm{C}\left(150\right.$ to $200^{\circ} \mathrm{F}$ ). The materials of construction can include steel, polyethylene, or other corrosion-resistant materials.

\section{Input Streams}

Input streams consist of wet, saturated tlue gas streams. These can have droplets of water, acids, scrubber liquors, or other liquids, as well as entrained solid particulate.

\section{Output Streams}

Output streams consist of demisted, but still saturated thue gas stream, and a liquid stream of the collected mist. The liquid stream typically drains back into the scrubber or other vessel. 


\section{Advantages}

Advantages of demisters include (1) demisters are inexpensive, can be corrosion resistant, and have low pressure drop, (2) they can conserve scrubber liquor that would be carried over out of the scrubber, (3) can be a final, cheap medium for gas-liquid interface for mass transter, and (4) since they remove mist, they can reduce downstream corrosion and fouling, reduce visible plume from stacks, and help to control emissions of any materials such as metals, acids, and particulate that may be dissolved or captured in the liquid mist.

\section{Disadvantages}

Disadvantages of demisters include (1) sticky or sludgy materials may foul or plug the demister, and (2) demisters, like the other gas treatment equipment, are subject to damage from upset conditions such as high temperatures, changes in composition of the mist, ctc.

\section{Technology Status}

Proven: Demisters are a simple and well developed technology, which is typically incorporated into scrubber and other integrated systems.

\subsection{Acid Gas Removal (TT23300)}

Most incineration processes that treat a variety wastes will exhaust acid gases as products of combustion. Depending on the process design and operation and waste composition, the levels of acid gases can be in the hundreds or thousands of parts per million (ppm). Essentially all sulfur and halogens in the waste will be oxidized to sulfur oxides $\left(\mathrm{SO}_{2}\right.$ and $\left.\mathrm{SO}_{3}\right)$ and halogen acids $(\mathrm{HCl}, \mathrm{HF}$, and $\mathrm{HBr}$ ). Some small amounts of diatomic halogens (mainly $\mathrm{Cl}_{2}$ and $\mathrm{I}_{2}$ ) may also $b=$ formed. Oxides of nitrogen (mainly $\mathrm{NO}$, but also $\mathrm{NO}_{2}$ and $\mathrm{N}_{2} \mathrm{O}$ ) will also be formed from nitrogen in the waste (fuel $\mathrm{NO}_{x}$ ) and from oxidation of diatomic nitrogen $\left(\mathrm{N}_{2}\right)$ combustion air (thermal $\mathrm{NO}_{\mathrm{x}}$ ). The predominant acid gases are typically $\mathrm{HCl}$ (which may cxceed a thousand ppm when high-plastics wastes are processed) and $\mathrm{NO}_{\mathrm{x}}$. Levels of $\mathrm{NO}_{\mathrm{x}}$ may exceed several hundred ppm from high temperature operations.

Typically, incinerator processes are required to remove a percentage of acid gases and/or ensure compliance of emission levels to emission standards. This will be especially true when some of the acid gases may contain radioactive elements such as isotopes of iodine. Although many variations of acid gas removal systerns are available, these can be grouped into two main categories, wet and dry scrubbers. For this report, semidry scrubbers are considered to be a variation of dry scrubbers.

All scrubbing devices rely upon the same principle of converting the acid to a salt by reacting with an alkali reagent. Once converted, the salt can be collected as a dry particulate, or dissolved in a liquid solution. The most commonly used reagents are either sodium-based or calcium-based. The choice of which reagent to use depends upon whether the process is wet. dry, or semidry, and other considerations such as solubility and byproduct disposal. In wet scrubbing, aqueous solutions of sodium hydroxide are often used. This reagent is reactive and is readily handled as a liquid (with proper caustic liquid precautions). For dry systems, powdered hydrated lime (CAO) or sodium bicarbonate are often used. 
These scrubber systems are not especially effective for $\mathrm{NO}_{x}$ control, because the majority of $\mathrm{NO}_{\mathrm{x}}$ emissions is typically NO. For most combustion systems, tie $\mathrm{NO}_{2}$ level is only about $5 \%$ or less of the $\mathrm{NO}$ level, and the level of $\mathrm{N}_{2} \mathrm{O}$ is often even lower. $\mathrm{NO}$ and $\mathrm{N}_{2} \mathrm{O}$ are not efficiently captured in these conventional scrubber systems, although $\mathrm{NO}_{2}$ is elfectively captured in wet scrubbers. $\mathrm{NO}_{x}$ control is discussed separately in this report in Section 14.4.

\subsubsection{Wet Scrubbing (TT23320)}

The five most common types of wet acid gas removal devices are venturi scrubbers, packed-bed scrubbers, tray scrubbers, wet fluidized bed scrubbers, and spray scrubbers. These are all variations of gas-liquid contactors for absorbing acid yas molecules from the flue gas stream to the scrubbing liquor stream. These variations have several features in common. Since the scrubbing liquor for these systems are aqueous solutions, these contactors will also quench the thue gas stream to below the water boiling temperature. Typical operating temperatures are around $66^{\circ} \mathrm{C}\left(150^{\circ} \mathrm{F}\right)$. Each system includes a demister at the outlet to reduce entrained mist in the saturated outlet gas stream.

Another side benefit of wet scrubbers is the removal of entrained particulate. Depending on the contacting device design and operation, highly efficient particulate removal may be achieved, although not usually as efficient as baghouses. In many industries, wet scrubbing using water is a preferred method for particulate removal. In mixed waste incineration, wet scrubbers will usually be followed by HEPA filters to efficiently remove remaining particulate from the gas stream. The gas stream may require limited reheating, to prevent moisture condensation in the HEPA filters.

The proper $\mathrm{pH}$ of the caustic liquor must be maintained. If the liquor $\mathrm{pH}$ is below 7, then acid gases may not be efficiently collected in the unit. If the pH exceeds 10, carbon dioxide in the thue gas may also be significantly absorbed. unnecessarily consuming the cilustic reagent. Also, highly caustic scrubber blowdown streams are less easily handled and disposed of.

Continuous or periodical blowdown of scrubber liquor is necessary to remove accumulated salts and dissolved and suspended particulate. Makeup water and caustic solution is used to replace the liquor blowdown. In the case of radioactive waste treatment, the blowdown may also contain some nuclides including tritiated water and isotopes of iodine and heavy metals that partitioned to the entrained particulate or devolatilized into the gas stream, and later condensed in the scrubber.

Wet scrubbers of various types are in ten low level waste incineration lacilities worldwide. Descriptions of the most common wet scrubbers are summarized below.

14.3.1.1 Packed-Bed Scrubbers (TT23322). 1,23,4.22.23 The most common packed-bed scrubbers are vertically oriented vessels tilled with a packing material. A schematic is shown in Figure 14-6. ${ }^{1}$ The gas stream enters near the bottom, and thows up through the packing, exiting out the top. The liquid flows countercurrent or downward through the packing. The gas inlet is configured to provide adequate gas distribution through the packing to minimize channeling. Spray nozzles or an arrangement of weir troughs at top of the tower provide liquid distribution. The packing is held in place by packing support grids. An intermediate structure is sometimes used in the packing to redistribute the liquid. 


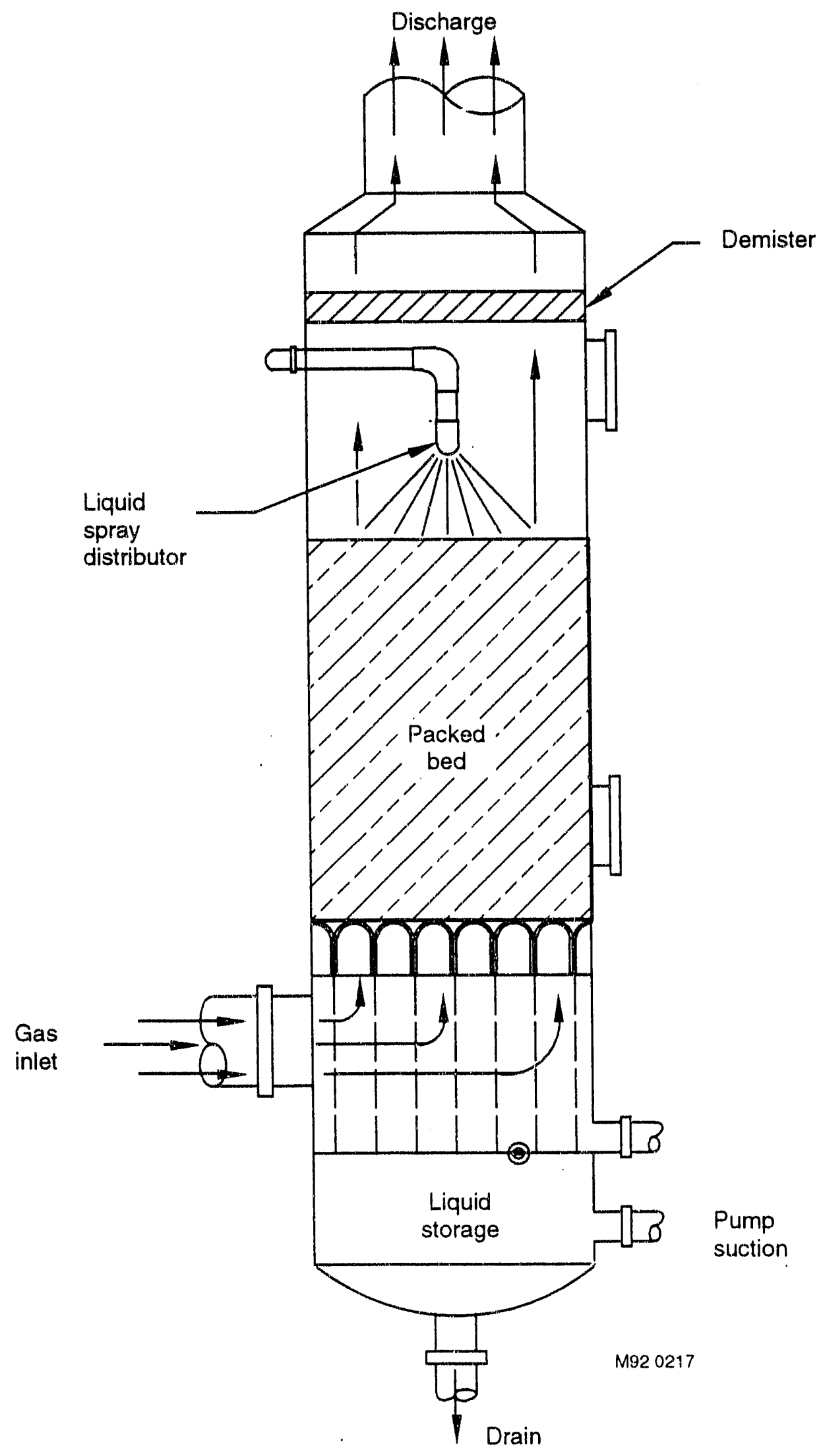

Figure 14-6. Schematic of a packed-bed scrubber. 
The packing medium in the tower is most often plastic or ceramic Raschig rings, Berl saddles or other uniquely-shaped materials of various sizes and designs. Packed randomly in the bed, this material is designed increase the amount and intimacy of gas-liquid contact by dispersing the flowing liquid and the uptlowing gas, and becoming wetted on all sides by the liquid to create a large liquid surface area. This can result in high mass transfer rates of acid gases into the liquid. Liquid-to-gas ratios of 15 to $20 \mathrm{gpm}$ per $1000 \mathrm{acfm}$ are common, and the bed depth is typically 1.2 to $1.8 \mathrm{~m}$ (4 to $6 \mathrm{ft})$. The packing is designed to provide up to $3.7 \mathrm{~m}^{2}\left(40 \mathrm{ft}^{2}\right)$ of area per cubic feet of packing and still have in excess of $93 \%$ voids in the bed. The packing is also designed to be easily wetted so that dry spots are minimized.

Variations in packing techniques include using structured packing, and mesh pads. In structured packing, rigid or semirigid members that may have a unique shape are used to form patterns such as grids or chevrons. Occasionally, a series of mesh pads are used as packed bed, but are more frequently used only as mist eliminators at the gas outlet of the tower.

\section{Input Streams}

Inputs consist of a hot off-gas stream which may contain particulates and acid gases, scrubber solutions, and makeup water.

\section{Output Streams}

Outputs consist of (1) cooled, saturated, treated olf-gas stream with acid gases and significant amount of particulate removed, and (2) scrubber liquor blowdown solutions including scrubbed acid gases and scrubbed particulates.

\section{Advantages}

The most notable advantage of the packed-bed scrubber is the high acid gas removal efficiencies. $\mathrm{HCl}$ removal in excess of $99 \%$ is common and $\mathrm{SO}_{2}$ removal of approximately $99 \%$ also is common. These high removal efticiencies are obtained using 5\% more caustic than what is theoretically required. This low excess caustic requirement not only results in a cost savings for the caustic, but also results in less volume of scrubber blowdown and byproduct. Another advantage is the low power requirement, as only 2 to 5 in.- $\mathrm{H}_{2} 0$ pressure drop are required. Packed-bed scrubbers also are simple to operate.

\section{Disadvantages}

Operational problems with packed bed scrubbers include movement or compaction of random packing, causing gas channeling and poor liquid distribution. This will reduce gas-liquid contact and lower removal efficiencies. Packed-beds also are subject to louling from particulate and dried salts. Once fouled, mass transfer will decrease and the gas pressure drop will increase.

Variations in the gas and liquid flows will also hamper removal efficiency. Nominal gas velocities range between approximately 400 to 600 act $m$. If the gas velocity is increased beyond these design limits, it hinders the liauid from draining down through the packing. Packed towers also have a low turn down of approximately 2:1. Higher turndown results in poorer liquid and gas distribution. 


\section{Techaology Status}

Available: Packed towers are a well established and well used technology in many industries. Packed beds are often used together with venturi scrubbers in incineration operations "o improve removal efficiencies and disassociate the venturi spray liquid from the gas stream. This is a likely and available technology for low level waste incineration.

14.3.1.2 Tray Scrubbers (TT23324). 1,3,4,6 Tray scrubbers are wet scrubbers consisting of a vertical colunn with one or more trays mounted in the column. A cross-section of a spray tower is shown in Figure 14-7. The trays are the components used to accomplish liquid/gas contact. Lowpressure liquid enters near the top of the tower, flows across the first tray, then cascades down to the next tray, and then the next, and so on. Each tray has an overflow weir that is used to control the depth of the liquid on the tray.

The gas enters the tower near the bottom and flows up through numerous small openings in each tray. These openings can have small caps or valves that allow the gases to freely pass through from the bottom of the tray but prevent the scrub liquid from flowing through from the top of the tray. Alternatively, the tray may be just a pertorated plated that relies on gas velocity to prevent liquid passage down through the holes. This latter tray is referred to as a sieve tray and is a more popular design.

As the gas passes through the openings, the velocity is increased so that many small jets are created in the liquid pool on each tray. These jets form numerous small bubbles within the liquid layer. The small bubbles have a large surface area-to-volume ratio, which is necessary for intimate gas/liquid contact. The jet of bubbles also results in turbulence that agitates the liquid. The localized effect is a crosscurrent flow at each tray. However, the overall tlow is countercurrent as the gas passes upward and the liquid moves stepwise downward.

One plate is equivalent to approximately $2.4 \mathrm{~m}(8 \mathrm{ft})$ of packing, so normally only one or two trays are required. The pressure drop across each tray is roughly 2 to 3 in. $-\mathrm{H}_{2} \mathrm{O}$, or less than 6 in. $-\mathrm{H}_{2} \mathrm{O}$ for a two-tray tower. Acid gas removal efficiencies are similar to those obtained in a packed tower, i.e., $99 \%$ or more removal for both $\mathrm{HCl}$ and $\mathrm{SO}_{2}$. In addition, at this pressure drop the tray tower has better removal efficiency for small particulate less than $5 \mu \mathrm{m}$ in diameter than most wet particulate scrubbers, such as a venturi scrubber, operating at the same pressure drop.

\section{Input Streams}

Inputs consist of a hot off-gas stream which may contain particulates and acid gases, scrubber solutions, and makeup water.

\section{Output Streams}

Outputs consist of (1) cooled, saturated, treated off-gas stream with acid gases and significant amount of particulate removed, and (2) scrubber liquor blowdown solutions including scrubbed acid gases and scrubbed particulates. 


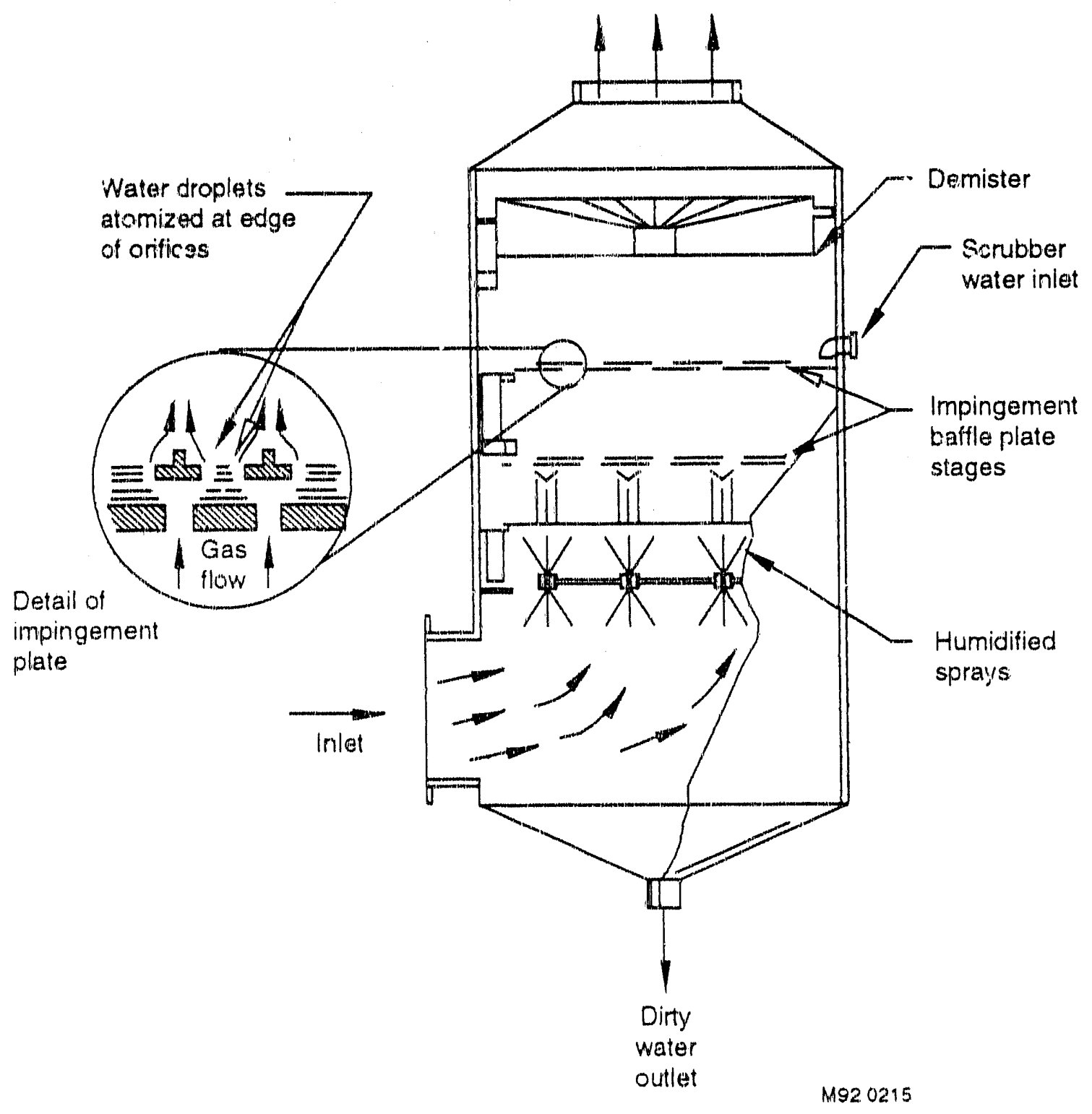

Figure 14-7. Schemalic of a tray scrubber. 


\section{Adtrantages}

The benefit of particulate removal can be enhanced by adding impingement targets above the tray o ening. The use of impingement devices for particulate removal is common and particularly effective in tray scrubbers. With the impingement targets, approximately $90 \%$ of all particulate down to 1 or $2 \mu \mathrm{m}$ car be removed at only a slight increase of pressure drop. These tray scrubbers can operate with a wide range of liquid-to-gas ratios; 1 to $20 \mathrm{gpm} / 1,000 \mathrm{actm}$ is common.

\section{Disadvantages}

Inherent with the use of small openings is the risk of plugging the openings. Th is is a concern that must be accounted for in the design. To operate properly, the gas flow must remain within design constraints. If the gas velocity is too high, flooding can occur; if the gas velocity is too low, the liquid may begin to weep through the taiy openings. These conditions may reduce the performance of the tray scrubber.

The gas-flow through the tray scrubber can normally only oe reduced to about $50 \%$ of design capacity. However commercial tray scrubbers are available with internal chambers and dampers so a porticn of the tray scrutber can be taken out of service if the flow rate is reduced heyond $50 \%$. With these tray scrubbers, the flow rate can be reduced $1012.5 \%$ of design llow. Another disadvantage related to the gas velority is the large size of the vessel required to maintain the proper velocity.

Though the scrubber can be operated at low liquid-to-gas ratios, the liquid tlow rate still must be controlled. If not enough liquid exists on the tray, the gases can blow the liquid away from the openings, resulting in little gas/liquid contact.

Due to materials and design requirements for the plates, capital costs may be high, as well as maintenance and corrosion repair costs.

\section{Technology Status}

Available: Tray towers are a well established and well used technology in many industries. They are available, although they are used less commonly in incineration ofli-gas treatment.

14.3.1.3 Wet Fluidized Bed Scrubbers (TT23326). ${ }^{1.2 .3}$ Wet lluidized bed scrubbers use fluidization of the packing material to increase liquid/gas contacting and mass transfer. A schematic is shown in Figure 14-8. ${ }^{2}$ The flue-gas enters in the bottom of the lower and llows up through a bed of small, light-weight, plastic spheres. The scrub liquor is distributed evenly into the top of the tower to flow downward through the bed. However, in this case the gas velocity and the liquid llow rate are maintained so that the bed is tlooded with liquid and the packing spheres are fluidized by the turbulent motion of the gas stream and the liquid. To accomplish this lluidization, gas velocities of 1.2 to $2.4 \mathrm{~m} / \mathrm{s}(4$ to $8 \mathrm{f} / \mathrm{s})$ are common, but velocities as high as $5.5 \mathrm{~m} / \mathrm{s}(18 \mathrm{l} / \mathrm{s})$ can be used.

The agitated motion allows the packing spheres to rotate and move around within the bed. In this way they are continuously wetted and contacted by other spheres, which prevents deposits and fouling. In addition to the scrubbing at the sphere surlace, the motion of the fluidized bed results 


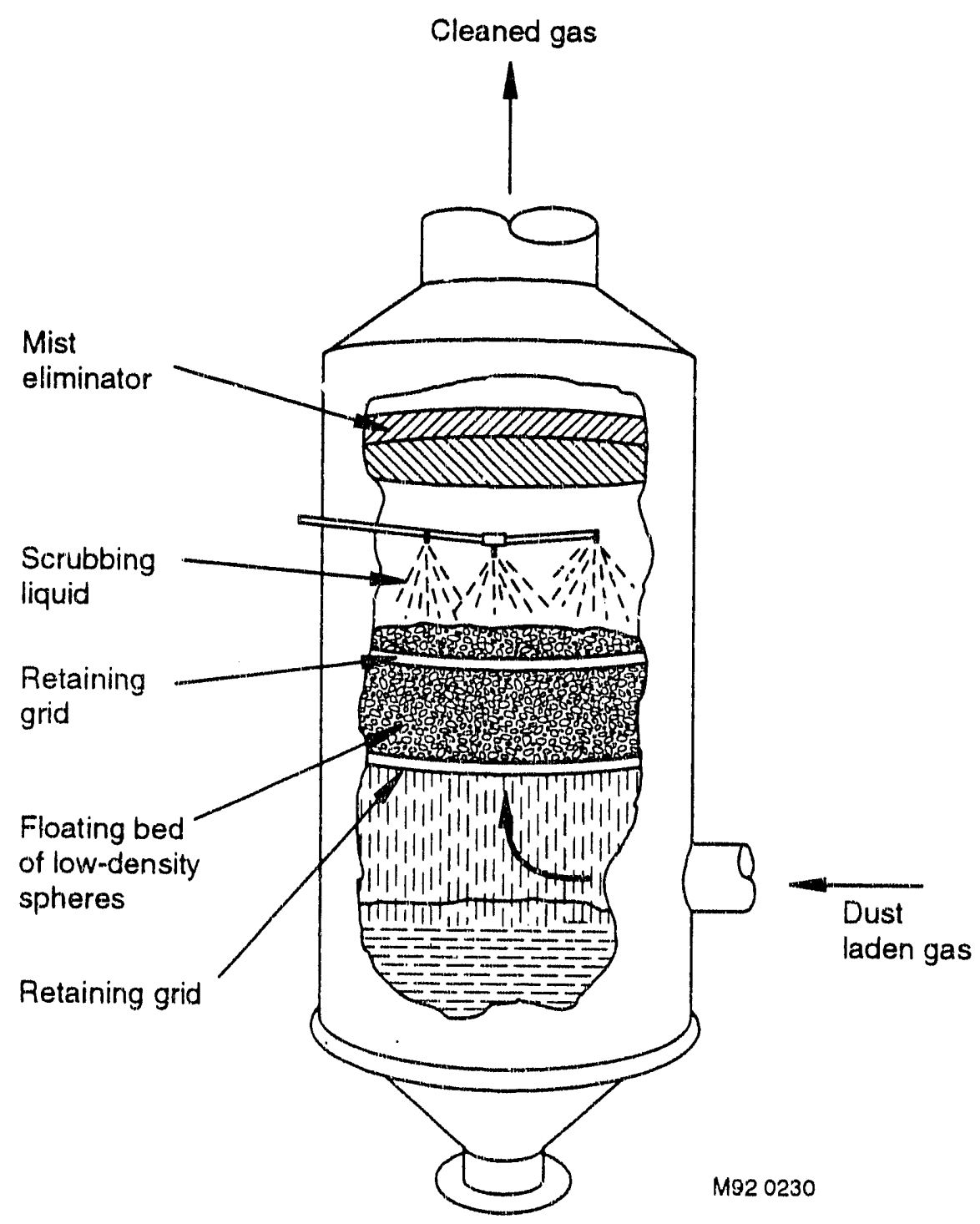

Figure 14-8. Schematic of a fluidized-bed scrubber. 
in gas/liquid mixing in spaces between the spheres. As with a packed-bed scrubber, the degree of acid gas removal obtained is dependent on the total height of the bed. A wet lluidized scrubber normally uses one or more shallow beds of $7.6 \mathrm{~cm}$ to $30.5 \mathrm{~cm}$ ( 3 to $12 \mathrm{in}$.) depth. Once fluidized, these beds expand to two to three times their normal height.

\section{Input Streams}

Inputs consist of a hot off-gas stream which may contain particulates and acid gases, scrubber solutions, and makeup water.

\section{Output Streams}

Outputs consist of (1) cooled, saturated, treated off-gas stream with acid gases and significant amount of particulate removed, and (2) scrubber liquor blowdown solutions including scrubbed acid gases and scrubbed particulates.

\section{Advantages}

The wet fluidized bed scrubber can handle a large range of gas llows simply by adjusting the liquid flow rate. Because of the high degree of agitation within the bed, the packing remains clean even when handling a gas with a high particulate loading. One manulacturer reports that $99.9 \%$ of particulate $2 \mu \mathrm{m}$ and larger is removed with a pressure drop of 8 to $10 \mathrm{in}$. $\mathrm{H}_{2}(0$. Acid gas removal efficiencies are reported to be similar to those of packed-bed towers. Also, the turbulent motion eliminates channelling in the bed.

\section{Disadvantages}

The pressure drop in a fluidized bed is slightly higher than other wet acid gas scrubters. A total pressure drop is approximately 8 to $10 \mathrm{in}$. $-\mathrm{H}_{2} \mathrm{O}$. Because plastic spheres are used for packing, the flue gas temperature must be limited or damage will occur. Other scrubbers have the ability to operate at much higher temperatures by using high temperature alloys for the vessel and by using ceramic materials for the packing. Another problem that has been encountered in wet fluidized bed scrubbers is more frequent packing replacement. The continuous motion of the packing will eventually wear out the spheres due to the constant rubbing and collisions with other spheres and the internal scrubber surfaces. This problem is made worse when the scrubber is operated with a high gas velocity. A high gas velocity can aiso result in lifting and holding the packing spheres against the top retention grid. The opposite condition can also occur where the gas velocity is too low and bed fluidization does not occur. Either condition will reduce performance.

\section{Technology Status}

Availahle: Wet fluidized bed scrubbers are a well established lechnology, originally designed to scrub $\mathrm{SO}_{2}$ gas. They are available, although they are used less commonly in incineration off-gas treatment.

14.3.1.4 Spray Scrubbers (TT23328). ${ }^{1,2,3,4.0}$ Spray scrubbers are perhaps the simplest acid gas removal device available. Vertical, countercurrent towers have a gas inlet in the side of the tower 
near the bottom. The gases typically pass though a gas distribution plate to evenly spread out the gas flow. With the exception of a mist eliminator at the top of the tower near the outlet, the only other internals in the tower are one or inore banks of liquid spray nozzles.

In operation the liquid droplets produced by the nozzles fall through the gas stream. These droplets thus must be large enough for their terminal settling velocity to be larger than the gas velocity up the tower. Typical gas velocities are .6 to $1.5 \mathrm{~m} / \mathrm{s}(2$ to $5 \mathrm{ft} / \mathrm{s})$ with a liquid-to-gas ratio of 3 to $30 \mathrm{gpm} / 1000 \mathrm{acfm}$. The pressure drop through these scrubbers is approximately 1 to 3 in.$\mathrm{H}_{2} 0$.

\section{Input Streams}

Inputs consist of a hot off-gas stream which may contain particulates and acid gases, scrubber solutions, and makeup water.

\section{Output Streams}

Outputs consist of (1) cooled, saturated, treated off-gas stream with acid gases and significant amount of particulate removed, and (2) scrubber liquor blowdown solutions including scrubbed acid gases and scrubbed particulates.

\section{Advantages}

Advantages of spray scrubbers include (1) spray scrubbers are simple to operate and are relatively inexpensive, and (2) spray scrubbers can remove some particulate, although less efficiently than other scrubbing devices, especially for smaller particulate less than $5 \mu \mathrm{m}$ in diameter.

\section{Disactvantages}

Acid gas removals are only moderate at approximately $90 \%$ for $\mathrm{HCl}$ and $80 \%$ for $\mathrm{SO}_{2}$. Because of these low-acid gas removal efficiencies, spray scrubbers can only be used with some other acid-gas removal technology, or when high removal efficiencies are not required. Nozzle wear and plugging can also be a problem.

\section{Technology Status}

Proven: Spray towers are a well established and well used technology in many industries. They are available, although they are used less commonly in incineration off-gas treatment.

14.3.1.5 Ventusi Scrubbers (TT23330). ${ }^{1,2,24}$ Venturi scrubbers are similar to spray scrubbers except that they incorporate swirling flow and venturi flow principles to improve the gas-liquid contacting. Venturi scrubbers also include a second stage to increase gas-liquid contacting for improved efficiency, and to finally separate the cleaned gas and liquor streams. A schematic of a venturi scrubbing system is shown in Figure 14-9..$^{24}$

In operation, the flue gas stream enters the venturi in a swirling flow. Scrubbing liquor is sprayed tangentially into the gas flow at the venturi inlet to continuously wet the venturi walls and 

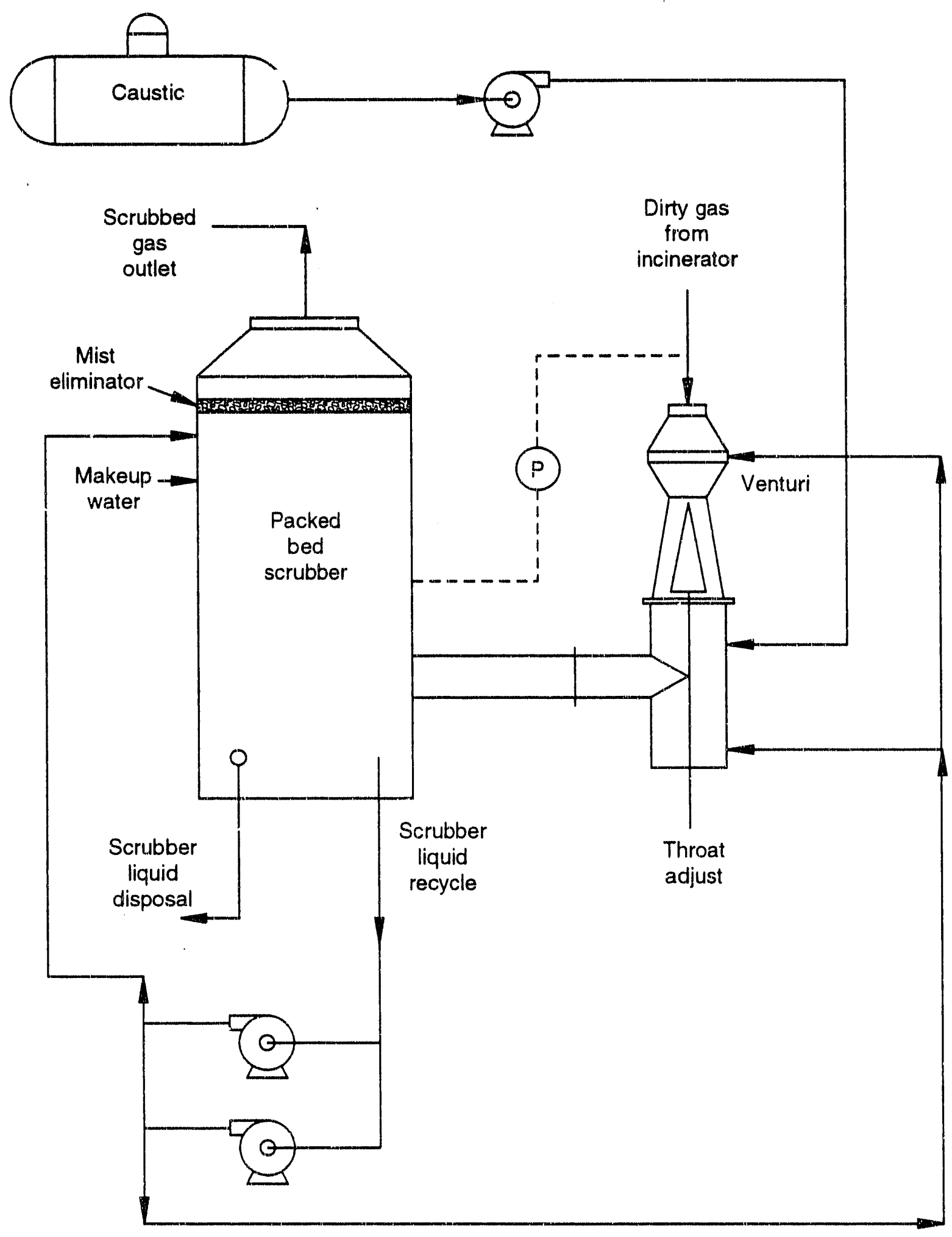

M92 0229

Figure 14-9. Schematic of a venturi-packed bed scrubber system. 
quench and saturate the high temperature [in excess of $260^{\circ} \mathrm{C}\left(500^{\circ} \mathrm{F}\right)$ ] flue gas. The scrubbing action begins in this spray at the venturi inlet. The quenched gas passes into the venturi throat where additional scrubbing solution is added. The throat can be controlled to optimize the throat velocity and mixing conditions in response to gas flow variations. The gas-liquid mixture continues on into the second stage. High efficiency scrubbers use a contacting device such as a packed bed separator as the second stage. Additional scrubber liquor is sprayed into the top to further the contacting process. The mist eliminator at the packed bed outlet removes the liquor droplets from the cleaned, saturated gas stream.

\section{Input Streams}

Inputs consist of a hot off-gas stream which may contain particulates and acid gases, scrubber solutions, and makeup water.

\section{Output Streams}

Outputs consist of (1) cooled, saturated, treated off-gas stream with acid gases and significant amount of particulate removed, and (2) scrubber liquor blowdown solutions including scrubbed acid gases and scrubbed particulates.

\section{Advantages}

Advantages of venturi scrubbers include (1) venturi scrubbers can take advantage of multiple gas-liquid contacting techniques (spray scrubbing, venturi flow, and packed bed contacting) to improve scrubbing efficiency for both acid gases and particulate, (2) acid gas removal efficiencies can exceed $99 \%$, and (3) the initial quench at the venturi inlet reduces the gas temperature to be compatible with less expensive, lower temperature construction materials downstream of that point.

\section{Disadvantages}

Disadvantages of venturi scrubbers include (1) capital and operation costs are somewhat higher due to the increased complexity of the venturi and secondary sections, and (2) since the system can be constructed of lower temperature materials (to lower costs), any upset in the scrubber liquor flow may result in insufficient gas cooling, leading to high temperature damage of the venturi/packed bed system.

\section{Technology Status}

Proven: Venturi scrubbers are a well established and well used technology in the waste incineration industry. They are available, although they are used less commonly in incineration offgas treatment than some other scrubbing systems.

\subsubsection{Dry Acid Gas Removal (TT23340) $)^{1,6,18,22,23,25,26,27,28}$}

Dry acid gas removal has been developed as an alternative to wet scrubbing, in an effort to lower the cost of operations and byproduct disposal. Less costly alkali reagents such as limestone can be used without the need for alkali preparations such as lime slaking, saving in both initial costs and 
operating costs. In addition, because a dry byproduct is generated, no need exists for wastewater treatment facilities or drying equipment. The result is a savings in initial costs and operating costs.

The general approach in dry acid gas removal is to inject calcium or sodium based sorbent material with the incinerator feed stream or, more commonly, into the oll-gas stream. The acid gases are absorbed by the sorbent, forming such compounds as calcium (sodium) sulfates and .alorides. These solids and the remaining sorbent material are collected with the tly ash in a baghouse. Indeed, much of the scrubbing efficiency is achieved in the baghouse, as the gas passes through the tilter cake on the surface of the bags.

The sorbent may be transported and injected either as a dry powder (Dry Sorbent Injection or DSI), or by mixing into in a water solution (Semidry Sorbent Injection).

14.3.2.1 Dry Sorbent Injection (TT23342). ${ }^{1,29}$ In dry sorbent injection (DSI), a dry powder sorbent, e.g., an alkali reagent, is injected at a point where the sorbent reacts with the acid gases that are present. The sorbent and any other particulate entrained in the llue gas is removed in a baghouse downstream of the sorbent injection point. A simplitied schematic is shown in Figure 14-10..$^{29}$ The sorbent is typically injected is via pneumatic transport through a nozzle, but mechanical feeders such as augers are also frequently used. For this process to perform as required, the flue gas velocity must be sufficiently high, and the sorbent particle size sufficiently low to entrain the dry powder in the gas stream. The powder must be uniformly dispersed in the the gas.

The sorbent may be injected at various locations in the incineration process, including delivery with the waste feedstream, in the incinerator, or into the fide gas duct upstream or downstream of any gas cooling equipment. In general, the process is more effective when the gas stream is cooled to approximately 121 to $149^{\circ} \mathrm{C}\left(250\right.$ to $\left.300^{\circ} \mathrm{F}\right)$ and the gas stream is kept noarly salurated. However, the temperature must be maintained above the dew point and not let the gases become saturated, as wet surfaces from condensation will quickly cake up with cement-like sorbent. Wet surfaces are also more subject to corrusion.

The benefits of the proper temperature range and the proper moisture content are not entirely known. One theory is that with the higher moisture content and lower temperature, the salt formed during acid conversion becomes hydrated and this moisture assists in the transport of acid molecules through the outer salt layers to the inner layers of the sorbent particle where unreacted alkali remains.

The alkali materials used in DSI are not as reactive as sodium hydroxide and the mixing of acid gases and alkali material is not as good as in a wet system. Therefore, an available sorbent-to-acid-gas ratio must be used of twice to three times that amount required for adsorbing the acid gases. With this excess sorbent material, $\mathrm{HCl}$ removal is typically above $90 \%$ and $\mathrm{SO}_{2}$ removal is typically above $50 \%$.

Higher acid gas removal efficiencies, with less excess alkali material, can be obtained by using a dry reactor chamber and recirculating a portion of the solids collected in the particulate removal. device to the reactor. The reactor provides a longer residence time and recirculating the dust: generates a high solids loading in the reactor, which increases contact between the acid gases and the: sorbent, and provides the sorbent with multiple opportunities to react, which improves alkali use. 


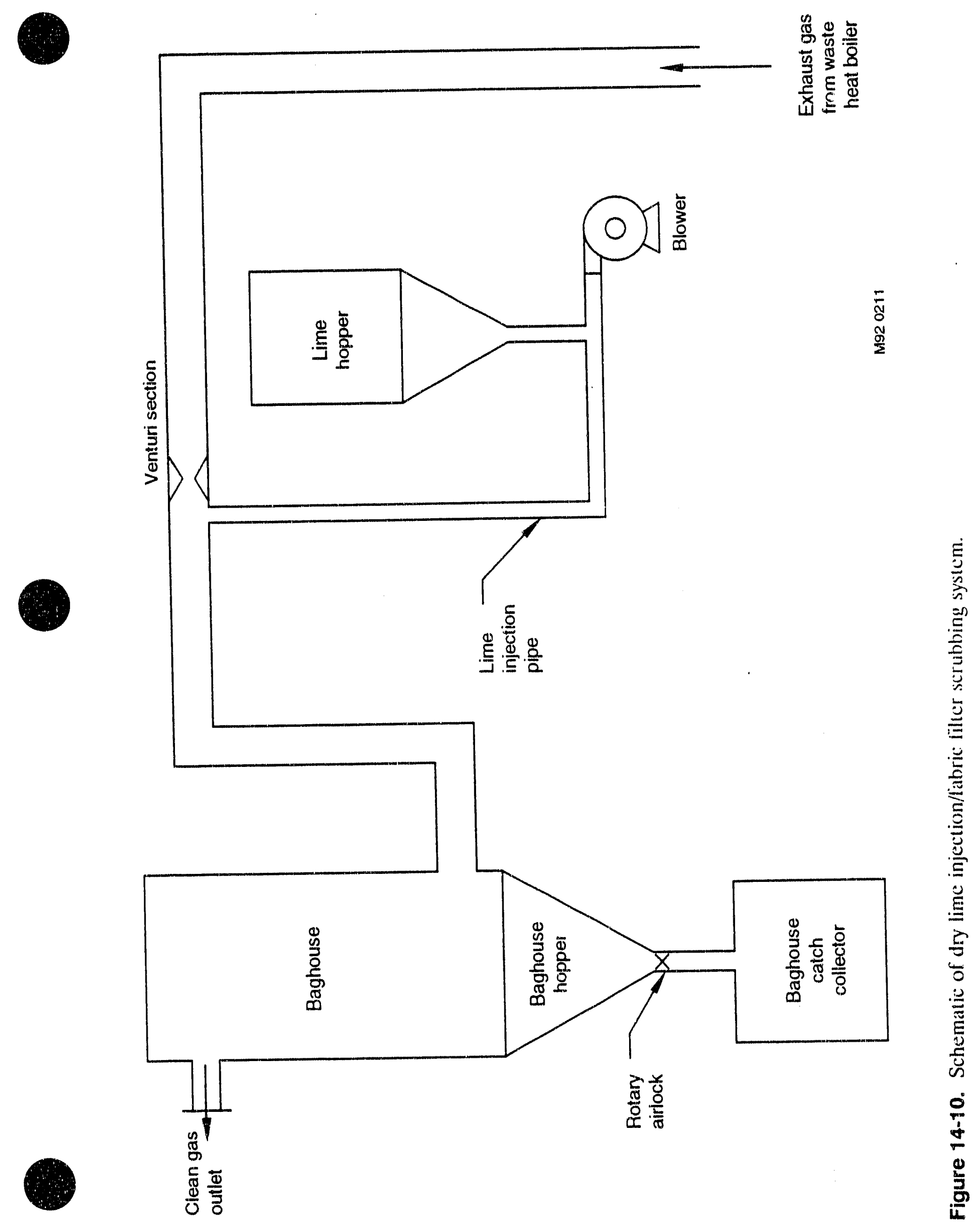


With solids recirculation, a large amount of unreacted alkali is present in the loop. As such, a buffer is available if acid gas formation suddenly surges or if the fresh alkali feeding system malfunctions. Removal efficiencies with a dry reactor and solids recycle can range from 95 to $99.9 \%$ for $\mathrm{HCl}$ and 70 to $98.8 \%$ for $\mathrm{SO}_{2}$ when using approximately 100 to $200 \%$ excess sorbent.

\section{lnput Streams}

Inputs consist of dry scrubber reagents and their carrying lluid (water, solution or atomizing air), offgas streams cooled as required to prevent c'amage to baghouses or other collection equipment.

\section{Output Streams}

Outputs consist of (1) treated offgas with acid gases and signiticant amounts of particulate removed, and (2) spent dry scrubbing reagent and collected particulate.

\section{Advantages}

The principal advantages to DSI include (1) a reduction in cost over other -cid gas control devices, (2) a dry byproduct, (3) the sorbent particles can also serve as condensation sites for condensible pollutants such as heavy metals and PICs, (4) the collected fly ash material is greatly diluted, reducing criticality and high concentration levels of metals and other hazardous materials, and can be made more amenable to cementation techniques, and (5) the process does not require or result in excessive cooling of tlue gases, minimizing moisture condensation, corrosion, and steam plumes, and preventing off-gas reheating requirements.

\section{Disadvantages}

The disadvantages of DSI include (1) the sorbent leeding system may oliten experience plugging or other difficulties, (2) the spent sorbent will affect disposal characteristics of the thy ash, especially volume of material and the $\mathrm{pH}$, (3) upon cooling, the spent sorbent may absorb moisture present from combustion or humid air, resulting in a paste or caking that can quickly plug key points in the removal system, such as the ash hopper rotary valve, and (4) the higher particulate loadings from the sorbent result in higher demands on particulate removal equipment.

\section{Technology Status}

Available: Dry sorbent injection with baghouse particulate removal is an established technology, used in the waste incineration industry. This technology is available for low level waste treatment.

14.3.2.2 Semidry Sorbent Injection (TT23344). ${ }^{1,4.22 .23,30.31 .32 .33 .34}$ This technology is similar to dry sorbent injection, but uses an aqueous sorbent mixture sprayed into the off-gas, rather than pneumatically transported dry sorbent. A schematic of a spray dryer absorber is shown in Figure 14-11.

In the spray dryer absorption process, water and pulverized sorbent are mixed to form a solution. The solution is then injected into a spray dryer absorber as a finely atomized spray. Acid gases present in the flue gas are absorbed into the small liquid droplets and are reacted with the 


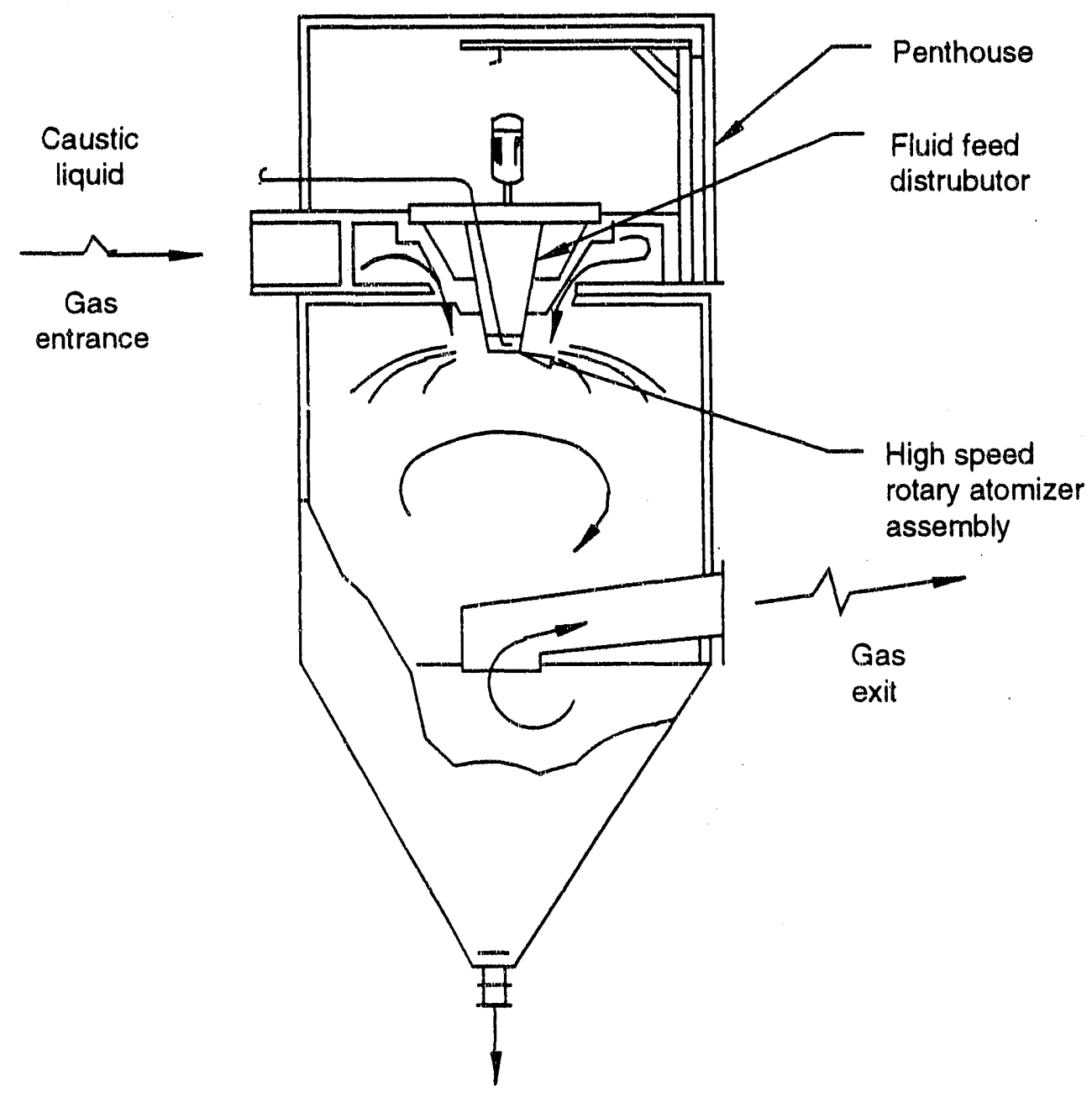

To ash and salt removal system

M92 0212

Figure 14-11. Schematic of a spray dry absorber. 
alkali reagent to form a salt. As the droplets pass through the reactor, heat from the flue gas evaporates the water, cooling the flue gas and forming solid particles of salt, unreacted alkali, and possibly fly ash. The dry solids are then collected downstream of the reactor in a particulate removal device.

The liquid scrub solution is normally atomized in one of two ways: (1) a two-fluid nozzle or (2) a rotary atomizer. The two-fluid nozzle is intageous in that it has a large scrub liquor passageway that is not easily plugged by solids. Thuse nozzles use a second lluid, either steam or air, at high pressure to atomize the scrub liquor. A second advantage of this type of nozzle is that it is easily serviced without cooling the reactor by simply unbolting a llange and removing the spray nozzle assembly.

The rotary atomizer uses a motor to drive a revolving disc at a high speed to atomize the liquid. The rotary atomizer has the advantage of a constant droplet size regardless of liquid flow rate and an excellent distribution of the droplets throughout the reactor. The disadvantage to the rotary atomizer is the increased maintenance required.

An important element of the spray dryer absorption technology is the distribution of the gas stream in the reactor. Various methods are employed to uniformly disperse the oflyas throughout the vessel. The dispersal device, however, is irequently considered proprietary with lew details available. Another important element is gas temperature. Lower gas temperatures result in better acid conversion, but the temperature must be maintained above the dew point or moist solids may solidify on internal surfaces, and corrosion problems could occur.

The flue gas temperature at the reactor exit is typically 7 to $10^{\circ} \mathrm{C}\left(20\right.$ to $\left.50^{\circ} \mathrm{F}\right)$ above saturation. The temperature and moisture levels are controlled by adding extra water through the atomizing nozzle. To allow for complete moisture evaporation and to maximize acid conversion, reactor residence times range from 4 to $20 \mathrm{~s}$, with approximately $10 \mathrm{~s}$ as the most common.

Using spray dryer absorption, acid gas removal can be as high as $99 \%$ lor $\mathrm{HCl}$ and $95 \%$ for $\mathrm{SO}_{2}$. To accomplish this a 50 to $100 \%$ excess of alkali reagent is normally used. To improve alkali use, the solids can be collected and either recycled as a dry powder or dissolved and injected through the atomizing nozzle.

\section{Input Streams}

Inputs consist of dry scrubber reagents and their carrying fluid (water, solution or atomizing air), offgas streams cooled as required to prevent damage to baghouses or other collection equipment.

\section{Output Streams}

Outputs consist of (1) treated offgas with acid gases and signiticant amounts of particulate removed, and (2) spent dry scrubbing reagent and collected particulate. 


\section{Advantages}

Sorbent solution injection systems share most of the same advantages as dry sorbent injection (DSI) systems. In addition, the injection system may be less trouble-prone than for the DSI systems. The generated waste is a dry, fairly homogeneous stream, as in DSI. Where the process is dry, corrosion rates are lower, and thus less expensive construction materials can be used.

\section{Disadvantages}

Controlling droplet size is important. If the particles are too small, they will dry out before sufficient absorption can take place. If the particles are too large, less surface area per volume is available, and gas mixing will be reduced. The droplet size also effects the size of solid particles produced. If the droplets are too small, a tine particulate is produced and particulate removal is difficult. Large particles may result in insulficient evaporation and may actually lead to a coating or buildup inside the reactor. In addition, when lime is used as the reagent, a deliquescent byproduct is produced. If the process is not properly controlled, the solids can become tacky or turn to paste, resulting in many operational problems.

\section{Technology Status} industry.

Emerging: Semidry sorbent injection is an emerging technology, used in the waste incineration

\section{$14.4 \mathrm{NO}_{\mathrm{x}}$ Control (TT23400)}

Oxides of nitrogen $\left(\mathrm{NO}_{x}\right)$ that are emitted from incineration processes include nitric oxide (NO), nitrogen dioxide $\left(\mathrm{NO}_{2}\right)$, and nitrous oxide $\left(\mathrm{N}_{2} \mathrm{O}\right)$. $\mathrm{NO}_{x}$ emissions are the result of oxidation of nitrogen in the fuel (fuel $\mathrm{NO}_{\mathrm{x}}$ ) and oxidation of molecular nitrogen $\left(\mathrm{N}_{2}\right)$ in the combustion air. $\mathrm{NO}_{x}$ formation mechanisms are complex depend on many variables, but the three dominant variables are the percentage of nitrogen in the fuei, the amount of excess air (oxygen) available for oxidation, and the combustion temperatures. Higher levels of fuel nitrogen, available oxygen and temperatures favor higher $\mathrm{NO}_{\mathrm{x}}$ formation. Except in oxygen-fired processes, molecular nitrogen is generally available from the combustion air so molecular nitrogen availability is usually not a limiting factor.

Uncontrolled $\mathrm{NO}_{x}$ emissions trom many combustion and incineration processes can exceed several hundred parts per million. In most well operated combustion processes including most incineration processes, about 90 to $95 \%$ of the total $\mathrm{NO}_{x}$ is $\mathrm{NO}$, with the remainder being $\mathrm{NO}_{2}$ and $\mathrm{N}_{2} \mathrm{O}$. The scrubber systems discussed in Section 14.3 are not especially effective for $\mathrm{NO}_{x}$ control, because $\mathrm{NO}$ (the majority of $\mathrm{NO}_{x}$ emissions) is not efficiently captured in those scrubber systems, although $\mathrm{NO}_{2}$ component is effectively captised in wet scrubbers.

$\mathrm{NO}_{\mathrm{x}}$ control is achieved most readily by limiting the amount of luel nitrogen entering the process, by limiting the formation of $\mathrm{NO}_{x}$, by chemical conversion of $\mathrm{NO}_{x}$ to other nitrogen compounds $\left(\mathrm{N}_{2}\right)$, or by scrubbing $\mathrm{NO}_{x}$ out of the llue gas. Most eflective $\mathrm{NO}_{x}$ control can be achieved using combination or hybrid of two or more control technologies. $\mathrm{NO}_{x}$ control technologies can be categorized as (1) reductions of fuel nitrogen, (2) in-lurnace $\mathrm{NO}_{\mathrm{x}}$ controls or (3) downstream offgas reduction methods. 
In incineration processes, reducing the fuel nitrogen is generally limited to sorting the waste streams to eliminate high organic nitrogen-content wastes. In some cases, physical or chemical separations are possible to reduce fuel nitrogen levels. However, these practices are limited, and only affect the formation of fuel $\mathrm{NO}_{\mathrm{x}}$. In this report, only in-furnace and downstream $\mathrm{NO}_{\mathrm{x}}$ controls are discussed. The most common $\mathrm{NO}_{\mathrm{x}}$ control measures are summarized in the following sections:

\section{Section Technology}

14.4.1 In-furnace $\mathrm{NO}_{\mathbf{x}}$ Cortrols (TT23410)

14.4.2 Selective Catalytic Reduction (TT23420)

14.4.3 Selective Noncatalytic Reduction (TT23430)

14.4.4 Nonselective Noncatalytic Reduction (TT23440)

14.4.5 Nonselective Catalytic Reduction (TT23450)

14.4.6 Direct Decomposition (TT23460)

14.4.7 Oxidation and Scrubbing (TT23470)

14.4.8 Chelation and Scrubbing (TT23480)

\subsubsection{In-furnace $\mathrm{NO}_{\mathrm{x}}$ Controls $\left(\mathrm{TT}_{23410)^{1}}\right.$}

In-furnace $\mathrm{NO}_{\mathrm{x}}$ controls involve processes that most generally limit the initial formation of $\mathrm{NO}_{\mathrm{x}}$, or which reduce $\mathrm{NO}_{x}$ levels in the combustion gases prior to departure of those gases irom the furnace regions of the combustion processes. The performance of these processes is highly dependent on in-furnace residence times, temperatures, concentration levels and mixing conditions. Since a multitude of combustion and incineration devices are available that exhibit a variety of operating conditions, a large variety of in-furnace $\mathrm{NO}_{x}$ control techniques and variations are available. In addition, new and ongoing research is adding to the range of in-lurnace $N \mathrm{O}_{x}$ control technologies. Examples include:

- Steam or water injection into the combustion zone 10 lower combustion temperatures and assist in the tormation of $\mathrm{N}_{2}$ rather than $\mathrm{NO}$

- Flue gas recirculation back into the combustion zone to reduce combustion zone temperatures and lower the concentrations of excess oxygen in the higher temperature zones

- Rapid heat transfer out of the combustion unit to reduce combustion zone temperatures

- Staged air addition, which affects mixing, lowers the oxygen levels in higher temperature zones and provides for final or complete combustion removed from the initial combustion zones

- Reburning using natural gas or other fuels, downstream of the initial combustion zone, to reduce $\mathrm{NO}_{\mathrm{x}}$ to $\mathrm{NO}$

- Specially designed low- $\mathrm{NO}_{\mathrm{x}}$ burners for waste gas, liquid wastes, and auxiliary fiuel burning

- Reducing the overall excess air levels to lowest reasonable lovels 
- Using pure oxygen, oxygen-enriched air, or synthetic air made of oxygen and argon, to reduce molecular nitrogen levels

These in-furnace $\mathrm{NO}_{x}$ control techniques are only moderately effective, achieving from 20 to $70 \% \mathrm{NO}_{\mathrm{x}}$ reduction, depending on the combustion system and the method or combination of methods employ d. Although this level of reduction may not be satisfactory in all cases, these technologies, along with fuel nitrogen reductions, should be used where appropriate, in addition with downstream $\mathrm{NO}_{\mathrm{x}}$ controls, to achieve the desired overall $\mathrm{NO}_{\mathrm{x}}$ control.

\section{Input Streams}

In addition to the waste feedstreams, and depending on the techniques used, input streams may include steam, water, low nitrogen fuels, staged air, pure oxygen, enriched oxygen, argon, or reburning fuels.

\section{Output Streams}

Output streams consist of high nitrogen sidestreams from preincineration waste sorting, and varied-composition off-gases from the $\mathrm{NO}_{x}$ control activities.

\section{Advantages}

Advantages of in-furnace $\mathrm{NO}_{\mathrm{x}}$ control include (1) depending on the waste and incineration system, these types of techniques may be easy to implement, and cost little to install or operate, and (2) although not highly efficient, use of these types of technologies may sufficiently reduce $\mathrm{NO}_{\mathrm{x}}$ levels without additional downstream $\mathrm{NO}_{x}$ control.

\section{Disadvantages}

Disad antages of in-furnace $\mathrm{NO}_{\mathrm{x}}$ controls include (1) implementation of any of these technolog is is highly dependent upon the design and operation of each incinerator system, and on the wast z being processed, (2) implementation of any $\mathrm{NO}_{x}$ control strategies generally requires a limited to extensive research and test prograrn to evaluate its incinerator performance before and after implementation. (3) in-furnace $\mathrm{NO}_{x}$ control strategies tend to hinder effective incinerator performance in other areas. including destruction and combustion efficiency, and (4) many strategies that reduce $\mathrm{NO}$ and $\mathrm{NO}_{2}$ may tend to increase $\mathrm{N}_{2} \mathrm{O}$.

\section{Technology Status}

Available: In-furnace $\mathrm{NO}_{\mathrm{x}}$ control is a well researched and developed technology, but ongoing research continues. In-furnace $\mathrm{NO}_{x}$ control strategies have been effectively implemented for years in combustion processes. Development of in-furnace $\mathrm{NO}_{x}$ control strategies for incinerators is less developed, because (1) $\mathrm{NO}_{x}$ emissions levels from incinerators are not as high as $\mathrm{NO}_{x}$ emission levels in other industries, and (2) regulations have not so strictly limited $\mathrm{NO}_{\mathrm{x}}$ emissions from incinerators. 


\subsubsection{Selective Catalytic Reduction (TT23420) $35,36,37$}

The selective catalytic reduction (SCR) process was developed nearly $30 \mathrm{yr}$ ago. Ammonia $\left(\mathrm{NH}_{3}\right)$ gas is reacted in this process with $\mathrm{NO}_{x}$ in the presence of a catalyst to form molecular nitrogen $\left(\mathrm{N}_{2}\right)$ and water. The process is referred to as selective because the ammonia preferentially reduces the $\mathrm{NO}_{\mathrm{x}}$ to $\mathrm{N}_{2}$ rather than participating in other reactions with other llue gas constituents. The process takes place inside a reactor and requires that the ammonia be evenly distributed throughout the gas flow. To accomplish this an injection grid is used that injects precisely controlled amounts of ammonia through a bank of small but numerous nozzles. The ammonia is then normally mixed in the flow with baffles, turns, etc. Gas tlow distributors are used to provide a uniform flow through the catalyst.

Originally, this process required a narrow temperature band, but improvements have been made that permit operating between 260 and $427^{\circ} \mathrm{C}\left(500\right.$ and $\left.800^{\circ} \mathrm{F}\right)$. Below this temperature range the catalyst activity is too low. Above this temperature range, the catalyst can be damaged by sintering. At higher temperatures, the process may actually increase the amount of $\mathrm{NO}_{x}$ that is present. Other important process parameters include initial $\mathrm{NO}_{x}$ concentration, removal efliciency required, amount of catalyst, residence time and the molar ratio of ammonia to nitrogen oxides $\left(\mathrm{NH}_{3} / \mathrm{NO}_{x}\right)$.

For $90 \% \mathrm{NO}_{x}$ removal, the $\mathrm{NH}_{3} / \mathrm{NO}_{x}$ ratio is approximately 0.6:1 to 1:1. Using this stoichiometric ratio, some unreacted ammonia, typically 1 to $5 \mathrm{ppm}$, will pass through the reaction section and be emitted to the atmosphere. Higher removal efficiencies up to $95 \%$ can be obtained by increasing the $\mathrm{NH}_{3} / \mathrm{NO}_{x}$ ratio to $1.1: 1$ to $1.3: 1$. However, this excess of ammonia can result in levels of unreacted ammonia up to $50 \mathrm{ppm}$.

Lowering the $\mathrm{NO}_{\mathrm{x}}$ removal efficiency will have the opposite elfect. In onc kest using $85 \% \mathrm{NO}_{\mathrm{x}}$ removal, ammonia releases were redueed down to below detection limits. If high removal efficiency and low ammonia emissions are required, a high $\mathrm{NH}_{3} / \mathrm{NO}_{x}$ ratio can possibly be used if a wet scrubber is installed downstream from the catalyst bed for excess ammonia removal.

Different versions of this process are commercially available. Each variation has its own advantages and disadvantages. A fixed-bed catalyst using a honeycomb structure is fairly common. Typically, the catalyst will contain itanium oxide, vanadium pentoxide, and tungsten oxide in proportions tailored to fit the particular gas strearn. These catalysts are filled with macro and micro pores resulting in a large surface area for a given volume. The gas stream llows through the catalytic reactor, which may contain two to four catalyst beds in series. In the catalyst beds. the ammonia and $\mathrm{NO}_{x}$ diffuse into the pores and react at a catalytic sile. Consequently, soot buildup or deposits of particulate on the catalyst can lower the $\mathrm{NO}_{x}$ conversion.

To mitigate these problems, soot blowers can be installed at the catalyst bed entrance. Bed designs have also been modified to minimize deposits. In addition, some catalysts can be cleaned by sandblasting or some other technique.

In another version of this process, the catalyst is supported on a pertorated grid. During operation, the catalyst is lluidized, resulting in a turbulent process where the gases and catalyst are well mixed. This process uses a nonnoble catalyst that is nonporous. The reactions occur on the outer surface of the catalyst. Because of the lluidization, however, the catalyst surface is continuously 
cleaned of deposits. This catalyst is resistant to fouling from chlorides, carbon monoxide, and sulfur dioxide. Additionally, in the fluid bed process the catalyst can be replaced without shutting the system down.

\section{Input Streams}

Input streams consist of flue gas to be treated, ammonia (or alternate reductant), occasionally replacement of spent catalyst.

\section{Output Streams}

Output streams consist of treated flue gas that contains 80 to $90 \%$ less $\mathrm{NO}_{\mathrm{x}}$ but which contains low levels of ammonia, ammonium sulfates and chlorides (if sulfates and chlorides are present in the gas stream, and occasional spent catalyst.

\section{Advantages}

Advantages of selective catalytic reduction include (1) this process is relatively simple and is capable of $\mathrm{NO}_{x}$ removal efficiencies of 80 to $90 \%$. (2) higher removal levels can be obtained by adding more catalyst beds or by increasing the $\mathrm{NH}_{3} / \mathrm{NO}_{x}$ ratio, (3) the major products are nonpolluting, e.g., water and nitrogen, (4) this technology is also relatively mature with many years of operating experience, (5) a computerized process model can be used to provide good design information even with the large number of process parameters, and (6) recent investigations have indicated that base metal catalysts oxidize carbon monoxide and other PICs to carbon dioxide and water.

\section{Disadvantages}

Because of the use of ammonia, significant auxiliary equipment requirements are necessary that are costly. Ammonia storage, metering, and vaporization equipment must be provided. In addition, some unreacted ammonia is released into the atmosphere. Typically, the ammonia release level is less than 5 ppm. However, as the catalyst activity declines, extra ammonia injection is required to achieve the same reduction efficiency, increasing the amount of ammonia released from the stack.

Problems with catalyst erosion may occur, although more resistant catalysts have been developed. Catalyst plugging and poisoning also can be problems although improvements in catalyst shape and type have mitigated these problems to a large degree. Also, some unwanted reactions may occur. The catalyst may convert sulfur dioxide to sulfur trioxide. Then, in the presence of the ammonia, the sulfur trioxide can be converted to ammonium sullate and ammonium bisulfate, which can corrode and foul downstream equipment and cause a visible plume from the stack. Ammonium bisulfate is particularly detrimental as it is acidic and hygroscopic. If the calalyst is used downstream of acid gas and particulate removal equipment in protect against plugging and crosion, a gas reheat system may be necessary to increase the gas temperature to the desired catalyst operating range.

Problems associated with the process variations may occur. The lluidized-bed process can have a moderately high pressure drop of 20 in. $-\mathrm{H}_{2}$ ), possibly causing higher fan installation and operating 
costs. The noble metal catalyst can also be expensive. Typically, the calalyst in these systems account for over half of the total system cost; therefore, catalyst replacement is expensive.

\section{Technology Status}

Emerging: This is a well developed technology for many combustion and incineration processes. It is an emerging technology and has not been proven for low level waste incineration because control of $\mathrm{NO}_{\mathrm{x}}$ emissions has not been a high priority compared to control of emissions of other acid gases, PICs, particulate, and nuclides.

\subsubsection{Selective Noncatalytic Reduction (TT23430) $)^{1,35,37,38,39,40}$}

Selective noncatalytic reduction (SNCR) was developed approximately $17 \mathrm{yr}$ ago. As it was originally developed, this technology was similar to selective catalytic reduction. Ammonia was injected through an injection grid into the offgas to react with $N O_{x}$ to reduce it to nitrogen and water. As with selective catalytic reduction, this process relies upon temperature control and effective ammonia dispersion in the llue gas to maximize $\mathrm{NO}_{x}$ removal and to minimize releases of unreacted ammonia. However, unlike selective catalytic reduction, this process does not use a catalyst and must be operated at a higher temperature, typically 709 to $1204^{\circ} \mathrm{C}\left(1600\right.$ lo $\left.2200^{\circ} \mathrm{F}\right)$, to provide sufficient energy for the reaction.

As the technology has matured, variations of the process have evolved. Lower operating temperatures can be used by also injecting hydrogen gas. Other reductants besides ammonia are now available, such as urea and cyaneric acid. For example, urea can be used because it will break down when heated to form the same type of reactive species as ammonia. Urea can be mixed with water and handled as a liquid, which typically requires less equipment. Liquid injection also is reported to have smaller energy requirements. The disadvantage of using urea is its potential to increase carbon monoxide emissions in the flue gas by 5 to $25 \mathrm{ppm}$.

Frequently, other chemicals are either added to the urea solution or are injected downstream of the urea injection point. These extra chemicals may include surlactants that help control the size of the droplets formed during injection into the llue gas, additives 10 make the reactants more reactive at lower temperatures, methanol to reduce emissions of unreacted reductant and to reduce deposits on heat transfer surfaces, and antiscaling agents to prevent the urea lrom reacting with the hardness in the water and forming deposits.

Improvements also have been made to the injection system. Wall injectors have been developed because of the concern of degradation of the injection grid because of high temperatures, acid corrosion, and erosion from particulate. These wall injectors consist of jets located at or near the boundary walls of the injection zone. Such injectors are simple, relatively inexpensive, and can be installed within the combustion zone of the equipment. If a large turndown is required, multiple injection nozzles can be used. Multiple injection ports also can be used to automatically change the reductant injection location to more optimum temperature regions as the temperature profile in the system changes. 


\section{Input Streams}

Input streams consist of flue gas to be treated, ammonia (or alternate reductant), and selected additional chemicals.

\section{Output Streams}

Output streams consist of treated flue gas that contains 70 to $80 \%$ less $\mathrm{NO}_{\mathrm{x}}$ but which contains low levels of ammonia, other injected chemicals, $\mathrm{CO}$, and ammonium sulfates and chlorides (if sulfates and chlorides are present in the gas stream).

\section{Advantages}

Selective noncatalytic reduction can provide moderate $\mathrm{NO}_{x}$ removal of 70 to $80 \%$. Higher $\mathrm{NO}_{\mathrm{x}}$ removal efficiency can normally be obtained by increasing the $\mathrm{NH}_{3} / \mathrm{NO}_{x}$ molar ratio, but this will also increase ammonia emissions. In general, ammonia emissions can be reduced by operating at a higher temperature. Increasing the temperature too much, however, may actually hinder $\mathrm{NO}_{\mathrm{x}}$ removal because the optimum operating temperature depends on various other operational parameters.

Other advantages are available when a catalyst is not involved. Catalyst bed pressure drop, fouling, poisoning and erosion problems are eliminated. Without the caltalyst, installation and operating costs can be lower.

\section{Disadvantages}

Selective noncatalytic reduction can also use ammonia and can have the problems generally associated with handling ammonia, including the costs associated with installing and maintaining the ammonia storage and feed system. Furthermore, il sullur compounds or chloride compounds are present in the llue gas, these compounds can react with the reductant to produce ammonium sulfate, ammonium bisulfate, and ammonium chloride. These byproducts will increase the salt particulate level, which can result in increased corrosion, louling, and plugging of heat transter devices, and plume formation.

Another disadvantage of this process is the loss of the reductant to adsorption and side reactions. Because this is a high-temperature process, the reductant is normally injected before the particulate has been removed. Unfortunately, the lly ash will absorb some reductant, preventing its participation in $\mathrm{NO}_{x}$ reduction. Furthermore, in the temperature range where selective noncatalytic reduction is used, some reductant will react with oxygen resulting in more losses. As a result, the reductant-to-nitrogen oxide ratio may need to be as high as $1.5: 1$.

Unreacted ammonia levels are often higher, due to the higher injection ratio. Consequently, emissions of unreacted ammonia can exceed $10 \mathrm{ppm}$. Use of additives such as methanol can reduce ammonia emissions to less than $1 \mathrm{ppm}$, but will result in an increase in CO emissions of approximately 5 to $10 \mathrm{ppm}$. 


\section{Technology Status}

Emerging: This is a well developed technology for many combustion and incineration processes. It is an emerging technology and has not been proven for low level waste incineration because control of $\mathrm{NO}_{\mathrm{x}}$ emissions has not been high priority compared to emissions of other acid gases, PICs, particulate, and nuclides.

\subsubsection{Nonselective Noncatalytic Reduction (TT23440) ${ }^{1,35,37,40,41}$}

One of the newer flue gas $\mathrm{NO}_{\mathrm{x}}$ reduction technologies, which may also be considered an infurnace reduction technique, is a nonselective noncatalytic reduction (NSNCR) process also referred to as reburning, methane injection, or natural gas injection. This process is similar to selective noncatalytic reduction except a less selective reductant is used. This process is referred to as nonselective because the reductant will not preferentially reduce $\mathrm{NO}_{x}$ but can easily react with other combustion gases, especially oxygen.

In nonselective noncatalytic reduction, natural gas or some other combustible gas is injected into the flue gas. This creates a reducing environment where the $\mathrm{NO}_{x}$ is reduced to molecular nitrogen and water or carbon monoxide. If other nitrogen compounds, such as ammonia or cyanide are present, the nitrogen in these compounds also can be converted to molecular nitrogen. After sufficient mixing and time to react, air is injected into the llue gas to burn the remaining combustible gases.

The process is sensitive to retention time between reductant addition and air addition. By increasing this time to $3 \mathrm{~s}, \mathrm{NO}_{\mathrm{x}}$ reduction will increase. However, beyond $3 \mathrm{~s}$, little additional $\mathrm{NO}_{x}$ reduction is gained. As would be expected, the amount of reductant added is also important to the degree of $\mathrm{NO}_{\mathrm{x}}$ reduction; however, the process is insensitive to temperature.

One variation that is being investigated includes tlue gas recycling (FGR), which by itself can be an effective $\mathrm{NO}_{x}$ control strategy. In this variation, $15 \%$ of the liue gas is recycled back to the combustion zone. Natural gas, at a flowrate amounting to $15 \%$ of the total heat input, is mixed with the recycled gas before injection into the combustion zone. Depending on the residence time used, this process can lower $\mathrm{NO}_{\mathrm{x}}$ levels by 40 to $65 \%$.

\section{Input Streams}

Input streams are combustion gas to be treated, reburning luel, staged air for tinal fuel oxidation.

\section{Output Streams}

Output stream is $\mathrm{NO}_{x}$-depleted tlue gas.

\section{Advantages}

Advantages of NSNCR include (1) because NSNCR uses fuel as a reductant, little additional equipment is needed if the same fuel is used lor the auxiliary heat input, (2) a lack of byproducts that 
need additional treatment, and (3) because ammonia is not used, ammonium salts that are corrosive and plug equipment are not generated.

NSNCR can also reduce levels of some other pollutants. Tests have demonstrated reductions in carbon monoxide of approximately 50\%. Similar reductions can be expected for other products of incomplete combustion. Importantly, these reductions were obtained while significantly reducing excess air.

\section{Disedvantages}

This technology is relatively new; not enough operating experience is available to identify all of the problems that will be encountered. However, there are a few areas of concern. Because this is not a selective process, the economics and possibly the performance will be affected by the amount of oxygen in the combustion gases. In addition, this technology was originally intended for coal-fired boiler applications and only recently tested on incineration application. NSNCR is emerging as a control strategy for incineration. Little data exist to demonstrate optimum operating conditions or the ability to handle wide process fluctuations in flow rate and composition. Lastly, no data were found concerning the use of this technology in extremely high $\mathrm{NO}_{x}$ loadings greater than $1 \%$.

\section{Technology Status}

Emerging: This is a less well developed technology for combustion and incineration processes. It is an emerging technology and has not been proven for low level waste incineration.

\subsubsection{Nonselective Catalytic Reduction (TT23450) $)^{1,35,37}$}

In this process, a nonselective reductant such as methane, hydrogen, or some other gaseous fuel is added to the tlue gas and then passed over a catalyst at approximatcly 570 to $850^{\circ} \mathrm{F}$. The nonselective nature of the process means that the reductants will react with oxygen and so extra reductant is needed. The reaction of the reductant with oxygen also generates excess heat resulting in a temperature rise of approximately $132^{\circ} \mathrm{C}\left(270^{\circ} \mathrm{F}\right)$ for every percent of oxygen in the thue gas. Therefore, if the flue gas has $210.3 \%$ oxygen. multiple reactors may be necessary, with interreactor cooling, to effectively remove the heat and stay within the desired temperature range.

In one variation of this technology that is commercially available, nonselective calalytic reduction is combined with other technologies previously discussed in this report to make a hybrid process. In the first step, excess fuel is added to the llue gas in a reduction chamber as is done in nonselective noncatalytic reduction. This step removes approximately $50 \%$ of the $\mathrm{NO}_{\mathrm{x}}$ but also results in a temperature rise. As such, the flue gases are then cooled using a heat exchanger or some other heat transfer device.

More combustion air is then added to the gas stream to keep the CO concentration between 750 and $1500 \mathrm{ppm}$. This step is necessary to maintain a high tevel of $N O_{x}$ reduction. If the $\mathrm{CO}$ conce thition falls below $750 \mathrm{ppm}$, then not enough reduclant is available lo mix with and react with the $\mathrm{NO}_{x}$. If the $\mathrm{CO}$ level increases above $1500 \mathrm{ppm}$, much of the $\mathrm{NO}_{\mathrm{x}}$ is reduced to combustible nitrogen composnds, i.e., the $\mathrm{NO}_{x}$ is converted to luel bound nitrogen that will react to reform $\mathrm{NO}_{x}$ 
in a subsequent step. Higher levels of $\mathrm{CO}$ may also occupy catalytic sites in the reduction catalyst that follows.

After adjusting the $\mathrm{CO}$ concentration, the flue gas is passed through a reduction catalyst at $399^{\circ} \mathrm{C}\left(750^{\circ} \mathrm{F}\right)$. In this step, the $\mathrm{NO}_{\mathrm{x}}$ level is reduced to below $25 \mathrm{ppm}$. The flue gas is then mixed with excess air and passed over an oxidation catalyst to burn out the remaining combustibles. The $\mathrm{CO}$ concentration in the flue gas is reduced to less than $50 \mathrm{ppm}$ in this last step. The outlet oxygen concentration is between 1.5 and $3.0 \%$.

\section{Input Strearns}

Input streams are combustion gas to be treated, reducing agent, occasional replacement catalyst.

\section{Output Streams}

Output streams are $\mathrm{NO}_{\mathrm{x}}$-depleted llue gas and occasional spent catalyst.

\section{Advantages}

Advantages of nonselective catalytic reduction include (1) the nonselective catalytic process has no byproducts to treat and dispose, (2) because ammonia is not used, no salts are generated that will plug, foul, and corrode downstream equipment. (3) the expense of ammonia storage, evaporation and delivery system is not needed, (4) high $\mathrm{NO}_{\mathrm{x}}$ removal efficiencies can be oblained, and (5) when using this hybrid process, $\mathrm{NO}_{x}$ removal in excess of $98 \%$ is achievable.

\section{Disadvantages}

Disadvantages of nonselective catalytic reduction include (1) since the technology is relatively new with little data available, there is higher uncertainty with this technology, (2) the use of a catalyst will increase cost and can increase operational problems such as poisoning and louling. (3) the hybrid process may also be difficult to control as incinerator processes typically have large periodic swings in carbon monoxide generation, and (4) as with the nonselective noncatalytic process, the process economics will be dependent on the arnount of oxygen that is present in the llue gas.

\section{Technology Status}

Emerging: This is a less well developed technology for combustion and incineration processes. It is an emerging technology and has not been proven for low level waste incineration.

\subsubsection{Direct Decomposition (TT23460) $)^{1,35,37,42}$}

Perhaps the simplest concept for $\mathrm{NO}_{x}$ abatement is the direct decomposition of $\mathrm{NO}_{\mathrm{x}}$ into molecular nitrogen and oxygen. In this process, no other reactants other than the $\mathrm{NO}_{\mathrm{x}}$ itself is involved. The $\mathrm{NO}_{\mathrm{x}}$ is brought into contact with a catalyst surlace where the $\mathrm{NO}_{\mathrm{x}}$ is split apart so $\mathrm{N}_{2}$ and $\mathrm{O}_{2}$ can form. No other byproducts or unreacted additives are released. Several researchers have studied the catalytic decomposition of $\mathrm{NO}_{x}$ into $\mathrm{N}_{2}$ and $\mathrm{O}_{2}$ using several dilferent catalysts made from oxides of iron, cobalt, nickel, copper, zirconium, and supported platinum and rhodium. Despite the 
amount of research carried out on direct $\mathrm{NO}_{x}$ decomposition, this method is still basically a laboratory process with no commercial system known to be available.

Because this technique is still in the research stages, operational parameters have not been defined. Operating temperatures under $38^{\circ} \mathrm{C}\left(100^{\circ} \mathrm{F}\right)$ have been tried, and a significant amount of work has been done in the 316 to $537^{\circ} \mathrm{C}\left(600\right.$ to $\left.1000^{\circ} \mathrm{F}\right)$ range. Many calalysts have been shown to produce only $\mathrm{N}_{2}$ and $\mathrm{O}_{2}$ at temperatures greater than $449^{\circ} \mathrm{C}\left(840^{\circ} \mathrm{F}\right)$.

\section{Input Streams}

Input stream is combustion gas to be treated and occasional replacement catalyst.

\section{Output Streams}

Output streams are $\mathrm{NO}_{\mathrm{x}}$-depleted the gas and occasional spent catalyst.

\section{Advantages}

This process is relatively simple, and depending on the type, amount, and useful life of the catalyst that is used, the process may be relatively inexpensive. Although some research has shown that nitrous oxide $\left(\mathrm{N}_{2} \mathrm{O}\right)$ can be produced, additional research demonstrates that at higher temperatures and with the proper catalyst no byproducts are detected. Under these conditions, the costs and problems associated with byproduct treatment and disposal would not be encountered. Likewise, the potential emissions of unreacted additives would also be climinated.

\section{Disadvantages}

The primary drawback to this process is the inhibiting eflect of oxygen. Current research suggests that oxygen adsorbs onto the catalyst surface and lakes up reaction sites. As the reaction sites begin to fill with oxygen, less of the $\mathrm{NO}_{x}$ is converted into $\mathrm{N}_{2}$ and $\mathrm{O}_{2}$. Because of this competition for reaction sites, this process can only be used when the oxygen content in the gas stream is less than approximately $3 \%$. This condition is highly restrictive and would preclude the use of this process for most thermal treatment systems.

\section{Technology Status}

Emerging: This is a less well developed technology lor combustion and incineration processes. It is an emerging technology and has not been proven for low level waste incineration.

\subsubsection{Oxidation and Scrubbing (TT23470 $)^{1,35,37}$}

For most thermal systems, nitric oxide constitutes $90 \%$ or more of the total $\mathrm{NO}_{\mathrm{x}}$. Because the nitric oxide has a low solubility in water, it is not readily scrubbed from the gas phase and it will not readily react with caustic scrubbing agents.

One strategy is to oxidize the $\mathrm{NO}$ to $\mathrm{NO}_{2}$, which is readily soluble, and then remove the $\mathrm{NO}_{2}$ by wet scrubbing. In this process, an oxidizer, such as ozone or hypochlorile, is lirst mixed with the 
flue gas, to oxidize the $\mathrm{NO}$ to $\mathrm{NO}_{2}$. Though the $\mathrm{NO}_{2}$ is more soluble, it is not as soluble as other acid gases such as $\mathrm{HCl}$. For this reason, the performance of the scrubbing process must be improved to obtain relatively high collection efficiency. Some improvements may include slower gas velocities (i.e., larger scrubber diameter), longer contacting time (longer scrubber sections), and higher liquid-togas ratios.

\section{Input Streams}

Input streams consist of the flue gas stream to be treated, oxidizing reagent, scrubber caustic solution and makeup water.

\section{Output Streams}

Output streams consist of the treated tlue gas stream, and scrubber liquor.

\section{Advantages}

Advantages of oxidation and scrubbing include (1) depending on process requirements, removal efficiencies as high as $99 \%$ can be obtained by improving scrubber performance, (2) this type of technology has been demonstrated to handle concentrations of $\mathrm{NO}_{\mathrm{x}}$ exceeding $10,000 \mathrm{ppm}$, (3) reagents such as ammonia or other reductants are not required, (4) no undesired byproducts occur such as $\mathrm{N}_{2} \mathrm{O}, \mathrm{CO}$, or other PICs that may result from reduction reactions, and (5) the same scrubbing process may be used to control $\mathrm{NO}_{x}$ and other acid gases.

\section{Disadvantages}

Because of the proprietary nature of this technology, little information concerning process descriptions and details is known. Additional costs and complexily due to the $\mathrm{NO}_{\mathrm{x}}$ oxidation step are likely. Other problems associated with packed towers will probably he encountered.

\section{Technology Status}

Emerging: This is an emerging technology for incineration processes, especially for mixed waste incineration. Details of the process are not well known because of proprietary constraints and because of the lack of proven development.

\subsubsection{Chelation and Scrubbing (TT23480) $)^{1,35,37,43,44,45}$}

As with the oxidation/absorption process, scrubbing with chelating agents was developed in order to overcome the extremely low solubility of $\mathrm{NO}$, which is the major lorm ol $\mathrm{NO}_{\mathrm{x}}$ lrom most thermal systems. In this process, a caustic scrubber is used as in other liquid scrubbers; however, a chelating agent is also added to the scrubbing liquor. The chelating agent will form a complex with NO to make the NO soluble in the scrubber liquor. Once in the liquid solution, the NO will react with the caustic agent in the same manner as other acid gases will. The chelating agent is then tree to complex with another NO molecule so the process can be repeated. 
This process is new with work continuing to improve the process. As new information about this process is learned, the process evolves to incorporate the latest advancements. During some of the early stages of development, work was conducted to find chelating agents with good potential for use in this process. During this testing, ferrous ethylenediaminetetraacetate [Fe(II)•EDTA] was identified as a chelating agent that readily complexed with $\mathrm{NO}$ and as a result would most likely be a good potential for this process. Further testing of this agent indicates that the ability to remove $\mathrm{NO}_{\mathrm{x}}$ drops rapidly from $60 \%$ or higher down to less than $30 \%$. This decline in removal efficiency would occur in less than $2 \mathrm{~h}$. Investigation of the problem indicated that the ferrous species was oxidized to the inactive ferric species.

As a result, three different processes are being researched to prevent the ferrous species from oxidizing and to reduce the ferric species back to the ferrous form if oxidation does occur. One of these methods uses a bisulfite $\left(\mathrm{HSO}_{3}\right)$ solution at $71^{\circ} \mathrm{C}\left(160^{\circ} \mathrm{F}\right)$ to reduce the lerric form back to a ferrous form after oxidation occurs. The second method also converts the lerric form vack to the ferrous form after oxidation has occurred. In this process an electrolytic cell is used to promote the conversion. In the last method, another additive is used in conjunction with the chelating agent. This additive simultaneously inhibits the oxidation reaction and promotes the reduction reaction.

\section{Input Streams}

Inputs consist of the flue gas stream to be treated, chelating agent, additives to support chelation, scrubber caustic solution and makeup water.

\section{Output Streams}

Outputs consist of the treated llue gas stream, and scrubber liquor.

\section{Advantages}

The use of a caustic solution in a scrubber will allow lor simultaneous removal of $\mathrm{NO}_{x}$ and other acid gases, such as $\mathrm{SO}_{x}$ and $\mathrm{HCl}$, in the same process. As a result, the capital costs are lower and the space requirements are lower. Testing of this process has demonstrated $\mathrm{NO}_{x}$ removal of 50 to $96 \%$ depending on the operating variables, such as type of caustic, amount of chelating agent used, and method to maintain a ferrous species. Removal efficiency for $\mathrm{SO}_{x}$ can easily be maintained at $90 \%$. Furthermore, when an antioxidant/reducing agent is added to the scrub solution, $\mathrm{SO}_{x}$.removal can increase from 90 to $99 \%$ while all other conditions remain the same.

\section{Disadvantages}

This process is new with many unknowns. Research is needed to optimize the process. Variables such as amount of excess chelating agent, type of scrubbing agent, and method of maintaining the ferrous state must all be incorporated 10 minimize cost and maximize pollutant removal. The operating costs are still unknown to a large degree and research on other improvements is still in progress. For example, the addition of urea has been found to improve the performance of agents used to prevent oxidation $(0)$ the chelating agent. In addition, injecting moisture into the flue gas has improved $\mathrm{NO}_{x}$ removal. 
Questions must also be resolved concerning other potential problerns, such as those encountered with other wet scrubbing technologies. Issues such as liquid byproduct generation rate and treatment must be addressed. Further investigations of other chelating agents is necessary.

\section{Technology Status}

Emerging: This is an emerging technology for incineration processes, especially for mixed waste incineration. Much additional development is necessary before this process can be proven.

\subsection{Heavy Metals Removal (TT23500)}

Emissions of heavy metals trom combustion sources is becoming critically evaluated due to the highly toxic and carcinogenic nature of most heavy metals. Metals that are of greatest concern include arsenic, beryllium, cadmium, total and hexavalent chromium, lead, mercury, and nickel. Others that are often considered include antimony, barium, lead, manganese, phosphorus, selenium, silver, thallium, vanadium, and zinc. For mixed waste incineration, heavy metal emissions not only include these toxic and carcinogenic metals, but can also include radioactive isotopes of some of these metals and others, including tritiated water, cobalt, iodine, and transuranic elements.

A variety of heavy metals are present in all waste streams. They are used as stabilizers in plastics and pigments in paints and dyes. Many products are made lrom processes that use heavy metals. As a result, heavy metal residues are present in the products. The late of metals in thermal processes is highly variable, depending on the waste physical and chemical lorm, the design and operation of the thermal process, and the design and operation of air pollution control equipment. Any metals in incinerator waste feedstreams may be relatively inert, or may react in high temperature oxidizing or reducing conditions to form various oxides, salts, or other compounds or complexes. The elemental metals or metal compounds will either remain a solid in the incinerator bottom ash or fly ash, or devolatilize to form a gas, fume, or vapor. Solid metals that partition to the bottom ash will not present an environmental or human threat unless these are immobilized in that waste form.

Devolatilized metal compounds and metal compounds in the entrained tly ash will partition to the off-gas. Unless these are removed from the oll-gas stream, they will be vented to the atmosphere. Some devolatilized metal compounds will cool and condense on cooler refractory and heat transfer surfaces within the off-gas system, though the majority will pass on through the system without additional control.

Particulate removal and acid gas removal systems can remove metal compounds that are partitioned to the fly ash, or that cool and condense onto fly ash or form relatively large sized aerosols. High efficiency particulate removal is required in these systems to effectively control recondensed metals because the majority of the recondensed metals may exist in and on the surfaces of the fine, difficult to collect, particulate.

Wet processes not only quench the gases but also generate mists and small licjuid droplets that will collect much of the heavy metals. Likewise, dry and semidry processes use gas cooling either before or while injecting alkali. The dry alkali solids will serve as seed particles for agglomeration and collection of heavy metals. Thus, when the acid gas removal and particulate removal devices are combined, many of the heavy metals will be eflectively removed. 
Heavy metals that may not be efficiently controlled include highly volatile metal compounds that may not condense sufficiently for removal under flue gas temperature conditions. These exceptions can include highly volatile mercury and some compounds of asenic, cadmium, lead and other metals. Mercury, for example, has a significant vapor pressure at a temperature as low as $149^{\circ} \mathrm{C}\left(300^{\circ} \mathrm{F}\right)$. As a result, mercury removal in many air pollution control devices may be as low as $30 \%$.

If extremely high mercury removal efficiencies are required, few processes cian be combined with acid gas and particulate removal devices to achieve removal efliciencies ol $99 \%$. These processes are relatively simple and described briefly in the following sections.

\section{Section $\quad \underline{\text { Technology }}$}

14.5.1 Activated Carbon Absorption (TT23520)

14.5.2 Sodium Sulfide Injection (TT23540)

14.5.3 Other Mercury Control Processes (TT23560)

\subsubsection{Activated Carbon Absorption (TT23520) ${ }^{1,46,47,48,49,50,51}$}

Activated carbon is a porous material lilled with deep pores and channels. Activated carbon has a surface area of 300 to $800 \mathrm{~m}^{2} / \mathrm{g}$. High grade carbon can have a surtace area of $1500 \mathrm{~m}^{2} / \mathrm{g}$. As a result, a small amount of carbon can be used to absorb a lot of impurities and is effective in removing trace levels of acid gases and PICs in addition to heavy metals.

Two methods are used to adsorb heavy metals with carbon. The first method involves injecting small quantities of activated carbon powder into the the gas. This process is similar to dry sorbent injection for acid gas control. Both the carbon and the acid gas sorbent can be injected together, through the same nozzle or port, in a mixture of typically $951098 \%$ sorbent and $2105 \%$ carbon. The carbon is then carried in the tlue gas with the sorbent and is collected in the particulate removal device, typically a baghouse.

The second method used to adsorb mercury onto carbon is to flow the llue gas through one or more beds of activated carbon. To prevent the beds from plugging, they are normally placed downstream of the particulate removal device. If the gas is not saturated, moisture condensation will not occur in the carbon bed. Carbon beds are available in a variely ol diflerent housings with one of the simplest being a filter frame fitting into a normal HEPA filter housing.

Occasionally, two beds in the series are used with the tïrst bed using a lower grade carbon and the second bed using a higher grade carbon. With this concept, low cost carbon lilters can do the majority of the work and, therefore, be replaced more often. The higher grade, more expensive carbon filters are then only used as a tinal element and do not have to be replaced as often.

\section{Input Streams}

Input streams are the gas to be treated, activated charcoal lilter beds or powdered activated charcoal (and tluidizing air). 


\section{Output Streams}

Output streams are treated tlue gas stream, spent charcoal lilter beds or loose powdered charcoal (mixed with tly ash).

\section{Advantages}

Advantages of carbon adsorption include (1) high mercury removal clficiency ( $99 \%$ and greater) obtained at a relatively low capital and operational cost, (2) this process is efl'cetive in removing trace quantities of other impurities, and (3) the process is simple to operale and maintain.

\section{Disadvantages}

Although only added in small quantities, the activated carbon lilters or powder adds to the amount of byproduct requiring disposal. It may also affect the treatment of the byproduct. Since the carbon may contain high mercury levels, the byproduct residue will most likely need some sort of stabilization. Alternatively, the mercury could be recovered from the carbon and then treated separately. Another disadvantage results when oxygen is present. If oxygen comes in contact with the activated carbon, it may self-ignite at temperatures as low as $\left.93^{\circ} \mathrm{C}(20)^{\circ} \mathrm{F}\right)$.

\section{Technical Status}

Available: Activated carbon filters are a proven collection medium lor many trace contaminants. Their use in incinerator off-gas streams is more limited, however, and should be considered available but not proven for any given incinerator process.

\subsubsection{Sodium Sulfide Injection (TT23540) $)^{1,49,50,52}$}

Another technique for mercury removal is sodium sullide injection. Sodium sulfide is a water soluble, crystalline solid. Sodium sulfide solution, sprayed into the llue gas before acid gas removal, can scrub the mercury from the flue gas. Lower sodium sulfide concentrations, approximately 2 to $4 \%$, have been found to give better pertormance than higher concentrations. When used with municipal waste incineration, approximately 0.04 to $0.45 \mathrm{~kg}(0.1$ to $1 \mathrm{lb})$ sodium sulfide is required per ton of waste.

\section{Input Streams}

Inputs are flue gas to be treated, and aqueous sodium sulfide solution.

\section{Output Streams}

Output streams are treated tlue gas, and scrubbing system byproduct containing mercury and sodium sulfide. 


\section{Advantages}

This process typically removes 50 to $90 \%$ of the mercury. Although not as high as activated carbon systems, it is better than using acid gas and particulate removal systems alone. This process is also simple and has a relatively low cost. especially if a spray dryer absorbing process is already being used for acid gas control.

\section{Disadvantages}

Disadvantages of sodium sultide injection include (1) sodium sullide forms a caustic aqueous solution and must be handled accordingly. (2) the solution should not be neutralized or toxic hydrogen sulfide gas will be emitted, (3) a concern exists of hydrogen sultide fumes releasing from the bags of sodium sulfide as the bags are opened, (4) sodium sulfide is hygroscopic and may be hard to handle. (5) problens have occurred with deposits in nozzles and in duct work, (6) problems occurred with sludge formation when dissolving the sodium sulfide in water due to impurities in the sodium sulfide and because of metals precipitating out of the solution. and (7) because of its hazardous nature, disposal of sodium sullide and its solutions cian be a problem.

\section{Technology Status}

Emerging: Sodium sulfide injection is a new technology employed by licw operational lacilities. Therefore, its performance in various systems is not proven.

\subsubsection{Other Mercury Control Processes (TT23560) $)^{1,49,50.51}$}

Dther, less-developed technologies are available lor mercury emissions control. These include a selenium tilter technique and mercury scrubbing.

The selenium tilter process, being developed in Sweden, uses a reaction between mercury and selenium to contain the mercury. The the gas entering the tiller must lirst be conditioned by removing the particulate, lowering the temperature to 60$\left.)^{\circ} \mathrm{C}(140)^{\circ} \mathrm{F}\right)$ or less, and still prevent saturation of the the gas. The tilter is sized to last approximatcly tive years. Because this is a new process being developed overseas, little is known about this process and no additional information can be presented at this time.

Mercury scrubbing may done by reactiny mercury with chemicals such as sodium hypochlorite or with a chelating agent and cupric chloride, 10 form a water soluble mercury compound. As such, mercury can be removed from the the gas using conventional wet scrubbing technologies. In this manner, mercury removal efficiencies of 90 io $95 \circ^{\circ}$, have been obtained. While this technology is relatively new and little intormation is known, it has excellent potential and may also be usetul in removing $\mathrm{NO}_{\mathrm{x}}$. Research into this process could be beneficial, especially lior those waste streams high in concentrations of mercury and fuel nitrogen. 


\subsection{Off-gas Cooling/Heating (TT23600)}

An entire incinerator off-gas treatment system can include several unit operations. The final incineration operations, prior to the start of off-gas treatment, may include secondary or alterburner sections and a particulate separation section, which recycles lluidized particulate back to the incinerator. The off-gas may then be processed by the following types of unit operations:

- Flue gas cooling, to recover heat, and/or to lower gas temperatures to ranges suitable for air pollution control operations and to prevent damage to downstream equipment

- Flue gas compression by an incinerator induced drafi (ID) fan to ensure sufficient negative pressure through the incineration and initial heat exchanger process

- Particulate, acid gas and heavy metals removal (this may include lurther gas cooling)

- Reheating of the gas stream to prevent saluration and moisture condensation

- High efficiency filtration

- Final compression by an ID lan

- Vent to atmosphere though a stack.

A complete system may include, in addition to the air pollution control equipment and blowers, one or more cooling steps and a reheating step. Cooling and reheating are commonly performed by:

Cooling

Air Dilution

Water Quench

Heat Exchange
Rehealing

Direct Heating

Hot air mixing

Heat Exchange

Off-gas cooling/heating systems are discussed in the following sections:

Section. Technology

14.6.1

14.6 .2

14.6 .3

Air Dilution (TT23620)

14.6 .4

Water Quench (TT23640)

Heat Exchanger (TT23660)

Flue Gas Reheating (TT23680)

\subsubsection{Air Dilution (TT23620) ${ }^{9}$}

One of the simplest and easiest cooling methods is to dilute the hot llue gas with ambient temperature air. This may be done using special mixing jets, or more simply by allowing a controlled damper or vent to allow air intlux. Since most incinerators operate under negative pressure, the furnace draft is sufficient motive torce to draw air into to the system. By controlling the damper 
action, this can also be used to control the draft in the incinerator, but this can result in less the gas temperature control. More positive and contained air dilution may be done by using air blowers with positively closing dampers, to prevent outflow of tlue gases during process upsets. This technique is most useful to cool hot incinerator gases to an intermediate temperature, and to prevent condensation as gases are cooled to temperatures even below $\left.93^{\circ} \mathrm{C}(2())()^{\circ} \mathrm{F}\right)$.

\section{Input Streams}

Input streams are hot incinerator gases and cool air.

\section{Output Streams}

Oitput streams are cooler mixed stream of the combined incinerator gases and the diluent air.

\section{Advantages}

Advantages of air dilution include (1) low installation and operation costs, (2) maintenance requirements are minimal, (3) this technique is especially eflective for high temperature gases that require only intermediate cooling, and (4) this is also especially elfective for diluting levels of moisture and acid gases to prevent condensation as the gas stream is cooled, even to temperatures below the boiling point of water.

\section{Disadvantages}

Disadvantages of air dilution include (1) the added diluent air increases the total volume of the gas, increasing the size requirements lor downstream equipment. (2) concentrations of contaminants are reduced due to dilution, which may result in more dillicult removal, (3) air dilution wili increase the levels of oxygen in the flue gas leading to potentially explosive mixtures in the exhaust system during upset conditions, and (4) increased oxygen levels will also limit the eflectiveness of some $\mathrm{NO}_{\mathrm{x}}$ control technologies.

\section{Technology Status}

Proven: This a simple, well established cooling method in many industries. It has been used in sixteen low level waste incineration facilities worldwide. It should be considered as a viable cooling technique where appropriate lor mixed waste incineration.

\subsubsection{Water Quench (TT23640) ${ }^{1}$}

Flue gas quenching is achieved by direct spraying of water into the tlue gas stream. The heat of evaporation for water rapidly quenches even high temperature gals streams, without signilicantly increasing the moles of total off-gas. Injection may be done either countercurrent or cocurrent with the gas flow. An example of a cocurrent system is shown in Figure 14-12. ${ }^{18}$ When the saturation level and amount of excess water droplets are not critical, watur may be injected into a duct or at the top of a spray tower. The water spray tends to llow down induced by gravity. The gas may thow up or down through the tower. When saturation and entrainment of droplets downstream of the system must be prevented, the water may be injected at the boltom of a spray lower in parallel llow with the 


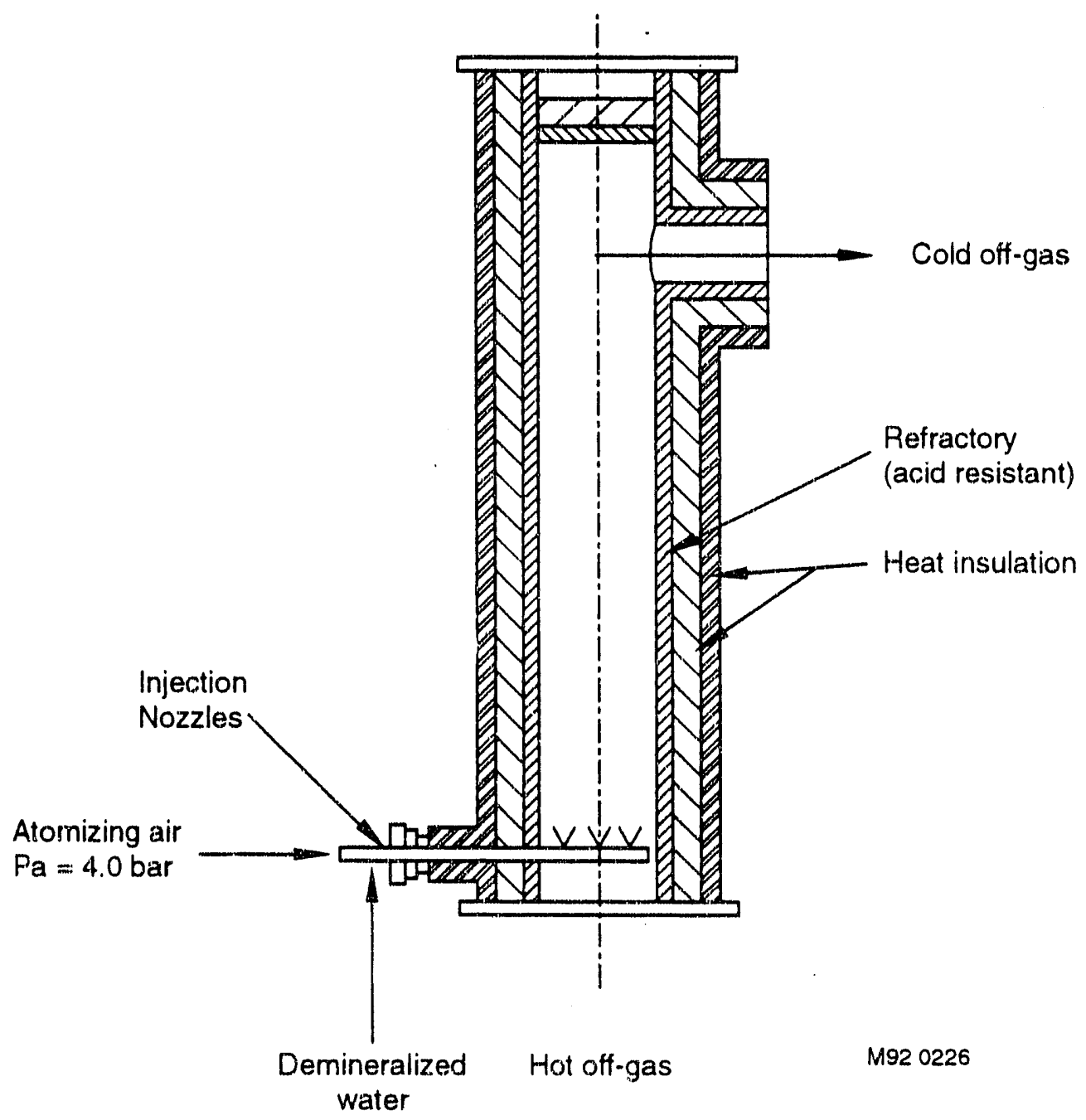

Figure 14-12. Schematic of a water injection cooling system. 
upflowing gas stream. This maximizes the residence time in the spray tower to ensure more complete evaporation of the spray water.

Demineralized water should be used to prevent hard water deposits and to prevent introducing additional contaminants into to the the gas stream. Desired water droplet size is less than $100 \mu \mathrm{m}$. achieved by pressure or air atomization. This process occurs whenever wet scrubbing or semidry scrubbing is employed for particulate and/or acid gas control.

\section{Input Streams}

Input streams are hot incinerator gases and demineralized water (optionally, including atomization air).

\section{Output Streams}

Output streams are cooled thue gas stream, containing a few molar percent higher evaporate water, and any remaining unevaporated water droplets.

\section{Advantages}

Advantages of water quench include (1) low installation and operation costs, (2) maintenance requirements are minimal, (3) this technique is especially effective for rapidly reducing gas temperatures, without significantly increasing the moles of gas llow, and (4) process is useful in adjusting the evaporated water content of the gas streams to optimize performance of some $\mathrm{NO}_{\mathrm{x}}$ and particulate control techniques.

\section{Disadvantages}

Disadvantages of water quench include (1) increases in the gas moisture levels are often undesirable, due to corrosion, particulate touling, plume formation, or other problems and (2) during upsets, other problems may include either insulticient water quenching, or pooling of unevaporated water throughout the system.

\section{Technology Status}

Proven: This a simple, well establishec cooling method in many industrics. It has been used in four low level waste incineration facilities worldwide. It should be considered as a viable cooling technique where appropriate for mixed waste incincration.

\subsubsection{Heat Exchanger (TT23660) ${ }^{1}$}

Heat exchangers for llue gas cooling can include gas/gas exchangers, gas/liquid exchangers, and boilers. The flue gas may pass through the lube-side of heat exchangers. Commercial waste heat recovery boilers are often, but not always, designed for the thue gas to pass through the equivalent of the shell-side. A schematic of a waste heat boiler is shown in Figure 14-13. ${ }^{53}$ 

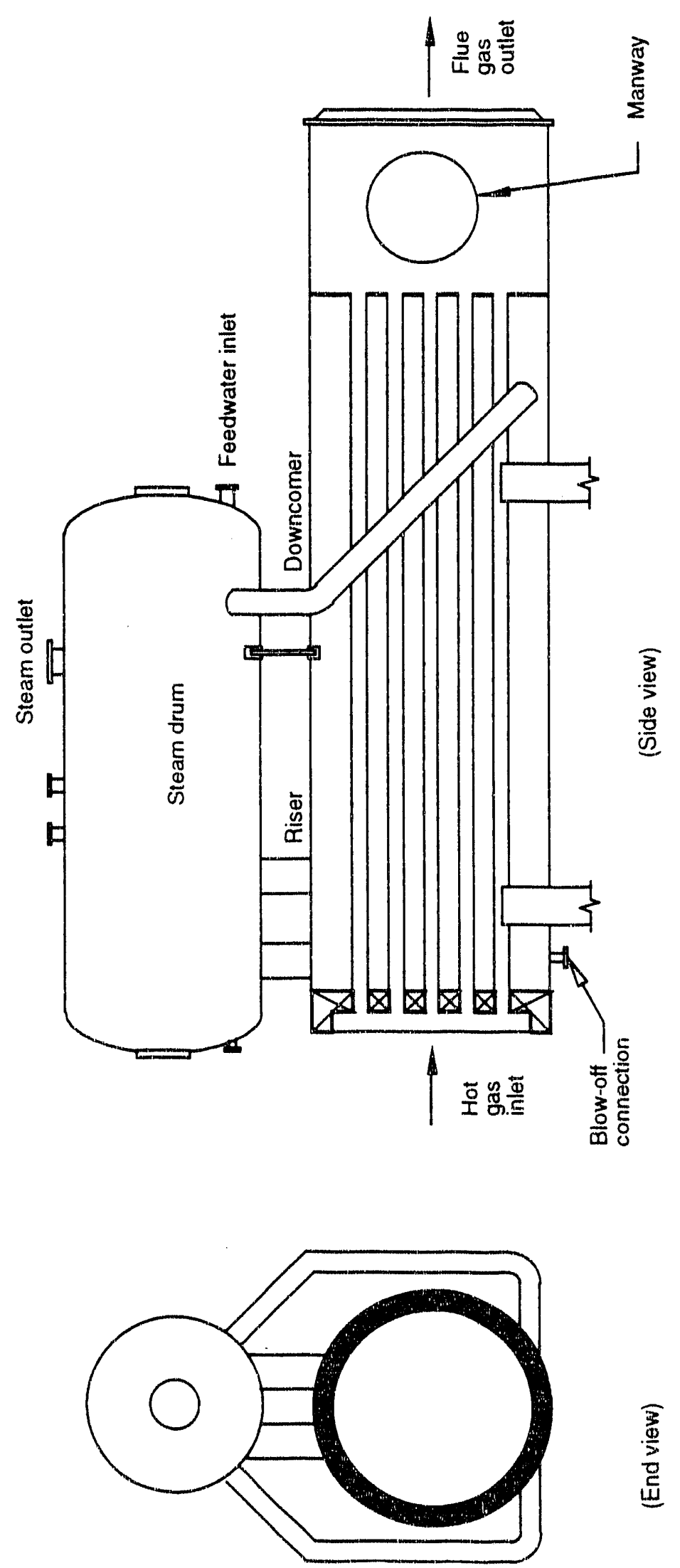

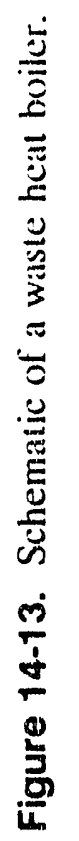




\section{Input Streams}

Input streams are hot incinerator gases and demineralized water, air, oil, or other cooling medium.

\section{Output Streams}

Output streams are cooled tlue gas stream and the heated (or boiled) coolant stream.

\section{Advantages}

One of the advantages of heat exchangers is the recovered heat may be used in the plant as preheated air, hot water or oil, or steam.

\section{Disadvantages}

Disadvantages of heat exchangers include (1) installation and maintenance costs are higher, (2) a boiler or heat exchanger can complicate the process, because process upsets on either the tlue gas side or the coolant side can damage the boiler and downstream equipment. (3) upsets or shutdowns on the boiler side will cause upsets and shutdowns of the incinerator process, and (4) plugging, corrosion, and other maintenance problems are more common.

One method to reduce some corrosion and other problems is to use air dilution upstream of the boiler to lower flue gas temperatures and reduce concentrations of corrosive contaminants. One method to minimize upsets of the boiler system due 10 incinerator oulages is to use gas or oil auxiliary firing in the boiler, to augment the heat input and ensure more continuous heat input even during incinerator upsets. Typically, incinerator systems equipped with boilers must have a bypass duct and emergency quench system through which oll-gases may be vented in the event of a boiler shutdown.

\section{Technology Status}

Proven: Heat exchange for cooling incinerator olf-gases is common and well established. Gas/gas heat exchangers have been used in 11 low level waste incineration facilities worldwide. Gas/liquid exchangers have been used in two low level waste incineration facilities.

\subsubsection{Flue Gas Reheating (TT23680) ${ }^{1}$}

If a wet offgas system is used, reheating the oflgas may be necessary to prevent moisture condensation in downstream equipment, or eliminate a stack steam plume. Reheating can be accomplished by using a resistance heating, direct llame, a heat exchanger, or by mixing with preheated air. The gas stream should be heated 11 to $22^{\circ} \mathrm{C}\left(20\right.$ to 4()$\left.^{\circ} \mathrm{F}\right)$ above its dewpoint to minimize corrosion or filter damage problems. 


\section{Input Streams}

Input streams consisted of saturated flue gases and entrained moisture droplets, and, depending on the reheating technique, hot air [around $316^{\circ} \mathrm{C}\left(600^{\circ} \mathrm{F}\right)$ ], fuel for direct-fired or indirect-fired burners, or other heating fluid.

\section{Output Streams}

Output streams consist of reheated flue gas stream, and byproducts of the heating medium (diluent air or combustion gases mixed with the flue gas, etc.).

\section{Advantages}

Advantages are reduced corrosion and better operation for downstream equipment.

\section{Disadvantages}

Disadvantages of flue gas reheating include (1) high levels of water droplets in the flue gas stream are difficult to completely vaporize without extensive heat input and efficient heat and mass transfer, (2) sorne reheating techniques, such as gas fired indirect or direct heating, will result in increased emissions of combustion products, (3) air dilution and direct fired heating will increase both the moles and the actual volume of flue gas processed by HEPA filters and other downstream equipment, and (4) indirect heating will not increase the moles of flue gas processed by HEPA filters, but will increase the actual volume due to the increased temperature and vaporized water droplets.

\section{Technology Status}

Proven: Reheating saturated flue gases for low level incinerator processes is probably required for those operations using wet scrubbers and HEPA filters. Reheating was used at the LANL Controlled Air Incinerator for TRU Contaminated Wastes, the SRL TRU incinerator, the controlled air incinerator for alpha contaminated wastes at the Leningrad Nuclear Power Plant, and other mixed waste incineration facilities worldwide. 


\subsection{References}

1. D. Dalton, E. M. Steverson, and G. L. Anderson, Air Pollution Control In Thermal Treatment, EGG-WTD-10038, January 1992.

2. R. H. Perry and C. H. Chilton, Chemical Engineers Handbook, 5th ed., New York: McGrawHill, 1973.

3. P. N. Cheremisinoff, Fine Particulate Control in Air Pollution, Northbrook, Illinois: Pudvan, 1988.

4. S. V. Sheppard, "Seven Ways to Control Air Pollution," CPI 100, January/February 1986.

5. Western Precipitation Division, Joy Manufacturing Co., Basic Handbook of Air Pollution Control Equipment, 1975.

6. C. R. Brunner, Hazardous Air Emissions from Incineration. New York: Chapman and Hall, 1985 .

7. J. R. Donnelly, "Overview of Air Pollution Controls for Municipal Waste Combustors," presented at Air and Waste Management Association 84th Annual Meeting, Vancouver, B. C., Canada, June 1991.

8. W. Gregg, "Design and Operation of Pulse-Jet Fabric Filters For Incineration Air Pollution Control," presented at Air and Waste Management Association Municipal Waste Combustion Conference, Tampa, Florida, April 1991.

9. B. Brown et al., "Dust Collector Design Consideration lior MSW Acid Gas Cleaning Systems," presented at 7th Clean Air Congress, Sydney, Ausiraliu, August 1980.

10. J. R. Donnelly et al., "Baghouse and Precipitator Applications In Dry FGD Systems," presented at 7th Clean Air Congress, Sydney, Australia, August 1986.

11. E. C. Zievers, and J. F. Zievers, "A Comparison of Cylindrical Porous Ceramic Elements Used for Hot Gas Filtration, presented at the Incineration Conference, San Diego, California, May 1990.

12. S. Carpentier, and C. de Tassigny, "Experience with High-Temperature Filtration ol Incineration Flue Gases," Presented at the Incineration Conference, San Diego, Califorria, May 1990.

13. H. Leibold et al., "Particulate Emissions from a LLW Incinerator and Olf-Gas Cleaning with a New Type of Ceramic Candle Filter," Presented at the International Conference on Incineration of Hazardous, Radioactive, and Mixed Waste, San Francisco, California, May 1988.

14. E. C. Ziervers et al., "Porous Ceramics can be Tailored to the Hot Gas Filtration Job," Presented at the Incineration Conference, Knoxville, Tennessee, May 19830. 
15. S. Carpentier et al., "Research and Development on New High-Temperature Filter for Dry Scrubbing of Incineration Flue Gases," Presented at the Incineration Conference, Knoxville, Tennessee, May 1989.

16. Power Generation Newsletter, Pall Process Filtration Company, Pall Power Generation Group, East Hills, New York, December 1990.

17. H. L. Marshall et al., "New Oregon Incinerator Demonstrates Process Innovation to Protect Both Air and Water," Presented at AWMA Specialty Conference--Thermal Treatment of Municipal, Industrial, and Hospital Waste, Pittsburgh, Pennsylvania, November 1989.

18. Treatment of Off-Gas from Radioactive Waste Incinerators, Technical Reports Series No. 302 , Vienna, Austria: International Atomic Energy Agency, 1989.

19. J. R. Donnelly, "Overview of Air Pollution Controls for Municipal Waste Combusters," presented at Air and Waste Management Association Municipal Waste Combustion, Tampa, Florida, April 1991.

20. Pilot-Scale ESP (Electrostatic Precipitator) and Hydro-Sonic Scrubber Parametric Tests for Particulate, Metals and $\mathrm{HCl}$ Emissions, PB90-129362, prepared for U.S. EPA by John Zink Company, Tulsa, Oklahoma, June 1989.

21. H. Leibold et al., "Particulate Emissions from a LLW Incinerator and Olf-Gas Cleaning with a New Type of Ceramic Candle Filter," Waste Management, 9/2/89.

22. R. G. Barton et al., "State-of-the-Art Assessment of Medical Waste Thermal Treatment." Energy and Environmental Research Corporation, Irvine, California, April 1991.

23. J. Brady, "Emission Control Systems for Incincrators," TR 89-9()()239. Andersen 2000), Inc., Peachtree City, Georgia, February 1989.

24. G. England, D. Hansell, J. Newhall, and N. Soelberg, Michigan Hospital Incinerator Emissions Test Program, Final Report, Volume III: Site Summary Report, University of Michigan Medical Center Incinerator, Energy and Environmental Research Corporation, August 1991.

25. R. M. Darcey and H. P. Beutner, "Operating Experience and Performance of a Dry Injection Scrubbing System on a Municipal Waste Incinerator," presented at Air and Waste Management Association 82nd Annual Meeting, Anatieim, CA.

26. E. B. Mull, Jr., and H. P. Beutner, "Dry Addilive Process lior Cortrol of Acid Gas and Particulate Emissions," presented at ASME Solid Waste Division-..Western Chapter Meeting, Salt Lake City, Utah, April 1988.

27. A. Larosee and E. B. Mull, Jr., "Medical Waste Incinerator Installation at West Babylon, New York--A Success Story," presented at the Association of the Nonwoven Fabrics Industry INDA's Filtration Conference, March 1991. 
28. B. J. Lerner, 'The BECO Alka/Sorb' Process Application to Biomedical Waste Incinerators," presented at Air and Waste Management Association 84th Annual Meeting, Vancouver, B.C., Canada, June 1991.

29. G. England, D. Hansell, J. Newhall, and N. Soelberg, Michigan Hospital Incinerator Emission Test Program, Final Report, Volume II: Site Summary Report, Borgess Medical Center Incinerator, Energy and Environmental research Corporation, August 1991.

30. J. R. Donnelly and S. K. Hansen, "Joy/Niro Spray Dryer Acid Gas Removal System for Hazardous Waste and Sewage Sludge Incineration," Presented at HMCRI-Sludge '87, Boston, Massachusetts, May 1987.

31. P. S. Tarapore and J. M. Towarnicky, "Advances in Pollution Control in the Glass Industry: An Improved System for Effective Dry $\mathrm{SO}_{\mathrm{x}}$ and Particulate Control," Presented at 76th Annual Meeting of the APCA, Atlanta, Georgia, June 1983.

32. Comprehensive Report to Congress Clean Coal Technology Program--10MW' Demonstration of Gas Suspension Absorption, DOE/FE-0198P, July 1990.

33. Draft Test Report and a Performance Test on a Spray Diyer; Fabric Filter, and Wet Scrubber System, PB90-120544, prepared for U.S. EPA by Radian Corp., Herndon, Virginia, October 1989.

34. R. Vanbrabant et al., "Off-Gas Treatment of an Incineration Installation," Presented at the International Conference on Incineration of Hazardous, Radioactive, and Mixed Wastes, San Francisco, California, May 1988.

35. E. S. Behrens et al., "SCR Operating Experience on Coal-Fired Boilers and Recent Progress," Presented at 1991 EPA/EPRI Joint Symposium on Stationary Combustion NO Control, 1991.

36. H. Bosch and F. Janssen, "Catalytic Reduction of Nitrogen Oxides-A Review on the Fundamentals and Technology," Catalysis Today, 2, 1988.

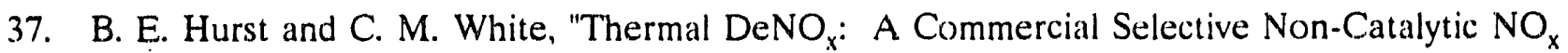
Reduction Process for Waste-to-Energy Applications." Presented at the ASME 12th Biennial National Waste Processing Conference, Denver; Colorado, June 1980.

38. D. G. Jones et al., "Two-Stage DeNO Process Tust Dala lor 330) TPD MSW Incineration Plant," Presented at the Air ar.d Waste Management Association 82nd Annual Meeting, Anaheim, California, June 1989.

39. "The Non-Catalytic Denitrification Process (Thermal DeNO ${ }_{x}$ ) for Glass Melting Furnaces," Presented at the Society of Glass Technology Symposium, York, England, May 1982.

40. W. R. Seeker, et al., "Advanced Pollution Control in Municipal Waste Combustors Using Natural Gas," Presented at the Air and Waste Management Association 82nd Annual Meeting, Anaheim, California, June 1989. 
41. H. A. Abbasi et al., "Pilot-Scale Assessment of Natural Gas Reburning Technology for $\mathrm{NO}_{\mathrm{x}}$ Reduction from MSW Combustion Systems," Presented at the International Conference on Municipal Waste Combustion, Hollywood, Florida, April 1989.

42. M. H. Mendelsohn and J. B. L. Harkness, "Strategies for Uitilizing Ferrous EDTA Chelate as an Additive in Combined $\mathrm{SO}_{2} / \mathrm{NO}_{x}$ Aqueous Scrubbing System." Presented at the 25th Intersociety Energy Conversion Engineering Conference, Reno, Nevada, August 1990.

43. M. H. Mendelsohn et al., "Combined $\mathrm{SO}_{2} / \mathrm{NO}_{x}$ Control Using Ferrous EDTA and a Secondary Additive in a Lime-Based Aqueous Scrubber System," Argonne National Laboratory, Energy Systems Division, Argonne, Illinois.

44. J. B. L. Harkness and R. D. Doctor, "Development of Combined Nitrogen Oxide/Sulfur Oxide Environmental-Control Technology", ANL/ECT-14, Argonne National Laboratory, Argonne, Illinois, August 1985.

45. "TSCA Incinerator Burn Schedule," Martin Mariclla, Oak Ridge, Tennessee, November 1990.

46. M. J. Clarke, "A Review of Activated Carbon Technologies lor Reducing MSW Incinerator Emissions," Presented at the Air and Waste Management Association Second Annual International Specialty Conference on Municipal Waste Combustion, Tampa, Florida, April 1991.

47. U. Cleve, "Application of Carbon Based Absorbers for Washing of Flue Gases," Presented at the 1989 Incineration Conference, Knoxville, Tennessee, May 1989.

48. T. G. Brna, "Toxic Metal Emissions from MWCs and Their Control," Presented at the Air and Waste Management Association Second Annual International Specialty Conference on Municipal Waste Combustion, Tampa, Florida, April 1991.

49. D. M. White et al., "Municipal Waste Combustors: A Survey of Mercury Emissions and Applicable Control Technologies," Presented at the Air and Waste Management Association Second Annual International Conference on Municipal Waste Combustion, Tampa, Florida, April 1991.

50. H. Braun and A. Gerig, "Mercury Emissions Monitoring on Municipal Waste Combustion," Presented at the Air and Waste Management Association Second Annual International Specialty Conference on Municipal Waste Combustion. Tampa, Florida, April 1091.

51. C. Anderson and B. Weimer, "Mercury Emission Control--Sodium Sulphide Dosing at the Hogdalen Plant in Stockholm," Presented at the Air and W'aste Management Association Second Annual International Specialty Conference on Municipal Waste Combustion, Tampa, Florida, April 1991.

52. K. J. Herbert, "Catalysts for Volatile Organic Compound Control in the 1990s," Presented at the 1990 Incineration Conference, San Diego, California, May 1990.

53. P. N. Cheremisinotf, Pollution Engineering Flowsheets, Hazardous Material, United States: Cahners Publishing Co., 1988. 

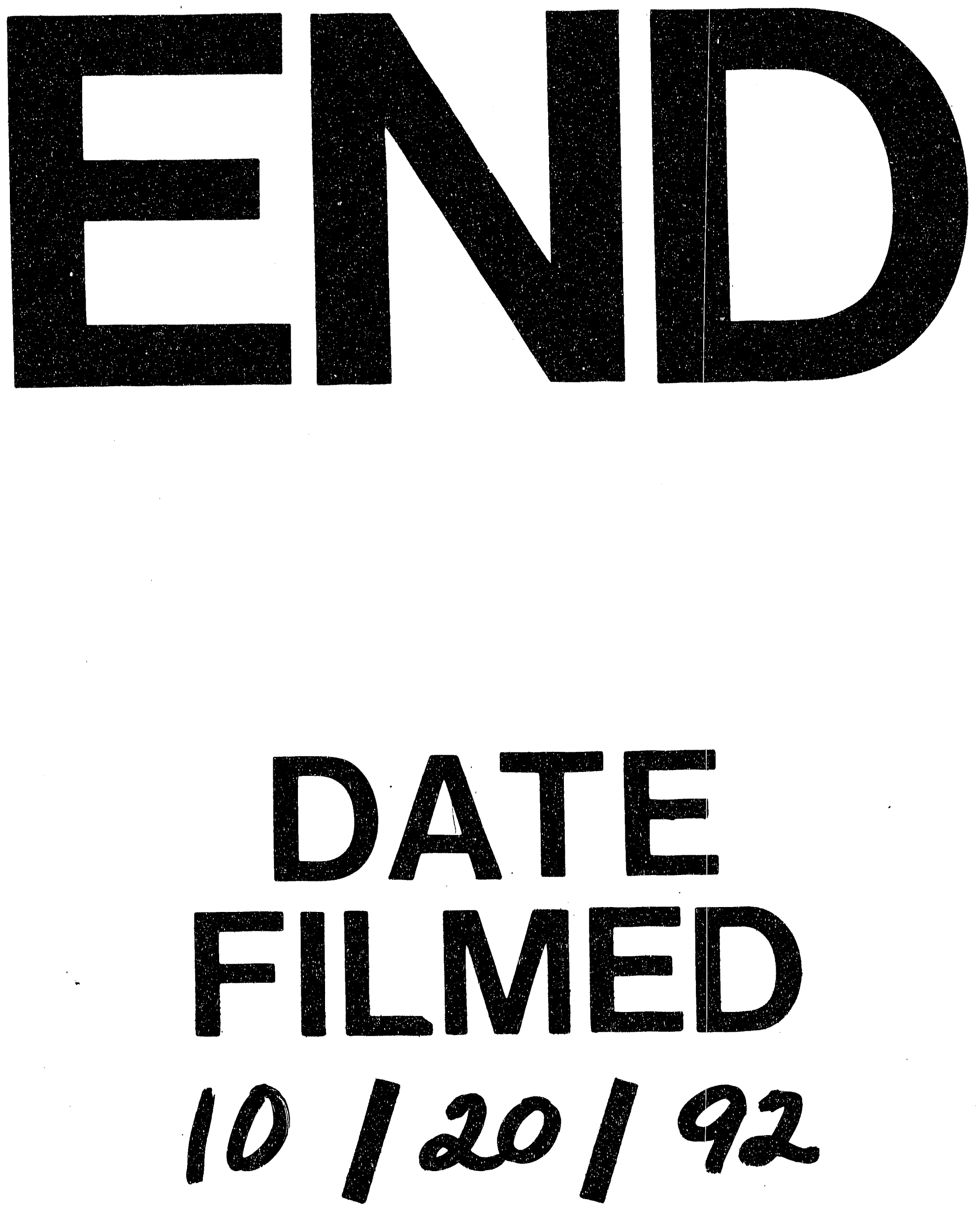
